

\section{Learning Demonstration Interim Progress Report - July 2010}

Technical Report NREL/ TP-560-49129

September 2010

K. Wipke, S. Sprik, J. Kurtz, and T. Ramsden

Prepared under Task No. H270.8100

National Renewable Energy Laboratory

1617 Cole Boulevard, Golden, Colorado 80401-3393

303-275-3000 • www.nrel.gov

NREL is a national laboratory of the U.S. Department of Energy

Office of Energy Efficiency and Renewable Energy

Operated by the Alliance for Sustainable Energy, LLC

Contract No. DE-AC36-08-GO28308

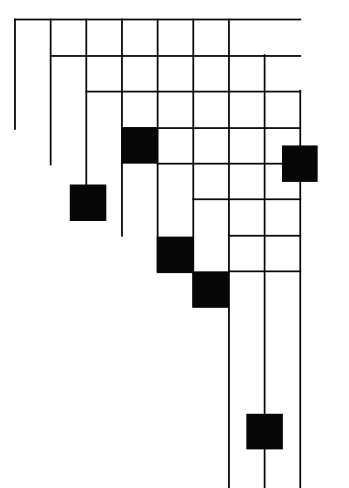




\section{NOTICE}

This report was prepared as an account of work sponsored by an agency of the United States government. Neither the United States government nor any agency thereof, nor any of their employees, makes any warranty, express or implied, or assumes any legal liability or responsibility for the accuracy, completeness, or usefulness of any information, apparatus, product, or process disclosed, or represents that its use would not infringe privately owned rights. Reference herein to any specific commercial product, process, or service by trade name, trademark, manufacturer, or otherwise does not necessarily constitute or imply its endorsement, recommendation, or favoring by the United States government or any agency thereof. The views and opinions of authors expressed herein do not necessarily state or reflect those of the United States government or any agency thereof.

Available electronically at http://www.osti.gov/bridge

Available for a processing fee to U.S. Department of Energy and its contractors, in paper, from:

U.S. Department of Energy

Office of Scientific and Technical Information

P.O. Box 62

Oak Ridge, TN 37831-0062

phone: 865.576 .8401

fax: 865.576 .5728

email: mailto:reports@adonis.osti.gov

Available for sale to the public, in paper, from:

U.S. Department of Commerce

National Technical Information Service

5285 Port Royal Road

Springfield, VA 22161

phone: 800.553.6847

fax: 703.605.6900

email: orders@ntis.fedworld.gov

online ordering: http://www.ntis.gov/ordering.htm 


\section{Executive Summary}

This report documents and discusses key results based on data through December 2009 from the U.S. Department of Energy's (DOE) Controlled Hydrogen Fleet and Infrastructure Validation and Demonstration Project, also referred to as the National Fuel Cell Electric Vehicle (FCEV) Learning Demonstration. This report serves as one of many mechanisms to help transfer knowledge and lessons learned within various parts of DOE's Fuel Cell Technologies program, as well as externally to other stakeholders. It is the fourth such report in a series, with previous reports being published in July $2007^{[1]}$, November $2007^{[2]}$, and April $2008^{[3]}$.

This report also marks a transition with the makeup of the industry participants who initiated the project in 2004. The projects started with four automotive OEM \& energy partner teams. Since that time, DOE's California Hydrogen Infrastructure Project began providing data, and additional hydrogen fueling infrastructure is being installed in California under state and local funding that will also soon be providing data to DOE's National Renewable Energy Laboratory (NREL). We have also seen the completion of the project for two of the four original OEM and energy partner teams, who provided their last data by early 2010 . New analytical results generated after this report will need to be approached differently, given the fact that there are only two automotive companies now providing data, and their sensitive data still needs to be protected from competitors. Therefore, while this report is not a final report from the project, it is potentially the last comprehensive report to provide new commentary on the data involving all four original automotive OEM teams up to December 2009.

NREL has now analyzed data from almost five years of the seven-year project. During this time, 144 vehicles were deployed, 23 project refueling stations were placed in use, and no fundamental safety barriers were identified. We have analyzed data from over 436,000 individual vehicle trips covering 2,500,000 miles traveled and over 130,000 kg hydrogen produced or dispensed. Key objectives of the project are to evaluate fuel cell durability, vehicle driving range, and onsite hydrogen production cost. Progress towards these objectives will be briefly highlighted.

Fuel Cell Stack Durability: Many improvements have been made in NREL's fuel cell durability analysis methodology, including using a two-segment linear fit and using a weighting algorithm to come up with a more robust and automatic fleet average. Now that the data submissions are complete on first-generation stacks (no new first-generation stack data is being received), we can make some final conclusions about that generation of technology. The maximum number of hours a first-generation stack accumulated without repair is 2,375 , which is the longest stack durability from a light-duty vehicle FCEV in normal use published to date that we are aware of. On average, the slope of the initial power degradation is steeper in the first 200 hours and becomes more gradual after that. We also found that around 1,000 hours of data were required to reliably determine the slope of the more gradual secondary degradation. Finally, with significant drops in power observed at 1,900-2,000 hours, it appears as though this is a solid upper bound on first-generation stack durability (characterizing 2003-2005 technology). For second-generation fuel cell stacks (2005-2007 technology), the range of maximum hours accumulated from the four teams is now approximately 800 to over 1,200 hours, with the range of team average hours accumulated of approximately 300 to 1,100 hours. Relative to projected durability, the Spring 2010 results indicate that the highest average projected team time to 10\% 
voltage degradation for second-generation systems was 2,521 hours, with a multi-team average projection of 1,062 hours. Therefore, the 2,000-hour target for durability has been validated.

Vehicle Driving Range: In FY 2008, the driving range of the project's FCEVs was evaluated based on fuel economy from dynamometer testing (EPA adjusted) and on-board hydrogen storage amounts and compared to the 250-mile target. The resulting second-generation vehicle driving range was between 196 - 254 miles from the four teams, and met the 250-mile range objective. In June 2009, an on-road driving range evaluation was performed in collaboration with Toyota and Savannah River National Laboratory. The results indicated a 431-mile on-road range was possible in southern California using Toyota's FCHV-adv fuel cell vehicle ${ }^{[4]}$. More recently, the significant on-road data that have been obtained from second- and first-generation vehicles allowed a comparison of the real-world driving ranges of all the vehicles in the project. The data show that there has been a $45 \%$ improvement in the median real-world driving range of second-generation vehicles ( 81 miles) as compared to first-generation (56 miles), based on actual distances driven between over 25,000 refueling events. Obviously the vehicles are capable of two to three times greater range than this, but the median distance travelled between refuelings is one way to measure the improvement in the vehicles' capability and the way in which they are actually being driven.

On-Site Hydrogen Production Cost: Cost estimates from the Learning Demonstration energy company partners were used as input to an $\mathrm{H} 2 \mathrm{~A}$ analysis to project the hydrogen cost for 1,500 $\mathrm{kg}$ /day early market fueling stations (H2A is DOE's suite of hydrogen analysis tools, with the $\mathrm{H} 2 \mathrm{~A}$ Production model focused on calculating the costs of producing hydrogen). Results indicate that on-site natural gas reformation could lead to a range of $\$ 8-\$ 10 / \mathrm{kg}$ and on-site electrolysis could lead to $\$ 10-\$ 13 / \mathrm{kg}$ hydrogen cost. While these results do not achieve the $\$ 3 /$ gge cost target, two external independent review panels commissioned by DOE concluded that distributed natural gas reformation could lead to $\$ 2.75-\$ 3.50 / \mathrm{kg}^{[5]}$ and distributed electrolysis could lead to $\$ 4.90-\$ 5.70^{[6]}$. Therefore, this objective was met outside of the Learning Demonstration project.

We have summarized the previously discussed key performance numbers, along with other metrics of interest such as fuel economy and fuel cell efficiency, and compared them to DOE targets in Table 1. The table shows that this project has exceeded the expectations established in 2003 by DOE, with all of the key targets being achieved except for on-site hydrogen production cost, which would have been difficult to demonstrate through this project.

Additional data accumulated and analyzed in 2010 - 2012 will assess the latest generations of FCEV technology, which include improvements over the second-generation systems included in the results to date. Future assessments will also include data analysis from many new hydrogen stations being commissioned in California, all of which will have 700-bar fueling capability. All 80 composite data products (CDPs) published to date are included in this report as well as directly accessible from our Hydrogen Technology Validation Web site. 
Table 1: Learning Demonstration key performance metrics summary

\begin{tabular}{|c|c|c|c|}
\hline Vehicle Performance Metrics & Gen 1 Vehicle & Gen 2 Vehicle & 2009 Target \\
\hline Fuel Cell Stack Durability & & & 2,000 hours \\
\hline $\begin{array}{l}\text { Max Team Projected Hours to } \\
10 \% \text { Voltage Degradation }\end{array}$ & 1,807 hours & $\underline{2,521}$ hours & \\
\hline Average Fuel Cell Durability Projection & 821 hours & 1,062 hours & \\
\hline $\begin{array}{l}\text { Max Hours of Operation } \\
\text { by a Single FC Stack to Date }\end{array}$ & 2,375 hours & 1,261 hours & \\
\hline Driving Range & $103-190$ miles & $196-\underline{254}$ miles & 250 miles \\
\hline FuelEconomy (Window Sticker) & $42-57 \mathrm{mi} / \mathrm{kg}$ & $43-58 \mathrm{mi} / \mathrm{kg}$ & no target \\
\hline Fuel Cell Efficiency at $1 / 4$ Power & $51-58 \%$ & $53-\underline{59} \%$ & $60 \%$ \\
\hline Fuel Cell Efficiency at Full Power & $30-54 \%$ & $42-\underline{53} \%$ & $50 \%$ \\
\hline
\end{tabular}

Infrastructure Performance Metrics

\begin{tabular}{|c|c|c|}
\hline $\mathrm{H}_{2}$ Cost at Station (early market)* & $\begin{array}{l}\text { On-site natural gas } \\
\text { reformation } \\
\$ 7.70-\$ 10.30\end{array}$ & $\begin{array}{c}\text { On-site } \\
\text { Electrolysis } \\
\$ 10.00-\$ 12.90\end{array}$ \\
\hline
\end{tabular}

Average $\mathrm{H}_{2}$ Fueling Rate
$0.77 \mathrm{~kg} / \mathrm{min}$
2009 Target

\$3/gge

$1.0 \mathrm{~kg} / \mathrm{min}$

*Outside of this project, DOE independent panels concluded at 500 replicate stations/year: Distributed natural gas reformation at $1500 \mathrm{~kg} /$ day: $\$ 2.75-\$ 3.50 / \mathbf{k g}$ (2006)

Distributed electrolysis at $1500 \mathrm{~kg} / \mathrm{day}: \mathbf{\$ 4 . 9 0 - \$ 5 . 7 0}(2009)$ 


\begin{tabular}{|c|c|}
\hline \multirow{2}{*}{\multicolumn{2}{|c|}{ 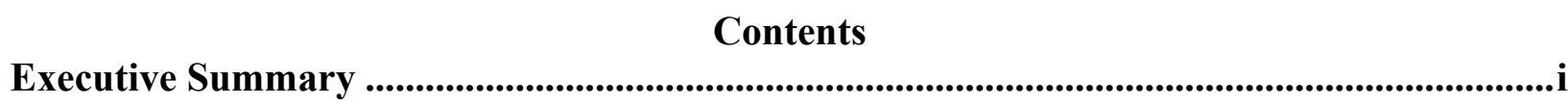 }} \\
\hline & \\
\hline 1 & 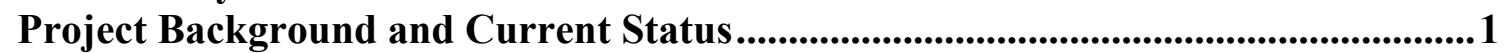 \\
\hline 1.1 & 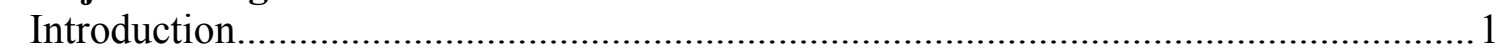 \\
\hline 1.2 & Approach.......... \\
\hline 1.3 & Status.......................... \\
\hline 1.4 & 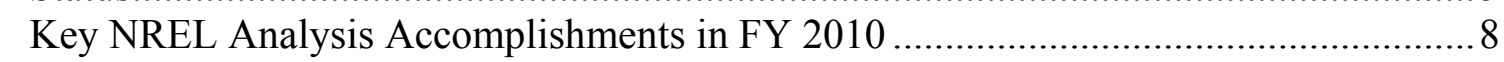 \\
\hline 2 & Results \\
\hline 2.1 & Vehicle Results \\
\hline 2.2 & Infrastructure Results... \\
\hline 2.3 & Conclusions and Future Directions.... \\
\hline 2.4 & Recent Publications/Presentations ............ \\
\hline 2.5 & References............ \\
\hline 2.6 & Composite Data Products Referenced in Previous Discussion............................... 30 \\
\hline
\end{tabular}

\section{Figures}

Figure 1: Photographs of the industry partners providing data to NREL on hydrogen fuel cell electric vehicles and fueling infrastructure included in this report (Photo credit: Keith Wipke)

Figure 2: Four examples of hydrogen production and refueling facilities (Photo credit: Keith Wipke) ..........................................................................................................

Figure 3: Data flow for Hydrogen Secure Data Center (HSDC) analysis and results, overlaid on

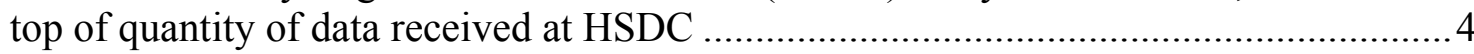

Figure 4: Introductory screen of NREL's Fleet Analysis Toolkit.................................................. 5

Figure 5: Cumulative number of vehicles deployed, by hydrogen storage type and status ............6

Figure 6: Cumulative stations commissioned with current status ..................................................

Figure 7: Type and number of hydrogen stations with current status ........................................

Figure 8: Current location of hydrogen stations in the United States as of August 2010 ............... 8

Figure 9: Thumbnail images of the 80 CDPs published in spring 2010 .................................... 9

Figure 10: Screen capture from NREL's composite data product Web site.................................... 10

Figure 11: Approach for characterizing voltage transient cycles................................................... 18

Figure 12: Fuel cell system efficiency (CDP08) ........................................................................ 30

Figure 13: Fuel cell system operating power (CDP46) .............................................................30

Figure 14: Fuel cell system energy within power levels (CDP53)................................................31

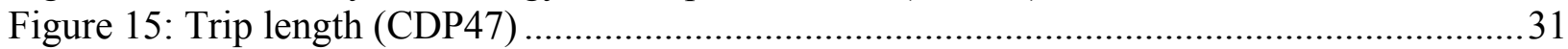

Figure 16: Fuel cell electric vehicle with comparison to standard drive cycles (CDP66) .............32

Figure 17: Percent idle in trip with comparison to standard drive cycles (CDP65).......................32

Figure 18: Fuel cell system energy in trips (CDP55) ..................................................................3

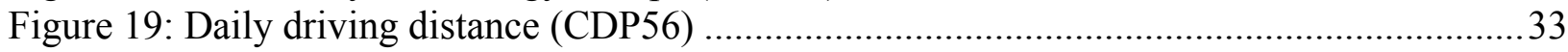

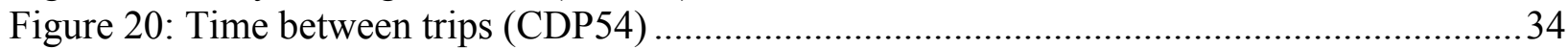

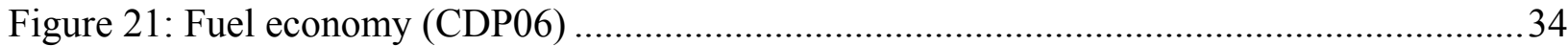

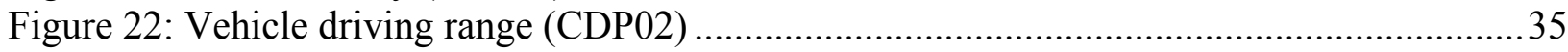

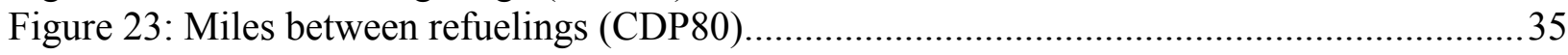

Figure 24: Percentage of theoretical range traveled between refuelings (CDP33) .......................36

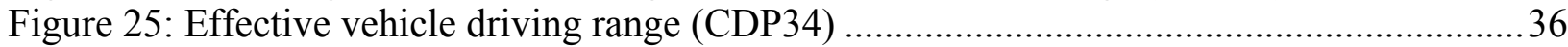

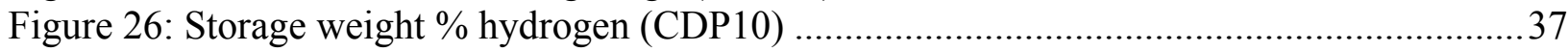




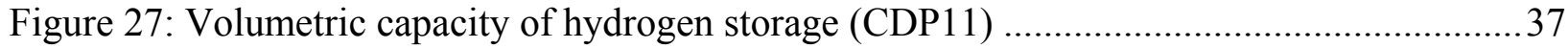

Figure 28: Hydrogen storage system mass and volume breakdown (CDP57) .............................38

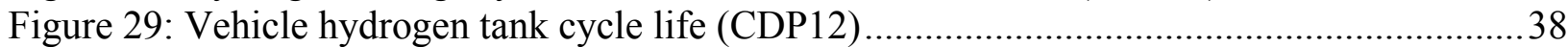

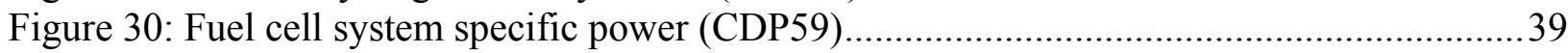

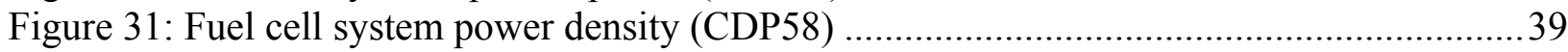

Figure 32: Fuel cell system specific power, including hydrogen storage (CDP04) ...................40

Figure 33: Fuel cell system power density, including hydrogen storage (CDP03) ....................40

Figure 34: Hours accumulated and projected hours to 10\% stack voltage degradation (CDP01) 41

Figure 35: Maximum fuel cell power degradation - Gen 1 (CDP69) .........................................41

Figure 36: Maximum fuel cell power degradation - Gen 2 (CDP70) ......................................42

Figure 37: Fuel cell stack projected hours as a function of voltage drop (CDP73) ...................42

Figure 38: Power drop during fuel cell stack operating period (CDP68) .................................43

Figure 39: Projected hours to OEM low power operation limit (CDP71) .................................43

Figure 40: Fuel cell stack operation hours (CDP67) ...........................................................4

Figure 41: Fuel cell stack trips per hour histogram (CDP16) .............................................. 44

Figure 42: Statistics of trips/hour vs. operating hour (CDP17) .........................................45

Figure 43: Primary factors affecting learning demonstration fleet fuel cell degradation (CDP48)

Figure 44: Primary factors affecting learning demonstration team fuel cell degradation (CDP49)

Figure 46: Fuel cell transient voltage and time change (CDP75) ............................................47

Figure 47: Fuel cell transient cycles by mile and by minute (CDP74) ...................................47

Figure 48: Fuel cell transient rate by cycle category (CDP76) ............................................ 48

Figure 49: Fuel cell transient voltage changes by cycle category (CDP77) .............................48

Figure 50: Percentage of trip time at steady state (CDP79) .................................................49

Figure 51: Fuel cell transient cycles outside of specified voltage levels (CDP78) .....................49

Figure 52: Fuel cell electric vehicle maintenance by system (CDP64) ....................................50

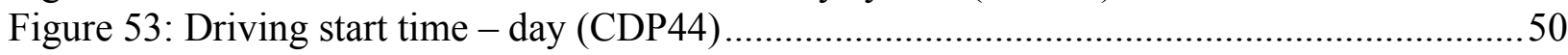

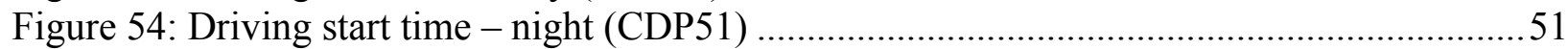

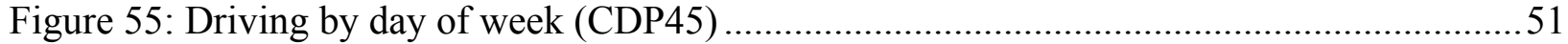

Figure 56: Safety reports - vehicles (CDP09)................................................................52

Figure 57: Range of ambient temperature during vehicle operation (CDP21) ..........................52

Figure 58: Fuel cell start times from sub-freezing soak conditions (CDP05) ............................53

Figure 59: Time between trips \& ambient temperature (CDP19) ...........................................53

Figure 60: Difference between tank and ambient temperature prior to refueling (CDP72).........54

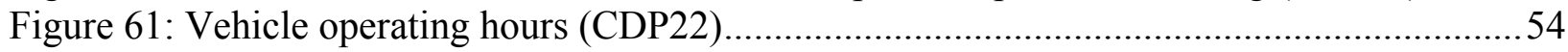

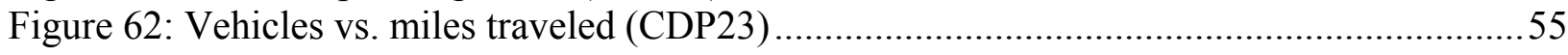

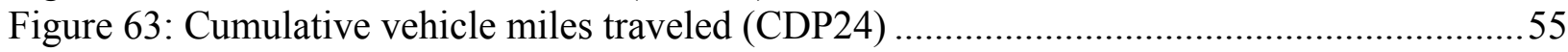

Figure 64: Onsite hydrogen production efficiency (CDP13) ................................................56

Figure 65: Onsite hydrogen production efficiency vs. capacity utilization (CDP60) .................56

Figure 66: Learning Demonstration vehicle greenhouse gas emissions (CDP62) .....................57

Figure 67: Refueling station compressor efficiency (CDP61) ..........................................5

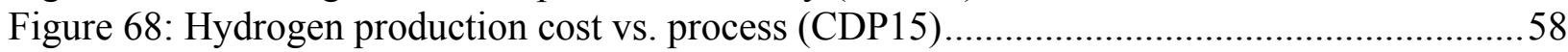

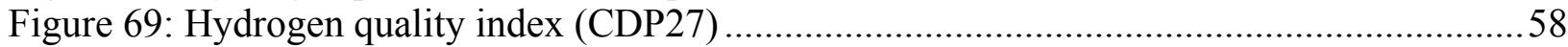

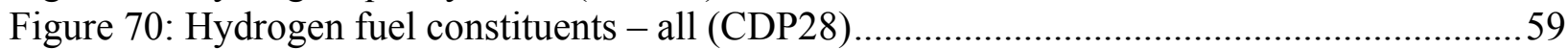


Figure 71: Hydrogen fuel constituents - sulfur (CDP28) …………….....................................59

Figure 72: Hydrogen fuel constituents - total hydrocarbons (CDP28) ..........................................6

Figure 73: Hydrogen fuel constituents - total halogenates (CDP28) ...........................................6 60

Figure 74: Hydrogen fuel constituents - particulate concentration (CDP28) ...............................61

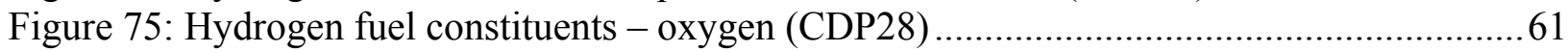

Figure 76: Hydrogen fuel constituents - nitrogen (CDP28) .....................................................62

Figure 77: Hydrogen fuel constituents - nitrogen + helium + argon (CDP28) ................................6. 62

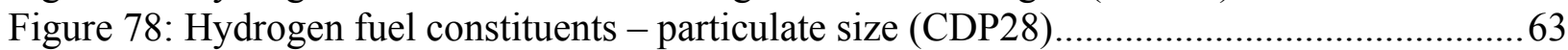

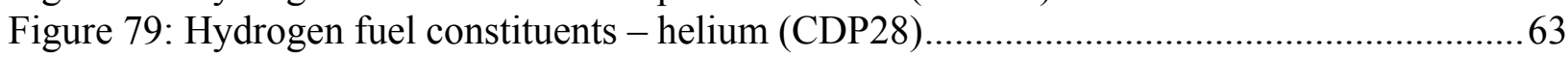

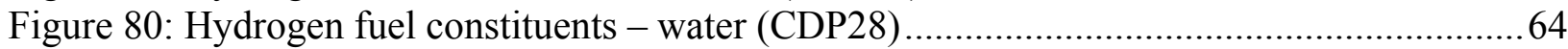

Figure 81: Hydrogen fuel constituents - formic acid (CDP28) ...................................................64

Figure 82: Hydrogen fuel constituents - formaldehyde (CDP28) ……………………................65

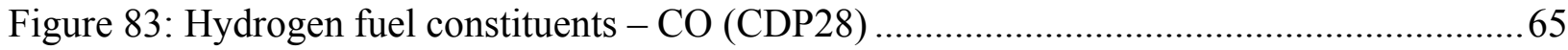

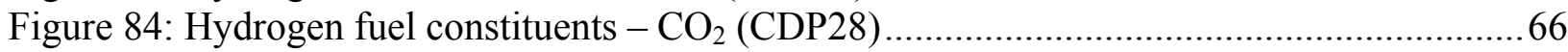

Figure 85: Hydrogen fuel constituents - total (CDP28).............................................................6 66

Figure 86: Hydrogen fuel constituents - argon + nitrogen (CDP28) ...........................................6 67

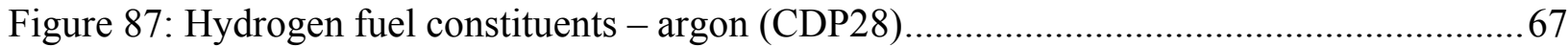

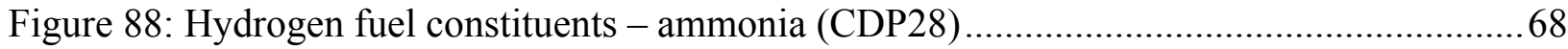

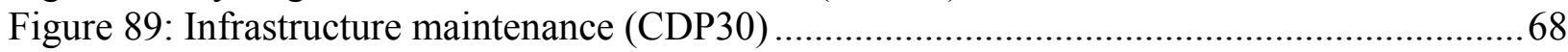

Figure 90: Hydrogen fueling station maintenance by system (CDP63)........................................69

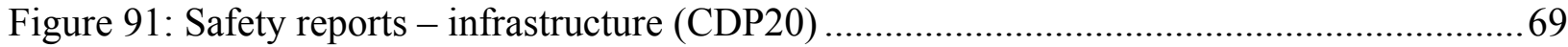

Figure 92: Primary factors of infrastructure reports (CDP37) ……………............................. 70

Figure 93: Average refuelings between infrastructure safety reports (CDP35) ………................ 70

Figure 94: Type of infrastructure safety report by quarter (CDP36) ........................................... 71

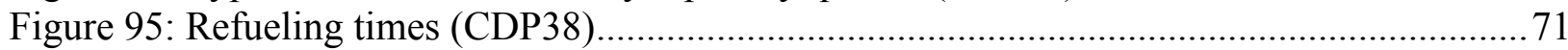

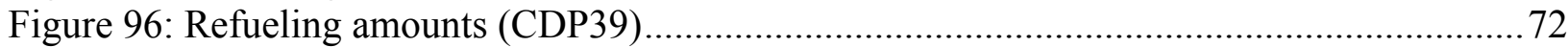

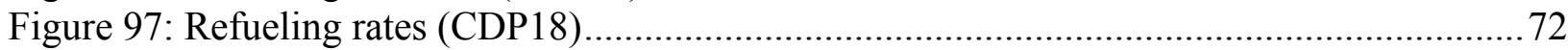

Figure 98: Fueling rates - communication and non-communication fills (CDP29) ......................73

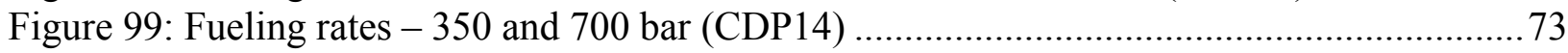

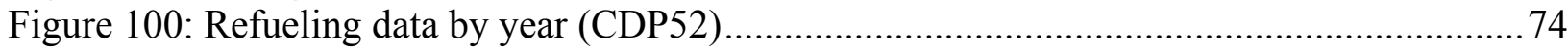

Figure 101: Hydrogen tank level at refueling (CDP40) ..........................................................74

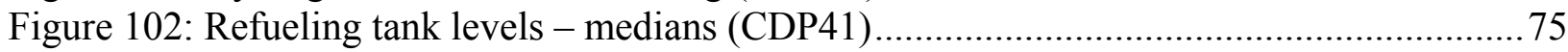

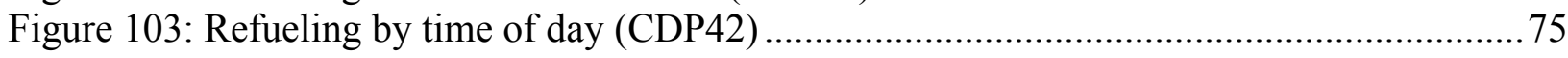

Figure 104: Refueling by time of night (CDP50).................................................................... 76

Figure 105: Refueling by day of week (CDP43).................................................................... 76

Figure 106: Cumulative hydrogen produced or dispensed (CDP26) ...........................................77 


\section{Project Background and Current Status}

\subsection{Introduction}

This report documents and discusses key results based on data through December 2009 from the U.S. Department of Energy's (DOE's) Controlled Hydrogen Fleet and Infrastructure Validation and Demonstration Project, also referred to as the National Fuel Cell Electric Vehicle (FCEV) Learning Demonstration. This report serves as one of many mechanisms to help transfer knowledge and lessons learned within various parts of DOE's hydrogen program as well as externally to other stakeholders. It is the fourth such report in a series, with previous reports being published in July $2007^{[1]}$, November $2007^{[2]}$, and April $2008^{[3]}$. Other mechanisms have included: briefings to FreedomCAR and Fuels technical teams, detailed data and methodology discussions with our industry partners, presentations at technical conferences, postings of individual results on the National Renewable Energy Laboratory's (NREL's) Web site, presentations at DOE's Annual Merit Review, and participation in groups such as the California Hydrogen Business Council, the California Fuel Cell Partnership, and various U.S. Fuel Cell Council working groups.

NREL has now analyzed data from almost five years of the seven-year project. During this time, 144 vehicles have been deployed, 23 project refueling stations were placed in use, and no fundamental safety barriers have been identified. We have analyzed data from over 436,000 individual vehicle trips covering 2,500,000 miles traveled and over 130,000 kg hydrogen produced or dispensed. Key objectives of the project are to evaluate fuel cell durability, vehicle driving range, and on-site hydrogen production cost. This evaluation is performed through validating the use of FCEVs and hydrogen refueling infrastructure under real-world conditions using multiple sites, various climates, and a variety of hydrogen sources. See Figure 1 for photographs of the first- and second-generation vehicles and structure of the industry teams providing NREL data and Figure 2 for examples of the four types of hydrogen refueling stations used in the project.

This report also marks a transition with the makeup of the industry participants who initiated the project in 2004. The projects started with four automotive original equipment manufacturers (OEM) and energy partner teams. Since that time, DOE's California Hydrogen Infrastructure Project executed by Air Products began providing data, and additional hydrogen fueling infrastructure is being installed in California under state and local funding that will also be providing data to NREL. We have also seen the completion of the project for two of the four original OEM and energy partner teams, who provided their last data by early 2010 . New analytical results generated after this report will need to be different, given the fact that there are only two automotive companies now providing data, and their sensitive data still need to be protected. Therefore, while this report is not a final report for the project, it is potentially the last comprehensive report to provide new commentary on the data involving all four automotive OEM teams up to December 2009. 

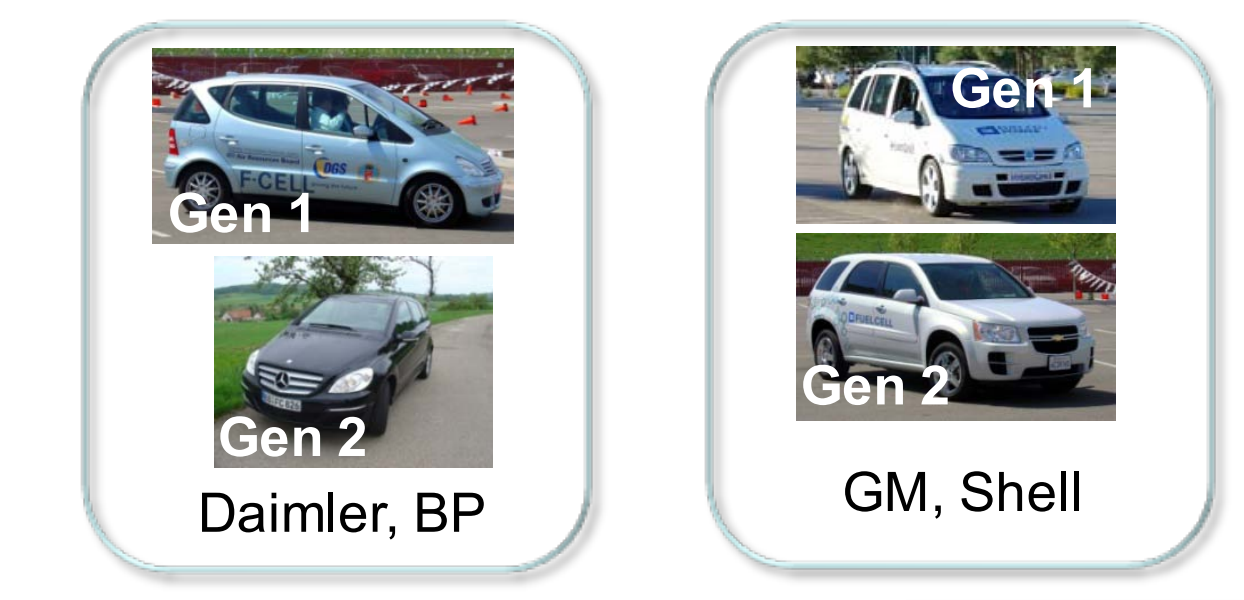

Chevron,
UTC Power, Hyundai-Kia Gen 82

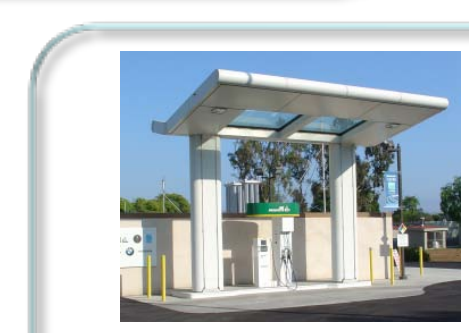

Air Products (CHIP)

Ford, BP
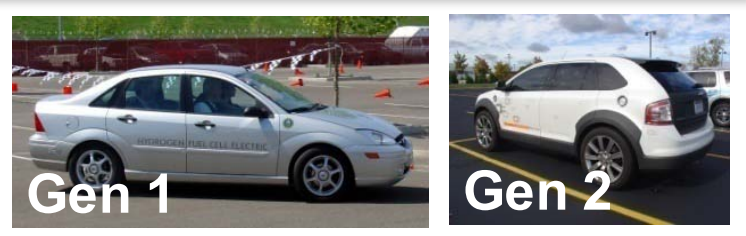

Figure 1: Photographs of the industry partners providing data to NREL on hydrogen fuel cell electric vehicles and fueling infrastructure included in this report (Photo credit: Keith Wipke) 


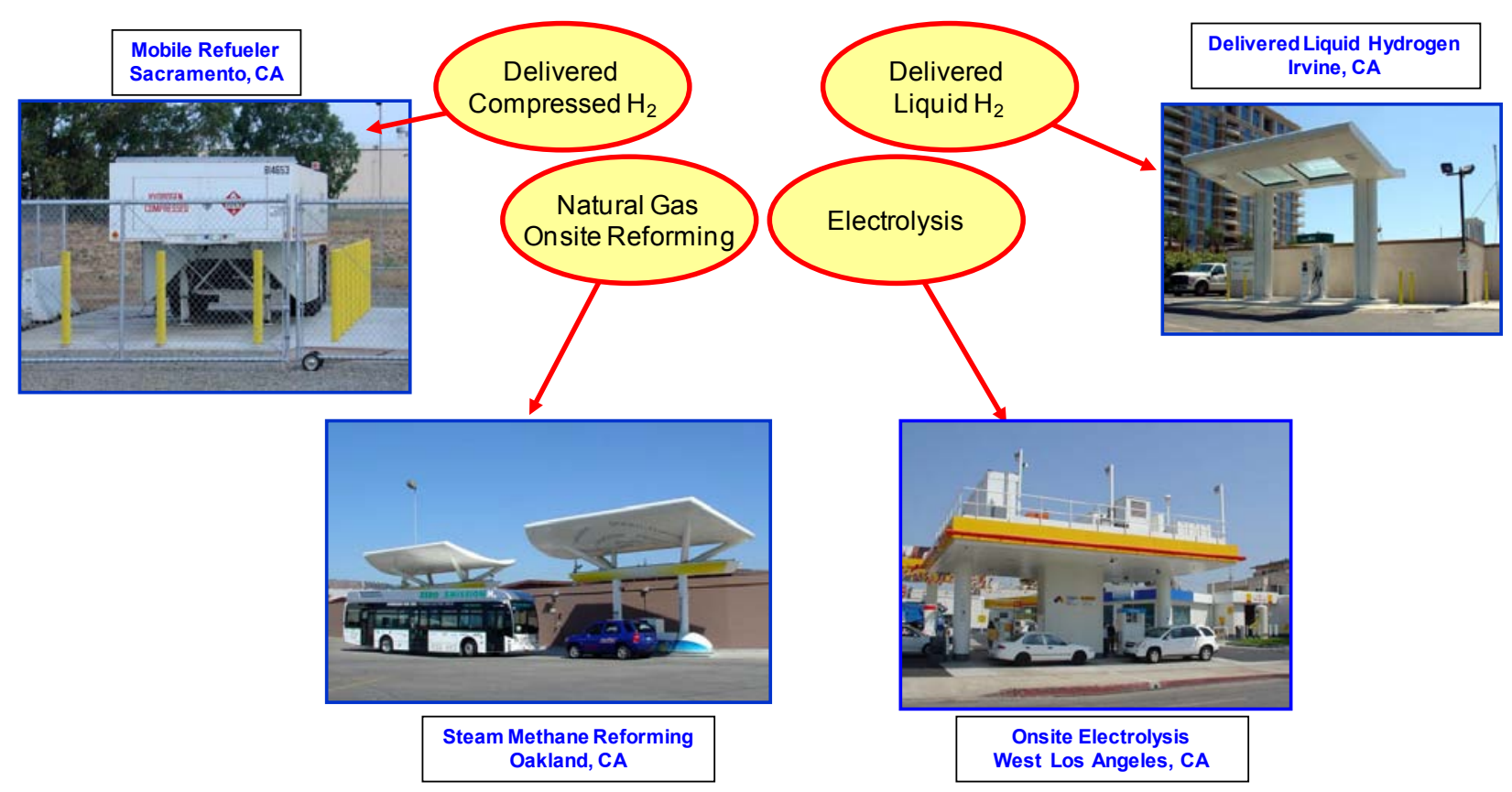

Figure 2: Four examples of hydrogen production and refueling facilities (Photo credit: Keith Wipke)

The three high-level objectives of this project are to validate hydrogen FCEVs and infrastructure against the following targets:

- 250-mile range

- 2,000-hour fuel cell durability

- $\$ 3 /$ gge hydrogen production cost (based on volume production).

NREL works to provide DOE and industry with maximum value from the data produced by this "learning demonstration." We seek to understand the progress toward the technical targets, and provide that information to the Fuel Cell Technologies (FCT) program research and development (R\&D) activities. This information will allow the program to move more quickly toward costeffective, reliable hydrogen FCEVs and the supporting fueling infrastructure.

\subsection{Approach}

NREL's approach to accomplishing the project's objectives is structured around a highly collaborative relationship with each of the industry teams: Chevron/Hyundai-Kia, Daimler/BP, Ford/BP, GM/Shell, and Air Products. We are receiving raw technical data on both the hydrogen vehicles and the fueling infrastructure that allows us to perform unique and valuable analyses across all teams. Our primary objectives are to feed the current technical challenges and opportunities back into the DOE Fuel Cell Technologies Program and assess the current status and progress toward targets.

To protect the commercial value of these data for each company, we established the Hydrogen Secure Data Center (HSDC) at NREL to house the data and perform our analysis. Figure 3 shows the flow of data and results, overlaid on top of the quantity of data received at the HSDC. 
To ensure value is fed back to the hydrogen community, we publish composite data products (CDPs) twice a year at technical conferences. These data products report on the progress of the technology and the project, focusing on the most significant results. Additional CDPs are conceived as additional trends and results of interest are identified. We also provide our detailed analytical results from each individual company's data back to them to maximize the industry benefit from NREL's analytical work and obtain feedback on our methodologies. These individual company results are not made available to the public.

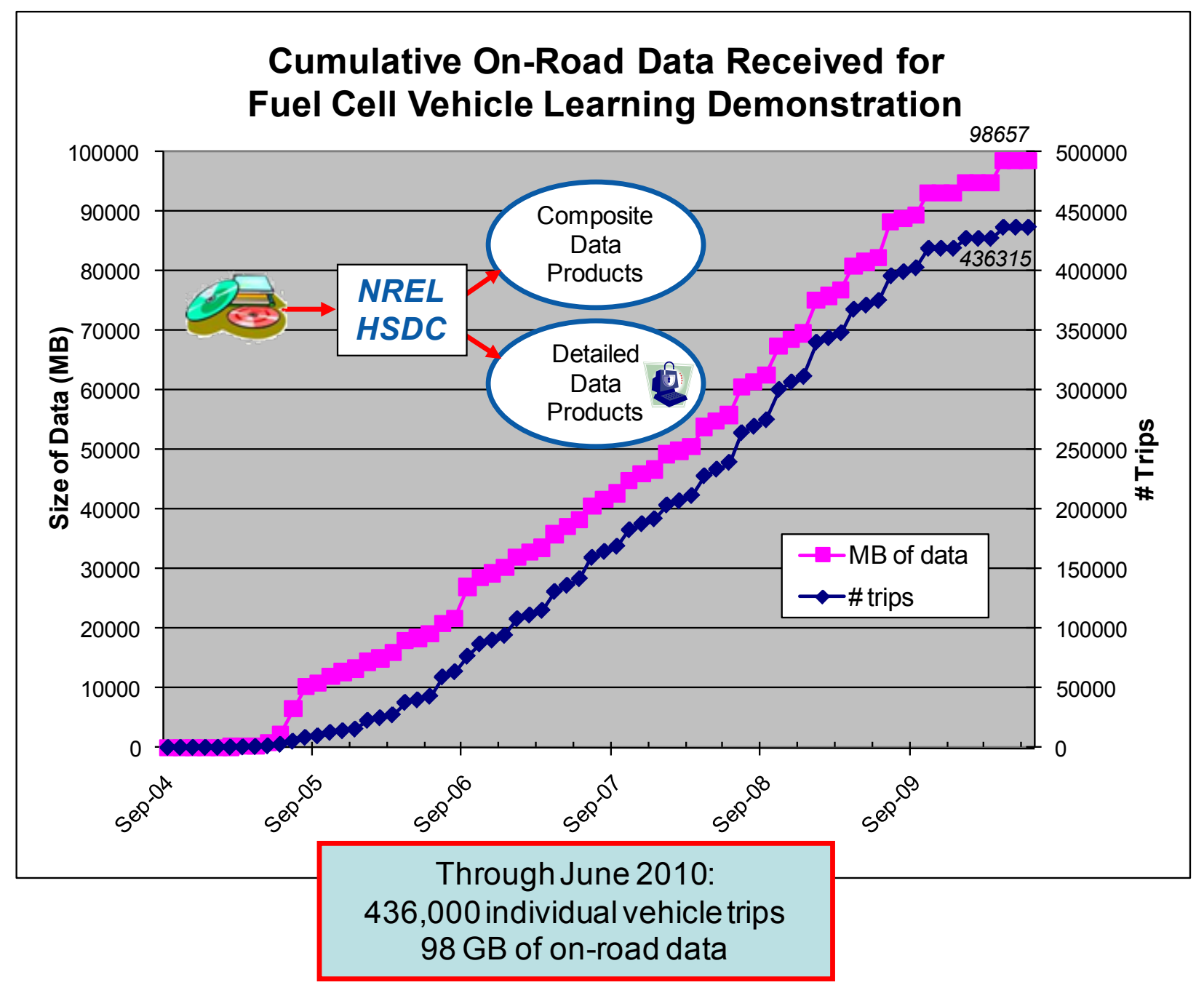

Figure 3: Data flow for Hydrogen Secure Data Center (HSDC) analysis and results, overlaid on top of quantity of data received at HSDC

In order to be able to evaluate such a large data set, NREL developed an in-house tool called the Fleet Analysis Toolkit (NRELFAT), which helped organize and automate the various analyses being performed on both the vehicles and the infrastructure. Figure 4 shows a screen capture of the initial screen. The tool has recently undergone a major rework to allow the analysis functions to be applied not only to FCEVs, but also to fuel cell buses, fuel cell forklifts, laboratory fuel cell data, backup fuel cells, stationary fuel cells, and plug-in hybrid vehicles. The overall functionality of the NRELFAT has been covered in previous publications, so it will not 
be discussed in detail here. Having such a sophisticated tool in-house allowed us to rapidly respond to DOE's and the Department of Defense's needs for evaluation of early market fuel cell applications.

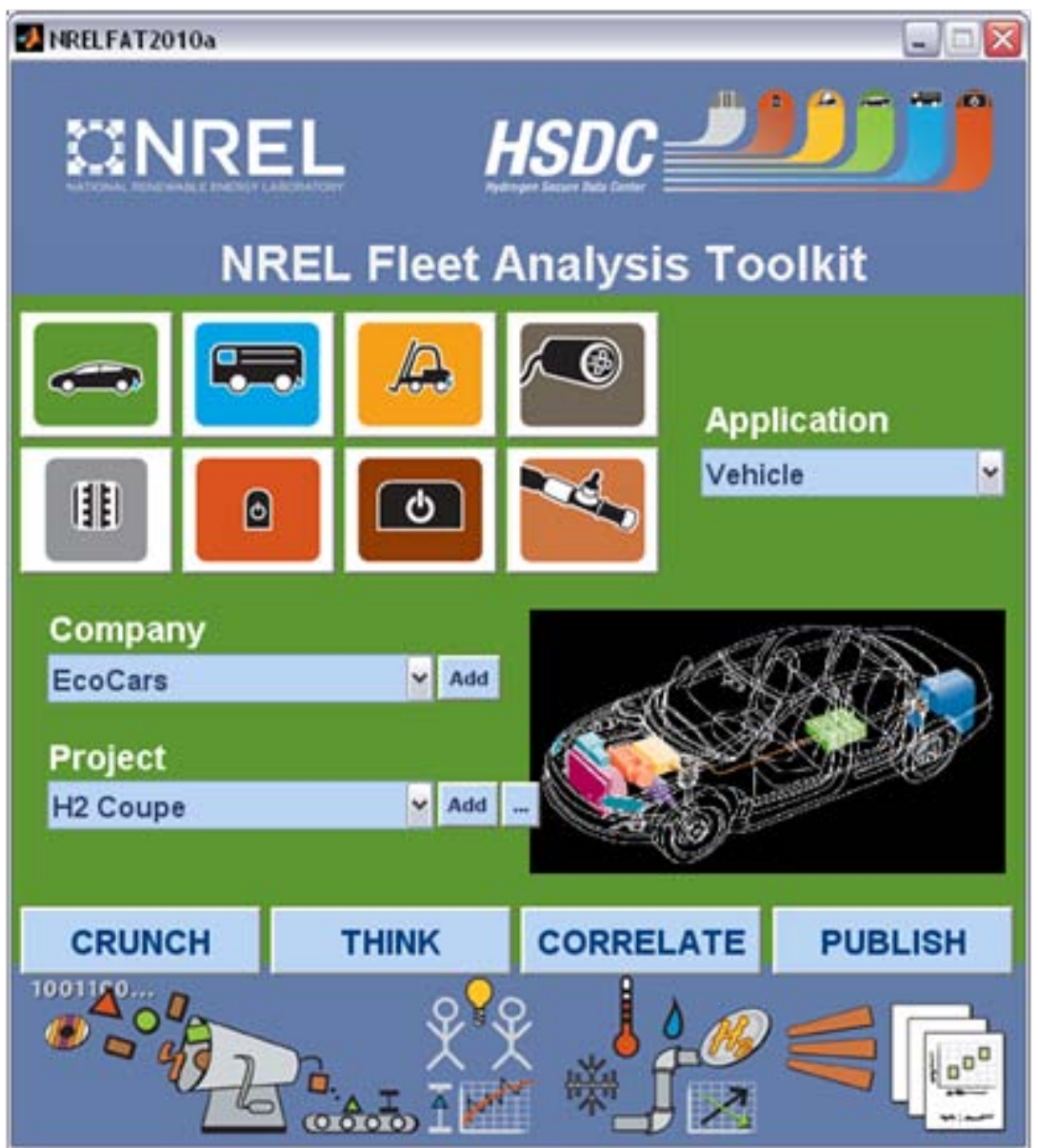

Figure 4: Introductory screen of NREL's Fleet Analysis Toolkit.

\subsection{Status}

Industry teams were selected by DOE for this project in April 2004. The first data started flowing to NREL in September 2004 after DOE had signed cooperative agreements with the industry partners. Since that time, as shown in Figure 3, data has been flowing continuously to NREL on a monthly or quarterly basis from the teams. The project was originally scheduled to be completed in September 2008, but was extended through September 2009. Two of the teams, Ford/BP and Chevron/Hyundai-Kia, completed their projects as scheduled in September 2009, while two other teams led by Daimler and GM continued beyond that time with a new scheduled completion date of September 2011. There will be 40 vehicles evaluated in the final portion of this project to track performance improvements from the latest technology. By the end of the project, it is anticipated a cumulative total of 170 vehicles will have been evaluated.

This transition is reflected in some of the CDPs, which show the number and status of FCEVs (Figure 5) and hydrogen fueling stations (Figure 6 and Figure 7). As shown in Figure 5, there were a gradual number of vehicles retired through 2008 (approximately 20 vehicles), with a 
much larger number retired by the fourth quarter of 2009, when the two teams completed their projects. Notice that all of the first-generation vehicles utilizing 350-bar pressurized hydrogen storage or liquid hydrogen have now been retired with only 700-bar storage vehicles continuing to operate.

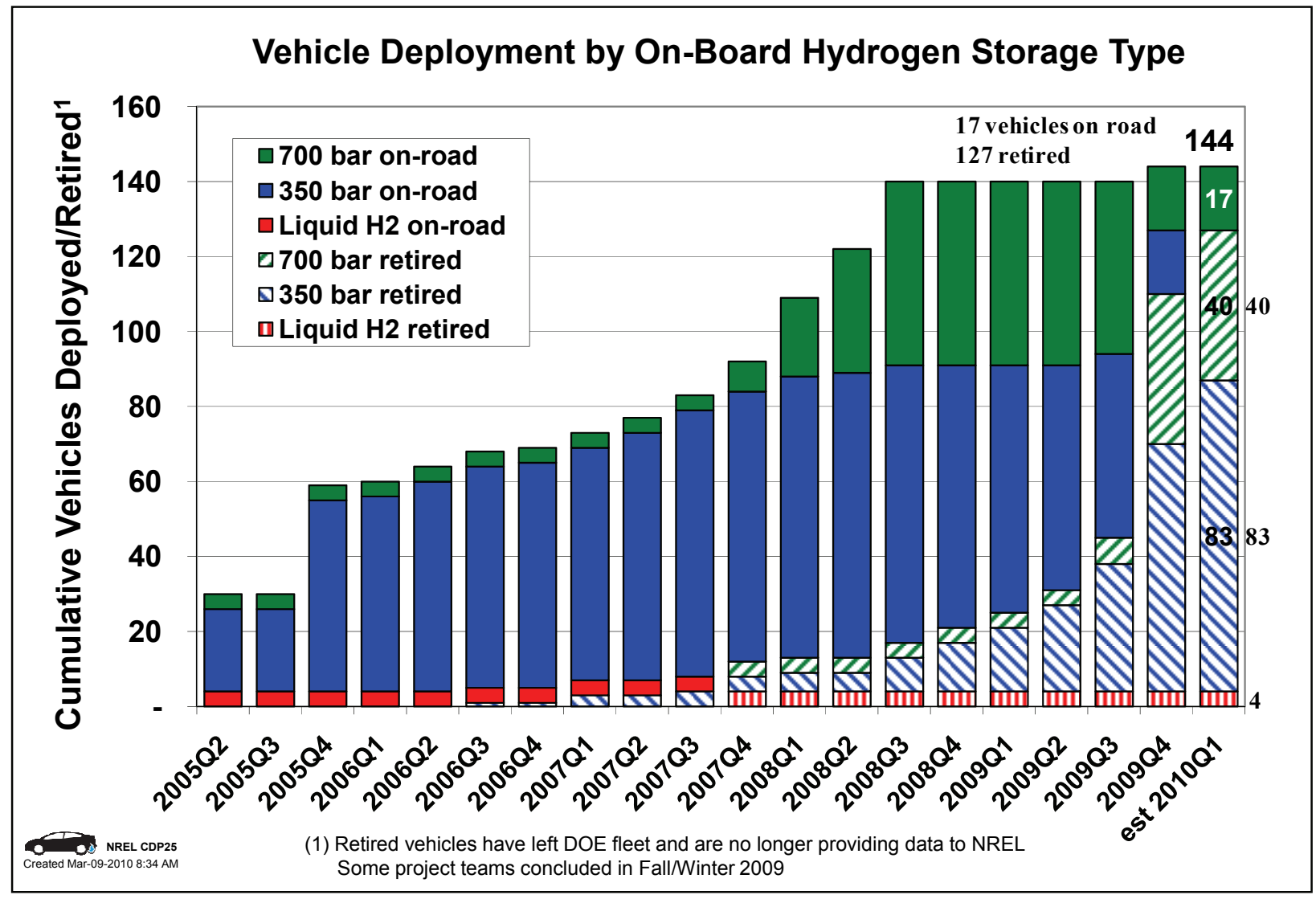

Figure 5: Cumulative number of vehicles deployed, by hydrogen storage type and status

Figure 6 shows the cumulative number of stations deployed as 23. Of those 23, as of December 2009, 8 have been decommissioned, 10 are continuing operation outside of the project, and 5 are continuing within the project. However, several of the 10 that are shown as continuing outside of the project are expected to be decommissioned in 2010. Figure 7 shows the type of production or delivery technology demonstrated by each station. The highest number of stations used delivered compressed hydrogen, followed by on-site electrolysis. Over half of the electrolysis stations have been retired, whereas only one of the five on-site natural gas reformation stations has been retired.

While many of the project stations may come to the end of their useful demonstration life in the next few years, many new or upgraded stations are being opened in California as a result of the combined efforts of the California Air Resources Board, the California Energy Commission, and the South Coast Air Quality Management District. These new stations are helping provide a bridge from the early demonstration stations (from the Learning Demonstration and other demonstrations) to a point in the future when the number of FCEVs is large enough to create a market pull for private sector investment. 


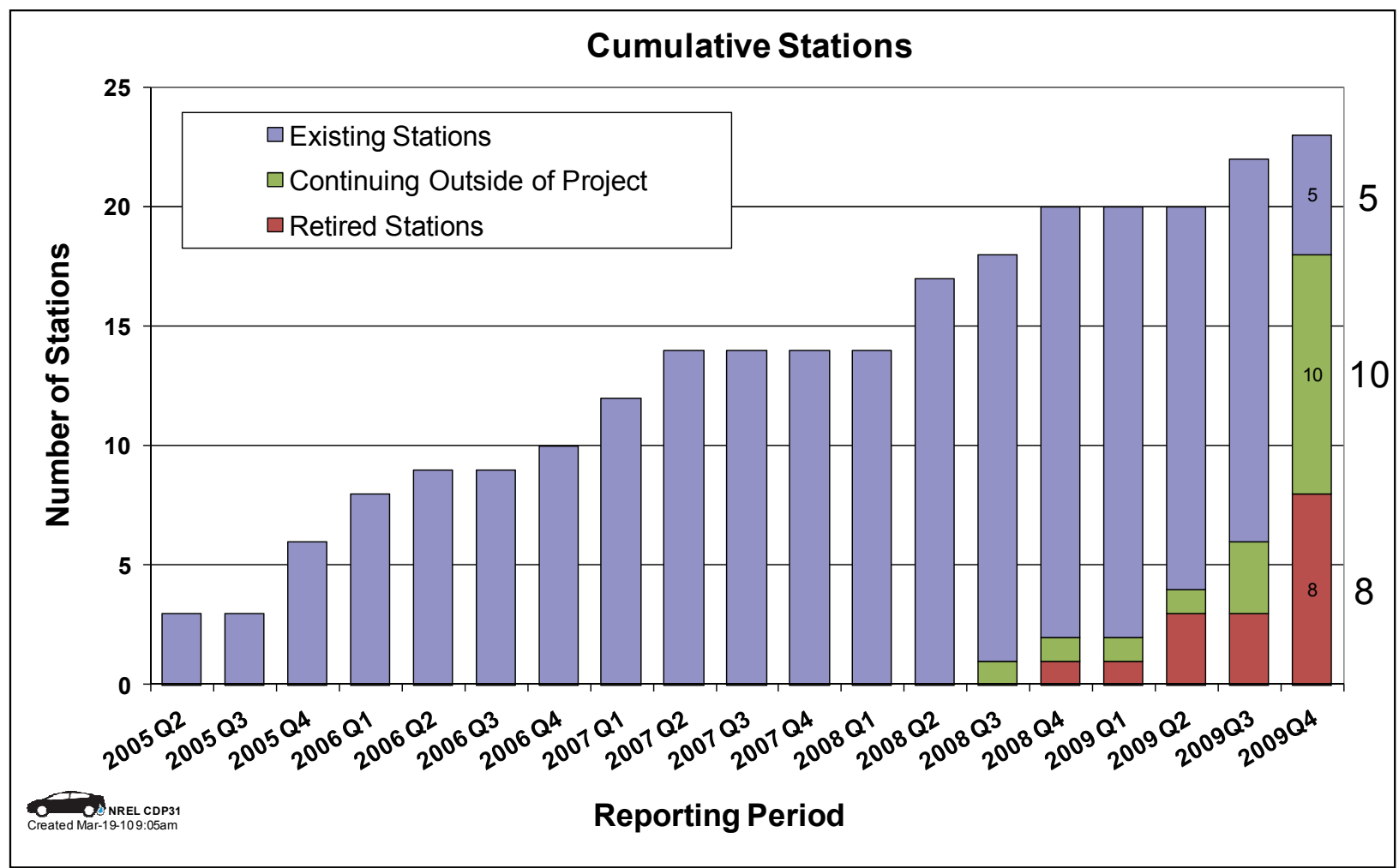

Figure 6: Cumulative stations commissioned with current status

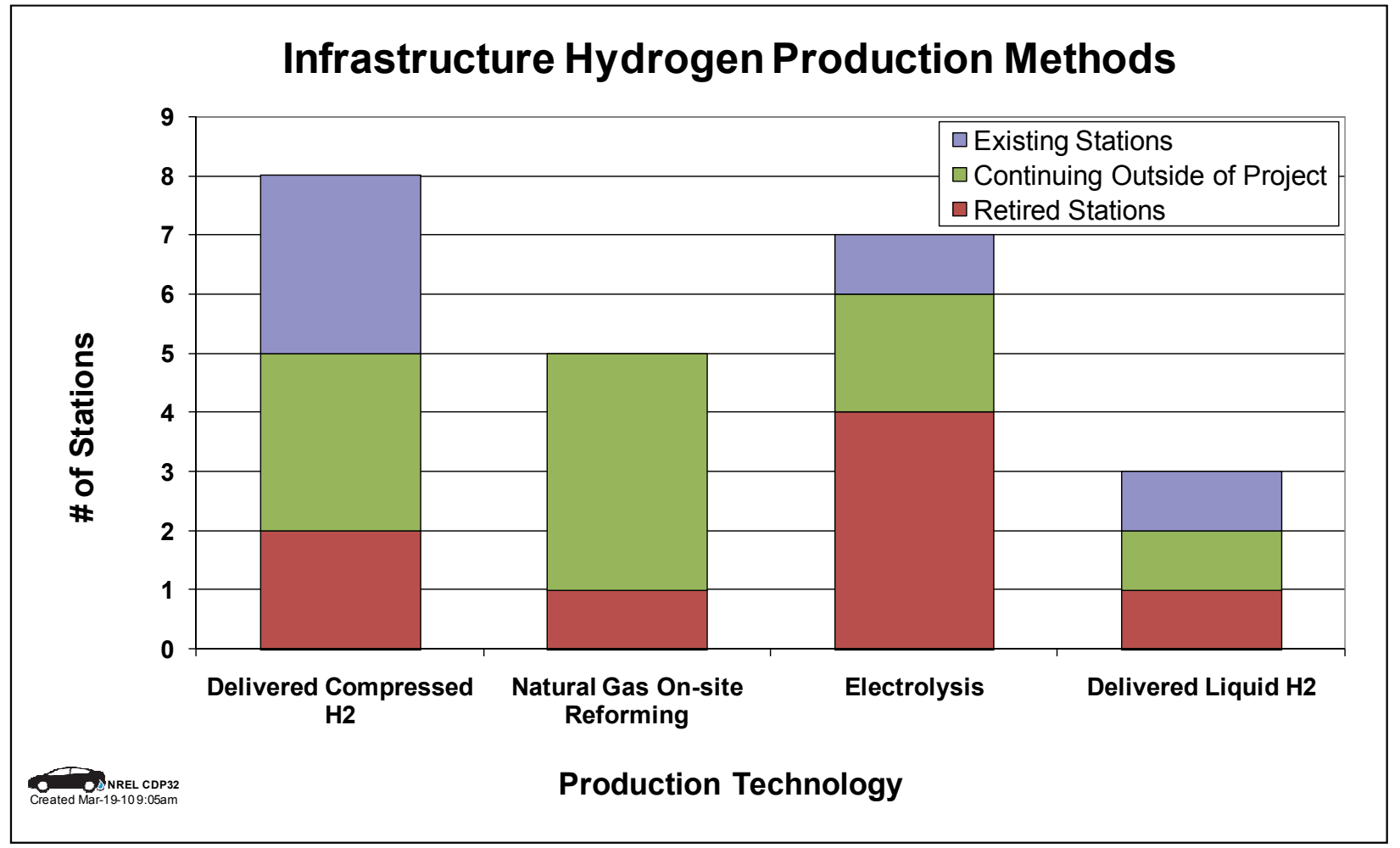

Figure 7: Type and number of hydrogen stations with current status 
In order to obtain a variety of data, the project included geographically diverse locations for demonstration of the vehicles and infrastructure. Initially, there were five regions of the country involved, including the San Francisco Bay area, the Los Angeles area, the Detroit area, Orlando, and a corridor from Washington, DC, to New York. In the last year, as two of the teams completed their portions of the project, some of the stations have been decommissioned, including all of the stations in Florida. The current project (and other) stations in the United States are shown in Figure 8.

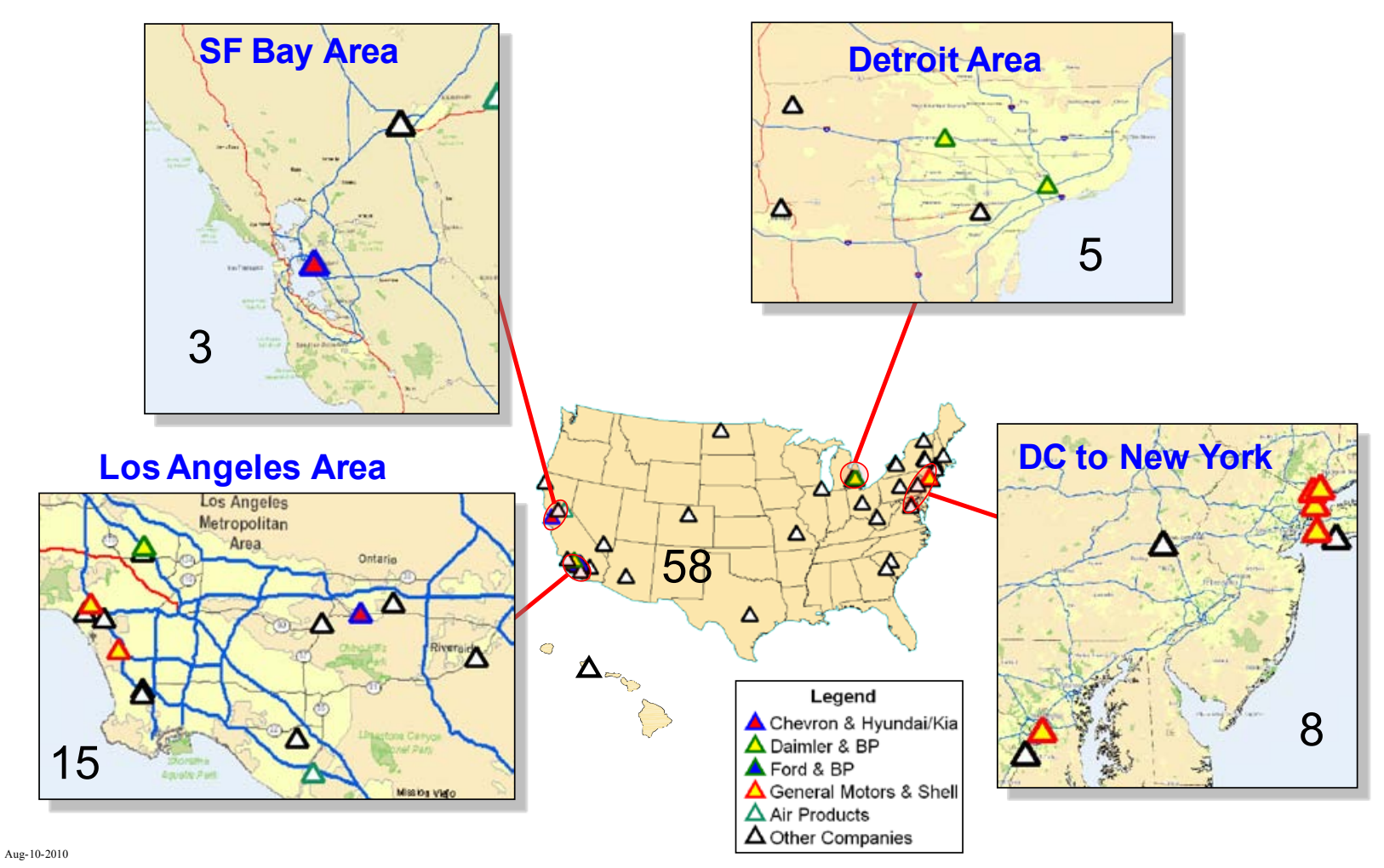

Figure 8: Current location of hydrogen stations in the United States as of August 2010.

\subsection{Key NREL Analysis Accomplishments in FY 2010}

- Created and published 80 CDPs (the ninth and largest set of public results) representing results from analyzing almost five years of Learning Demonstration data. See Figure 9 for thumbnail images of all 80 results.

- Received and processed data from a total of 436,000 individual vehicle trips, amounting to over $98 \mathrm{~GB}$ of on-road data, since inception of the project.

- Documented and archived each quarter's analysis results in the NRELFAT GUI.

- Executed NRELFAT to produce detailed data results and CDPs in parallel for easier industry and internal review. 
- Presented project results publicly at the Fuel Cell Seminar, the California ZEV Technology Forum, the National Hydrogen Association conference, the World Hydrogen Energy Conference, and the 2010 DOE Fuel Cell Technologies Program Merit Review meeting.

- Maintained NREL's Web page at http://www.nrel.gov/hydrogen/cdp topic.html to allow direct public access to the latest CDPs organized by topic, date, and CDP number.

- Provided presentations of results to key stakeholders, including two FreedomCAR and Fuel technical teams (storage and fuel cells).

- Leveraged NREL tools and capabilities to enable analytical results to be generated from fuel cell forklifts and other early-market fuel cell applications.

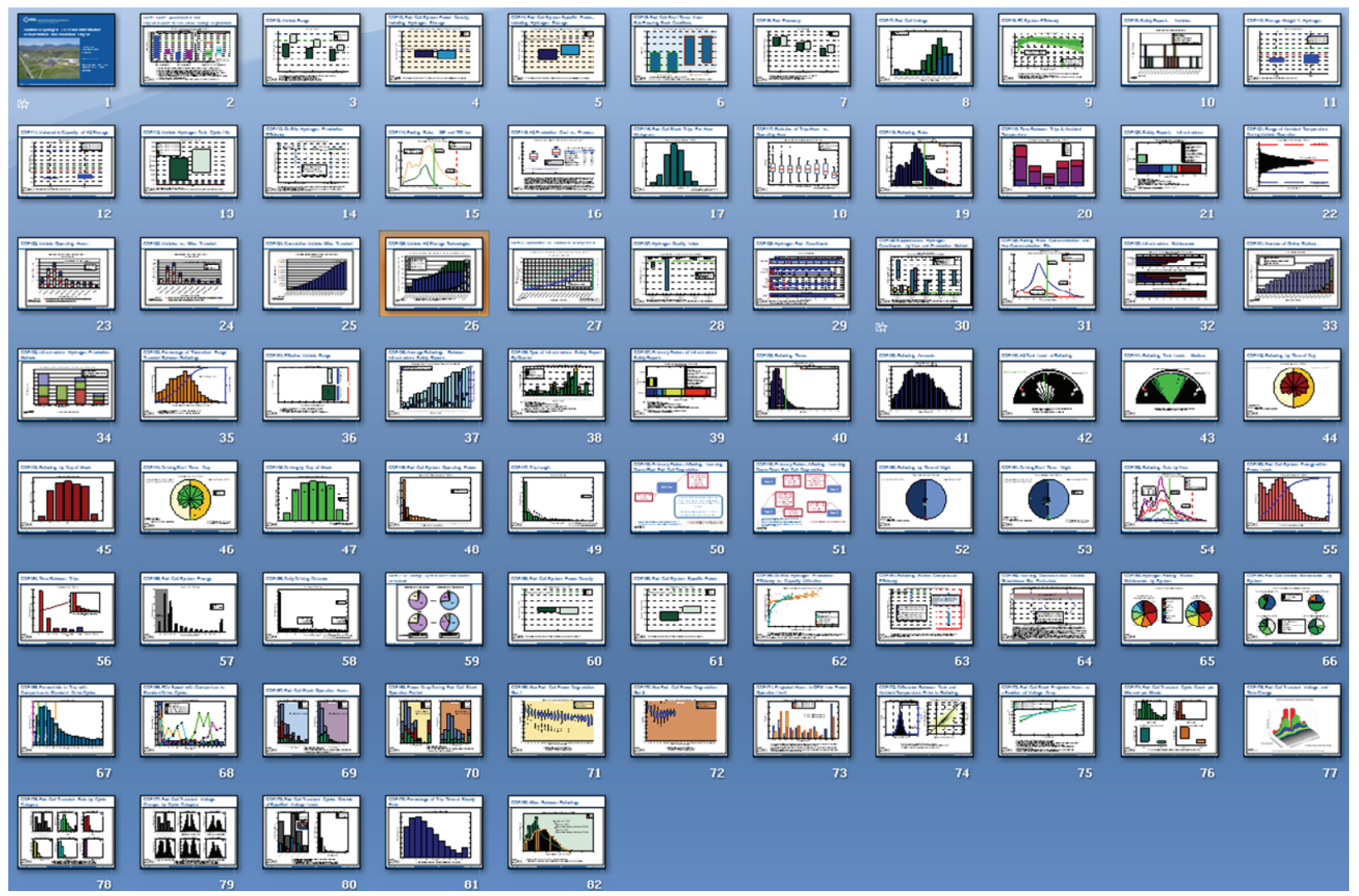

Figure 9: Thumbnail images of the 80 CDPs published in spring 2010 


\section{Results}

The results discussed in this report came from analyzing almost five years of vehicle and infrastructure data (through December 2009). This resulted in a total of 80 new or updated CDPs that were published and could be presented publicly. To accomplish the analysis, we continued to improve and revise our in-house fleet analysis tool, NRELFAT. Since there are so many technical results from the project, they cannot all be discussed during 15-20 minute conference presentations. Therefore, in January 2007 NREL launched a Web page at http://www.nrel.gov/hydrogen/cdp topic.html to provide the public with direct access to the results (see Figure 10 for a screen capture of this Web page). The Web site makes current and archived CDPs available to the public. Highlights from the most recent CDPs were presented publicly at the National Hydrogen Association conference and the DOE Annual Hydrogen Program Merit Review as the Spring 2010 Results. In order to focus on high-level results, conclusions, and trends, this report will discuss the results in bullet form, organized by technical topic. The last section includes all of the CDPs in the order they are referenced.

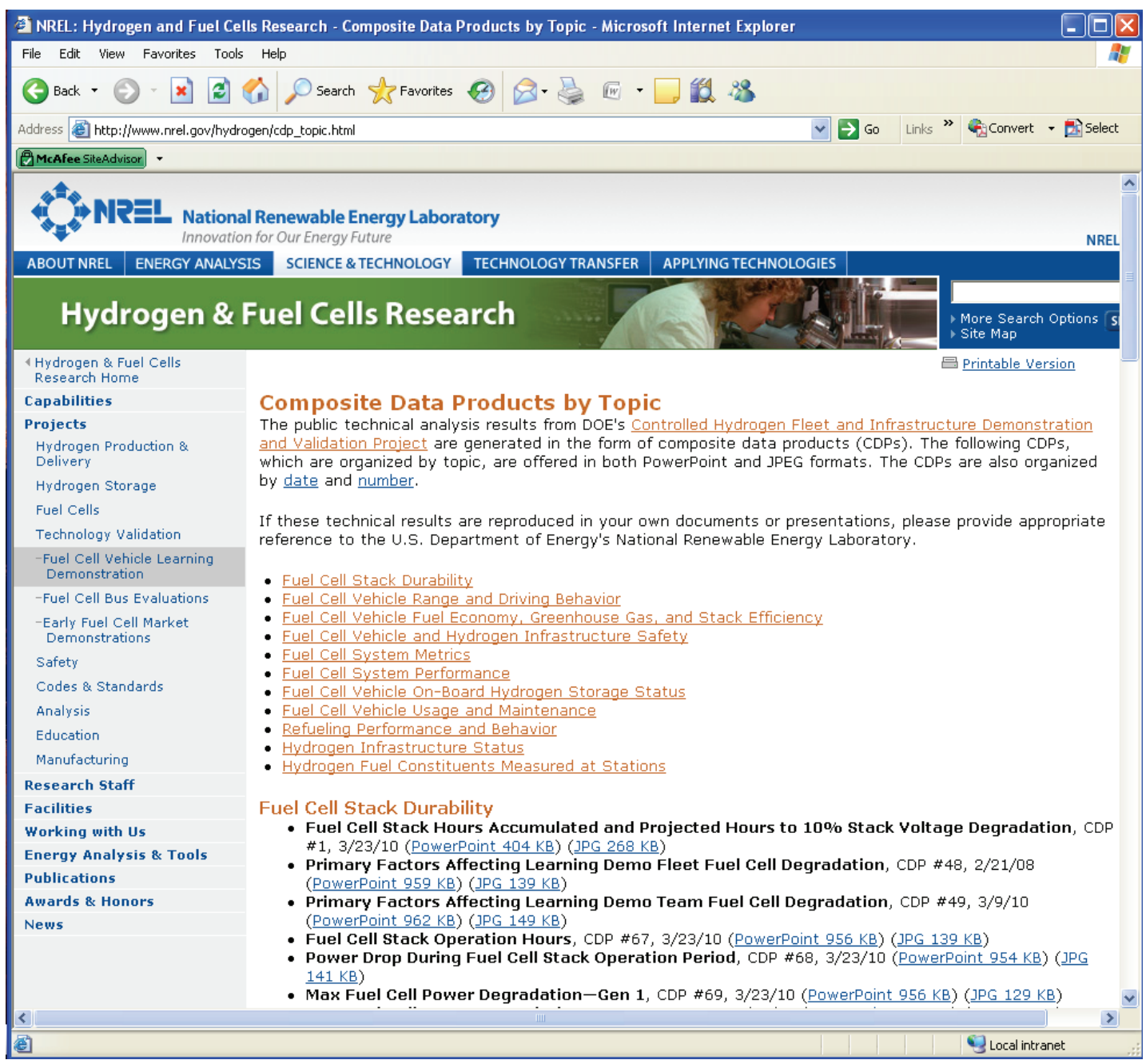

Figure 10: Screen capture from NREL's composite data product Web site 


\subsection{Vehicle Results}

- Fuel Cell System Efficiency: Researchers from the car companies measured fuel cell system efficiency from select vehicles on a vehicle chassis dynamometer at several steady-state points of operation. NREL worked with the data and the companies to ensure that appropriate balance-of-plant electrical loads were included. This ensured that the results were comparable to the target and based on the entire system rather than just the stack. DOE's technical target for net system efficiency at quarter-power is $60 \%$. Baseline data from the four Learning Demonstration teams several years ago showed a range of net system efficiency from $51 \%$ to $58 \%$ for first-generation systems, which was very close to the target. As second-generation vehicles were introduced, the companies also performed baseline dynamometer testing that revealed an efficiency of $53 \%$ to $59 \%$ at quarter-power, within one percentage point of the target. Since the last progress report was published, we have also expanded this CDP to include a comparison of the efficiency at full power, where DOE's target was 50\% net system efficiency (Figure 12). The data show first-generation systems as having 30\% to 54\% efficiency full power while secondgeneration systems have $42 \%$ to $53 \%$ efficiency, exceeding the $50 \%$ target.

Additionally, we published the ranges of efficiency data from the four teams with the two shaded green sections, showing that Gen 2 data are more closely clustered than Gen 1 data.

- Fuel Cell Operating Points: Since a fuel cell system's peak efficiency is normally at low powers (typically $10 \%$ to $25 \%$ ), we evaluated the fuel cell system operation from a number of different perspectives to better understand whether the unique performance characteristics of the fuel cell system were being maximized. As reported in the last progress report ${ }^{[3]}$, a significant amount of time is being spent at low fuel cell system power (Figure 13). In fact, the teams' average amount of time spent at $<5 \%$ of peak power was over $50 \%$. We subsequently subdivided these bars into the time with zero speed (new since last progress report) to show that almost all of the time with zero speed is at less than $10 \%$ fuel cell system power. However, for overall vehicle fuel efficiency, the amount of energy spent at various power levels and the efficiency at those power levels are the critical metrics. We found that much of the fuel cell energy (about 40\%) is expended at fuel cell power levels between $20 \%$ and $50 \%$ of peak power (Figure 14). This matches up very well with the peak fuel cell system efficiency points (at approximately $25 \%$ power) previously discussed. Only about $20 \%$ of the energy is expended at powers less than $15 \%$ of peak power, indicating that low power efficiency is not as important as the percentage of time spent there would imply.

- Duty-Cycle Evaluation: In order to understand why so much time was spent at low power, we analyzed the lengths of all trips and compared the results to national statistics (Figure 15). With more than $40 \%$ of the Learning Demonstration trips being less than one mile, it is clear that the amount of time spent at low fuel cell power is due in part to a large number of short trips for which the vehicle is not likely accelerated to higher speeds. This differs from the national driving statistics (overlaid with pink diamonds on this same graph), which show that only about $10 \%$ of the national average trips are less than one mile. If a large number of starts/hour is one of the major degradation factors, as has been reported at the laboratory scale, then this large number of short driving trips could be prematurely shortening the life of the Learning Demonstration fuel cells. 
Further investigation is necessary before that linkage can be made based on our analysis of the real-world data.

Since then we have received many questions about how the vehicles were driven; therefore, we created two new CDPs that compared the Learning Demonstration driving with well-known dynamometer drive cycles. Figure 16 compares the distribution of operating time to that of four dynamometer drive schedules. We can see that the large amount of time spent at 0-5 mph matches most closely to the Japanese 10-15 mode drive schedule ( $40 \%$ of time spent in this speed bin), and has a very low percentage of time at the higher speeds contained in the HWFET (highway driving) and US06 (aggressive acceleration/deceleration) driving schedules. This is not surprising, given that many of the vehicles were deployed in congested traffic regions such as New York and Los Angeles. We also have a portion of the $0-5 \mathrm{mph}$ bar that shows the zero-speed idle time, shown in gray, which makes up about $28 \%$ of all Learning Demonstration vehicles' driving time. Figure 17 compares the distribution of the trip idle time percentages within each trip to the same four drive cycles. The Learning Demonstration most closely matches the percentage idle of the UDDS (urban driving) cycle with about $12 \%$ of the trips matching that idle time of about $19 \%$.

- The Impact of Short Trips: There has been much public attention on the potential for plug-in electric vehicles (PEVs) to improve the United States' oil-dependency situation. The Learning Demonstration vehicle data were evaluated to see how these early FCEVs were being driven (mostly in fleet operation) and what impact these duty cycles would have on plug-in vehicles and potential future plug-in versions of these FCEVs. We first looked at the amount of energy consumed by all Learning Demonstration vehicle trips (Figure 18) and found that about $35 \%$ of the trips required less than $0.5 \mathrm{kWh}$ of energy to be produced by the fuel cell system (red FC bar in the figure). This indicates that a battery would not require much storage energy to handle several plug-in FCEV trips for the Learning Demonstration vehicles, provided that the battery could also provide the peak power required and survive the larger swings in state-of-charge. However, this is not the entire story, and if the assumption is that PEVs will primarily be recharged slowly during off-peak/night times, then these data need to be analyzed with both the daily miles traveled (Figure 19) and the amount of time between trips (Figure 20) in mind.

What we find is that an effective 20-mile electric range would electrify about one-half of the Learning Demonstration fleet's daily miles traveled. However, this would satisfy only about one-quarter of the national daily average miles traveled. An effective 40-mile electric range would electrify over two-thirds of the Learning Demonstration vehicle miles, and just over half of the national daily miles traveled. While the large number of Learning Demonstration vehicle "hot-starts" could be beneficial for fuel efficiency of a FCEV (about $60 \%$ of trips occur within one hour of the previous trip), this also indicates that there may be limited opportunities for daytime opportunity charging (almost $60 \%$ of the trips are separated by less than one hour, and half of those are separated by less than 10 minutes). Having an engine [internal combustion engine (ICE) or fuel cell] on-board increases the ability to electrify the maximum number of miles and discharge the battery without being forced to recharge during the day for fear of running out of charge before evening. The bottom line is that a thorough analysis of actual target-market duty cycles must occur for the benefits of PEVs to be understood, preferably through using actual 
PEV fleets and recharging behavior. Such an evaluation has been initiated by DOE's Vehicle Technologies Program.

- Vehicle Fuel Economy: Vehicle fuel economy was measured using city and highway drive-cycle tests (Figure 21) on a chassis dynamometer using draft SAE J2572 (left two bars, representing the range of four points, one from each OEM). These raw test results were then adjusted according to U.S. Environmental Protection Agency (EPA) methods to create the "window-sticker" fuel economy that consumers see when purchasing the vehicles ( $0.78 \times$ Hwy, $0.9 \times$ City) (center two bars). This resulted in an adjusted fueleconomy range of 42 to 57 miles $/ \mathrm{kg}$ hydrogen for the four teams for first-generation vehicles, as compared to 43 to $58 \mathrm{miles} / \mathrm{kg}$ for second-generation vehicles. As with all vehicles sold today, including gasoline hybrids, actual on-road fuel economy is slightly lower than this rated fuel economy (right two bars). The on-road fuel economy spans the range of $31 \mathrm{miles} / \mathrm{kg}$ hydrogen to $45 \mathrm{miles} / \mathrm{kg}$ hydrogen for Gen 1 and 36 to $52 \mathrm{miles} / \mathrm{kg}$ hydrogen for Gen 2. This last comparison shows an important finding, which is that Gen 2 vehicles have been made quite a bit more robust to allow higher fuel economy (relative to Gen 1) to be obtained even when driven under all different kinds of conditions.

Note that the EPA has adjusted its testing and reporting methodology, beginning with model-year 2008 vehicles, to try to make the window-sticker fuel economy better reflect on-road driving performance, but this project is using the EPA adjustment that was in place when the vehicles were introduced to avoid performing retests or applying the new corrections that have not been validated for application to hydrogen FCEVs.

- Vehicle Driving Range: Vehicle driving range was calculated using the fuel economy results discussed above and multiplying them by the usable hydrogen stored onboard each vehicle (Figure 22). Using the EPA-adjusted fuel economy resulted in a firstgeneration vehicle range in FY 2008 from just over 100 miles up to 190 miles from the four teams. The second-generation vehicles subsequently pushed this range higher, to 196 to 254 miles using 700-bar storage and met the DOE 250-mile range objective established for this project. In June 2009, an on-road driving range evaluation was performed in collaboration with Toyota and Savannah River National Laboratory. The results indicated a 431-mile on-road range was possible in southern California using Toyota's FCHV-adv FCEV ${ }^{[4]}$. More recently, the significant on-road data obtained from second- and first-generation vehicles allowed a comparison of the real-world driving ranges of all the vehicles in the project (Figure 23). The data show that there has been a $45 \%$ improvement in the median real-world driving range of second-generation vehicles (81 miles) as compared to first-generation (56 miles), based on actual distances driven between over 25,000 refueling events. Obviously, the vehicles are capable of two to three times greater range than this, but the median distance travelled between refuelings is one way to measure the improvement in the vehicles' capability and the way in which they are actually being driven.

Two other CDPs relating to range were also generated and previously reported on. Figure 24 shows a histogram of the distance vehicles actually traveled between fuelings as a percentage of each vehicle's dynamometer range. This shows that the majority of the vehicles $(75 \%)$ travel less than $50 \%$ of the dynamometer range between fuelings. This is due to several factors, but the dominant ones are limited hydrogen infrastructure, fear of running out of fuel, and actual on-road fuel economy being lower than the 
dynamometer fuel economy, as has already been discussed. Figure 25 shows the on-road range of the four teams (green bars) as a percentage of their dynamometer range. The spread of this on-road range has decreased significantly for Gen 2 (light green) compared to Gen 1 (dark green), showing this robustness to driving styles relative to vehicle fuel economy and subsequent range even more clearly that in the fuel economy CDP.

- On-Board Hydrogen Energy Storage System Status: Storage data were reported to NREL using a hydrogen storage system spreadsheet. This spreadsheet includes the breakdown of the mass and volume due to the hydrogen itself, the pressure vessel, and the balanceof-plant. The balance-of-plant category includes:

○ Controls and measurement (hydrogen storage-specific electronics)

- Fuel delivery to power plant (plumbing)

- Hazard mitigation components [hydrogen sensors, pressure release devices (PRDs)], venting)

○ Fueling equipment (filters, nozzle receptacle, piping, communications, grounding)

$\circ$ Mounting brackets, auxiliary equipment (thermal management, etc.).

Figure 26 shows the difference in the ranges of mass (as a percentage of the total mass) stored in the teams' 350-bar and 700-bar systems. We can see the potential for the percentage of system mass to increase in the second-generation systems, but we need to realize that the second-generation (700-bar) systems also typically have the benefit of economies of scale because they will have a larger total mass of hydrogen stored to meet customer range expectations.

Figure 27 shows the same type of 350-bar vs. 700-bar comparison but for the volumetric capacity (how much hydrogen can be stored per storage system volume). This is where the advantage of going to a higher pressure really shines, showing the potential for a significant increase in the mass of hydrogen stored per liter, making the packaging of the system on a vehicle more attractive.

Finally, the percentage breakdown by each of these categories was averaged across the four teams so that pie-charts of the differences between 350 bar and 700 bar could be examined for the mass and volumetric characteristics (Figure 28). The comparison shows that while the average hydrogen weight percentages are similar for 350 and 700 bar (within 1\%), and the pressure vessel and balance-of-plant for 700 bar take up a larger percentage of the system volume, the 700-bar systems ultimately allow for a more compact package and extended range. Figure 29 shows the tank cycle life, which now includes second-generation data and shows some improvement in tank cycle life, still far exceeding DOE's cycling goals set for advanced materials-based technologies.

- Fuel Cell System Power Density and Specific Power: DOE's target for fuel cell system power density in 2010 and 2015 is $650 \mathrm{~W} / \mathrm{L}$ and for fuel cell system specific power is $650 \mathrm{~W} / \mathrm{kg}$. System level data were gathered from the fuel cell teams and aggregated into ranges for first- and second-generation systems separately. First-generation fuel cell systems had a specific power of 183 to $323 \mathrm{~W} / \mathrm{kg}$, while second-generation systems improved to the range of 306 to $406 \mathrm{~W} / \mathrm{kg}$ (Figure 30). Fuel cell system power density (Figure 31 ), on the other hand, stayed the same or dropped slightly (staying in the range of 300 to $400 \mathrm{~W} / \mathrm{L}$ ), perhaps because the Gen 2 systems had more balance of plant in order to support the freeze tolerance required. 
Because of the attention that plug-in hybrid vehicles were getting, we were asked to generate fuel cell system power density and specific power results that also included the hydrogen storage, and then compare to the FreedomCAR targets. We found that while Gen 1 to Gen 2 showed significant progress (Figure 32), the 178 to $261 \mathrm{~W} / \mathrm{kg}$ was still shy of the $325 \mathrm{~W} / \mathrm{kg}$ FreedomCAR research goal when the hydrogen storage system was included. The fuel cell system power density (Figure 33), when the hydrogen storage was included, came extremely close (with both Gen 1 and Gen 2) to satisfying the 2010 and 2015 FreedomCAR research goal of $220 \mathrm{~W} / \mathrm{L}$ (Gen 1 was 152 to $214 \mathrm{~W} / \mathrm{L}$, and Gen 2 was 127 to $213 \mathrm{~W} / \mathrm{L}$ ). This indicates that fuel cell systems are a relatively compact means of storing both energy and power relative to batteries.

- Fuel Cell Durability: Fuel cell stacks will need roughly a 5,000-hour life to enter the market for light-duty vehicles. For this demonstration project, targets were set by DOE at 1,000 hours in 2006 and 2,000 hours in 2009. Results were first published in the fall of 2006. These results were relatively preliminary because most stacks at that time only had a few hundred hours of operation or less accumulated on-road. Since DOE's target for 2006 was 1,000 hours, NREL developed a methodology for projecting the gradual degradation of the voltage based on the data received to date. This involved creating periodic fuel cell polarization curve fits from the on-road stack voltage and current data and calculating the voltage under high current. This enabled us to track the gradual degradation of the stacks with time and do a linear fit through each team's data. We then compared these results to the first-generation target of 1,000 hours for 2006.

Since those initial evaluations, many improvements have been made in NREL's fuel cell durability analysis methodology, including using a two-segment linear fit and using a weighting algorithm to come up with a more robust and automatic fleet average. Now that the data submissions are complete on first-generation stacks (no new first-generation stack data is being received), we can make some final conclusions about that generation of technology. The maximum number of hours a first-generation stack has accumulated without repair is 2,375 , which is the longest stack durability from a light-duty vehicle FCEV in normal use published to date (see left blue bar in Figure 34). As shown in Figure 35, on average, the slope of the initial power degradation is steeper in the first 200 hours and becomes more gradual after that. We also found that around 1,000 hours of data were required to reliably determine the slope of the more gradual secondary degradation. Finally, with significant drops in power observed at 1,900-2,000 hours, it appears as though this is a solid upper bound on first-generation stack durability (characterizing 2003-2005 technology).

For second-generation fuel cell stacks (2005-2007 technology), the range of maximum hours accumulated from the four teams is now approximately 800 to over 1,200 hours (Figure 34), with the range of team average hours accumulated of approximately 300 to 1,100 hours. Relative to projected durability, the Spring 2010 results indicate that the highest average projected team time to $10 \%$ voltage degradation for second-generation systems was 2,521 hours, with a multi-team average projection of 1,062 hours. Therefore, the 2,000-hour target for durability has been validated. Figure 36 shows that less data have been gathered on second-generation stacks (approximately 1,100 hours at most), and so the $10 \%$ durability projections are less certain for Gen 2 stacks than Gen 1 stacks. The continuation of the project into 2011 will allow more durability data to be gathered. 
Note that the $10 \%$ criterion, which is used for assessing progress toward DOE targets, may differ from the OEM's end-of-life criterion and does not address "catastrophic" failures such as membrane failure. We received many questions about the $10 \%$ voltage degradation value (some people felt it might be too aggressive), and so we varied the voltage drop allowed out to $30 \%$ to show the sensitivity to this value. As you can see in Figure 37, the diamond values on the left are the same as the average projections from Figure 34. The projected hours then increase as the voltage drop constraint is successively relaxed. The primary reason why the Gen 2 curve does not rise as fast as the Gen 1 curve is due to the fact that less data have been received for Gen 2, and so we have some limitations on the projection that are based on the quantity of data received to limit the extent of the extrapolations. For Gen 1, which has more data and fewer extrapolations, increasing the percentage from $10 \%$ to $30 \%$ roughly doubles the projected time to that voltage drop.

In addition to analyzing voltage drop, we examined the stack power drop since that is what is ultimately converted into propulsion through the electric motor. Figure 38 shows histograms for Gen 1 and Gen 2 percentage power drop for each stack, and the stacks' status. One thing you can see for Gen 1 is that many stacks had a power drop of over $40 \%$ before being retired, and some of those stacks continue to be operational. Both of the Gen 2 stacks that have been retired exhibited a high power drop (greater than 40\%), with a lot of the Gen 2 stacks ranging between $10 \%$ and $20 \%$ power drop. Since we calculated each stack's power drop, we were asked to examine the time to OEMacceptable power drops where each OEM provided an acceptable percentage for its vehicles. Figure 39 shows these results, with an additional distinction of separating out the projections that were made from stacks with less than 200 hours from those with more than 200 hours. In general, many of the low projections are based on stacks with low operating hours for both Gen 1 and Gen 2. Comparing to the 2009 2,000-hour target, $27 \%$ of Gen 1 stacks exceeded that projection, and 17\% of Gen 2 stacks exceeded it. As previously mentioned, more Gen 2 data are required to fully assess the durability of the second-generation systems, as can be seen in the stack-hour histogram shown in Figure 40, which also shows that only two Gen 2 stacks have been removed for low performance. The blue bars indicate the stacks that are no longer accumulating hours, but were not removed due to low performance. Most of these stacks that stopped accumulating data were due to the project teams that concluded at the end of 2009 or whose host vehicles were retired for a variety of reasons.

- Factors Affecting Fuel Cell Durability: In addition to evaluating the projected durability of the fuel cell stacks in this project, a significant amount of effort was expended in characterizing the factors that might be having a strong effect on the durability.

The first area of focus was on startup and shutdown of the fuel cell. While some vehicles may shut off the stack during idle or coast-down, all systems are shut off when the vehicle is turned off. In the laboratory, this has been shown to be one of the degradation mechanisms, and, given the large number of short trips discussed earlier, we wanted to quantify how frequently the field data showed startups and shutdowns. Therefore, we quantified the number of trips (meaning a key-on to key-off) per hour (Figure 41) and found a relatively normal distribution around three to four trips per hour. This data was requested by researchers in order to calibrate their accelerated testing against what was 
being seen in the field. We also wanted to see if the stacks that were demonstrating long life had more or fewer starts than those that had not yet achieved long life. Figure 42 shows the same trip/hour data as a function of stack operating hours (binned into 250hour operating hour groups). These results show that the stacks that have accumulated up to 2,000 hours did have fewer trips per hour (about half), but this correlation alone does not establish a causal relationship between fewer trips per hour and long life.

We embarked upon a multivariate study in 2007 to determine the dominant factors that are affecting the rates of degradation. We started out by creating a database of all of the Learning Demonstration stacks and various performance attributes. Each individual stack was examined for the hours of data accumulated to date and the confidence in the fit of the degradation slope. We then manually removed about one-third of the stacks from the degradation factors analysis to try to have as clean a data set as possible for the analysis. The database included the following key factors for each stack:

$\circ$ Average voltage degradation rate (key dependent variable)

- Ambient temperature

- Time at various voltages

- Time at various currents

- Number of cold and hot starts (based on time between trips)

$\circ$ Idle time

- Trip length

- Average number of stack starts/hour.

After trying many techniques, we focused on partial least squares regression (PLS) analysis because it was the most direct way of measuring how much of the variance in voltage degradation could be explained by specific groups of factors. We first performed the PLS on the stack data from all four teams to see if there were any overall trends that covered all of the technology involved (Figure 43). The trends across all four teams were not strong, which we soon discovered was because the trends among the companies were often different.

Next we looked at each team's data individually and performed the same PLS analysis (Figure 44). The connection between voltage degradation rate and the variables improved, and we were able to pull out groupings of factors that appeared to cause either higher or lower than average decay rates within each team. Note that the teams' PLS models have a high percentage of explained decay rate variance, but the models are not very robust and results are scattered. We found that while there were some common factors among several teams' results, there were also normally contradictory trends from one of the teams (an example of this conflicting trend is for high voltage time and low current time for team four vs. team two). The multivariate effort was put on hold for about a year, but we hope to include some of the new voltage cycling information (described next) and rerun the multivariate analysis. This work was done in close collaboration with each of our industry partners, who have also had challenges extracting dominant factors from the field data. If NREL is able to identify some of the dominant factors from the field data, we will see if there are opportunities to feed this back into the companies' research as well as into DOE's R\&D program.

In discussions with fuel cell researchers, the voltage cycling of the stack was identified as something that would be worth the team investigating further. Prior to this, only the 
amount of time spent at different voltages was evaluated (Figure 45), and not the rate of change of the voltage or the number of times the voltage changed. Figure 11 shows the overall approach we used to 1) define a voltage transient cycle, 2) find voltage transient cycles in the on-road stack data, and 3 ) categorize and collect voltage transient cycle details.

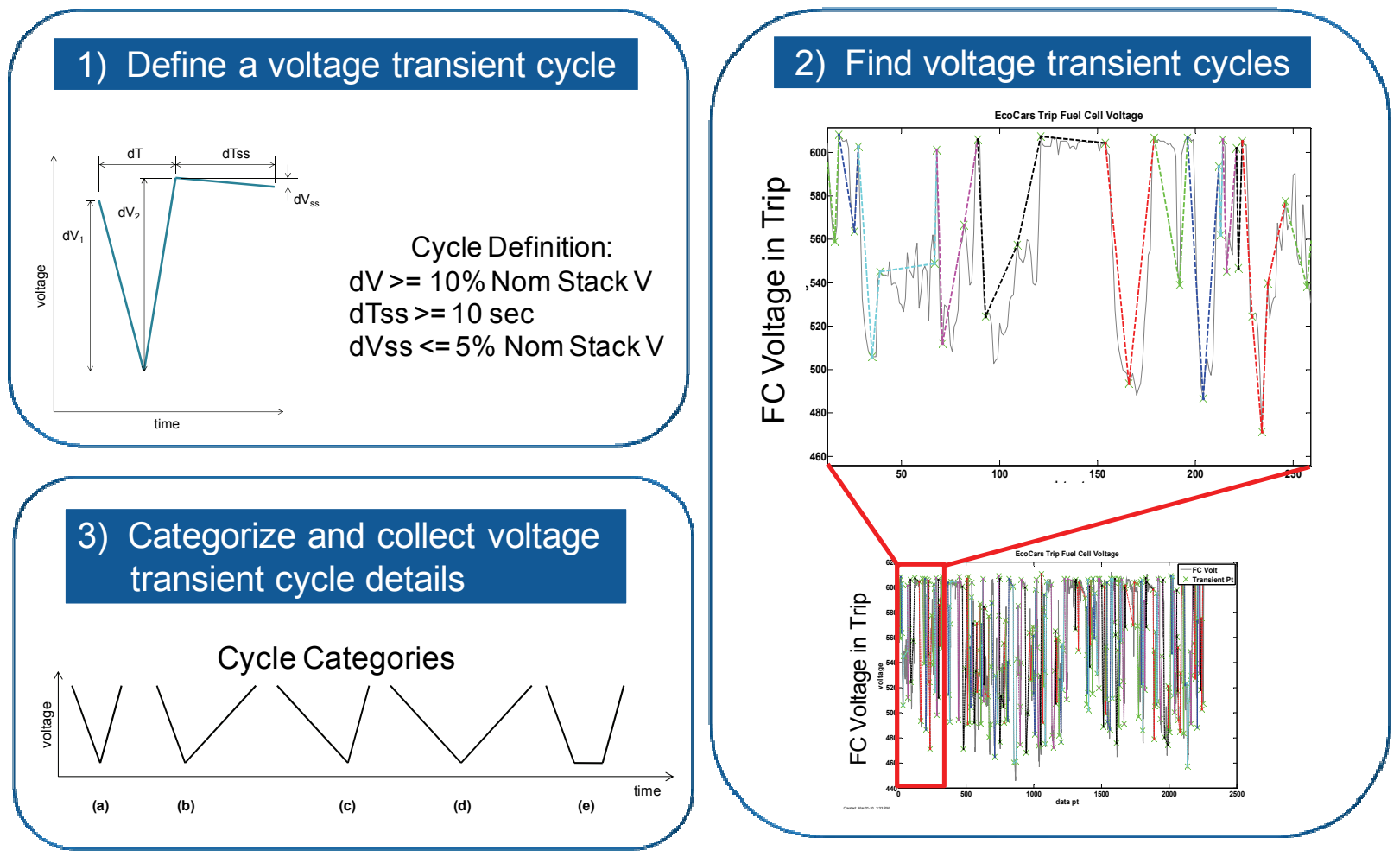

Figure 11: Approach for characterizing voltage transient cycles

Looking at the data graphically (Figure 46), we see a relatively symmetric distribution of the magnitude of voltage change about 0 , with most of the changes lasting less than 15 seconds. Once we had the voltage cycles characterized, the first thing we noticed was that the number of cycles per trip mile (and per trip minute) was drastically reduced between Gen 1 and Gen 2 for at least one team by a factor of 4 (Figure 47). We found that the dominant transient cycle category was the "SlowDown" category (Figure 48), which was a slow voltage drop followed by a fast voltage rise. This could come from a gradual acceleration of the FCEV, followed by taking the foot off the accelerator pedal due to traffic at a stop sign or light. The frequency of each of these five cycle categories is now available to us as a new input to our multivariate analysis. Figure 49 shows the same characterization, but includes the relative magnitude change in voltage rather than the rate of voltage change. Using this same data analysis technique, we took the subset of "steady-state" transients, which had a drop in voltage followed by a period of relative steady-state voltage, and evaluated the amount of trip time the stacks spent in this condition of steady state (Figure 50). The results showed that the most common bin was the $10-15 \%$ of time being held at steady state, but with some trips getting up to as high as $50 \%$ of the time at steady state. Finally, we also examined the number of the voltage 
cycles that were outside of a threshold between 70 and $90 \%$ of maximum stack voltage (Figure 51). We found that these more extreme voltage transients occurred on average less than twice per mile (accounting for about one-quarter of all voltage transients), with the drop below $70 \%$ maximum stack voltage occurring more times per mile than the rise above $90 \%$ maximum stack voltage.

- Fuel Cell System Maintenance: New since the last progress report is an evaluation of the fuel cell maintenance by system (Figure 52). We can see that only one-third of the FCEV maintenance events were due to the fuel cell system, while one-half of the labor hours were attributed to repairing the fuel cell system. Breaking down the maintenance events related to the fuel cell system, we find that $39 \%$ were associated with the thermal management, $23 \%$ with the air system, $13 \%$ with controls/electronics/sensors, $12 \%$ with the fuel system, and only $10 \%$ with the fuel cell stack itself. This indicates that the balance-of-plant needs some attention as the vehicles get closer to being a product for the marketplace if they are to meet customer expectations for reliability.

- Time of Day Vehicles Are Driven: Some questions were asked early in the project about whether the Learning Demonstration vehicles are being driven like conventional vehicles or whether their usage is being too "controlled" to match typical driving behavior. To investigate this, we looked at the time of day people initiated their trips and which day of the week the trips were occurring on. Figure 53 shows a clock-face radial histogram, with the green data representing the time of day when people initiated their trips. Overlaid on top of that, we have placed pink diamonds to show the national statistics based on the 2001 National Household Travel Survey (NHTS) data. What we find is that the Learning Demonstration vehicles are driven at similar times of day to the national statistics, with the exception of the late afternoon between 4 and 6 p.m. when the average person (nationally) is likely either picking up children from school, driving home from work, or running errands. Since the first-generation Learning Demonstration vehicles are primarily used for professional or fleet activities, it is not surprising that there would be a difference. The percentage of trips taken between 6 a.m. and 6 p.m. corresponds relatively closely to the national statistics $(85.3 \%$ vs. $81.5 \%)$. The nighttime driving behavior trend is also similar to the national statistics (Figure 54), although there are overall more evening trips driven nationally (18.4\%) than within the Learning Demonstration (14.7\%).

- Day of Week Vehicles Are Driven: We examined the days of the week that people drove the Learning Demonstration FCEVs and compared this with the national statistics. Figure 55 shows a bar for each day of the week, beginning with Sunday, and overlays a diamond symbol for the national statistics. We can easily see that nationally the trips are relatively uniform on weekdays, with a slight dip on the weekends, but that the Learning Demonstration vehicles are rarely driven on the weekends. Additionally, Learning Demonstration vehicles have significantly more trips Tuesday through Thursday as compared to Monday and Friday, which does not reflect typical national behavior. While the day of the week does not matter to the car's performance, it might be an indication that some of the weekend types of trips (for example: long trips to mountains or lots of short trips to the hardware store) are not being captured in this Learning Demonstration data set. 
- Vehicle Safety: The Learning Demonstration has had a very strong safety record to date. Figure 56 shows the number and type of vehicle safety reports by quarter. Within the last 2 years, there have only been two vehicle safety reports, both involving minor hydrogen leaks detected during fueling. Prior to this there were four traffic accidents in which there was no hydrogen released and only minor injuries due to the two-vehicle impact (not hydrogen related). For the case identified as "tank scratch," the team determined that the tanks had been scratched during service of a nearby system and that the scratches could be easily repaired without affecting the safety of the tanks.

- Vehicle Climate Compatibility: Figure 57 shows the range of ambient temperature during vehicle operation spanning $-5.8^{\circ} \mathrm{F}$ to $140^{\circ} \mathrm{F}$. Since the last progress report in 2008 , this CDP has been updated to include a distribution and some statistics. The data show that $28.2 \%$ of the trips were in temperatures hotter than $28^{\circ} \mathrm{C}$ and only $1.4 \%$ of the trips were in temperatures below $0^{\circ} \mathrm{C}$. Clearly, the vehicles are capable of operating in extreme temperature conditions. Special tests were performed in cold chambers to determine the ability of second-generation vehicles to start in sub-freezing temperatures. Figure 58 shows the fuel cell system start times in sub-freezing conditions, with the left two bars showing time to drive away, and the right two showing the time to maximum fuel cell power. It appears as though at one team has the time to drive away sufficiently short (approximately 15 seconds) while one team has some more improvements required (at just less than 5 minutes). All of the teams could probably improve their time to maximum power, with the fastest team being about a minute and a half and the slowest being around 9 minutes.

We also analyzed the time between trips and classified them by the ambient temperature range (Figure 59). This result shows a relative equal spread of the extreme temperatures between the different soak times, indicating that vehicles need to be designed for any duration of soak at any temperature; however, this data could be used to understand the probability of the vehicle being left for various times between trips when optimizing the system for energy efficiency. For example, it is 3 times more likely that the vehicle will be driven again in less than 10 minutes as it is that it will be driven again in 30 to 60 minutes.

Another climate consideration relates the temperature rise of the tank during fueling, with the constraint that the temperature of the tank should never exceed $85^{\circ} \mathrm{C}$. We were approached by the SAE J2601 committee, which was drafting the standard for filling hydrogen vehicles. They had made some assumptions about what the tank temperature would be when it arrived at a station to receive fuel, and wanted some real-life data from this project in order to calibrate their model inputs. Therefore, we created the two graphs in Figure 60 to provide them with publicly available data to use. The left graph shows that the mean temperature at which the tanks arrive for fueling is $-3.8^{\circ} \mathrm{C}$ below ambient temperature, with a standard deviation of $6.1^{\circ} \mathrm{C}$. The graph on the right shows a frequency surface plot of each of the tank/ambient temperature pairs.

- Other Vehicle Metrics: There are several other vehicle-related CDPs that will be briefly mentioned here as they do not logically fall into one of the other categories. Figure 61 shows the distribution of vehicle operating hours, showing a total of over 100,000 hours with a median of about 600 hours. The introduction of second-generation vehicles (with low hours initially) kept this median from rising much. Similarly, with vehicle miles 
traveled (shown in Figure 62), the peak number of vehicles occurs at 10,000 to 15,000 miles. Both of these graphs are now color-coded to indicate the vehicles that are still in operation (solid blue) as compared to the vehicles that have been retired (hashed red) from the project. You can see that the vehicles still in operation are spread relatively uniformly across the histograms, with many of the high hour and high mileage vehicles being the ones that are still in operation. The fleet has now accumulated over 2.5 million miles. Figure 63 shows that after the first few quarters, mileage accumulation has been relatively linear, with a slight decrease in slope at the end of 2009 as vehicles began to be retired. 


\subsection{Infrastructure Results}

- On-Site Production Efficiency from Natural Gas Reformation and Electrolysis: Detailed data on all of the energy inputs required to produce hydrogen on-site were gathered and analyzed and compared to DOE's program targets for 2010 for natural gas reformation and 2012 for water electrolysis. The results indicate that natural gas reformation efficiency was demonstrated close to the 2010 target of $72 \%$ through achieving a best quarterly efficiency of $67.7 \%$ and a best monthly efficiency of $69.8 \%$ (Figure 64 and Figure 65). The best quarterly efficiency for water electrolysis was $61.9 \%$ with a best monthly efficiency of $61.9 \%$ (compared to the 2012 target of $69 \%$ ). Note that targets for both of these technologies are for future years (2010 and 2012) and the results from 2005 to 2008 were not yet expected to have achieved future targets. Additionally, the targets are set for significantly larger stations $(1,500 \mathrm{~kg} /$ day of hydrogen) and higher utilization (70\% capacity factor) than we have in the Learning Demonstration. Figure 65 shows that, in general, the efficiency of the systems increases with capacity utilization, and that only during a few months were some reformation stations run at between 60 and $70 \%$ capacity utilization, and that electrolysis stations never had average capacity utilization above $35 \%$. The purpose of comparing our actual results to these future targets is to benchmark demonstrated progress toward the targets while technical R\&D development continues to improve the state of the art.

- Greenhouse Gas Emissions: Greenhouse gas emissions from the Learning Demonstration fleet have been assessed and compared to greenhouse gas emission estimates of conventional gasoline vehicles. The results indicate that when using hydrogen produced onsite via either natural gas reformation or water electrolysis, Learning Demonstration hydrogen FCEVs offer significant reductions of greenhouse gas emissions relative to conventional gasoline vehicles (Figure 66). Conventional gasoline mid-sized passenger vehicles emit $484 \mathrm{~g} \mathrm{CO}_{2}$-eq/mile (grams $\mathrm{CO}_{2}$ equivalent per mile) on a well-to-wheels (WTW) basis and conventional mid-size SUVs emit $612 \mathrm{~g} \mathrm{CO}_{2}$-eq/mi on a WTW basis. WTW greenhouse gas emissions for the Learning Demonstration FCEV fleet, which includes both passenger cars and SUVs, were analyzed based on the window sticker fuel economy of the Learning Demonstration fleet and the actual distribution of hydrogen production conversion efficiencies from onsite hydrogen production. Average WTW greenhouse gas emissions for the Learning Demonstration fleet operating on hydrogen produced from onsite natural gas reformation were $356 \mathrm{~g} \mathrm{CO}_{2}$-eq/mi and the lowest WTW GHG emissions for on-site natural gas reformation were $237 \mathrm{~g} \mathrm{CO}_{2}$-eq/mi. For the Learning Demonstration fleet operating on hydrogen produced from onsite water electrolysis (including some renewable sources of electricity), average WTW GHG emissions were $380 \mathrm{~g} \mathrm{CO}_{2}$-eq/mi, with the lowest emissions estimated to be $222 \mathrm{~g} \mathrm{CO}_{2}$ $\mathrm{eq} / \mathrm{mi}$ for the month with the best electrolysis production conversion efficiency.

- Fueling Station Compressor Efficiency: As part of our analysis of the fuel station subsystems, we gathered available data (which was limited) on compressor energy usage to evaluate compressor efficiency (Figure 67). We found that on average, the average station compressor efficiency (as defined by DOE's Multi-Year Program Plan [MYPP]) was just under 90\%, a few points lower than DOE's targets for 2010 and 2015. The compression energy was on average $15.4 \mathrm{MJ} / \mathrm{kg}$, with the best monthly data at $6.4 \mathrm{MJ} / \mathrm{kg}$. 
In layman's terms, this means that on average $11.3 \%$ of the energy contained in the hydrogen fuel is required for the compression process.

- Hydrogen Production Cost: On-Site Hydrogen Production Cost: Cost estimates from the Learning Demonstration energy company partners were used as input to an H2A analysis to project the hydrogen cost for $1,500 \mathrm{~kg}$ /day early market fueling stations. Results indicate that onsite natural gas reformation could lead to a range of $\$ 8-\$ 10 / \mathrm{kg}$ and onsite electrolysis could lead to $\$ 10-\$ 13 / \mathrm{kg}$ hydrogen cost (Figure 68 ). While these results do not achieve the $\$ 3 /$ gge cost target, two external independent review panels commissioned by DOE concluded that distributed natural gas reformation could lead to $\$ 2.75$ $\$ 3.50 / \mathrm{kg}^{[4]}$ and distributed electrolysis could lead to $\$ 4.90-\$ 5.70^{[5]}$. Therefore, this objective was met outside of the Learning Demonstration project.

- Hydrogen Quality: Hydrogen quality was determined by measuring the impurities and calculating the hydrogen fuel quality index as a percentage. SAE J2719 has established a $99.99 \%$ hydrogen fuel quality index target. The hydrogen fuel quality index from all the stations sampled ranged from $99.73 \%$ to $99.999 \%$, as shown in Figure 69. The values on the lower end were due to some high detection limits on inert gases, and likely do not really represent hydrogen fuel quality that low. Since the last progress report was published in 2008, we have separated the results by year and by production technology. With 5 years of data now analyzed, we can see that the hydrogen quality index of $99.97 \%$ has been achieved in all the quality samples for the last 3 years and does not seem to be an issue.

- Hydrogen Impurities: More important than the absolute hydrogen fuel quality index is the actual level of impurities by constituent. Impurities evaluated include particulates, inert gases $\left(\mathrm{N}_{2}+\mathrm{H}_{2}+\mathrm{Ar}\right), \mathrm{NH}_{3}, \mathrm{CO}, \mathrm{CO}_{2}, \mathrm{O}_{2}$, total $\mathrm{HC}, \mathrm{H}_{2} \mathrm{O}$, and total $\mathrm{S}$, and are shown in Figure 70. Subsequent to the last progress report, each of these constituents was broken out separately and shown as a function of year. There are 18 of these results (Figure 71 to Figure 88), so we will not discuss each one individually except to say that the detection limits continue to improve (get lower) through better gas analysis techniques, and there do not appear to be any major issues with any of the impurities. Impurity data from this project has been used by the hydrogen quality community on numerous occasions to answer the question of what is possible and what are the actual impurities found in hydrogen fuel made by various techniques.

- $\mathrm{H}_{2}$ Infrastructure Maintenance: An evaluation of all of the maintenance required on refueling station equipment found that roughly one-half of all labor hours were unscheduled, accounting for $60 \%$ of the maintenance events (Figure 89). With the large volume of infrastructure maintenance items over the past five years, we have not seen any shift in the split planned and unplanned maintenance events. Similar to the FCEV maintenance, we have now classified the parts of the fueling station systems that caused the maintenance events (Figure 90). The left pie shows the number of events $(2,491$ events) separated by subsystem while the right pie shows the number of labor hours (11,430 hours). The main conclusion from this result is that "system control \& safety" required both the most time to fix as well as were the most frequent system requiring maintenance. The rest of the maintenance was spread relatively evenly between the compressor, reformer, electrolyzer, and dispenser. 
- Infrastructure Safety: With respect to the hydrogen refueling infrastructure, there have been just a handful of events classified as incidents, according to DOE's Safety Panel definition. Most of these were due to equipment malfunction with one event having a minor hydrogen release that did not lead to ignition and another one involving a major hydrogen release and a fire. Details of this event are available from DOE's Safety Panel. At a less severe level (see Figure 91), there were about 50 events categorized as nearmisses and around 275 non-events (over 100 were alarms-only and about 70 were "system trouble, not alarm"). All but a handful of the near-misses involved a minor release of hydrogen with no ignition.

Figure 92 shows that no single primary factor led to the majority of infrastructure safety reports, but the top three most frequent primary factors for the non-events were 1) calibrations, settings, and software controls; 2) maintenance required; and 3) not yet determined (in other words insufficient information was provided to NREL for us to make a determination how to categorize some of the events).

Figure 93 shows that the number of refuelings normalized by the number of safety reports per quarter had improved by a factor of 10 (higher is better) since the beginning of the project, but then dipped down to 60-80 as new stations came online. It has since gone higher, staying above 100 for the last year. Figure 94 shows the apparent correlation between new stations coming online and a higher number of safety reports. On most of the safety CDPs we have now added the DOE definition of incident and near-miss that are being used for this project to remove any questions about what they mean since they are not necessarily obvious to the layman.

- Vehicle Fueling Rates: Hydrogen vehicle refueling needs to be as similar as possible to conventional vehicle refueling to allow an easier commercial market introduction. Over 25,000 refueling events have been analyzed to date, and the refueling amount, time, and rate have been quantified. The average time to refuel was 3.26 minutes with $86 \%$ of the refueling events taking less than 5 minutes (Figure 95). The average amount per fill was $2.13 \mathrm{~kg}$, reflecting both the limited storage capacity of these vehicles (approximately $4 \mathrm{~kg}$ maximum) and peoples' comfort level with letting the fuel gauge get close to empty (see Figure 96 for the shape of the distributions), which will be shown in a separate analysis. DOE's initial target refueling rate is $1 \mathrm{~kg} /$ minute, and these Learning Demonstration results indicate an average of $0.77 \mathrm{~kg} / \mathrm{min}$, with $23 \%$ of the refueling events exceeding 1 $\mathrm{kg} / \mathrm{minute}$ (Figure 97). Therefore, we can conclude that high-pressure gases are approaching adequate refueling times and rates for consumers; however, the challenge is still in packaging enough high-pressure hydrogen onboard to provide adequate range or finding alternate advanced hydrogen storage materials that can replace the need for highpressure tanks.

- Communication vs. Non-Communication Fueling Rates: The previous refueling histograms included all types of refueling events. There has been much interest from industry and from the codes and standards community about the potential for communication fills to occur at a higher rate and with a more complete fill. A communication fill means that the vehicle communicates data about the state of its hydrogen storage tank(s) to the refueling station, such as tank temperature, pressure, and max pressure rating. Figure 98 shows two curves: the red curve is a spline fit to the histogram for non-communication fills while the blue curve represents the 
communication fills. The center part of the graph shows a similar rate of fill for the communication and non-communication fills; however, the communication fills are capable of having a higher fill rate (up to around $1.8 \mathrm{~kg} / \mathrm{min}$ ). There is also a group of vehicle/station combinations still doing non-communication fills at the slower rate of $\sim 0.2 \mathrm{~kg} / \mathrm{min}$ on the left portion of the graph. This rate of fill was established many years ago in California to provide a conservative and safe approach for refueling vehicles before much real-world experience had been gained. With these differences in distribution in mind, the average fill rate for all communication fills is $0.86 \mathrm{~kg} / \mathrm{min}$ vs. $0.66 \mathrm{~kg} / \mathrm{min}$ for non-communication fills, with $30 \%$ and $12 \%$, respectively, exceeding DOE's $1 \mathrm{~kg} / \mathrm{min}$ target. We can thus conclude that communication fills in this project are, on average, faster than non-communication fills.

- Fueling Rate by Storage System (350 bar vs. 700 bar): Another partition of the fueling rate data we performed was by the storage system employed by each vehicle. Figure 99 shows the fueling rate for 350 bar fills and compares them to the fueling rate for 700 bar fills. Two major conclusions can be drawn from this graph. The first is that the project has experienced many more 350-bar fills $(19,659)$ than 700 -bar fills $(5,590)$, since the 700-bar fuelings mainly began with the second-generation vehicles halfway through the project. The second is that the fueling rate for the higher pressure fills is still slower than the lower pressure fills, with $29 \%$ of the 350 -bar fills exceeding $1 \mathrm{~kg} / \mathrm{min}$ and only $4 \%$ of the 700-bar fills exceeding the target. The average fill rate for 350-bar fills is 0.82 $\mathrm{kg} / \mathrm{min}$, while the average rate for 700-bar fills is 0.63 . This does not appear to be a limitation of the technology, as very high fill rates at 700 bar have been demonstrated in Germany and Canada, but rather a reflection of the current technology that has been deployed in this first wave of 700-bar stations. Station data received in the coming years from the new stations in California should demonstrate the full capability of 700-bar fueling.

- Fueling Rate by Year: In the final fueling rate analysis, we have sliced the same data by year (Figure 100). We can see that the number of fueling events has increased year-toyear during each of the 5 years of the project to date. While the fueling rate initially increased from 0.66 to $0.74 \mathrm{~kg} / \mathrm{min}$ to $0.81 \mathrm{~kg} / \mathrm{min}$, it has now settled at a value of 0.77 $\mathrm{kg} / \mathrm{min}$ for the last two years. Due to the number of automotive companies being reduced from four to two in 2010, the overall number of fueling events will decrease until the new California stations come online.

- Level in Fuel Tank When People Refuel: As previously mentioned, with limited hydrogen refueling infrastructure and limited on-board hydrogen storage, some drivers do not like to let the tank get close to empty to minimize the risk of running out of fuel. To investigate this further, NREL used the data submitted in a new and unique way, which was to look at what the fuel level in the tank was just prior to each refueling event. In some cases these data came from on-board data based on the pressure in the tank, and in other cases they came from refueling logs where each fill was assumed to be to the "full" level, allowing a subtraction of the amount fueled to determine the initial tank level.

Figure 101 shows the results of this analysis, where a histogram has been placed radially on an image of a fuel gauge to make interpreting the graph as intuitive as possible. The level at which people most commonly refuel the Learning Demonstration vehicles is at just over one-quarter full; this covers $14 \%$ of the refuelings. While some drivers are 
letting the tank get even lower than that, few let it get close to being empty. Additionally, we have placed a green needle on the chart that indicates the median tank level at fill (half above, half below), which is a little above three-eighths of a tank ( $42 \%$ of full). Figure 102 shows the collection of medians for each of the 144 vehicles in the Learning Demonstration fleet to show that there is a large spread in when individuals choose to refuel their vehicles, with several vehicles being refueled more than half of the time with greater than a half-full tank, but the majority being refueled between one-quarter and onehalf full, on average. In the future, we would like to compare these data results to data from conventional liquid-fueled vehicles, if they exist, to see if people are refueling their FCEVs differently than their conventional vehicles.

- Time of Day When People Fuel Their FCEVs: We examined the time of day people fueled their vehicles in order to understand the usage patterns at the hydrogen fueling stations and to better allow new stations to understand the potential demand by time of day. For traditional liquid fuels, with big tanker truck deliveries periodically, the time of day people refuel does not normally matter. Instead, the station operator must simply ensure that the next tanker comes before he runs out of fuel. For today's hydrogen fuel stations, with very limited storage capacity and some sites producing hydrogen throughout the day, it is important to know the time of day that people refuel in order to match the supply (onsite production) with the demand.

Figure 103 shows a radial histogram of the time of day Learning Demonstration vehicles were refueled between 6 a.m. and 6 p.m., with Figure 104 showing the time between 6 p.m. and 6 a.m. We found that $90 \%$ of the fills took place between 6 a.m. and 6 p.m., with $10 \%$ being done at night. The distribution is relatively uniform with steady usage between 8 a.m. and 4 p.m., and a mild peak just after lunchtime (9\%). The conclusion from this analysis is that with a uniform distribution of when people refuel during the day, a station that has on-site production can either be sized to meet that demand during the day and then essentially shut off at night, or it can be sized (smaller) for the average over a 24-hour period, have a larger on-site hydrogen storage buffer, and run continuously. Finally, we looked at what day of the week people were refueling (Figure 105 ) and found that the Learning Demonstration vehicles are almost exclusively fueled Monday through Friday, with very few vehicles fueled on the weekend. This is consistent with the days of the week that people are driving the vehicles most and when the hydrogen stations that have attendants are open.

- Other Infrastructure Metrics: The cumulative amount of hydrogen produced or dispensed has also been tracked by quarter (blue triangles) with the number of stations shown on the same graph (green squares) in Figure 106. Note that the amount of hydrogen produced is not the same as the amount dispensed because the project includes a power park where the unused hydrogen can be converted back into grid electricity during peak utility load periods in the afternoon (due to higher air-conditioning loads) using on-site fuel cells. 


\subsection{Conclusions and Future Directions}

NREL has now completed the first five years of the seven-year project with 144 vehicles deployed in fleet operation, 23 project refueling stations constructed, and no major safety barriers encountered. We have analyzed data from 436,000 individual vehicle trips covering 2.5 million miles traveled and $130,000 \mathrm{~kg}$ hydrogen produced or dispensed. We have published 80 technical CDPs to date and made them directly accessible to the public from an NREL Web site. We have summarized the key project performance numbers, along with other metrics of interest such as fuel economy and fuel cell efficiency, and compared them to DOE targets in Table 1. The table shows that this project has exceeded the expectations established in 2003 by DOE, with all of the key targets being achieved except for onsite hydrogen production cost, which would have been difficult to demonstrate through this project.

From all of the results that we have generated, it is our conclusion that FCEVs have advanced rapidly in the last five years, and are expected to continue at this same rate of development in the next five years. There do not appear to be any major technical hurdles that the automotive companies and their suppliers cannot overcome, and they appear to have a glide-path to getting the costs down to a manageable incremental cost. We therefore expect continued progress to lead to market-ready vehicles in the 2015 timeframe. Several vehicle manufacturers will introduce thousands of vehicles to the market in that timeframe, and the hydrogen community will have its first true test of whether the technology will be embraced by the public.

Additional data accumulated and analyzed in 2010-2012 will assess the latest generations of FCEV technology, which include improvements over the second-generation systems included in the results to date. NREL will create new and updated CDPs based on data collected through June 2010 (Fall 2010 CDPs) and present results for publication at 2010 Fuel Cell Seminar. We will support the automotive manufacturers, energy companies, and state organizations in California in coordinating early infrastructure plans. We will gather and analyze data from a hydrogen fueling station in Burbank, California, which has a relatively high-rate of onsite production from natural gas, along with many new stations that are being opened in California in the next year. NREL will continue to identify opportunities to feed findings from the project back into Vehicle Technologies and Fuel Cell Technologies programs and industry R\&D activities to maintain the project as a "learning demonstration." We will continue to gather data from FCEVs and hydrogen stations through 2011, and publish the Spring 2011 and Fall 2011 CDPs and potentially one final set of results in Spring 2012. As the last expected deliverable from this project, we will write a final summary report for publication, which will both include new results from the final two years as well as reference and build on the results included in this report.

Future assessments will also include data analysis from many new hydrogen stations being commissioned in California, all of which will have 700-bar fueling capability. All 80 CDPs published to date are included in this report as well as directly accessible from our Hydrogen Technology Validation Web site. 


\subsection{Recent Publications/Presentations}

1. Wipke, K., Anton, D., and Sprik, S., "Evaluation of Range Estimates for Toyota FCHV-adv Under Open Road Driving Conditions," prepared under SRNS CRADA number CR-04-003, August 2009. (paper)

2. Wipke, K., Sprik, S., Kurtz, J., and Ramsden, T., "Fall 2009 Composite Data Products for the Controlled Hydrogen Fleet and Infrastructure Demonstration and Validation Project," Golden, CO: National Renewable Energy Laboratory, September 2009. (presentation)

3. Wipke, K., Sprik, S., Kurtz, J., Ramsden, T., and Garbak, J., "National Fuel Cell Vehicle Learning Demonstration: Gen 2 Progress," presented at the California Air Resources Board 2009 ZEV Technology Symposium, Sacramento, CA, September 2009. (presentation)

4. Wipke, K, Sprik, S., and Kurtz, J., 2009 Annual Progress Report for NREL's "Controlled Hydrogen Fleet and Infrastructure Analysis Project," Section VIII.1, November 2009. (paper).

5. Wipke, K., Sprik, S., Kurtz, J., Ramsden, T., and Garbak, J., "Second-Generation Fuel Cell Stack Durability and Freeze Capability from National FCEV Learning Demonstration," 2009 Fuel Cell Seminar \& Exposition, Palm Springs, CA, November, 2009. (presentation)

6. Kurtz, J., Wipke, K., Sprik, S., and Ramsden, T., "Analysis of Real World Fuel Cell Degradation," Fuel Cells Durability \& Performance Conference, Alexandria, VA, December 2009. (presentation)

7. Wipke, K., Sprik, S., Kurtz, J., Ramsden, T., and Garbak, J., "U.S. Fuel Cell Vehicle Learning Demonstration: Status Update and Early Second-Generation Vehicle Results," World Electric Vehicle Association Journal, Vol. 3 - ISSN 2032-6653, December 2009. (paper)

8. Wipke, K., Sprik, S., Kurtz, J., and Ramsden, T., "Spring 2010 Composite Data Products for the Controlled Hydrogen Fleet and Infrastructure Demonstration and Validation Project," Golden, CO: National Renewable Energy Laboratory, March 2010. (presentation)

9. Wipke, K., Sprik, S., Kurtz, J., Ramsden, T., and Garbak, J., "Status and Results from National Fuel Cell Vehicle Learning Demonstration," General Motors Lunch and Learn Presentation, Honeoye Falls, NY, April 2010. (presentation)

10. Wipke, K., Sprik, S., Kurtz, J., and Ramsden, T., presentation of Learning Demonstration results to FreedomCAR and Fuels joint meeting of the Fuel Cell and Hydrogen Storage Tech Team, April 2010. (presentation)

11. Wipke, K., Sprik, S., Kurtz, J., Ramsden, T., and Garbak, J., "Exceeding Expectations: Learnings from FCEV Learning Demo," National Hydrogen Association Annual Hydrogen Conference, Long Beach, CA, May 2010. (presentation)

12. Wipke, K., Sprik, S., Kurtz, J., and Ramsden, T., "Session TA.5 - Demonstration Projects, Costs, and Market Introduction: Review Lecture," 2010 World Hydrogen Energy Conference (WHEC) in Messe Essen, Germany, May 2010. (presentation)

13. Wipke, K., Sprik, S., Kurtz, T., and Ramsden, T., "Controlled Hydrogen Fleet and Infrastructure Analysis," 2010 U.S. DOE Hydrogen Program and Vehicle Technologies Program Annual Merit Review and Peer Evaluation Meeting, Washington, D.C, June 2010. (presentation)

14. Wipke, K., Sprik, S., Kurtz, J., Ramsden, T., and Garbak, J., "DOE's National Fuel Cell Vehicle Learning Demonstration Project - NREL's Data Analysis Results," Electric and Hybrid Vehicles, Power Sources, Models, Sustainability, Infrastructure and the Market, Chapter 12, ISBN 978-0-44453565-8, NREL/CH-560-47111, Elsevier B.V., August 2010. 


\subsection{References}

1. Wipke, K., Sprik, S., Thomas, H., Welch, C., Kurtz, J., "Learning Demonstration Interim Progress Report - Summer 2007,” NREL/TP-560-41848, June 2007.

2. Wipke, K., Sprik, S., Kurtz, J., Thomas, H., "Learning Demonstration Progress Report-September 2007," NREL/TP-560-42264, November 2007.

3. Wipke, K., Sprik, S., Kurtz, J., "Learning Demonstration Progress Report—Spring 2008," NREL/TP560-42986, April 2008.

4. Wipke, K., Anton, D., and Sprik, S., "Evaluation of Range Estimates for Toyota FCHV-adv Under Open Road Driving Conditions," prepared under SRNS CRADA number CR-04-003, August 2009.

5. Fletcher, J., and Callaghan, V., "Evaluation Cost of Distributed Production of Hydrogen from Natural Gas - Independent Review," NREL/BK-150-40382, October 2006.

6. Genovese, J., Harg, K., Paster, M., and Turner, J., "Current (2009) State-of-the-Art Hydrogen Production Cost Estimate Using Water Electrolysis - Independent Review," NREL/BK-6A1-46676, September 2009. 


\subsection{Composite Data Products Referenced in Previous Discussion}

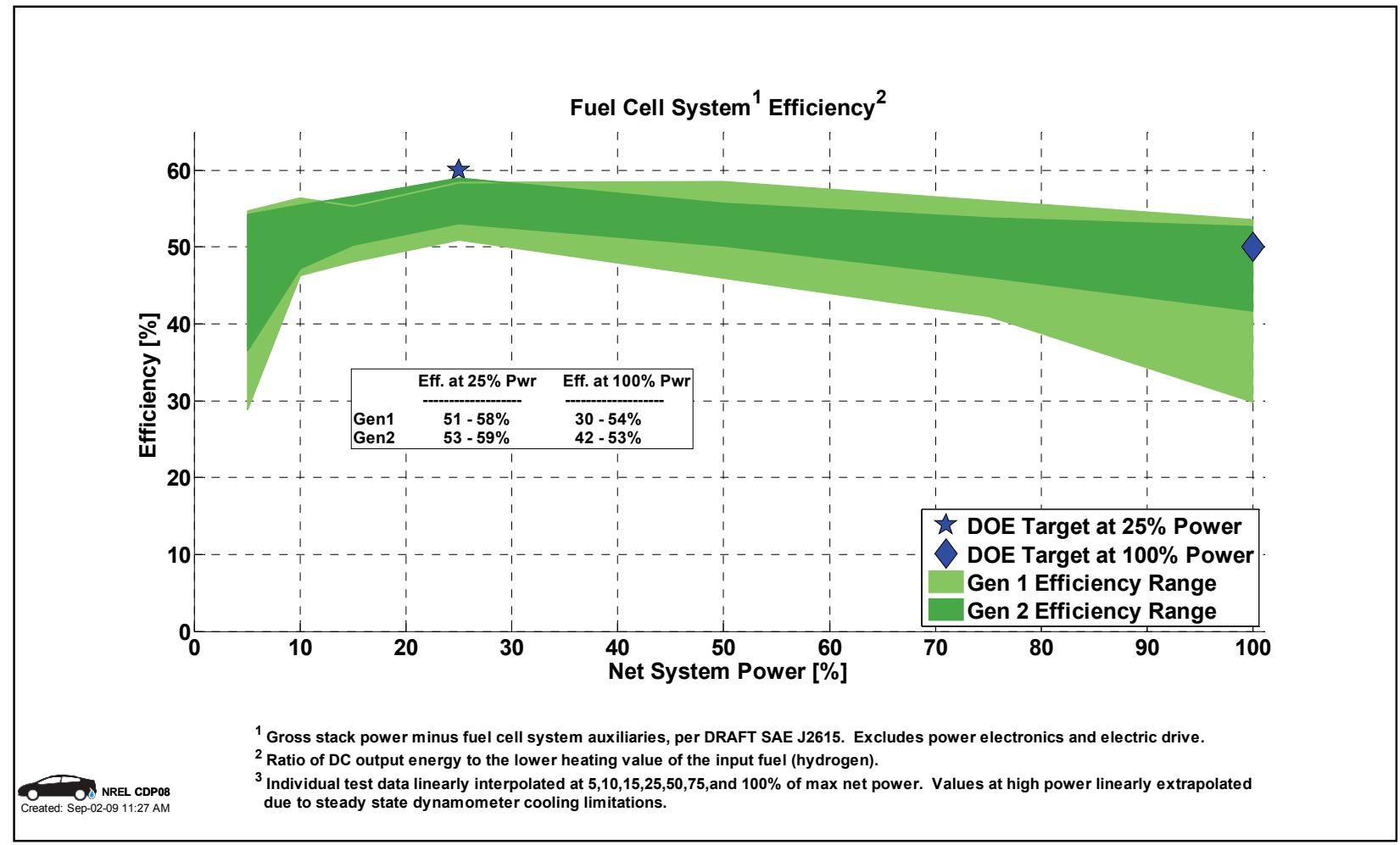

Figure 12: Fuel cell system efficiency (CDP08)

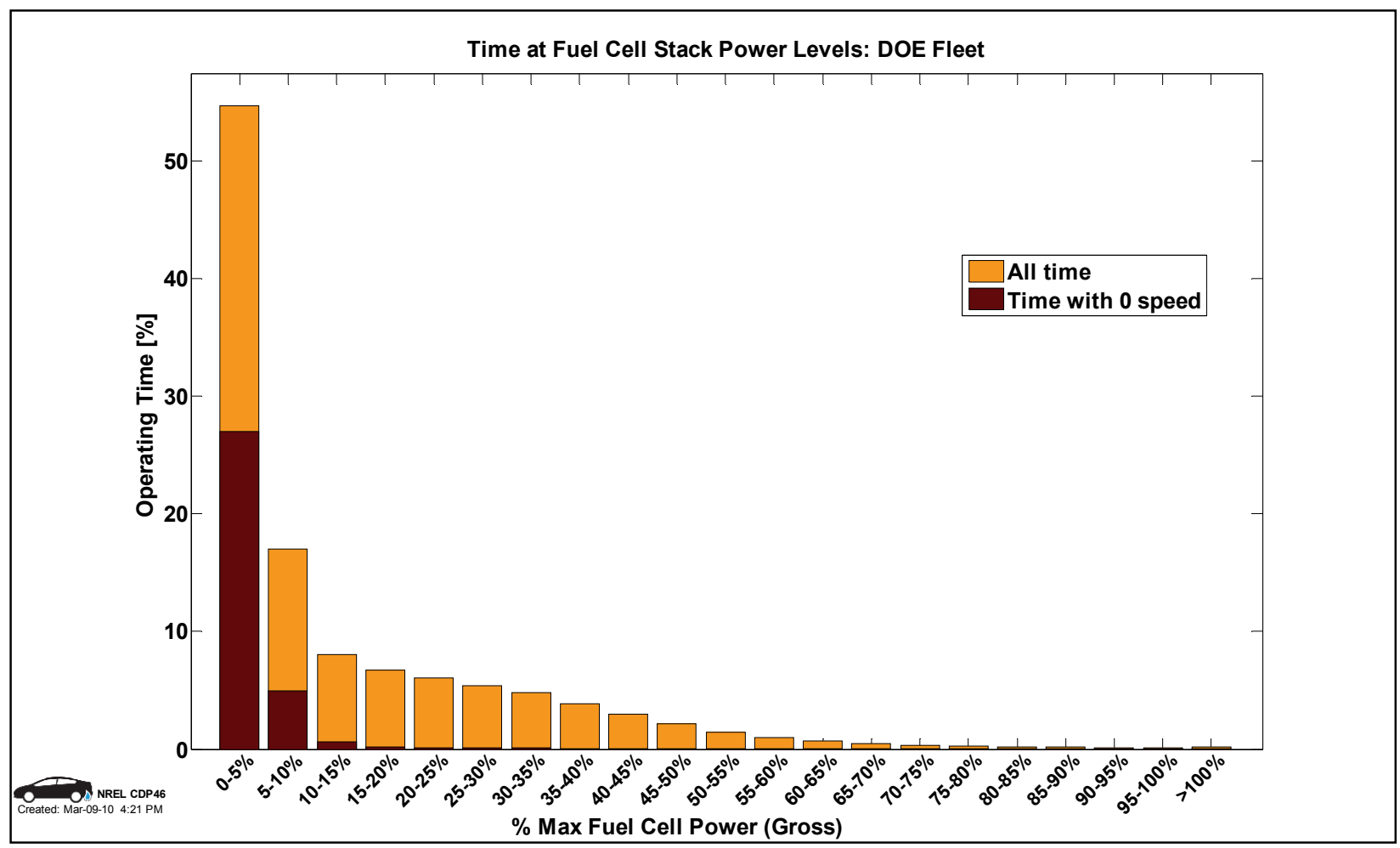

Figure 13: Fuel cell system operating power (CDP46) 


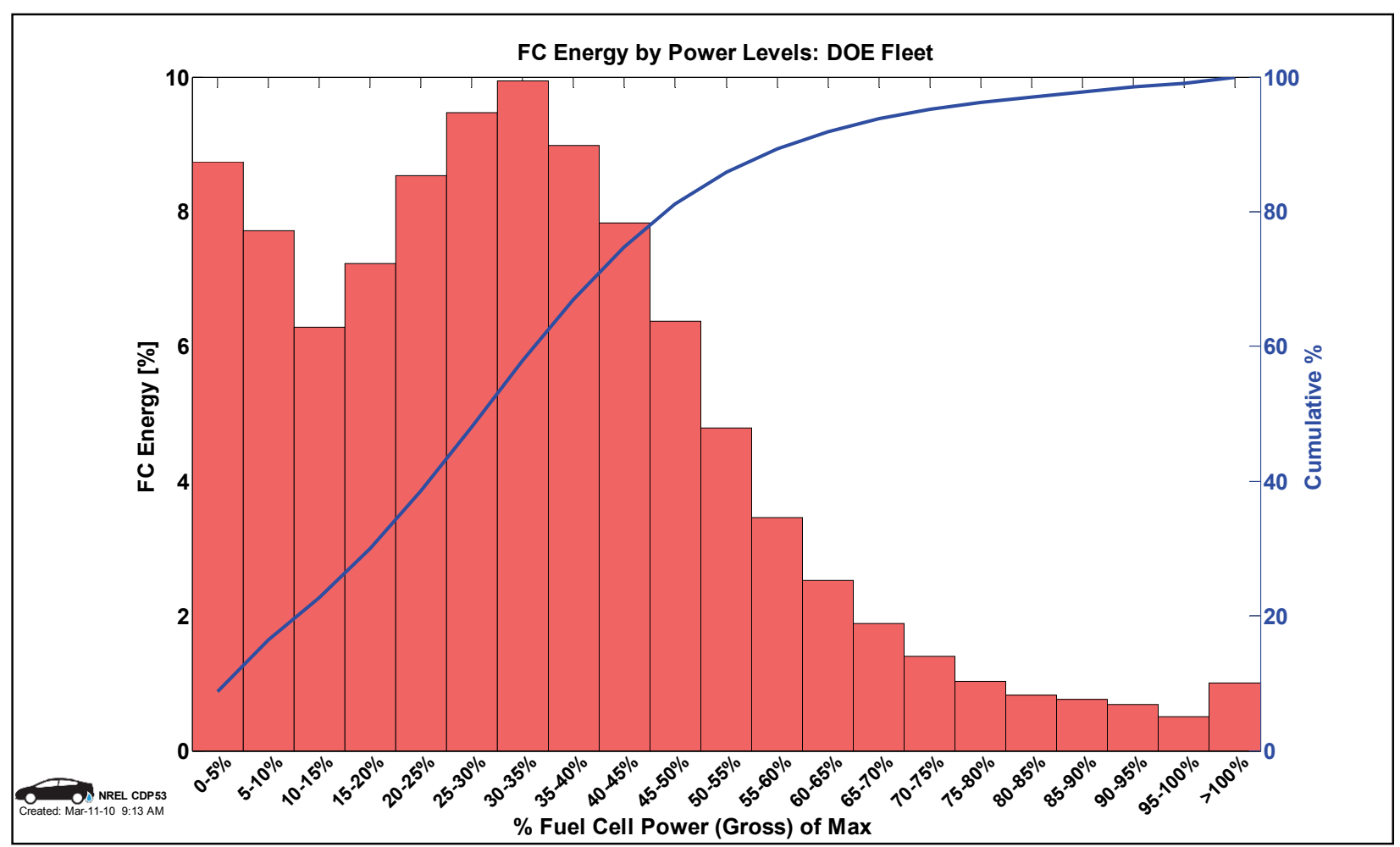

Figure 14: Fuel cell system energy within power levels (CDP53)

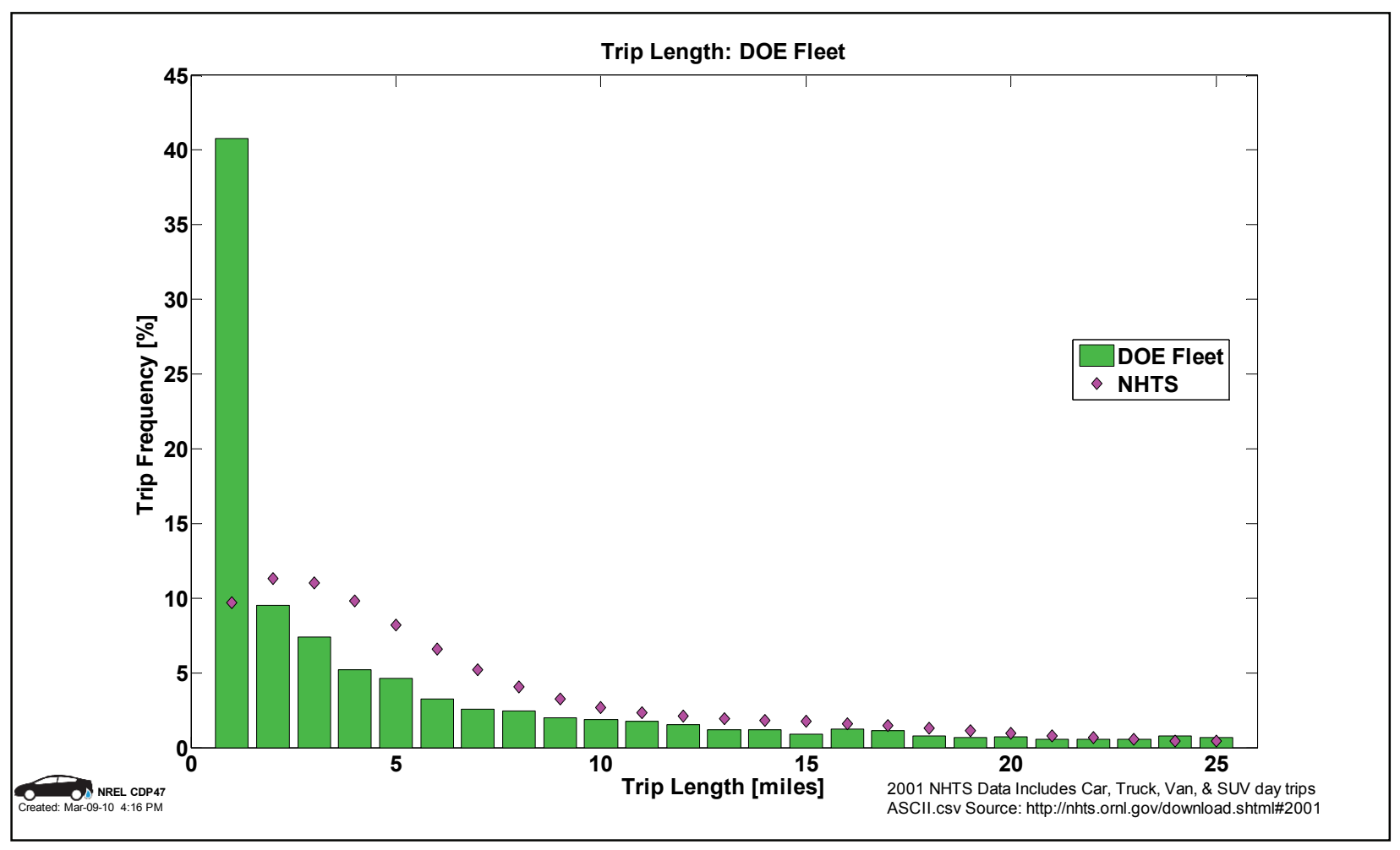

Figure 15: Trip length (CDP47) 


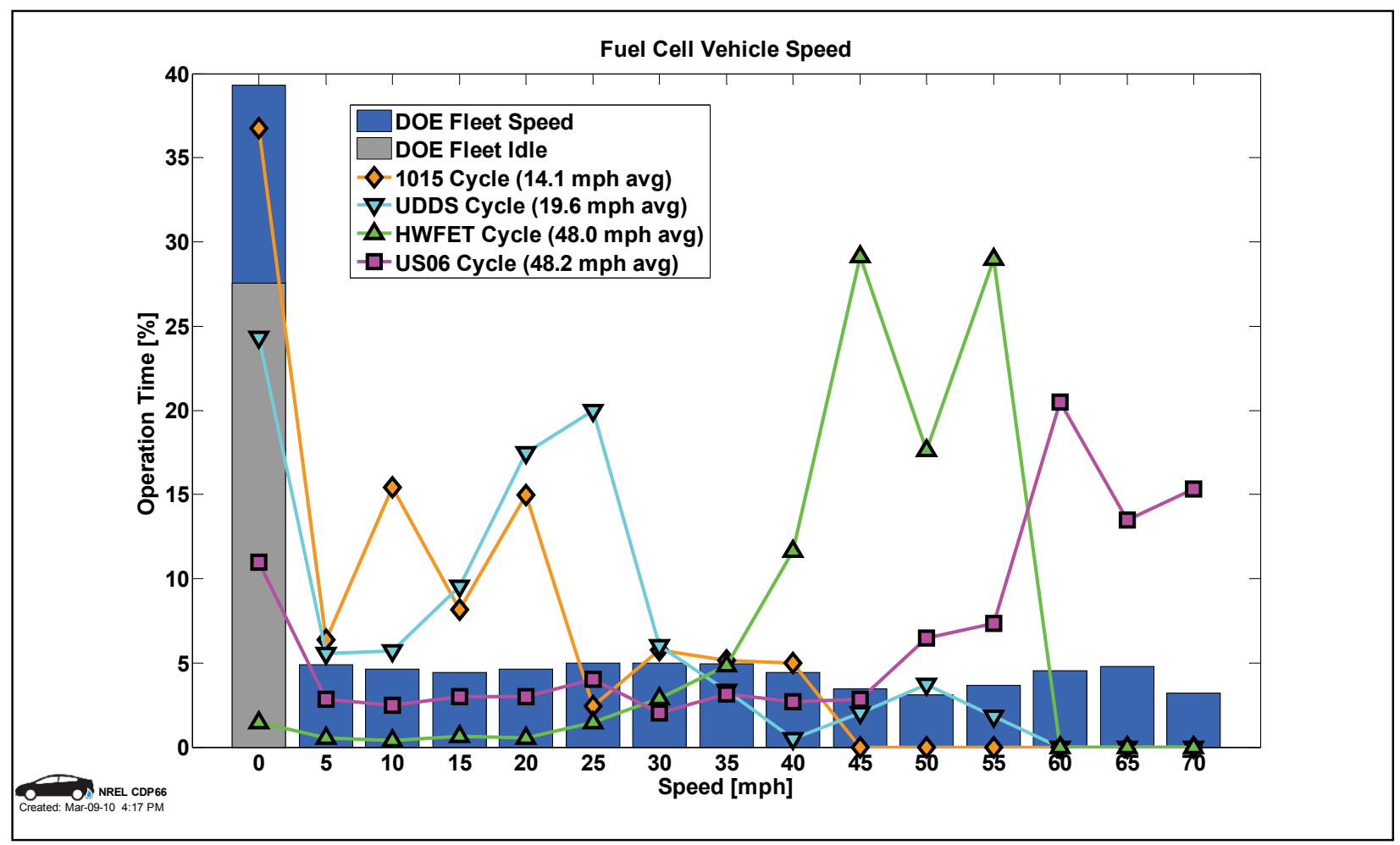

Figure 16: Fuel cell electric vehicle with comparison to standard drive cycles (CDP66)

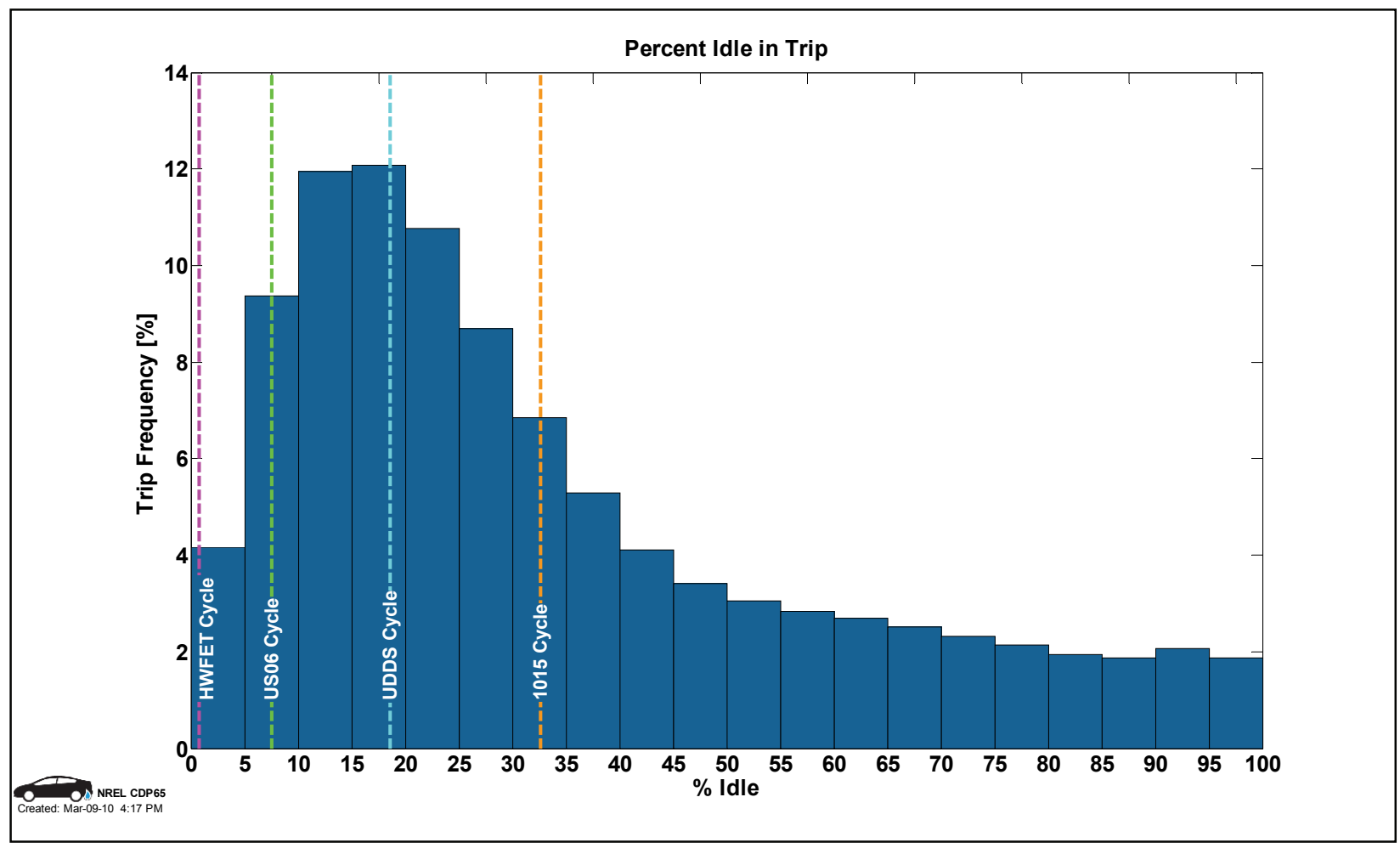

Figure 17: Percent idle in trip with comparison to standard drive cycles (CDP65) 


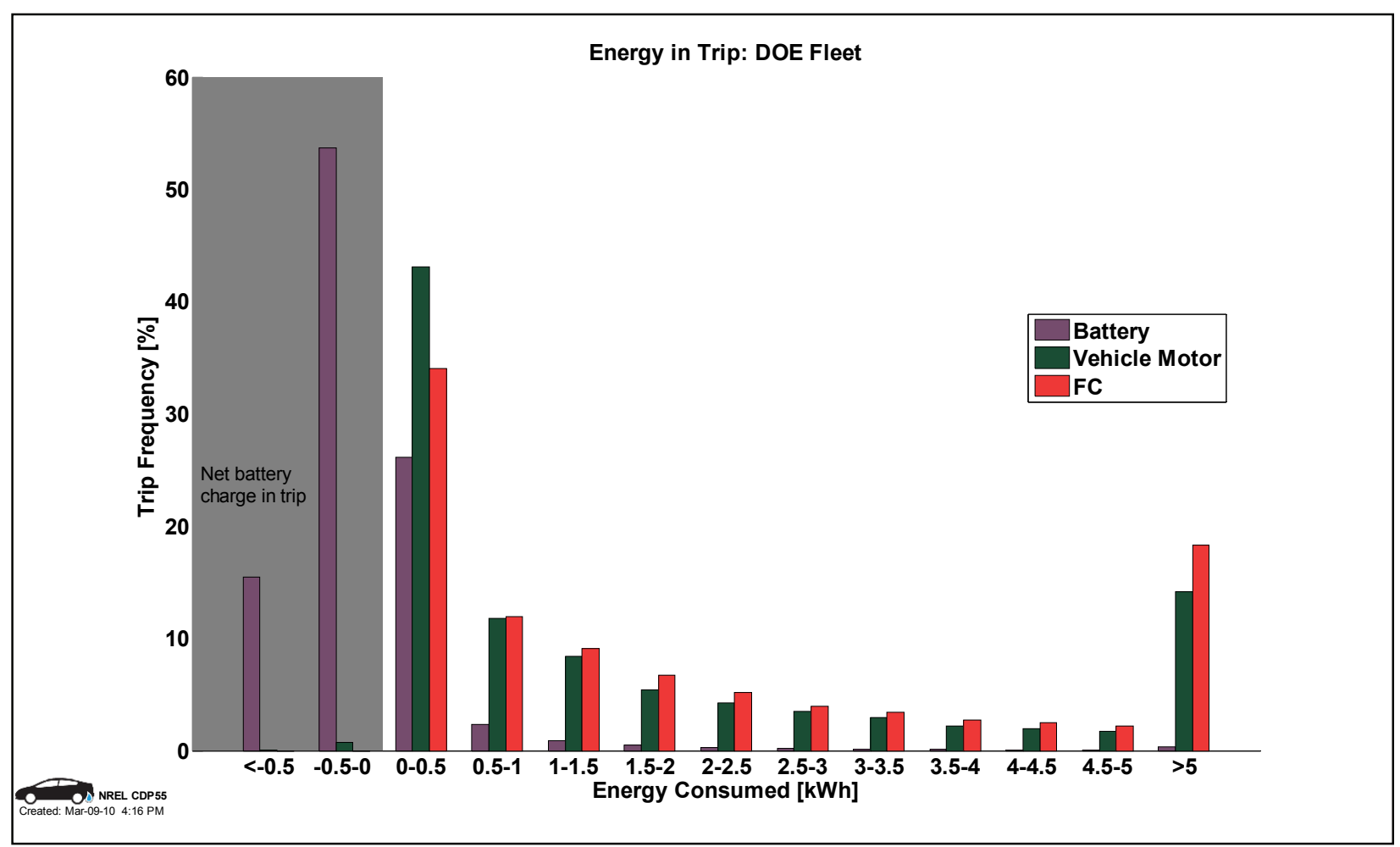

Figure 18: Fuel cell system energy in trips (CDP55)

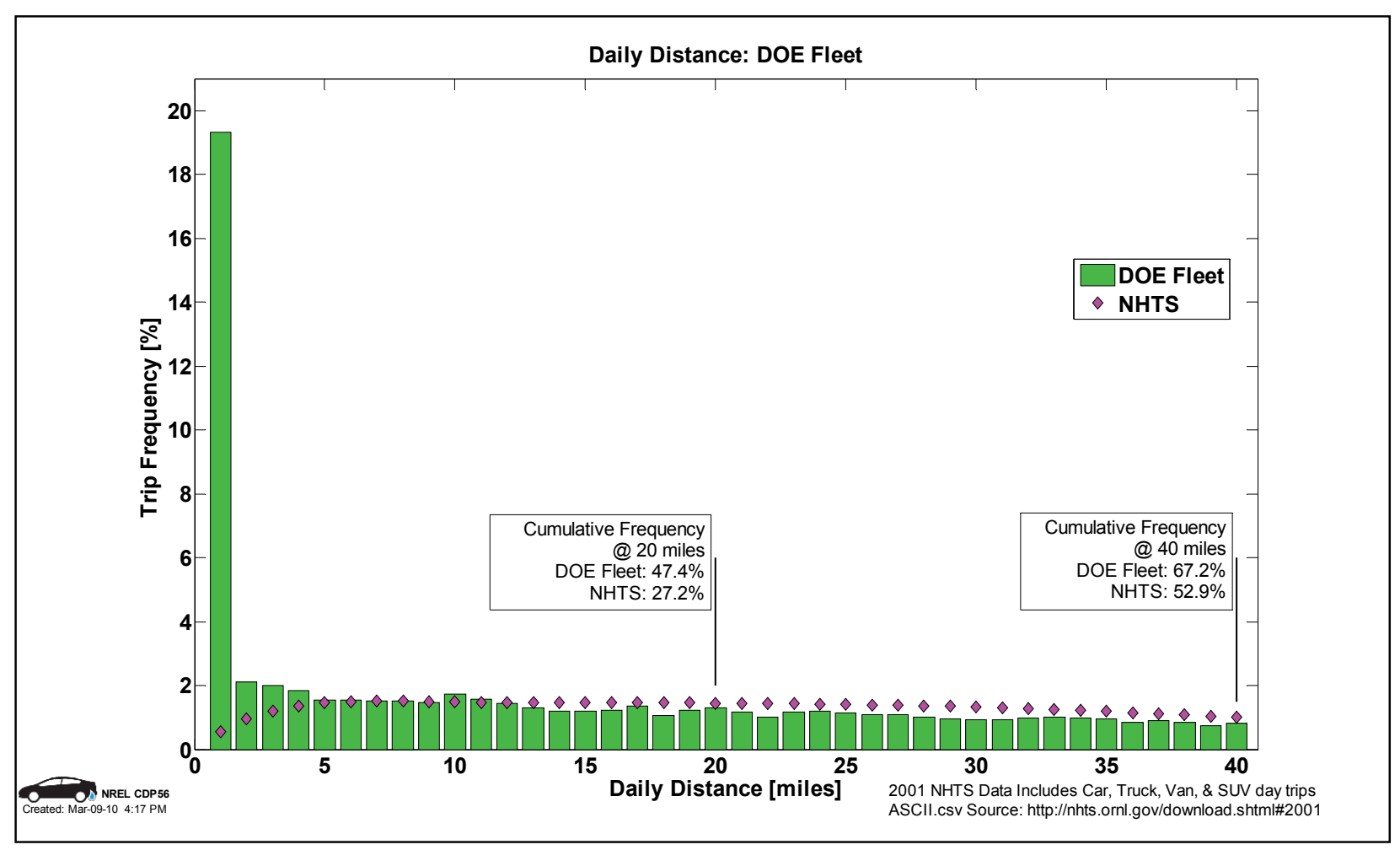

Figure 19: Daily driving distance (CDP56) 


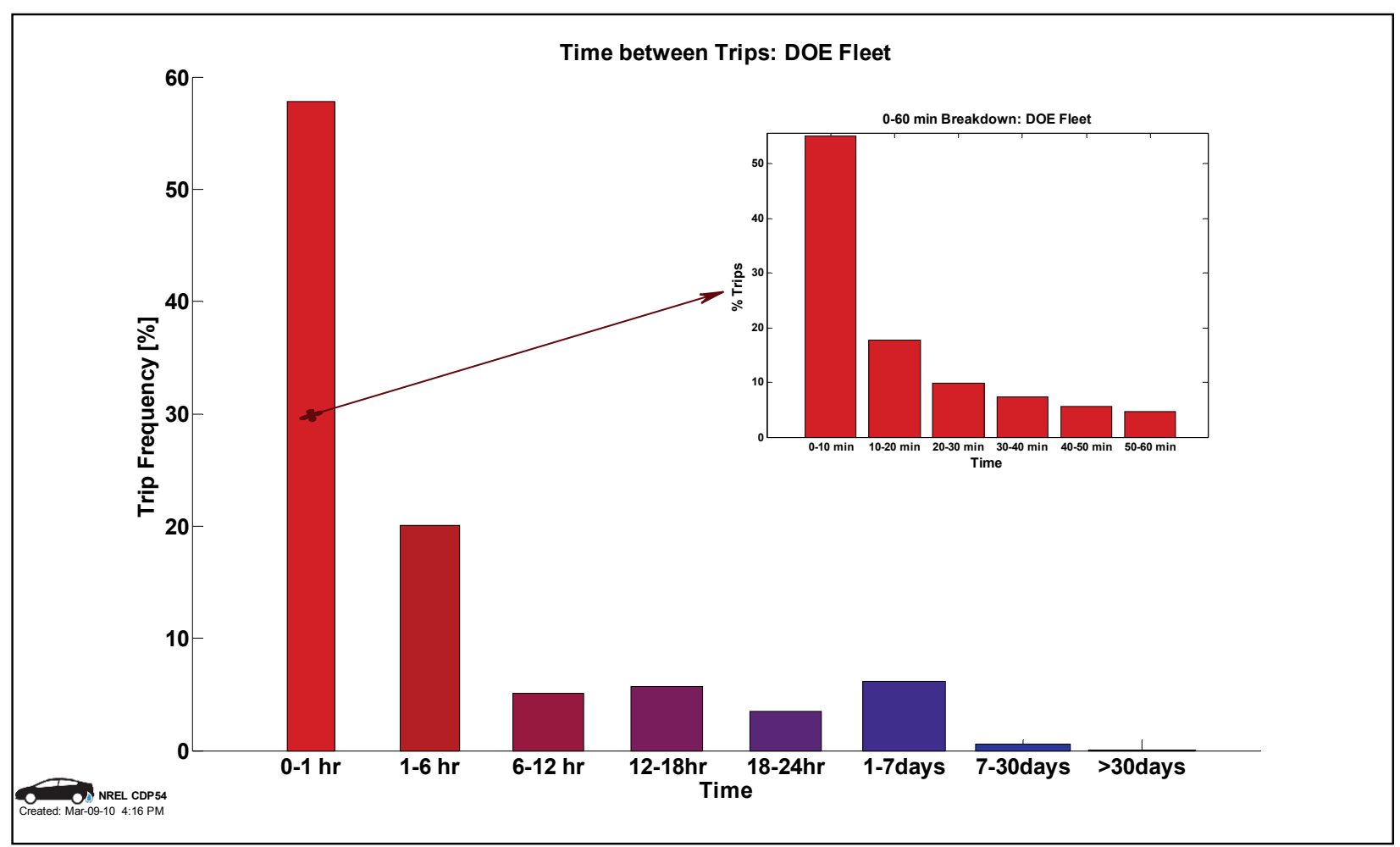

Figure 20: Time between trips (CDP54)

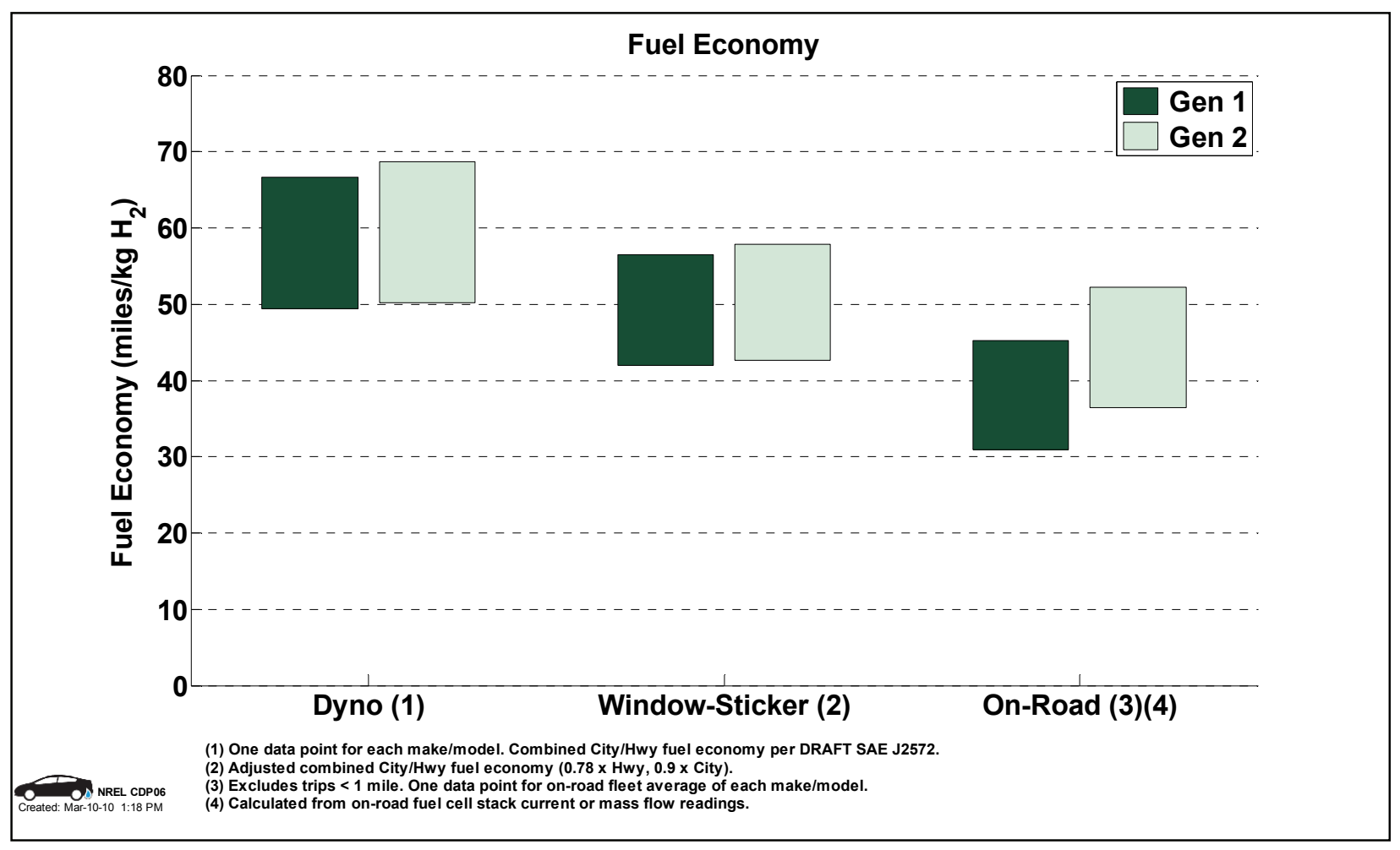

Figure 21: Fuel economy (CDP06) 


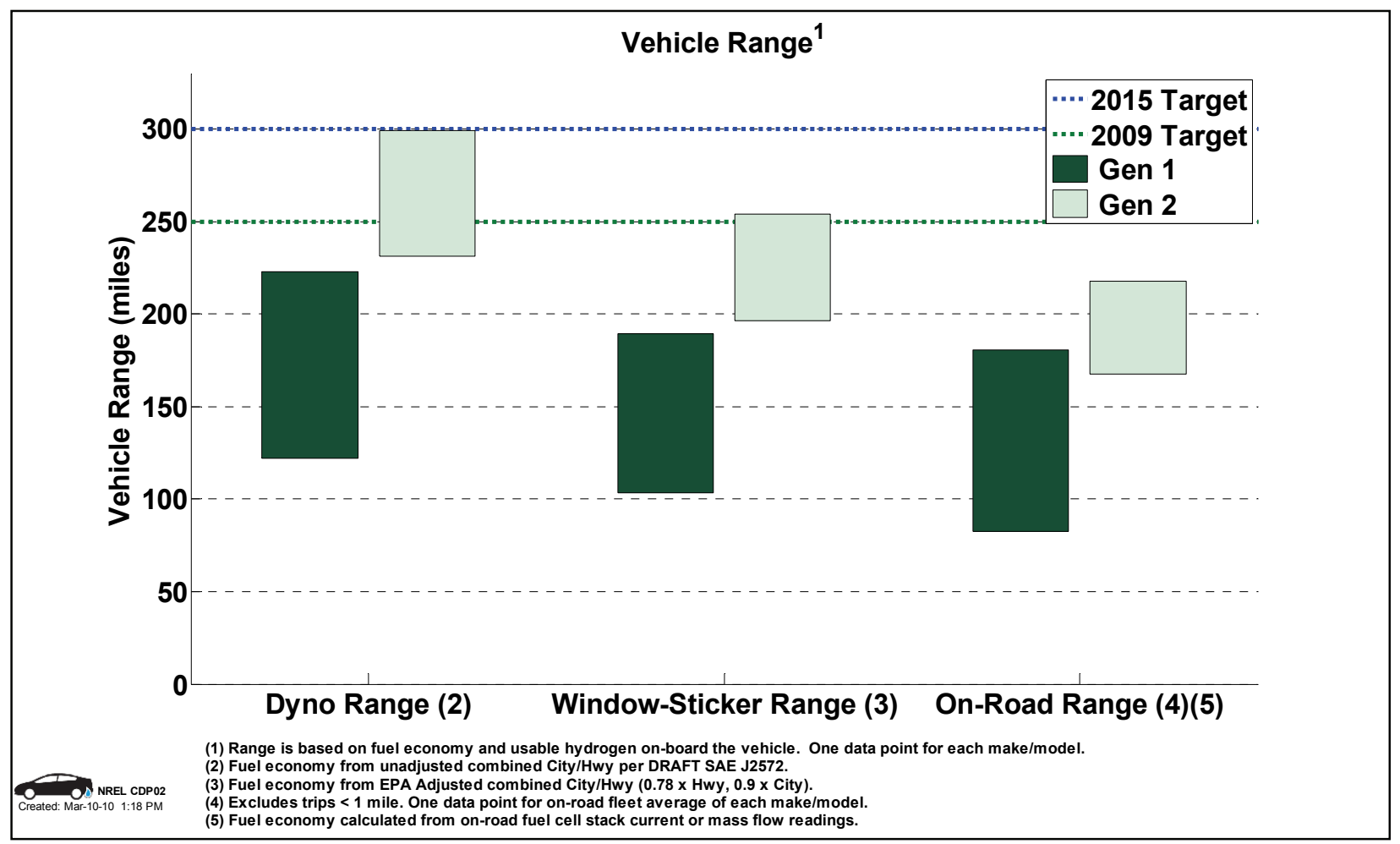

Figure 22: Vehicle driving range (CDP02)

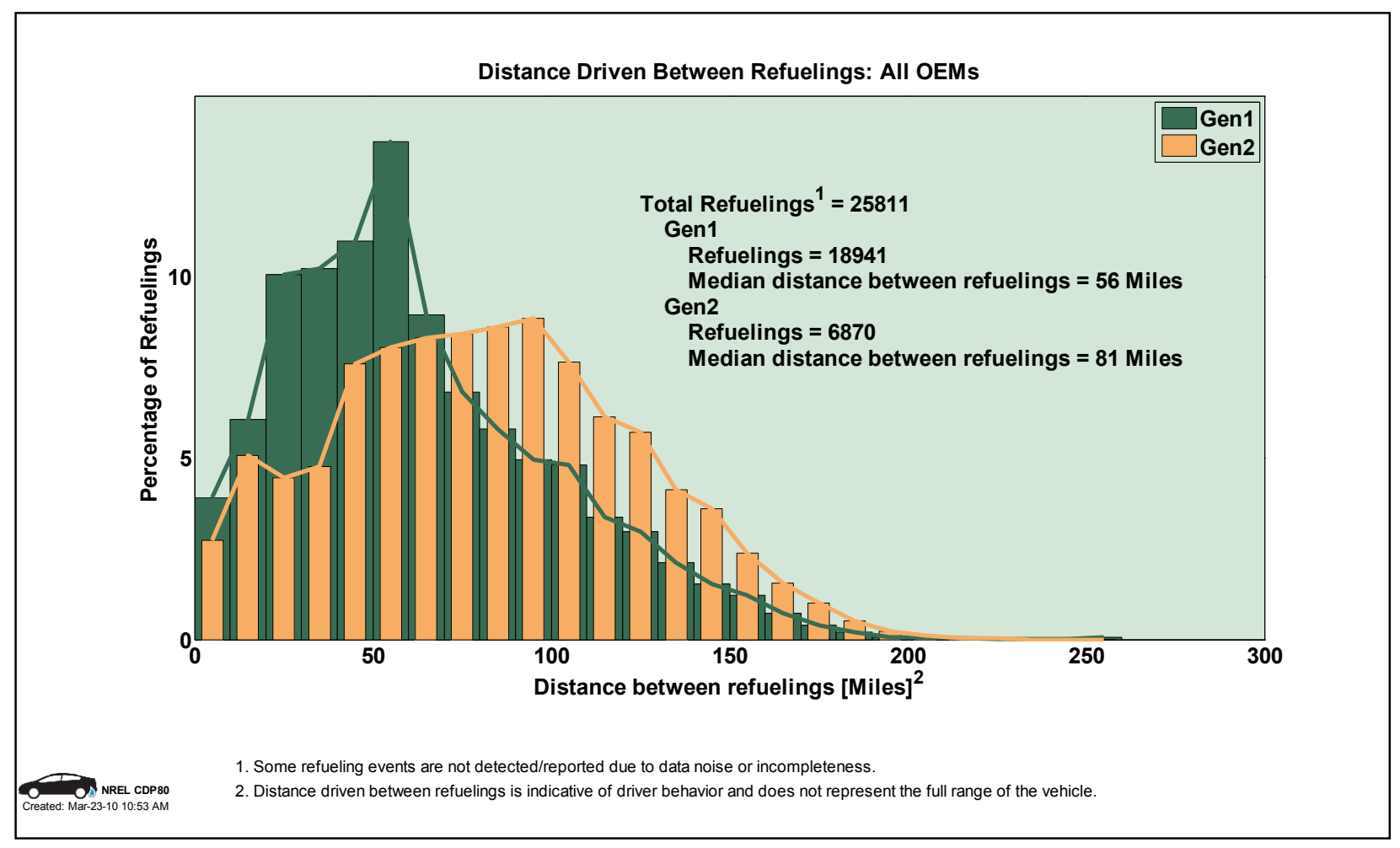

Figure 23: Miles between refuelings (CDP80) 


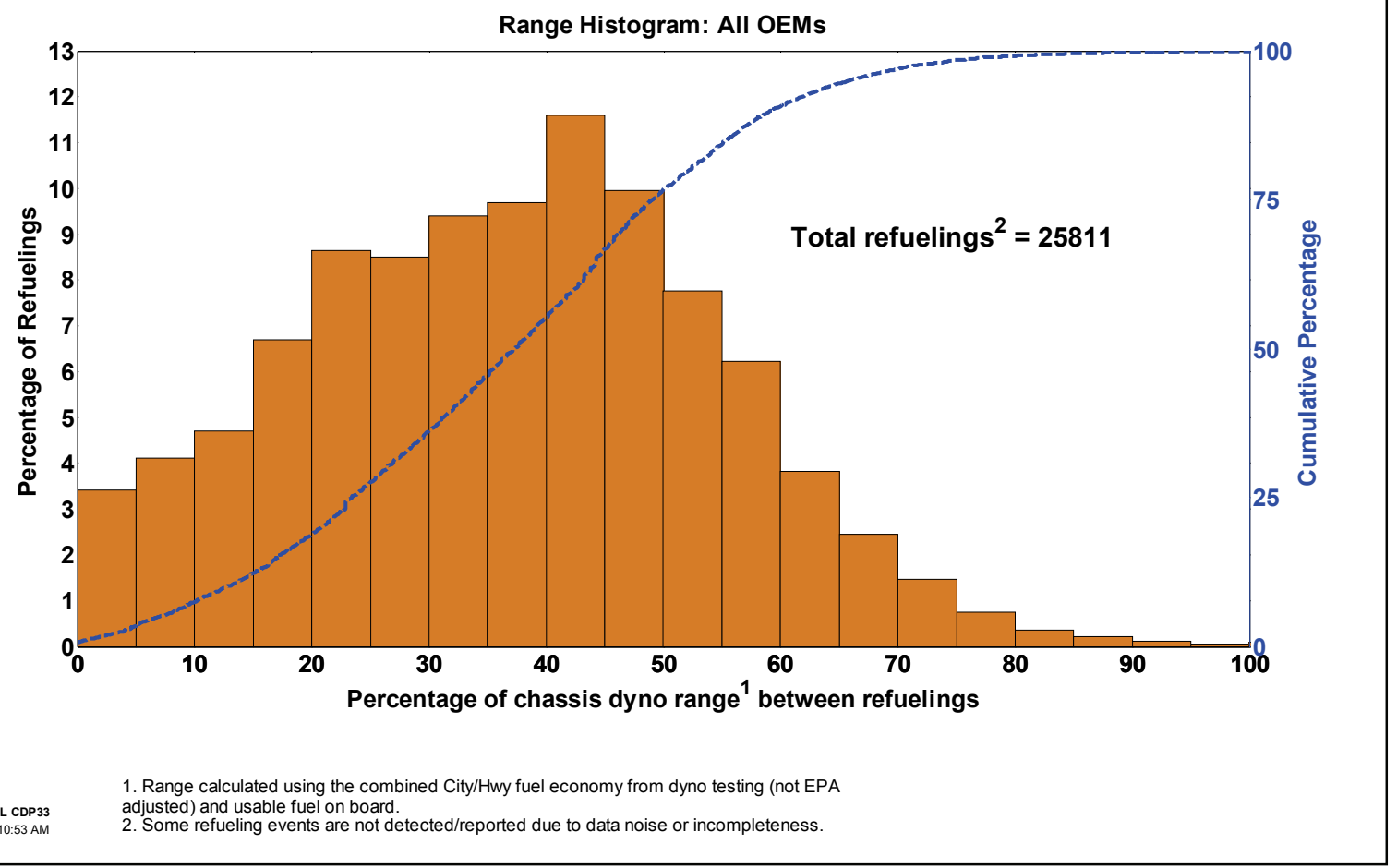

Figure 24: Percentage of theoretical range traveled between refuelings (CDP33)

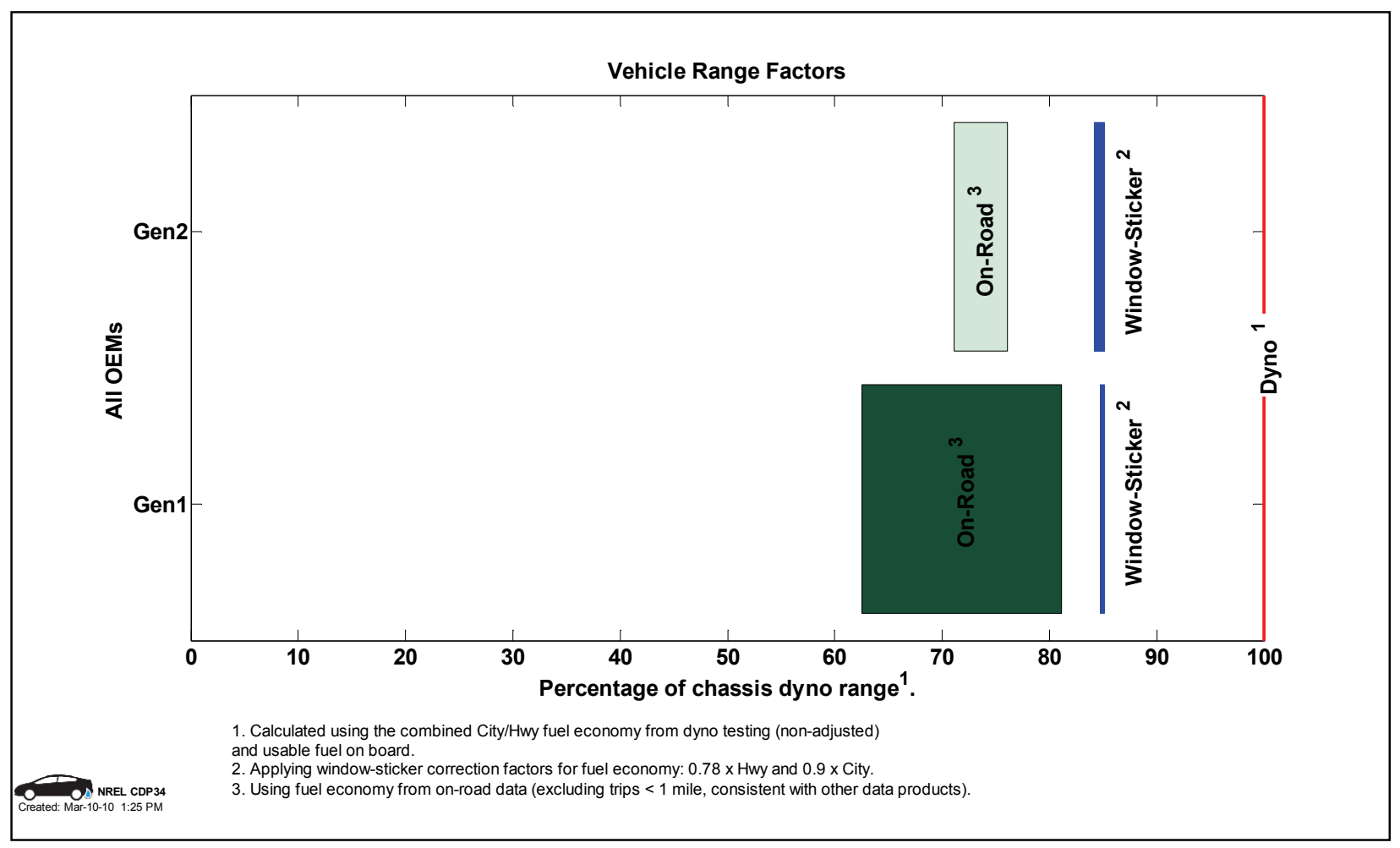

Figure 25: Effective vehicle driving range (CDP34) 


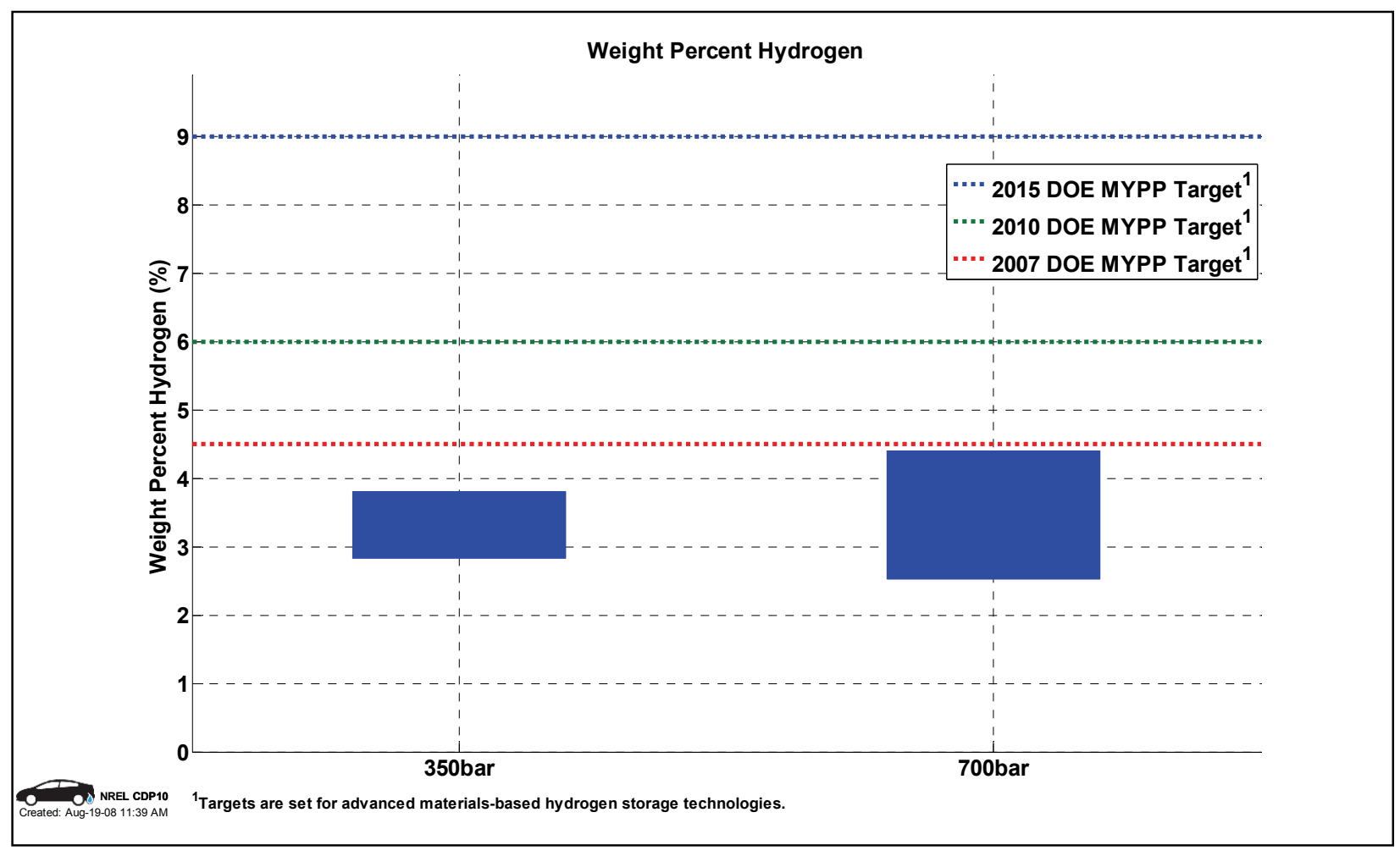

Figure 26: Storage weight \% hydrogen (CDP10)

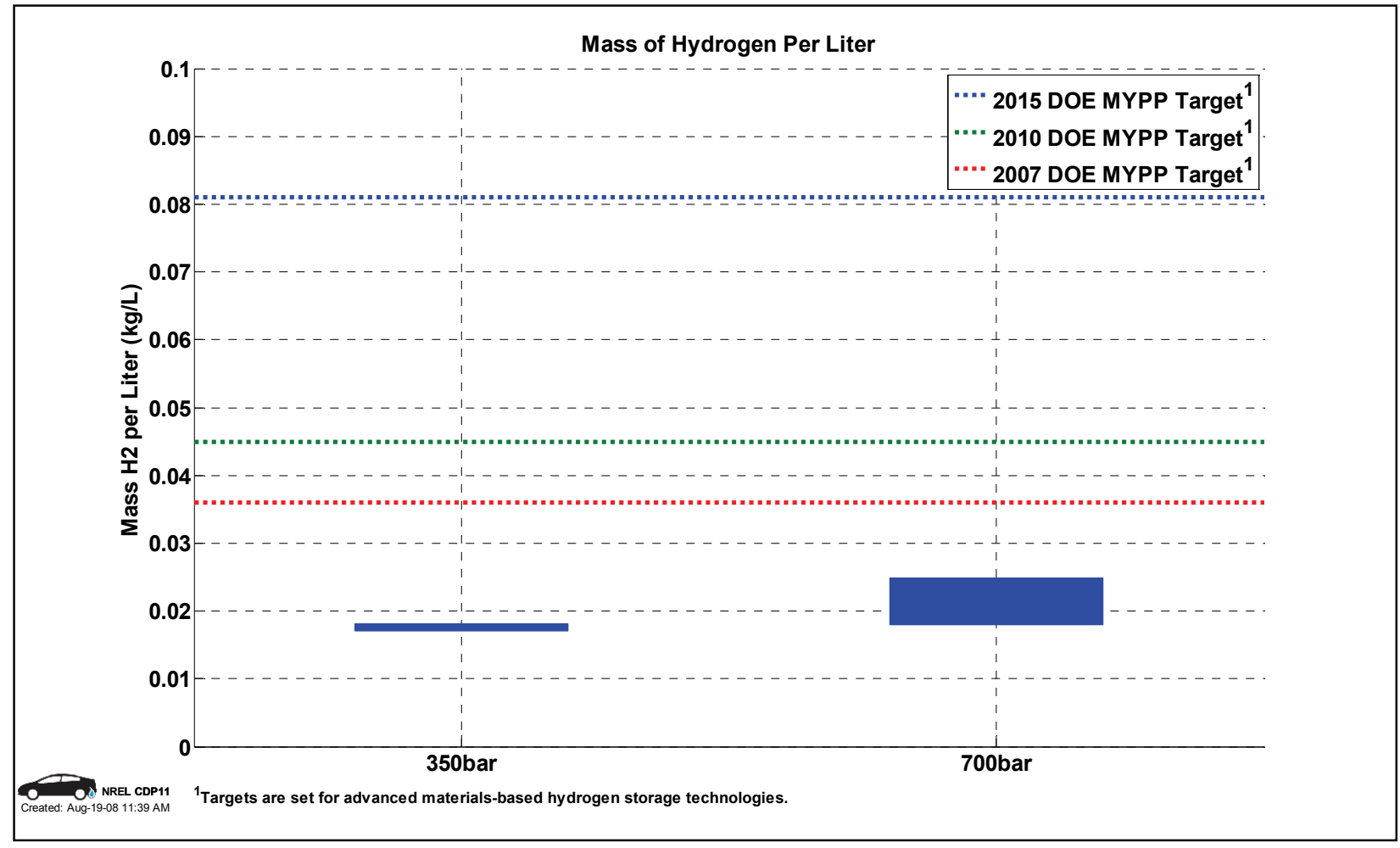

Figure 27: Volumetric capacity of hydrogen storage (CDP11) 


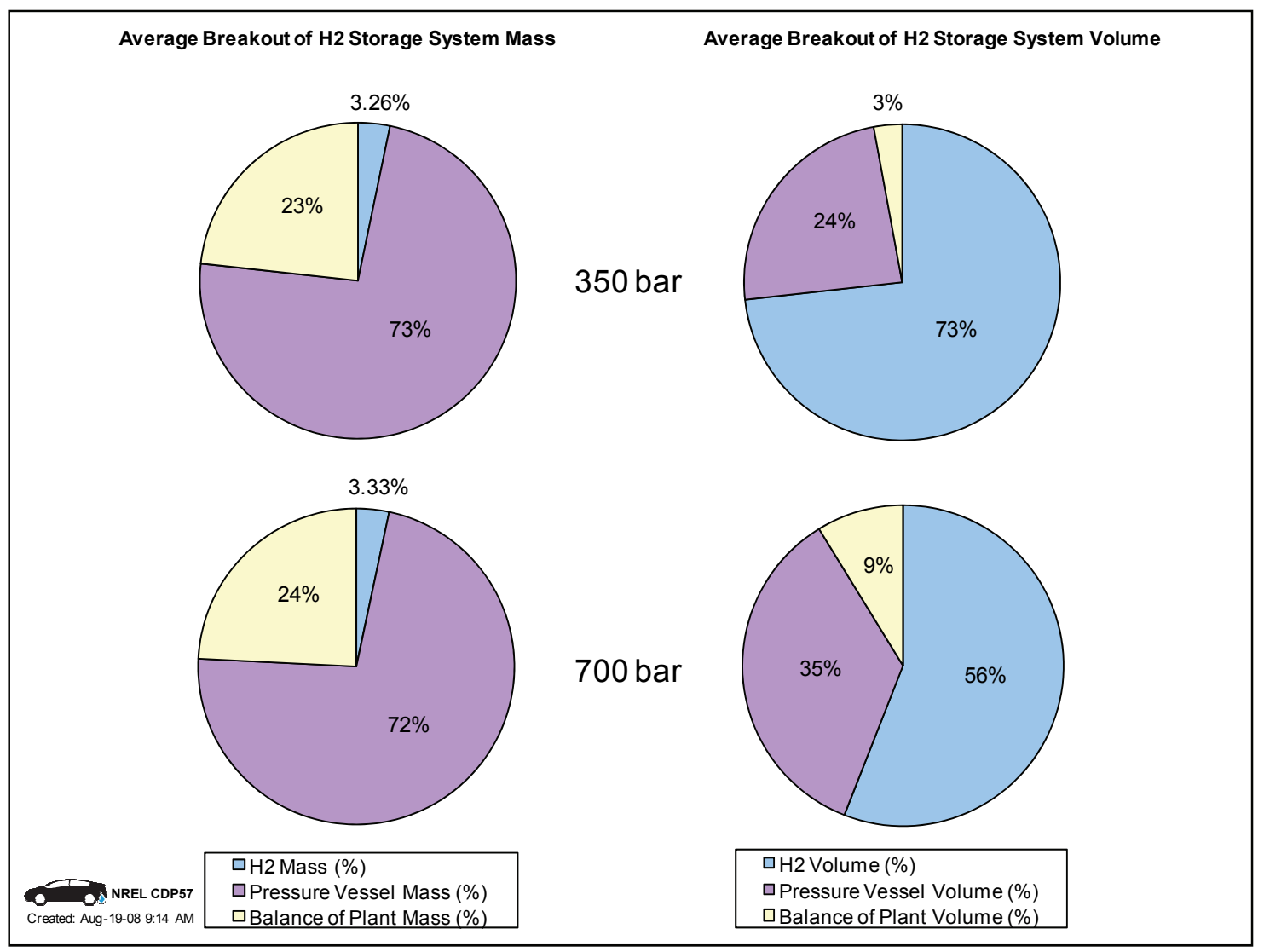

Figure 28: Hydrogen storage system mass and volume breakdown (CDP57)

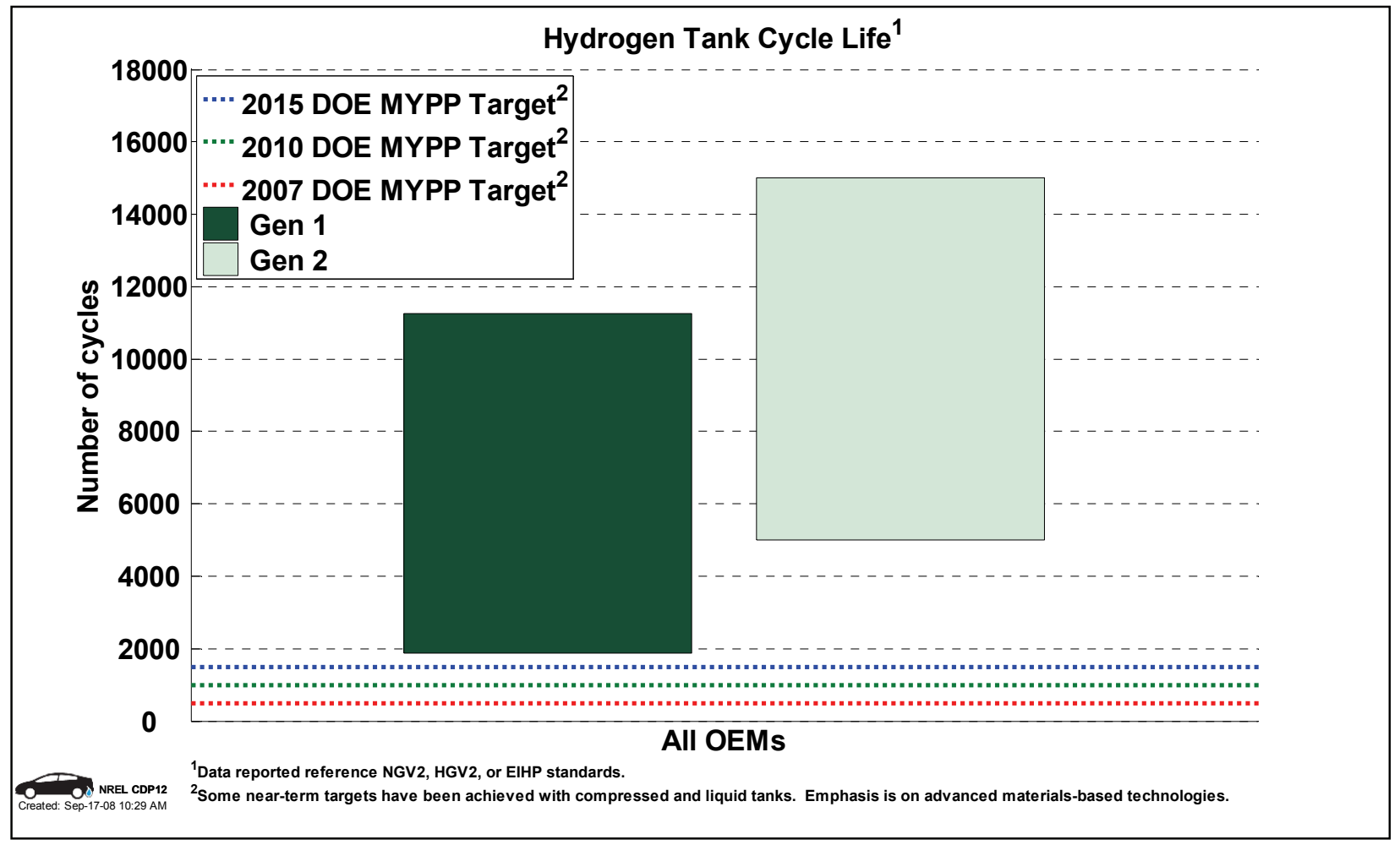

Figure 29: Vehicle hydrogen tank cycle life (CDP12) 


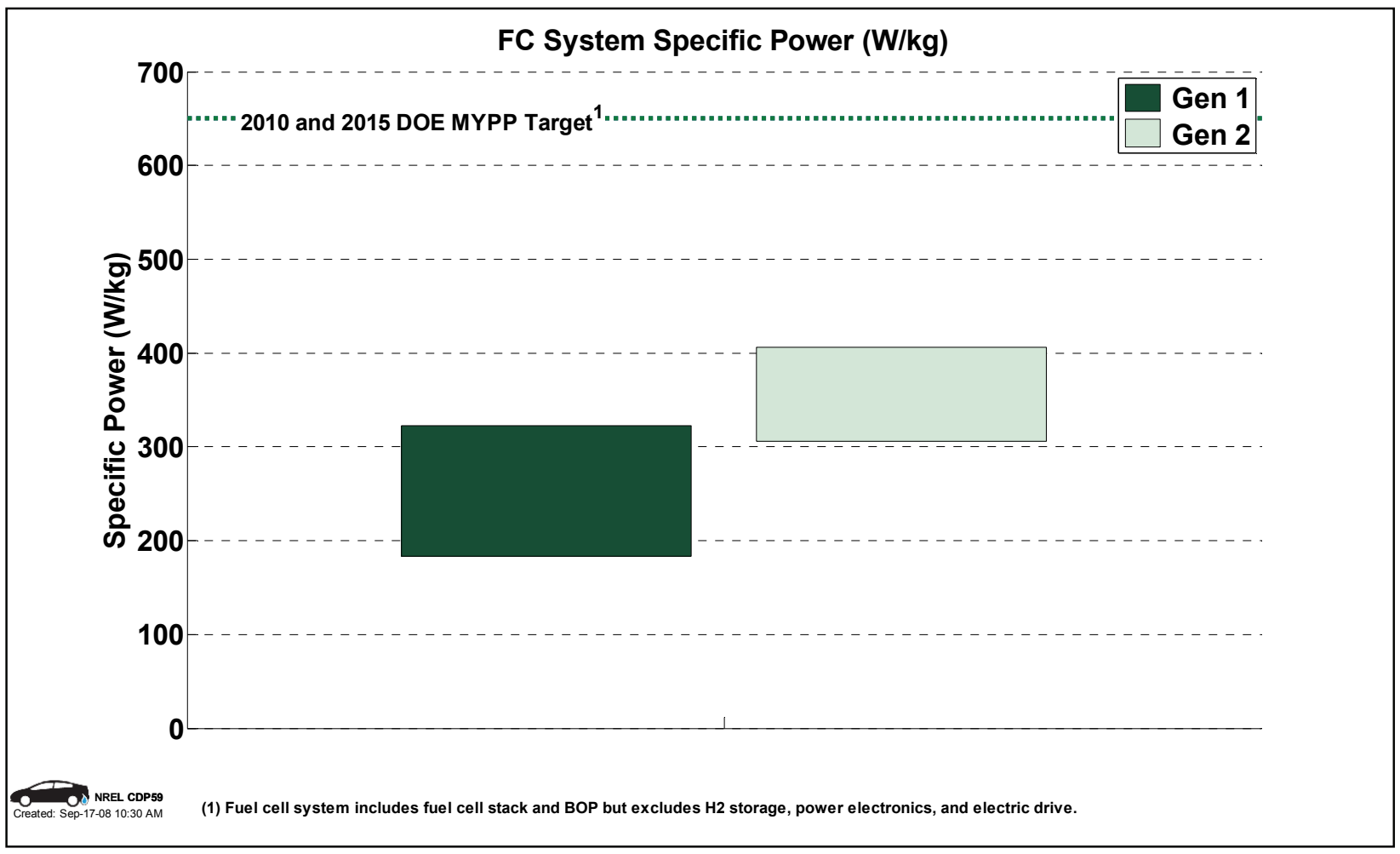

Figure 30: Fuel cell system specific power (CDP59)

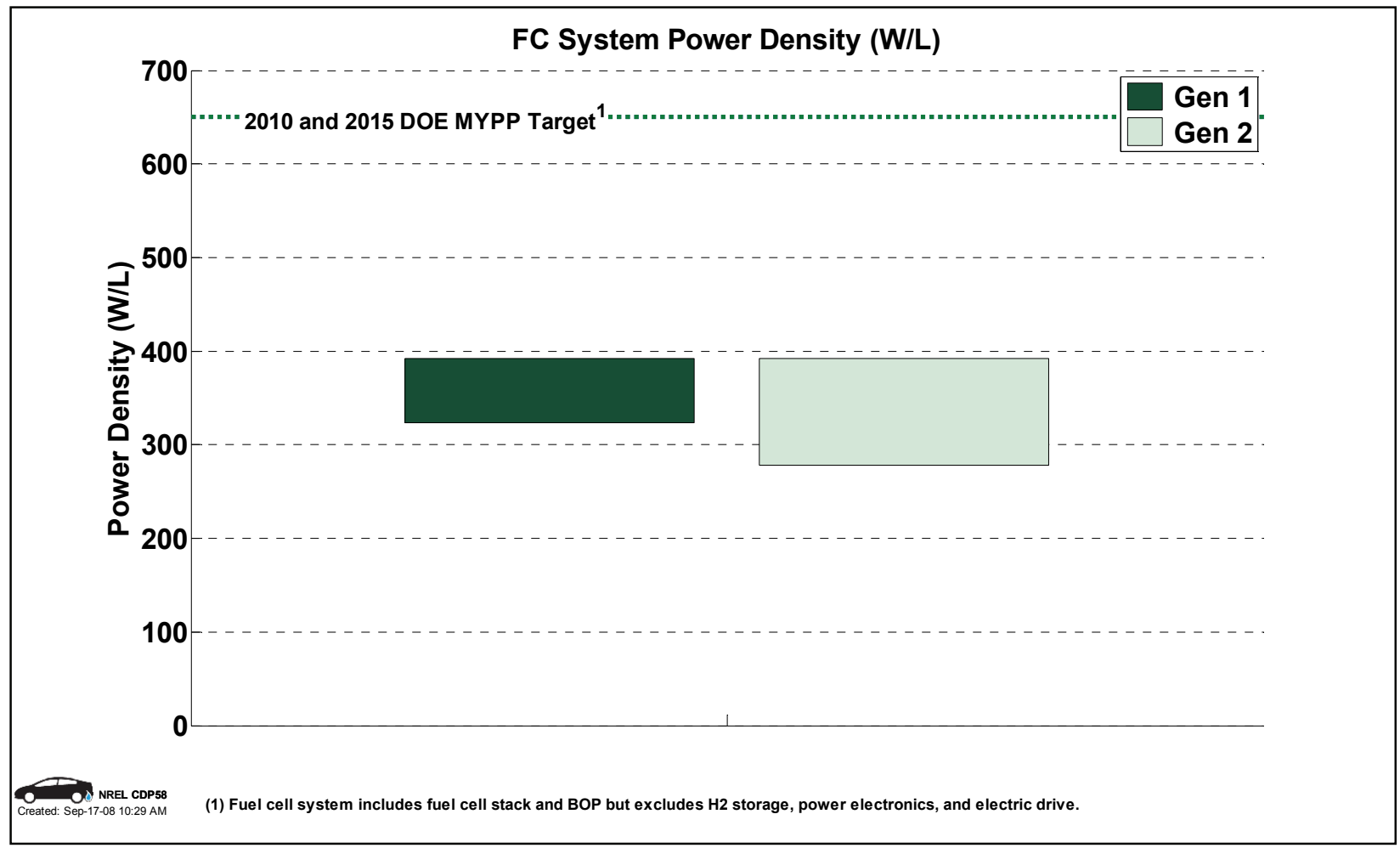

Figure 31: Fuel cell system power density (CDP58) 


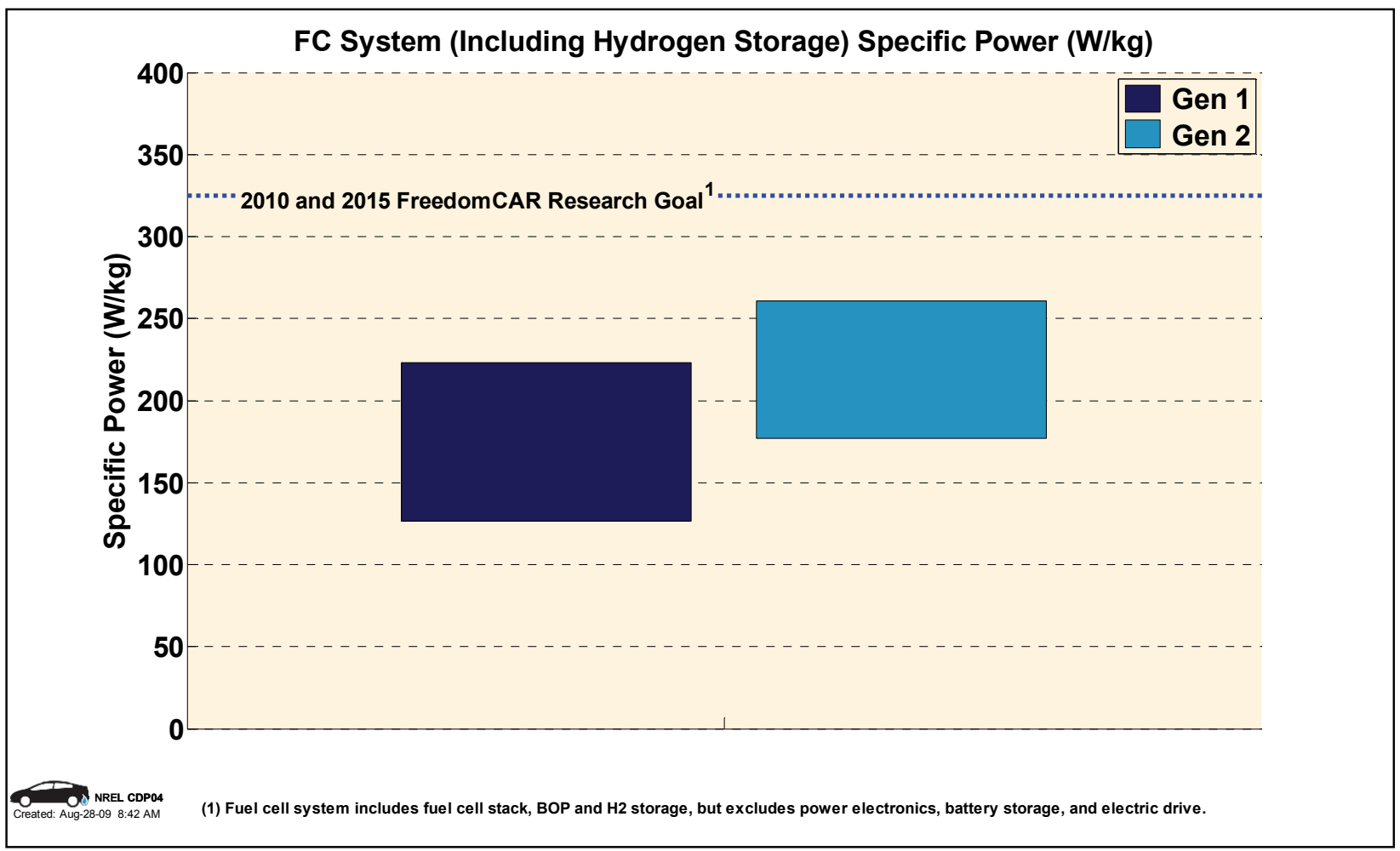

Figure 32: Fuel cell system specific power, including hydrogen storage (CDP04)

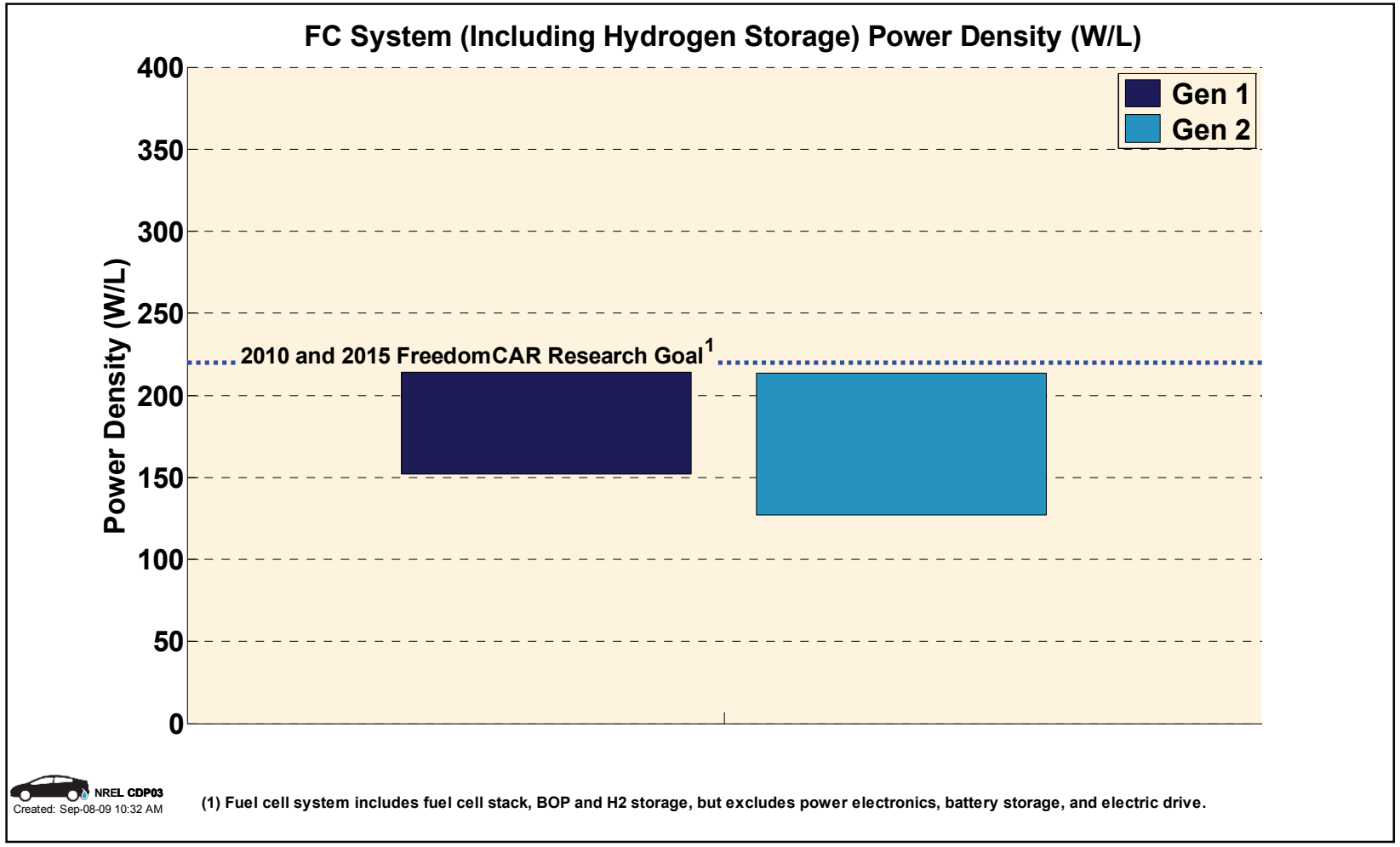

Figure 33: Fuel cell system power density, including hydrogen storage (CDP03) 


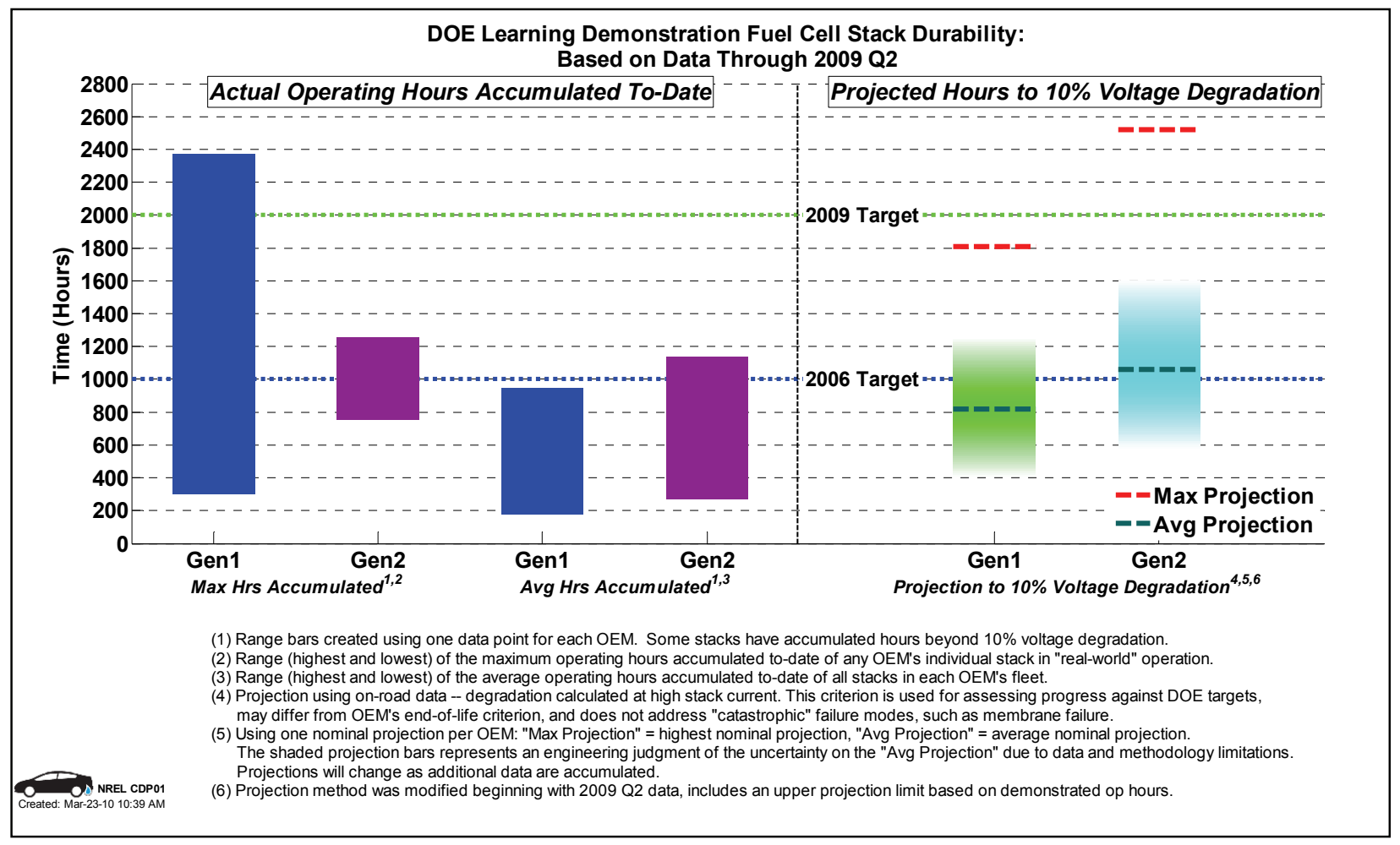

Figure 34: Hours accumulated and projected hours to $10 \%$ stack voltage degradation (CDP01)

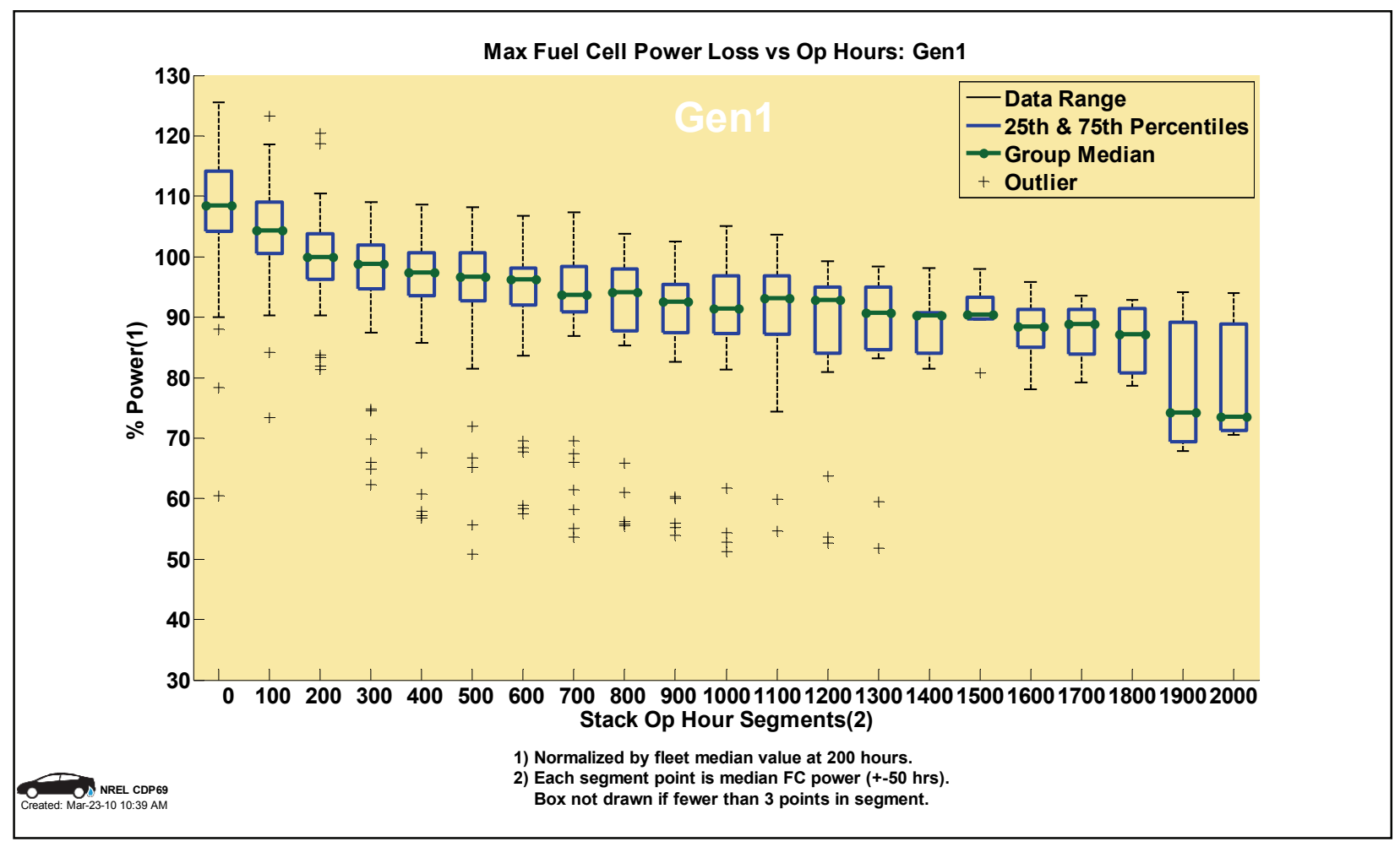

Figure 35: Maximum fuel cell power degradation-Gen 1 (CDP69) 


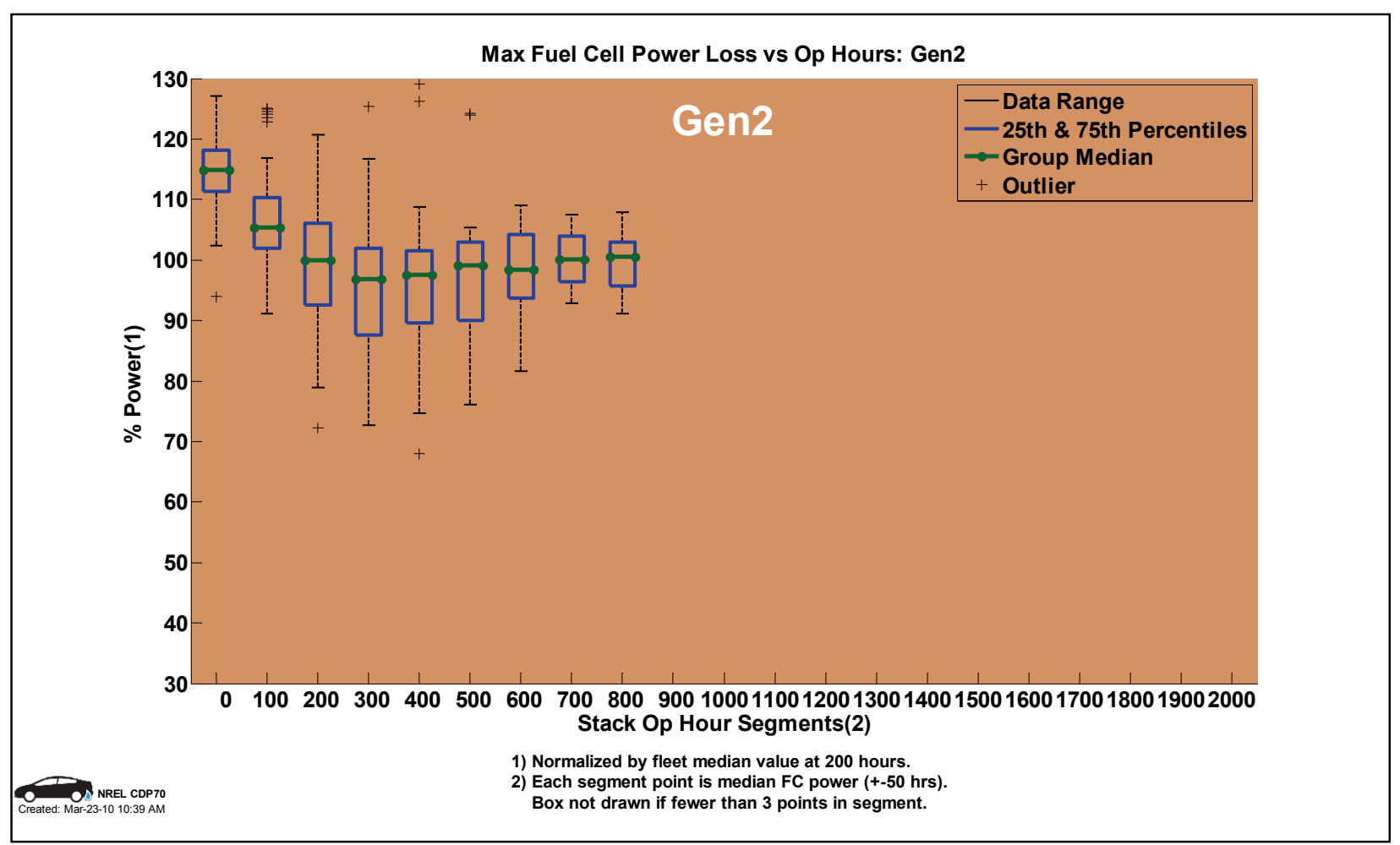

Figure 36: Maximum fuel cell power degradation-Gen 2 (CDP70)

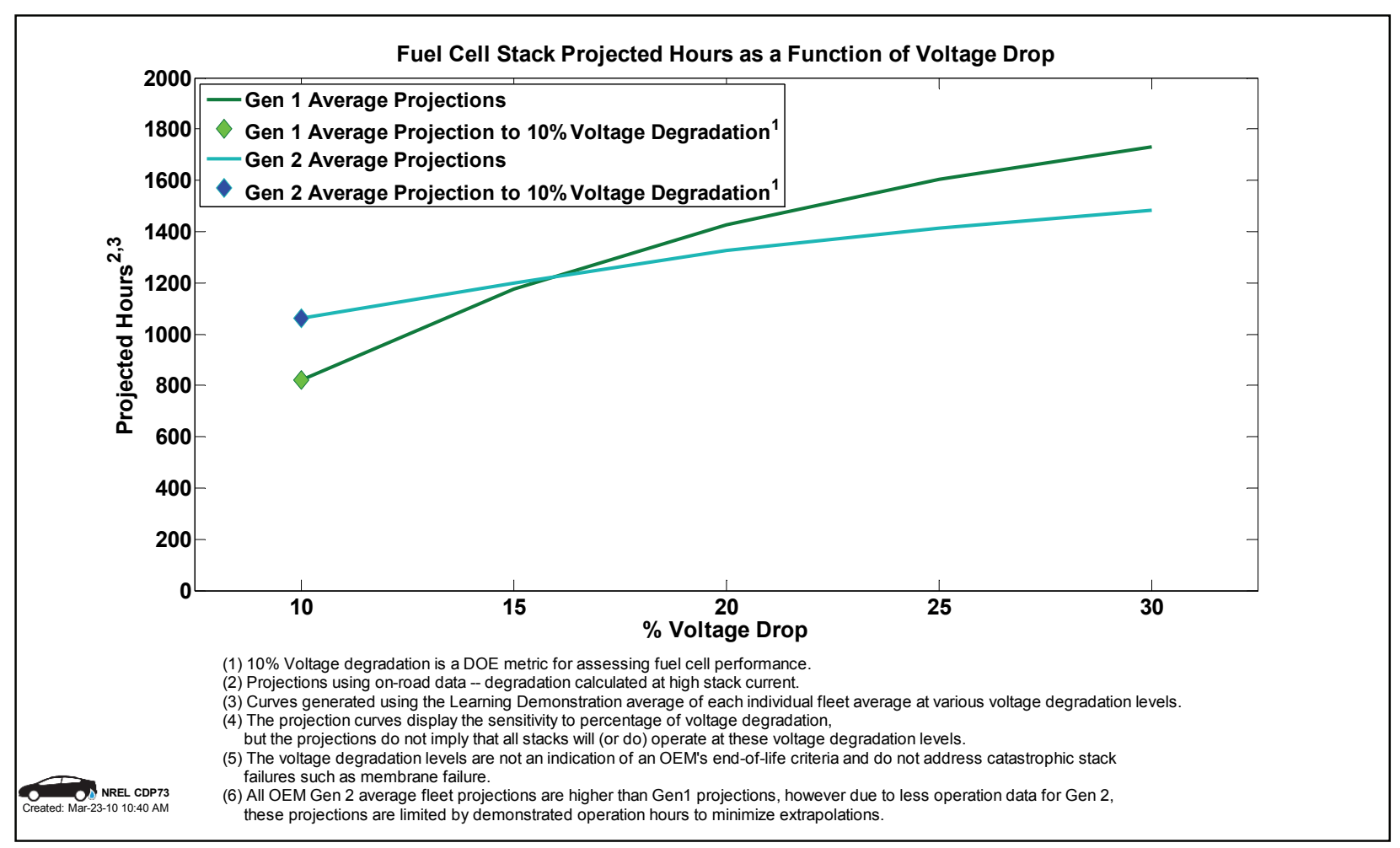

Figure 37: Fuel cell stack projected hours as a function of voltage drop (CDP73) 


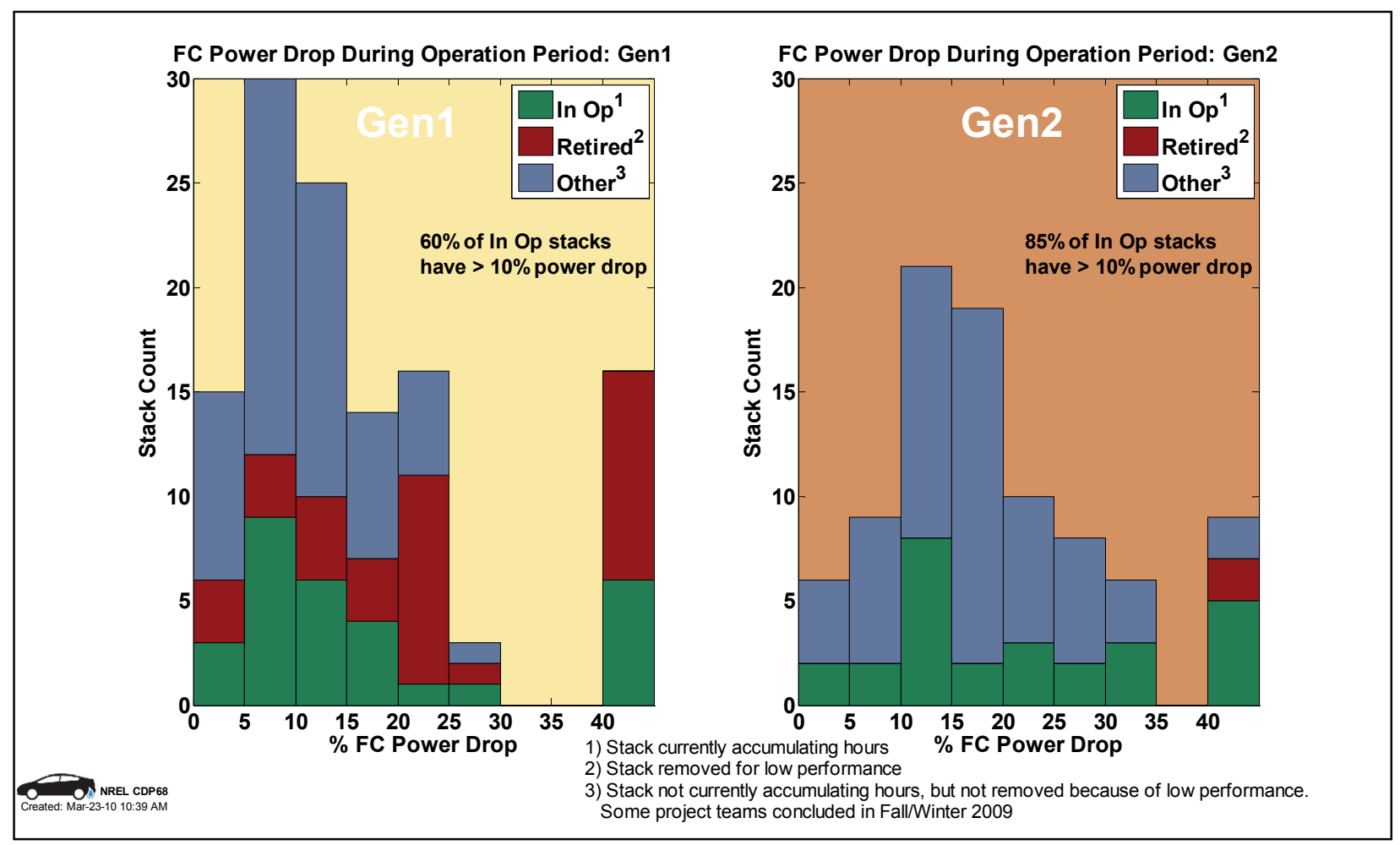

Figure 38: Power drop during fuel cell stack operating period (CDP68)

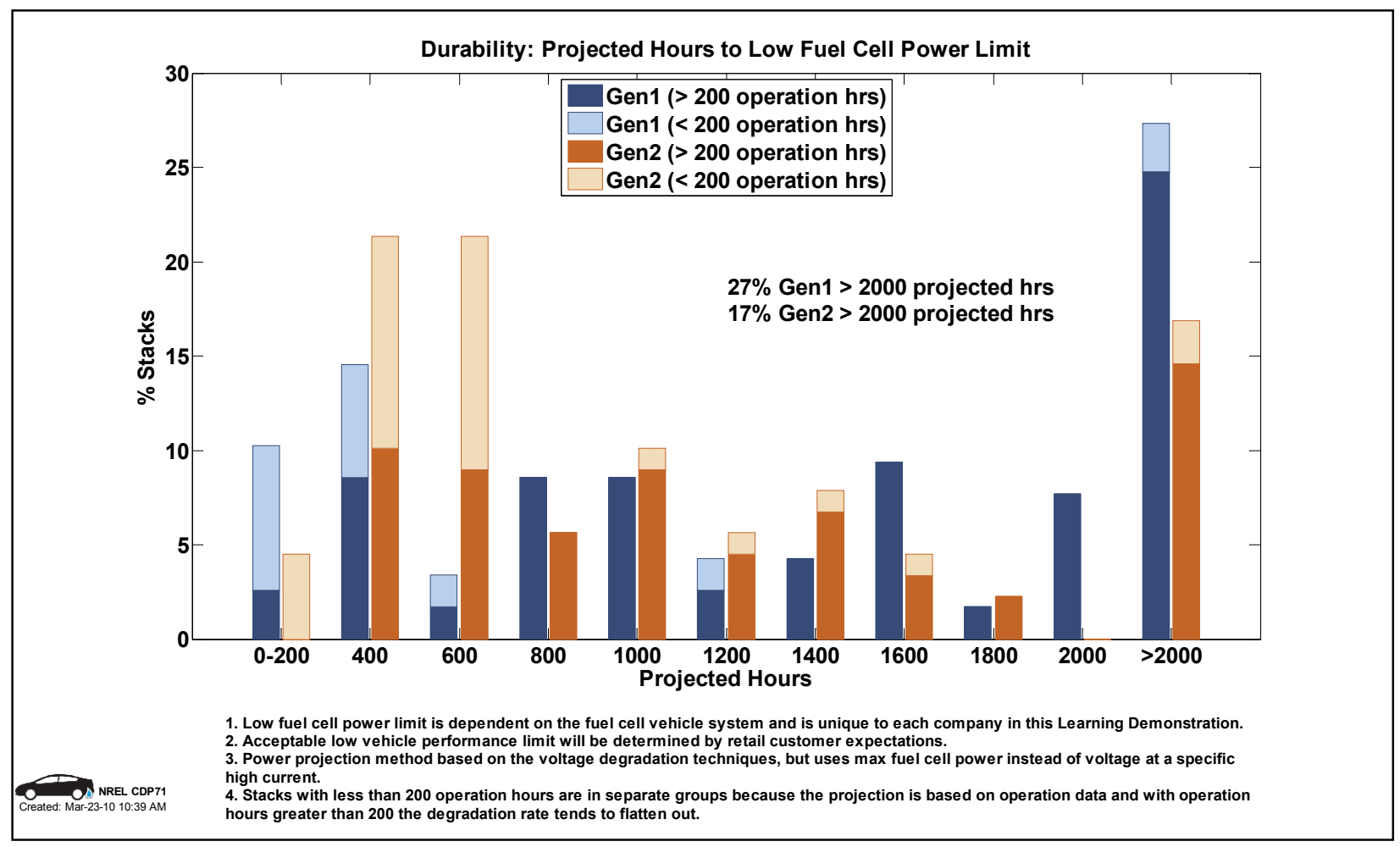

Figure 39: Projected hours to OEM low power operation limit (CDP71) 


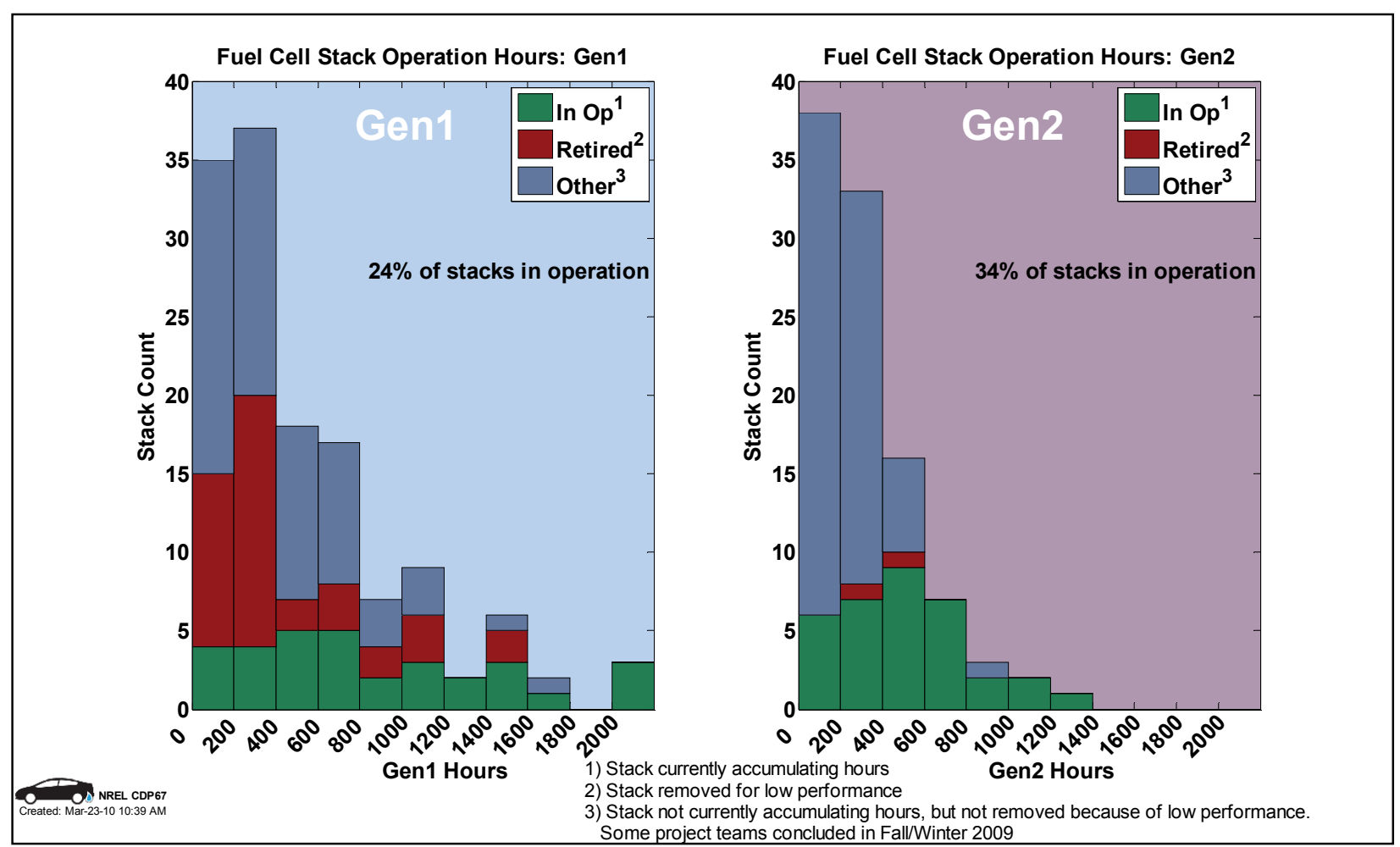

Figure 40: Fuel cell stack operation hours (CDP67)

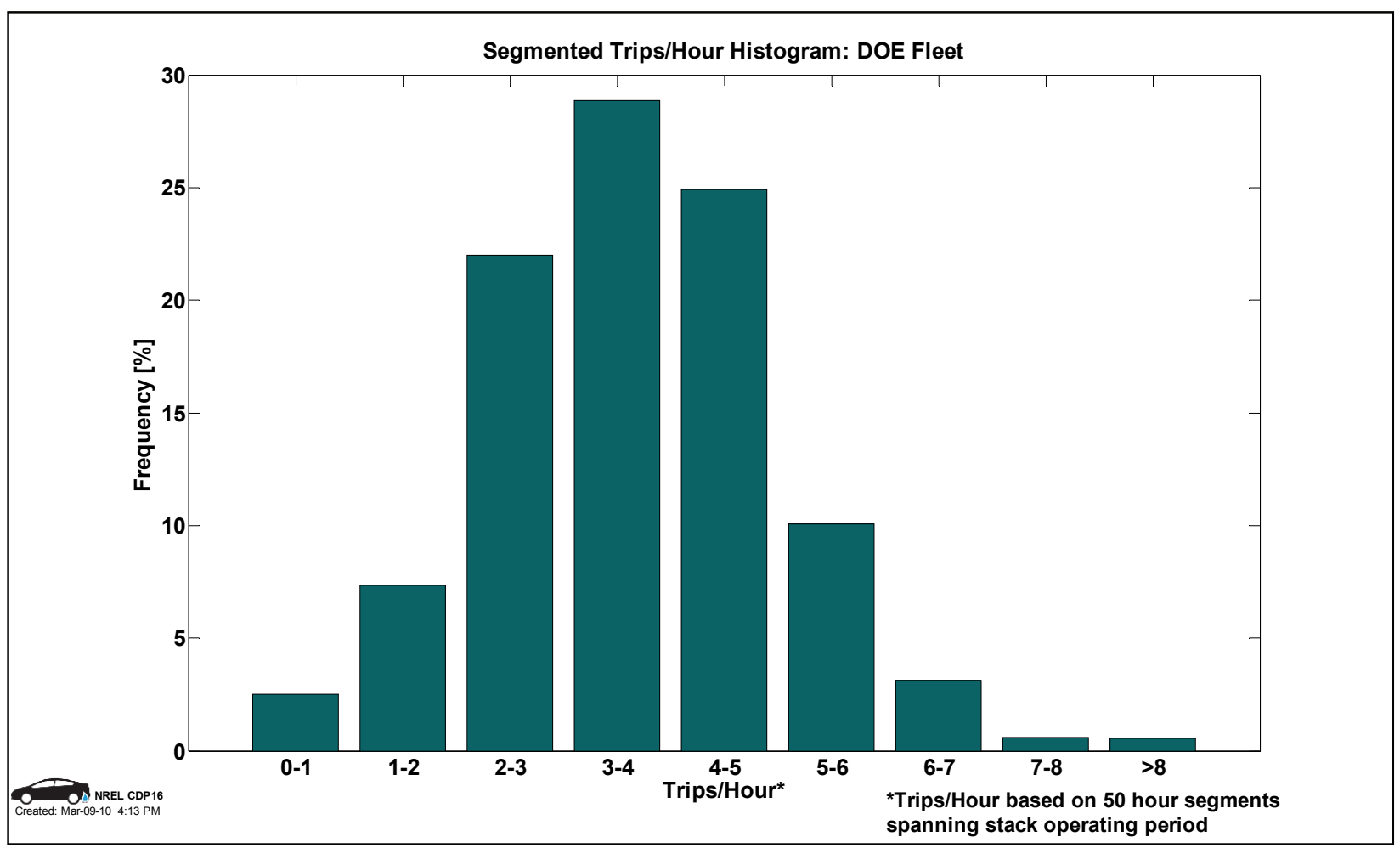

Figure 41: Fuel cell stack trips per hour histogram (CDP16) 


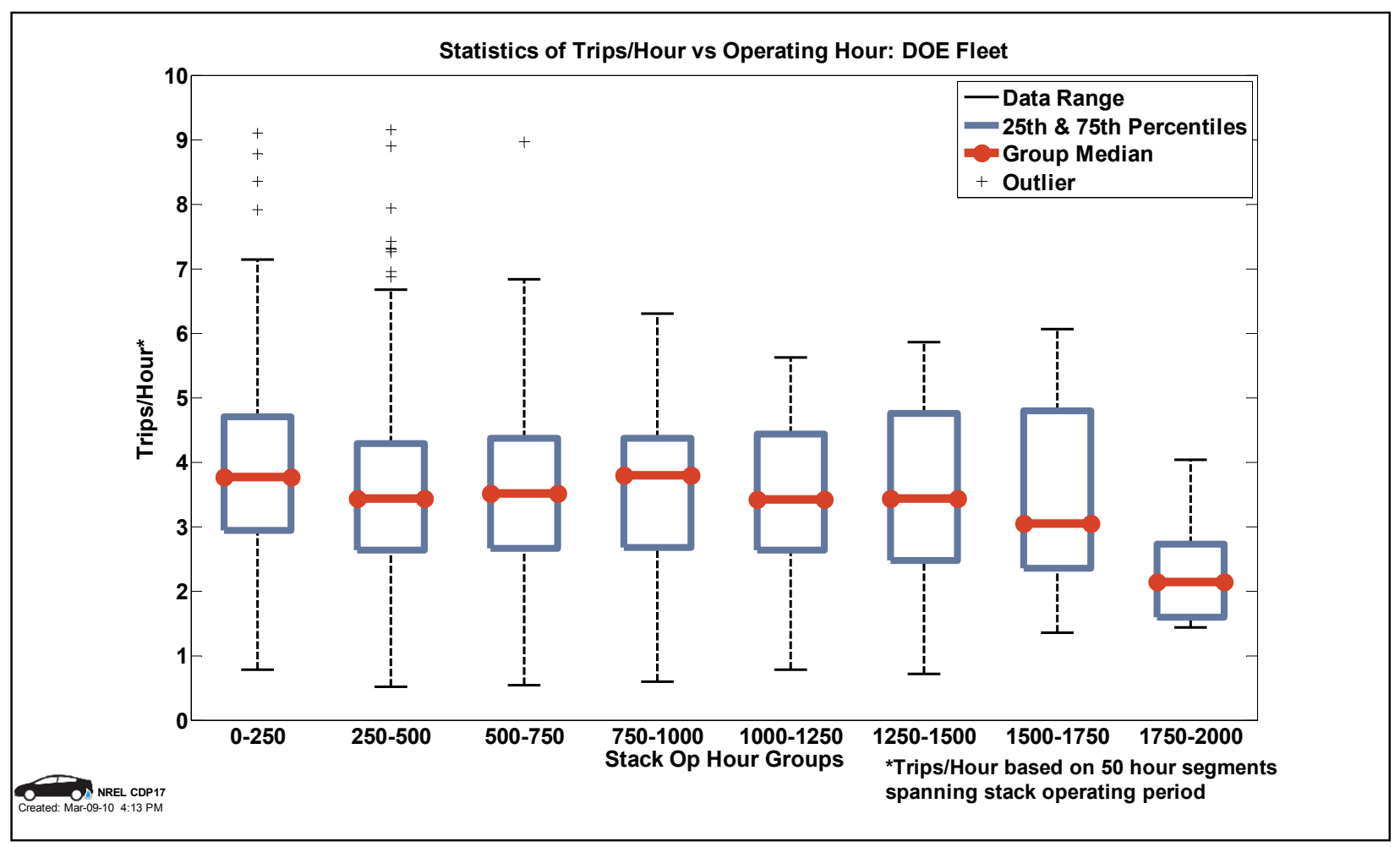

Figure 42: Statistics of trips/hour vs. operating hour (CDP17)

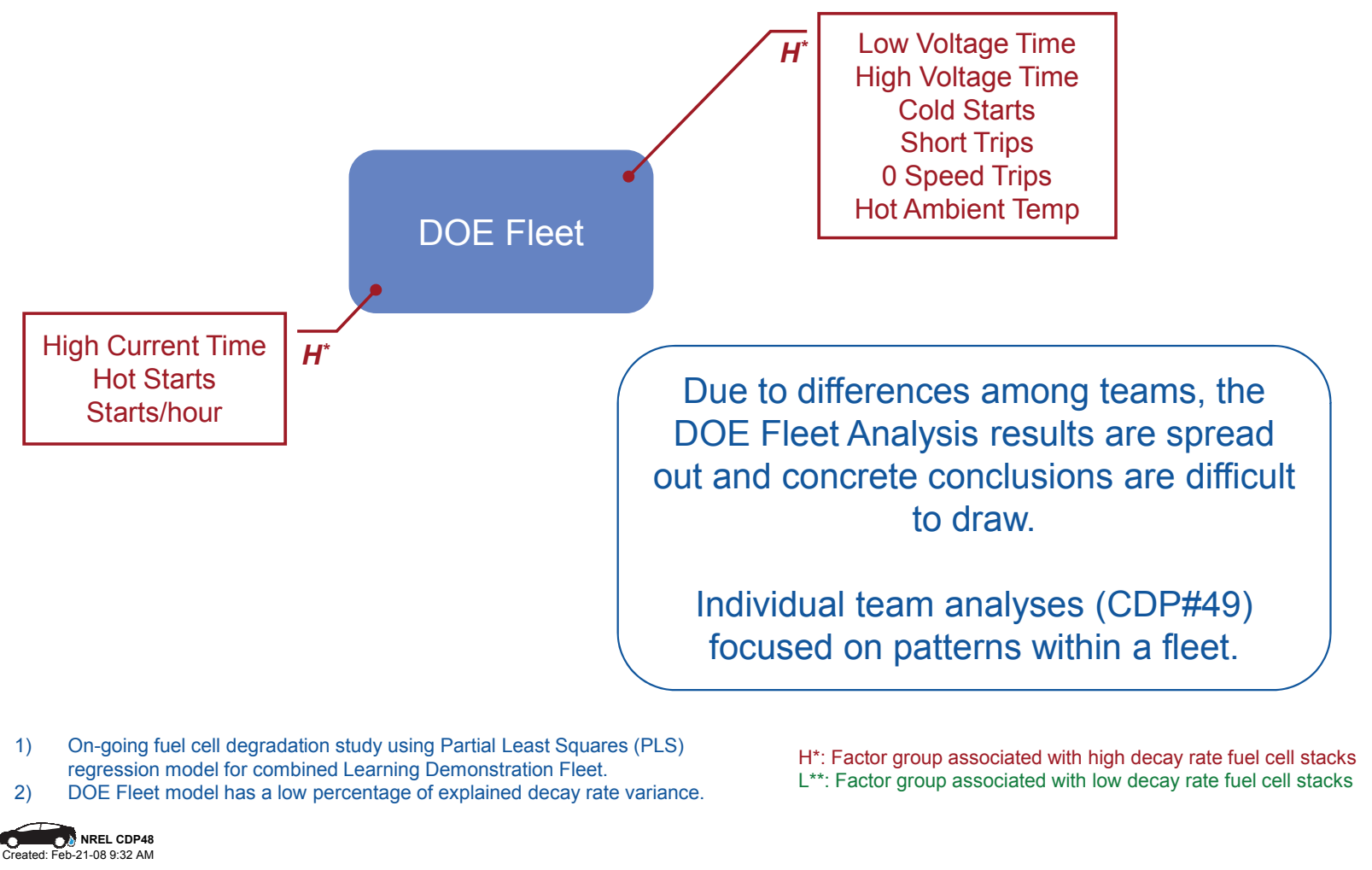

Figure 43: Primary factors affecting learning demonstration fleet fuel cell degradation (CDP48) 

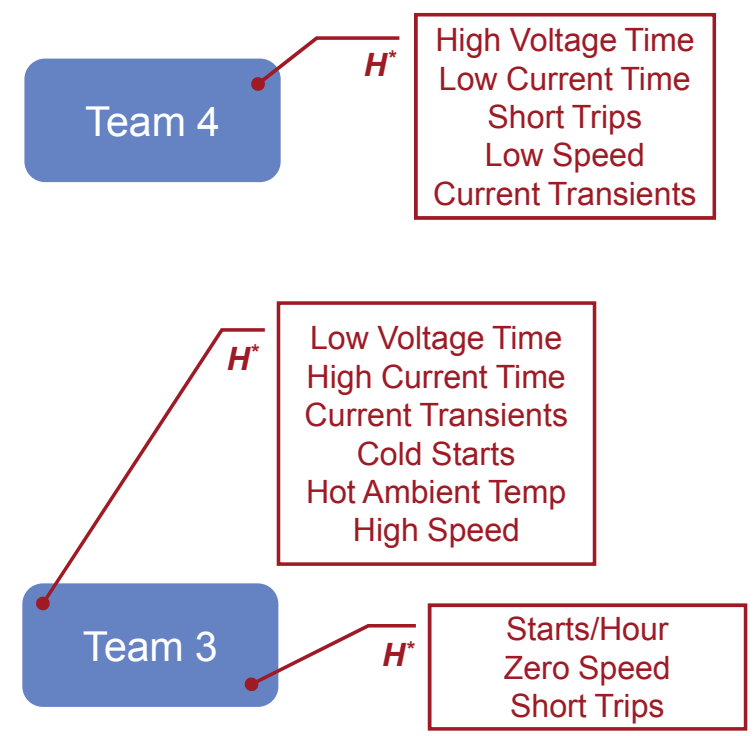

1) On-going fuel cell degradation study using Partial Least Squares (PLS) regression model for each team's Gen 1 fleet.

2) Teams' PLS models have a high percentage of explained decay rate variance, but the models are not robust and results are scattered.

3) Factor groups associated with stacks that are opposite to the identified groups here are not specified.
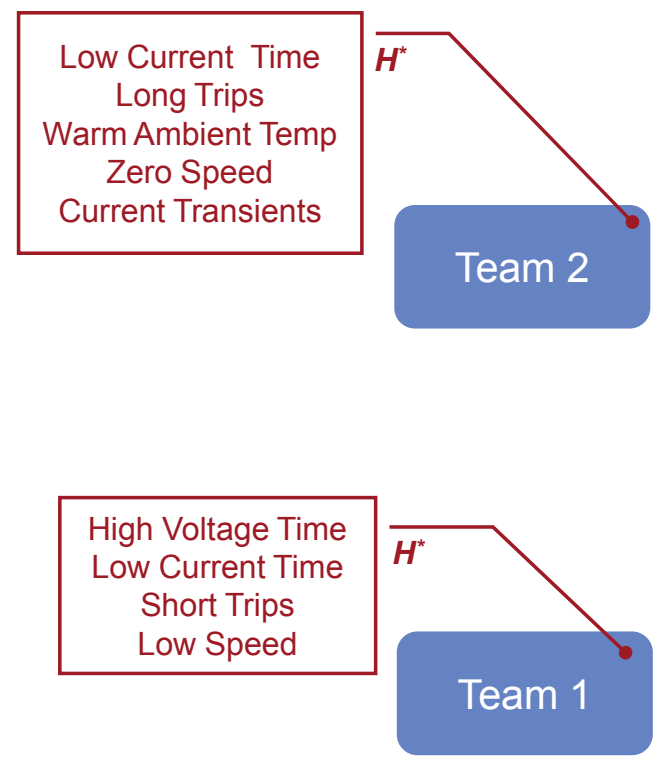

$\mathrm{H}^{*}$ : Factor group associated with high decay rate fuel cell stacks

Created: Mar-09-09 9:06 AM

Figure 44: Primary factors affecting learning demonstration team fuel cell degradation (CDP49)

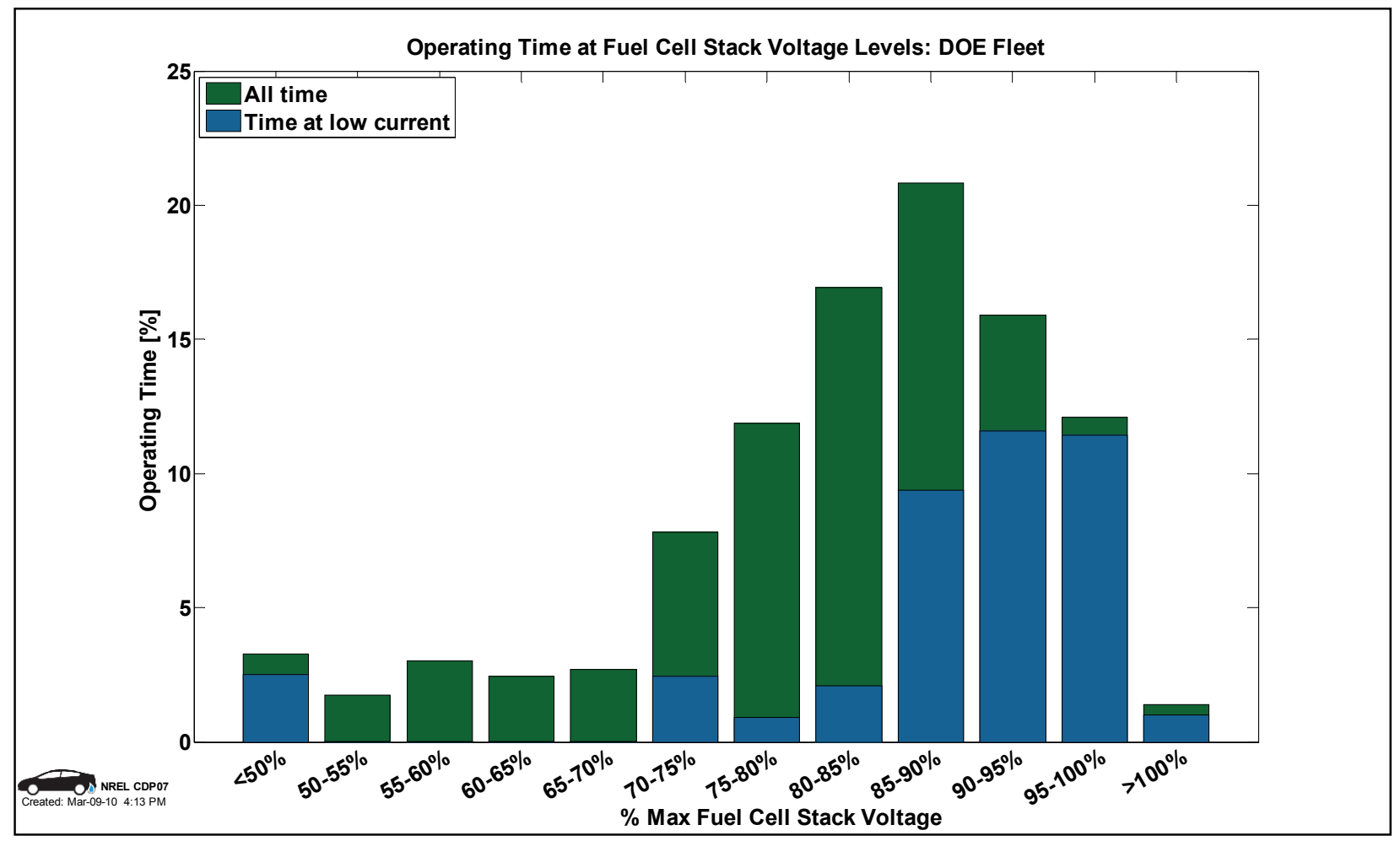

Figure 45: Fuel cell voltage (CDP07) 


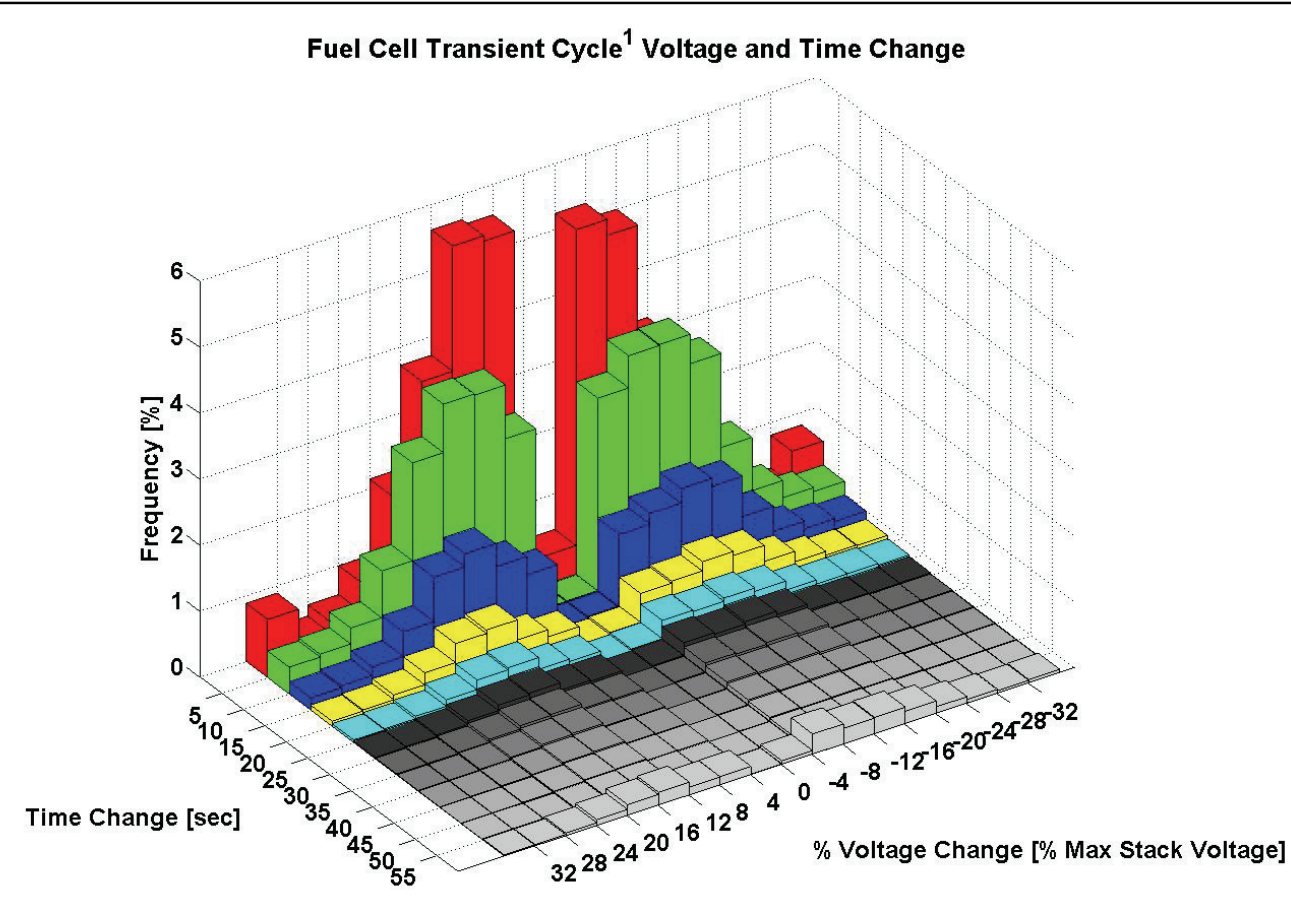

1) A fuel cell voltage transient cycle has a decrease and increase with a minimum delta of $5 \%$ max stack voltage.

Figure 46: Fuel cell transient voltage and time change (CDP75)
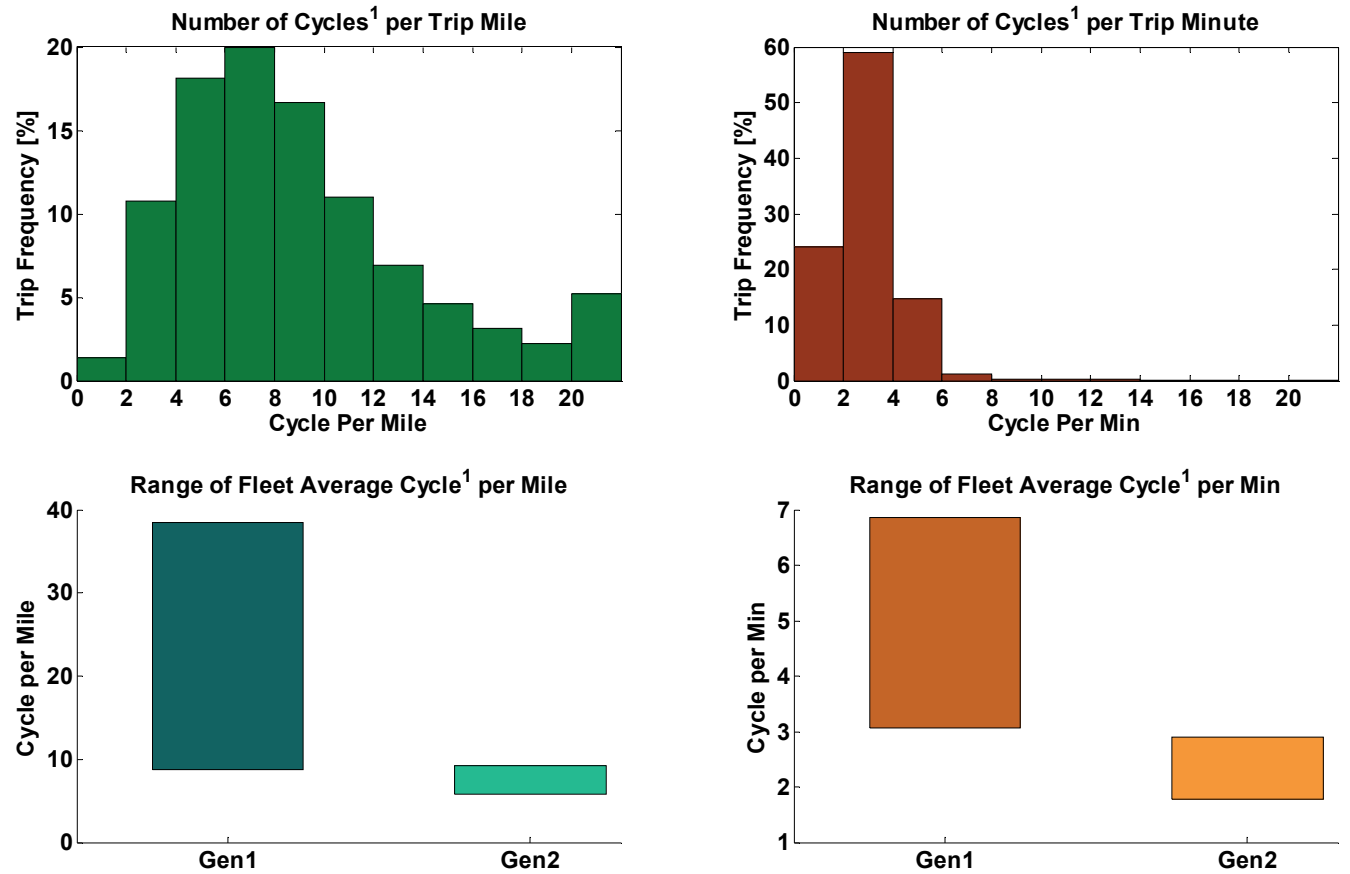

1) A fuel cell voltage transient cycle has a decrease and increase with a minimum delta of $5 \%$ max stack voltage

Figure 47: Fuel cell transient cycles by mile and by minute (CDP74) 

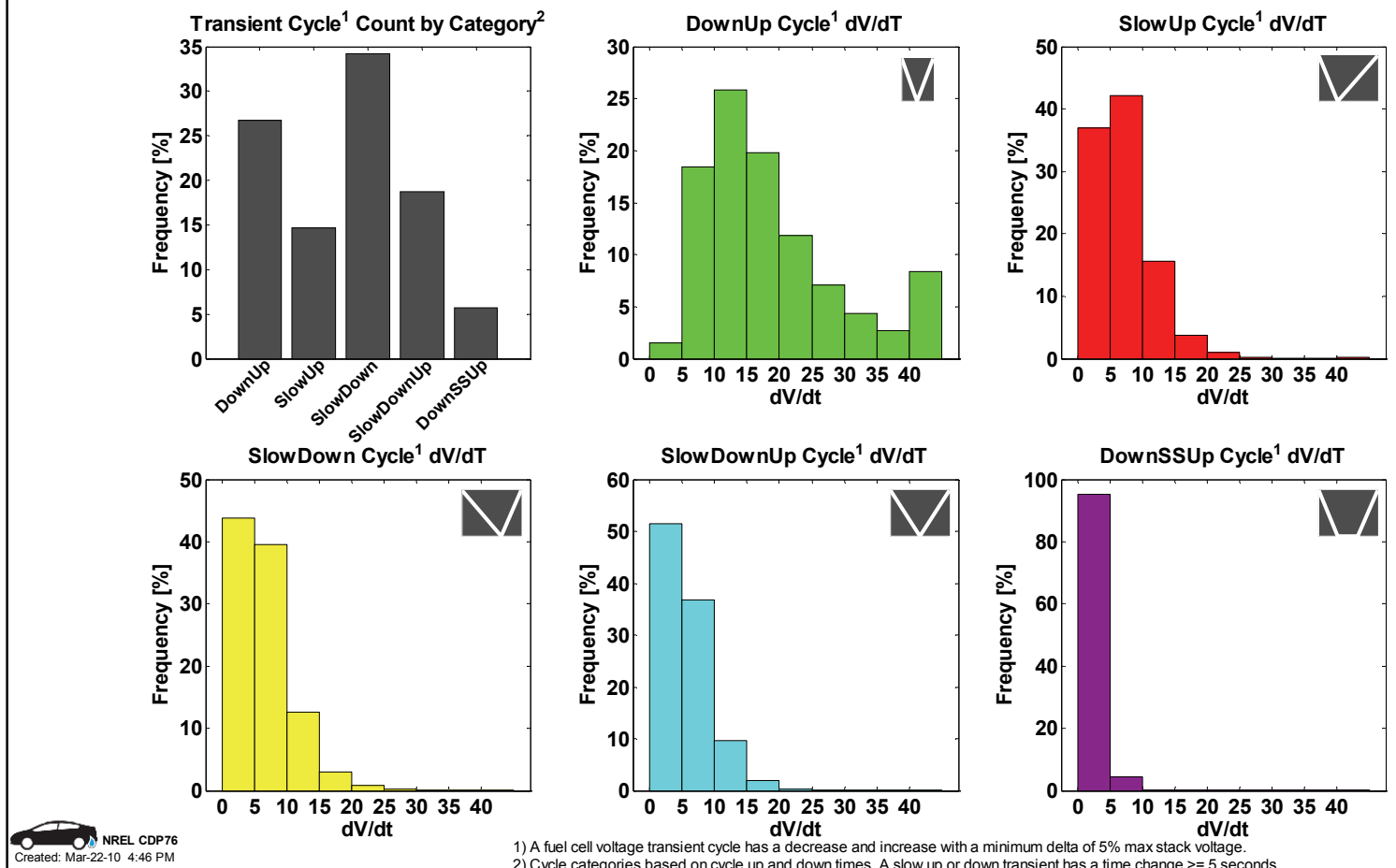

dV/dt

Cycle categories based on cycle up and down times. A slow up or down transient has a time change $>=5$ seconds.

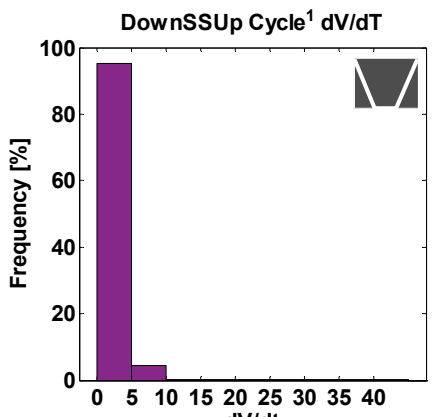

Steady State, where the time change is $>=10$ seconds and the voltage change is $<=2.5 \%$ max stack voltage.

\section{Figure 48: Fuel cell transient rate by cycle category (CDP76)}

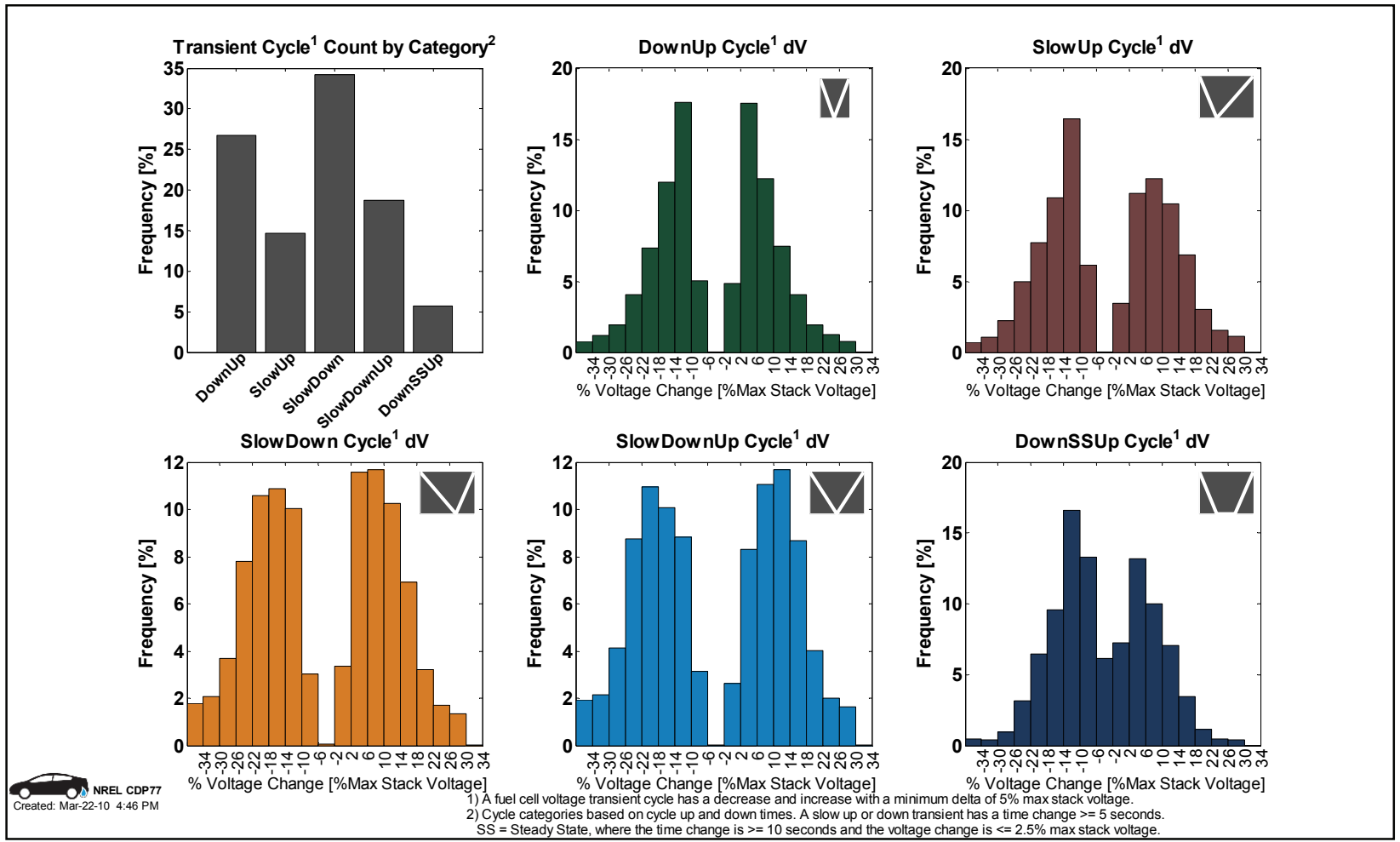

Figure 49: Fuel cell transient voltage changes by cycle category (CDP77) 


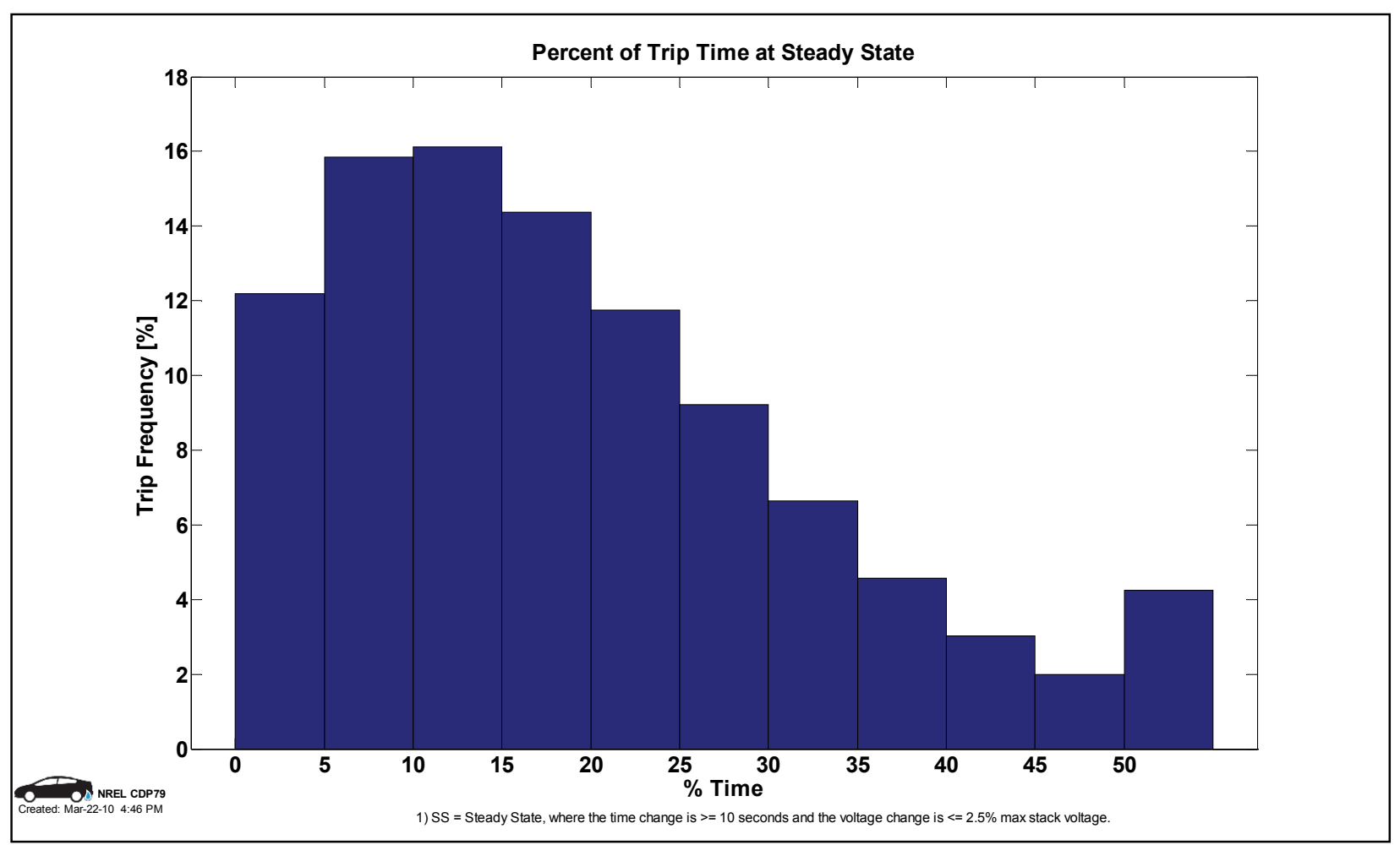

Figure 50: Percentage of trip time at steady state (CDP79)

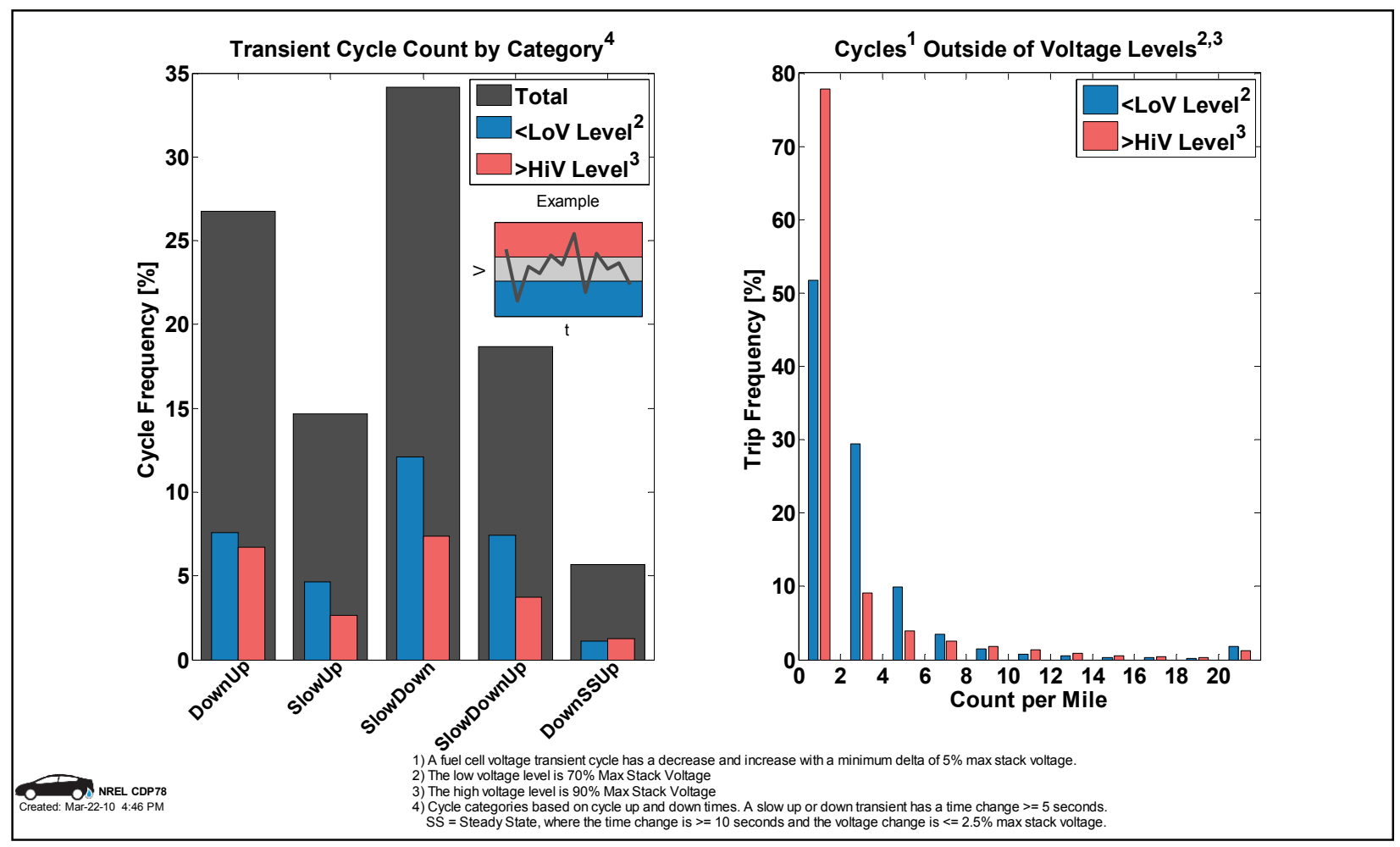

Figure 51: Fuel cell transient cycles outside of specified voltage levels (CDP78) 


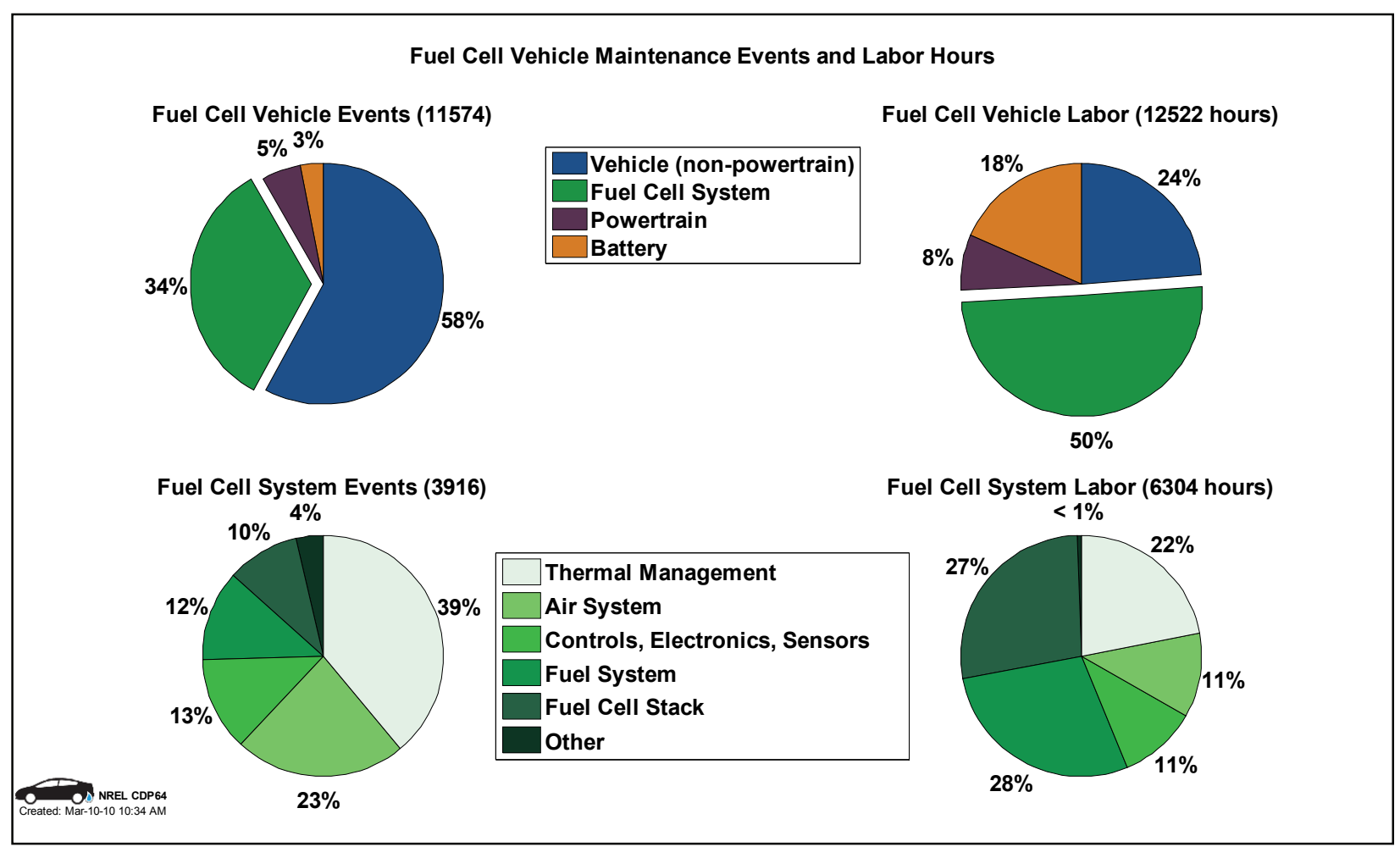

Figure 52: Fuel cell electric vehicle maintenance by system (CDP64)

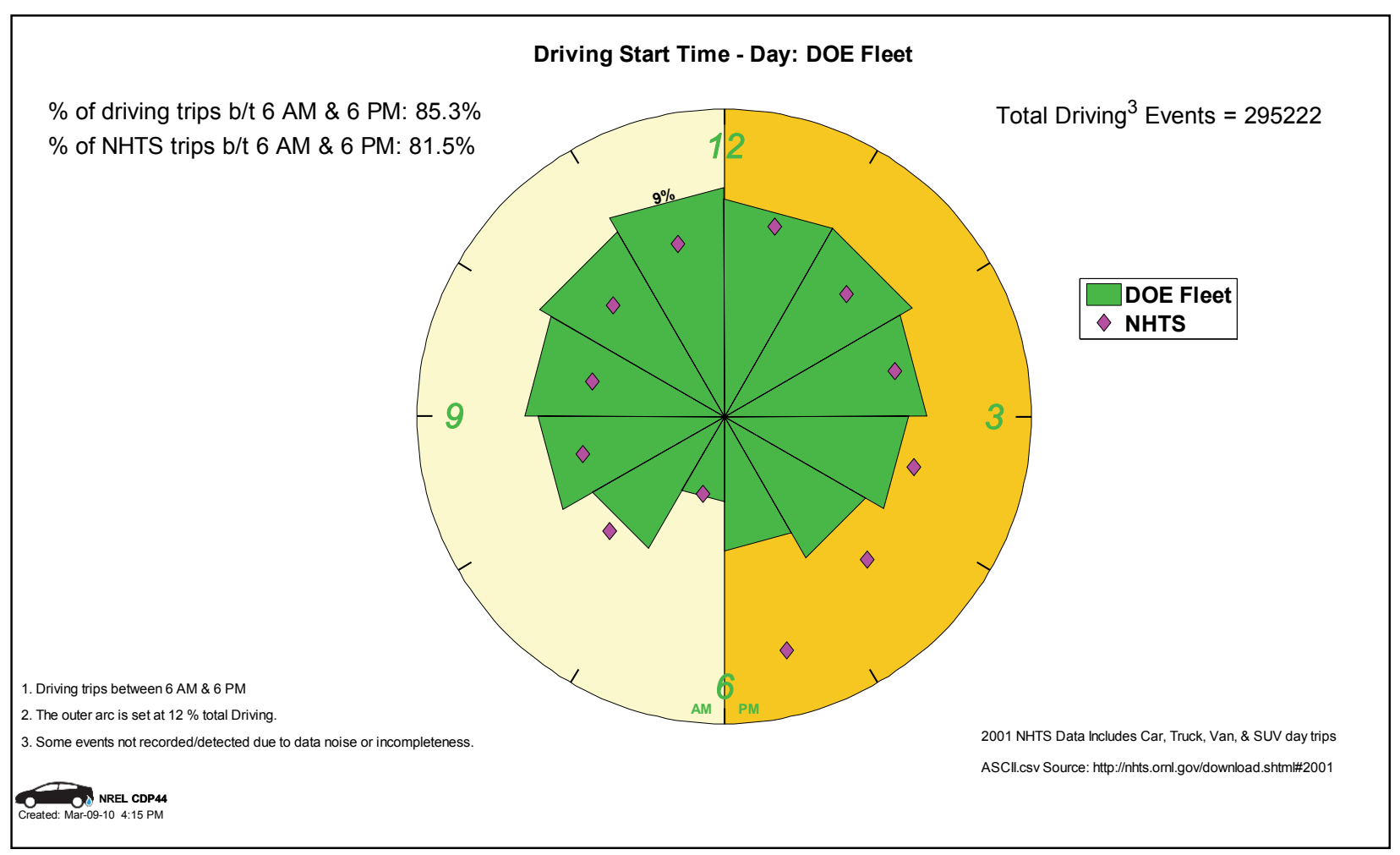

Figure 53: Driving start time - day (CDP44) 


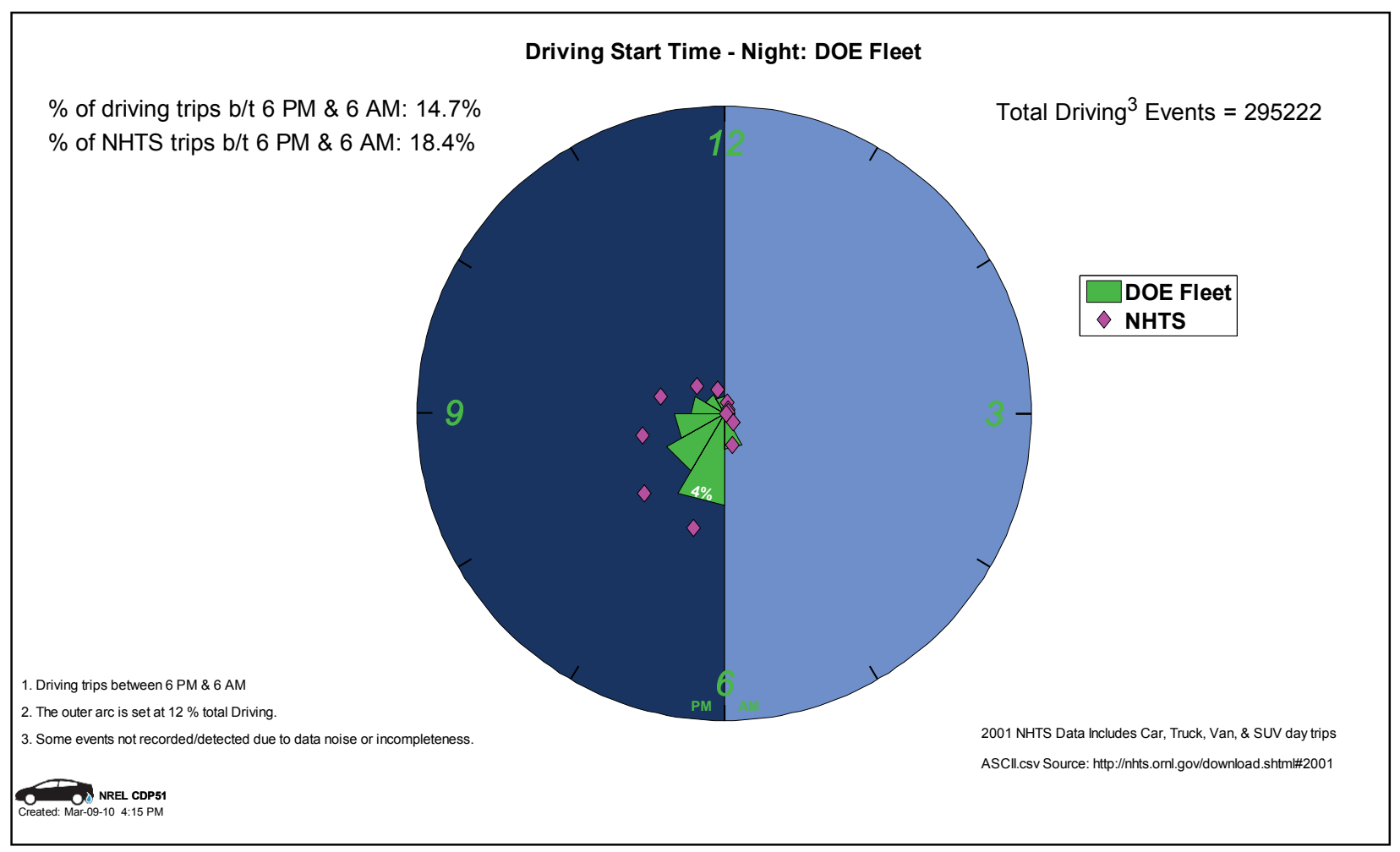

Figure 54: Driving start time - night (CDP51)

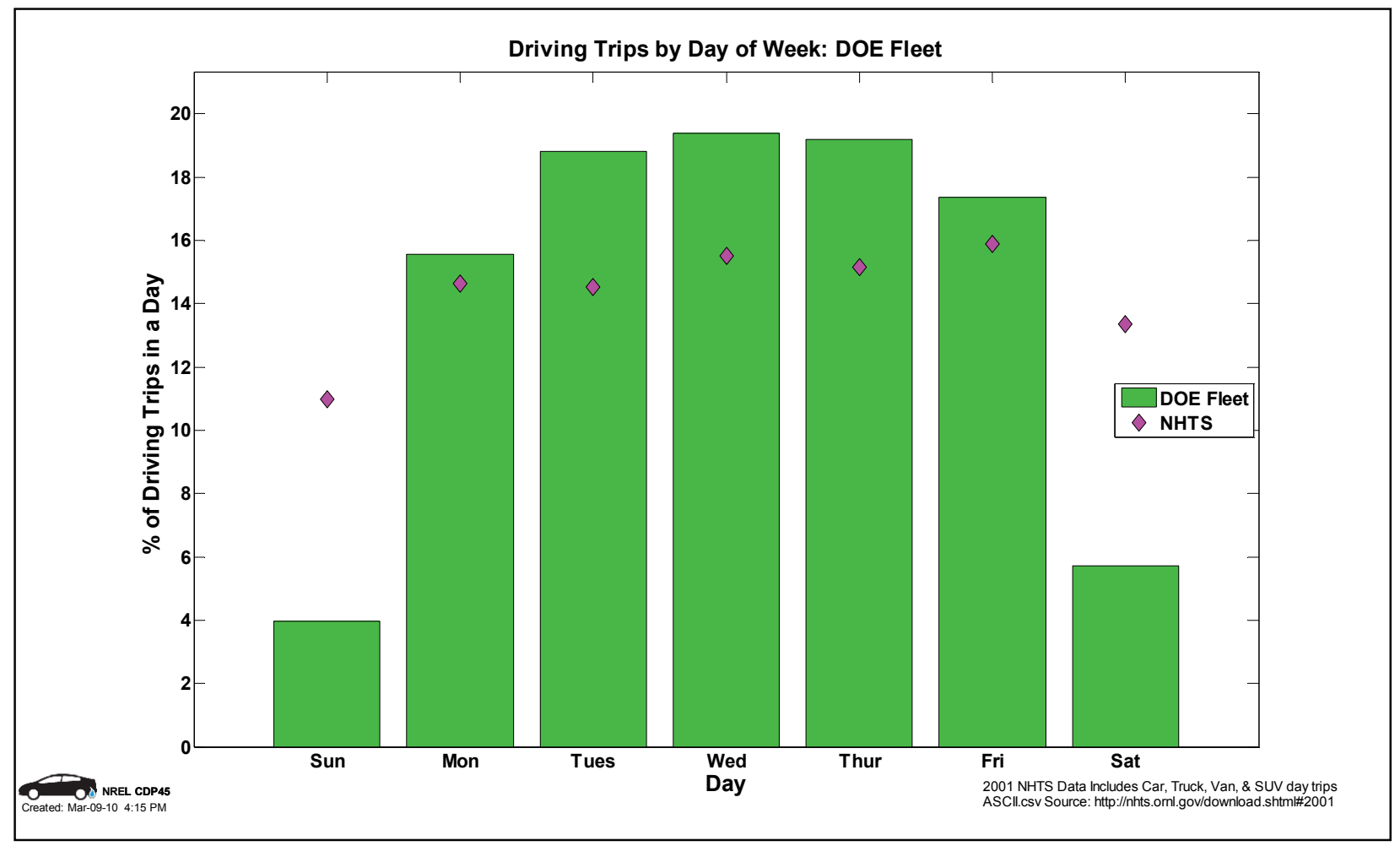

Figure 55: Driving by day of week (CDP45) 


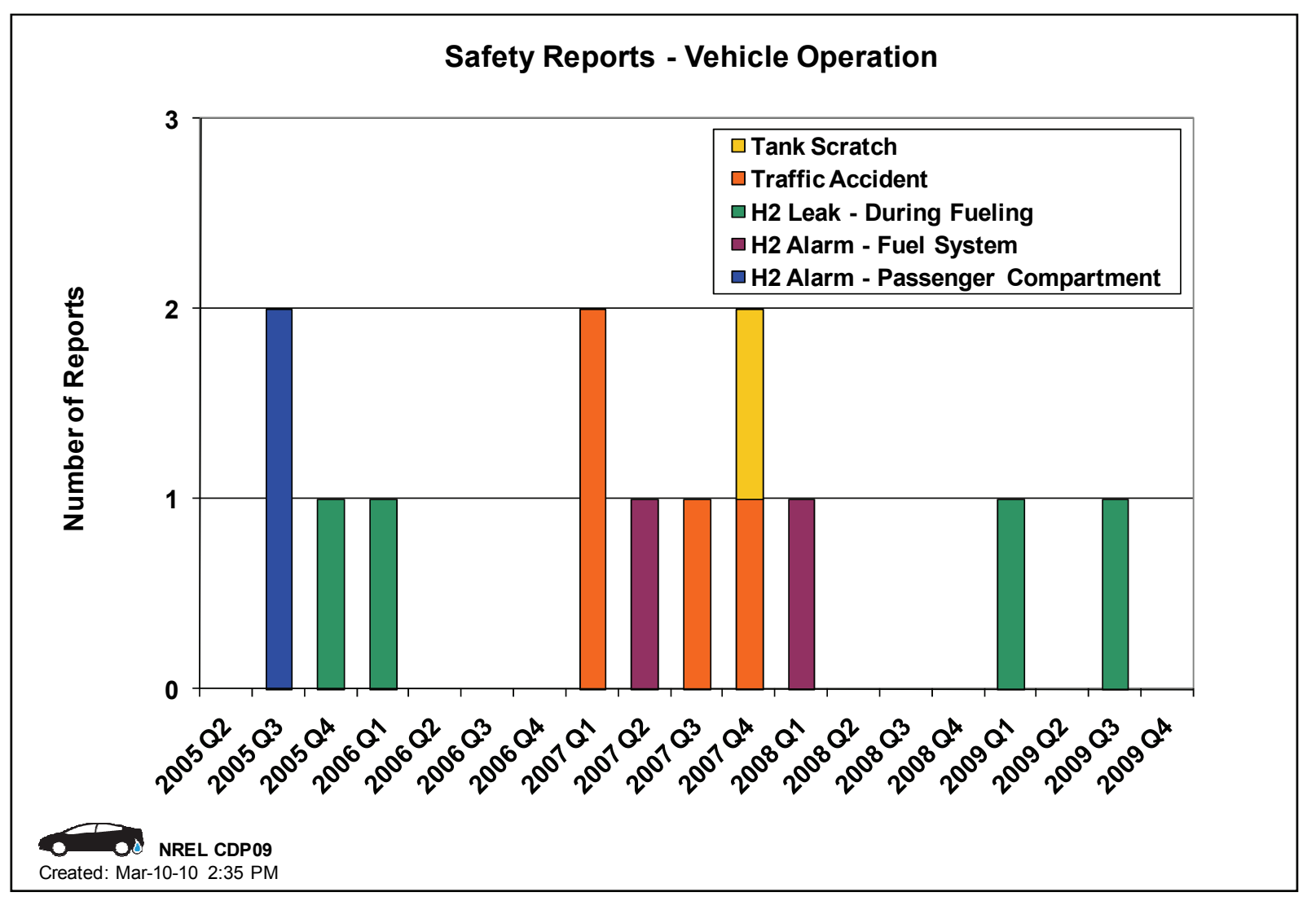

Figure 56: Safety reports - vehicles (CDP09)

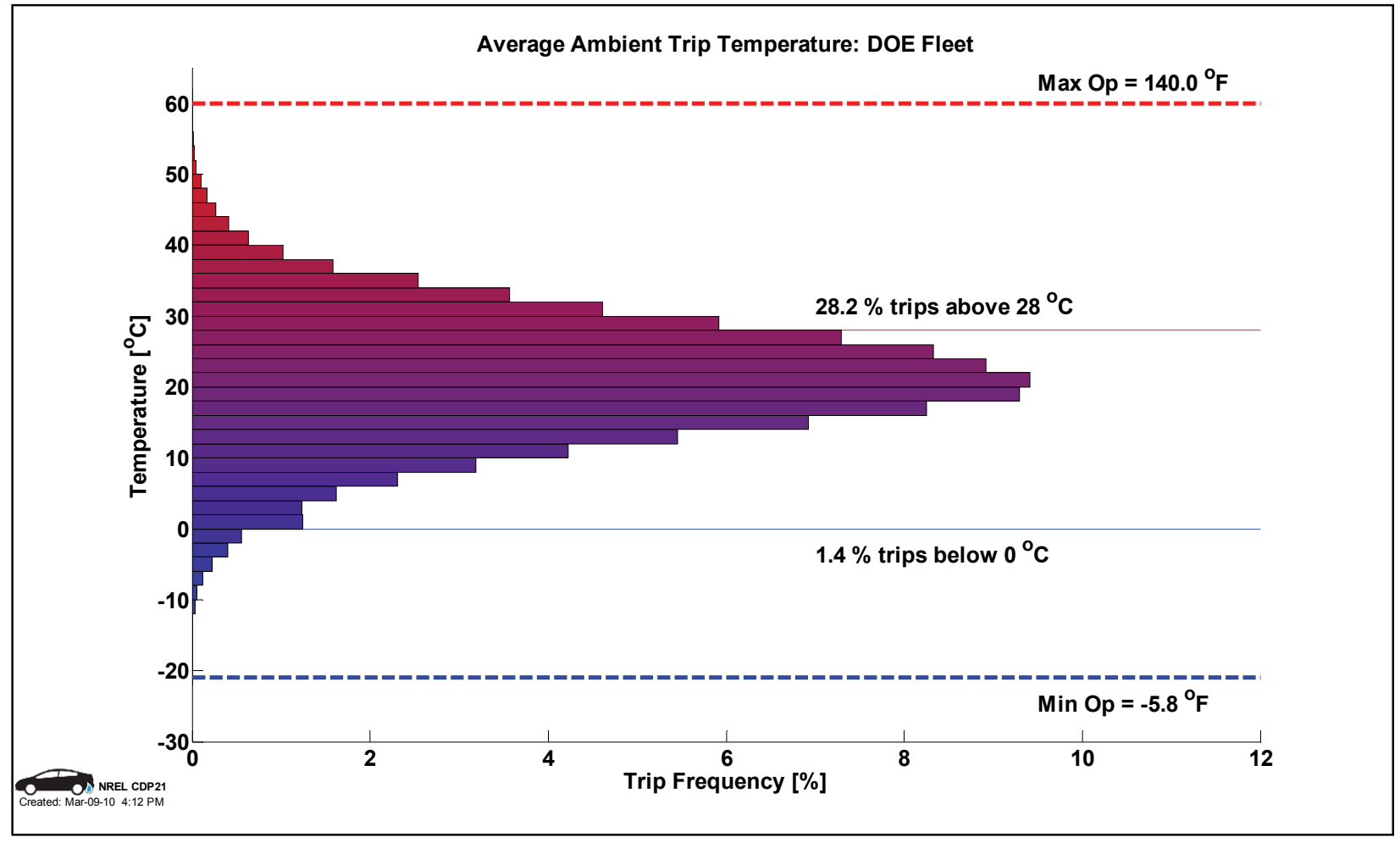

Figure 57: Range of ambient temperature during vehicle operation (CDP21) 


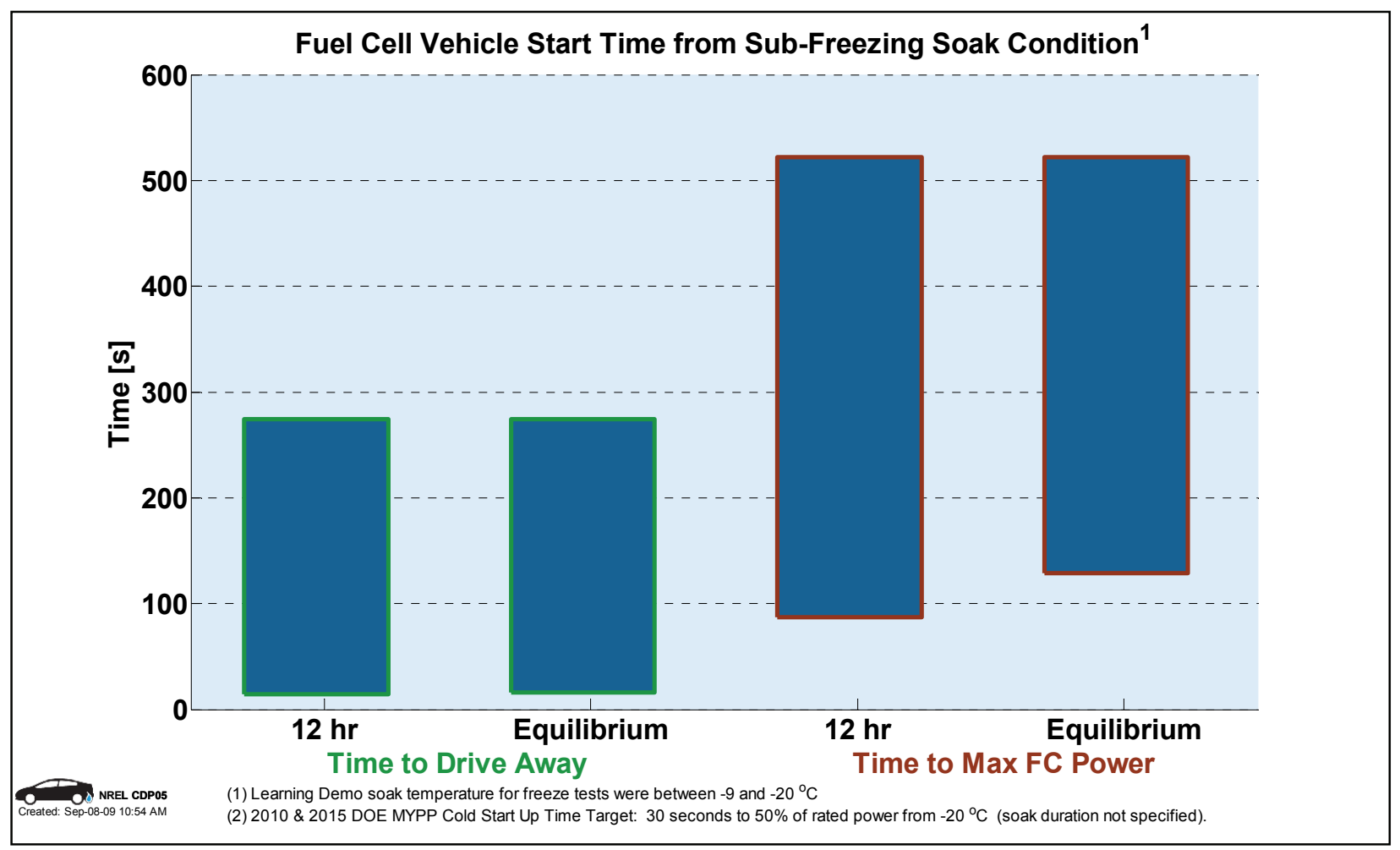

Figure 58: Fuel cell start times from sub-freezing soak conditions (CDP05)

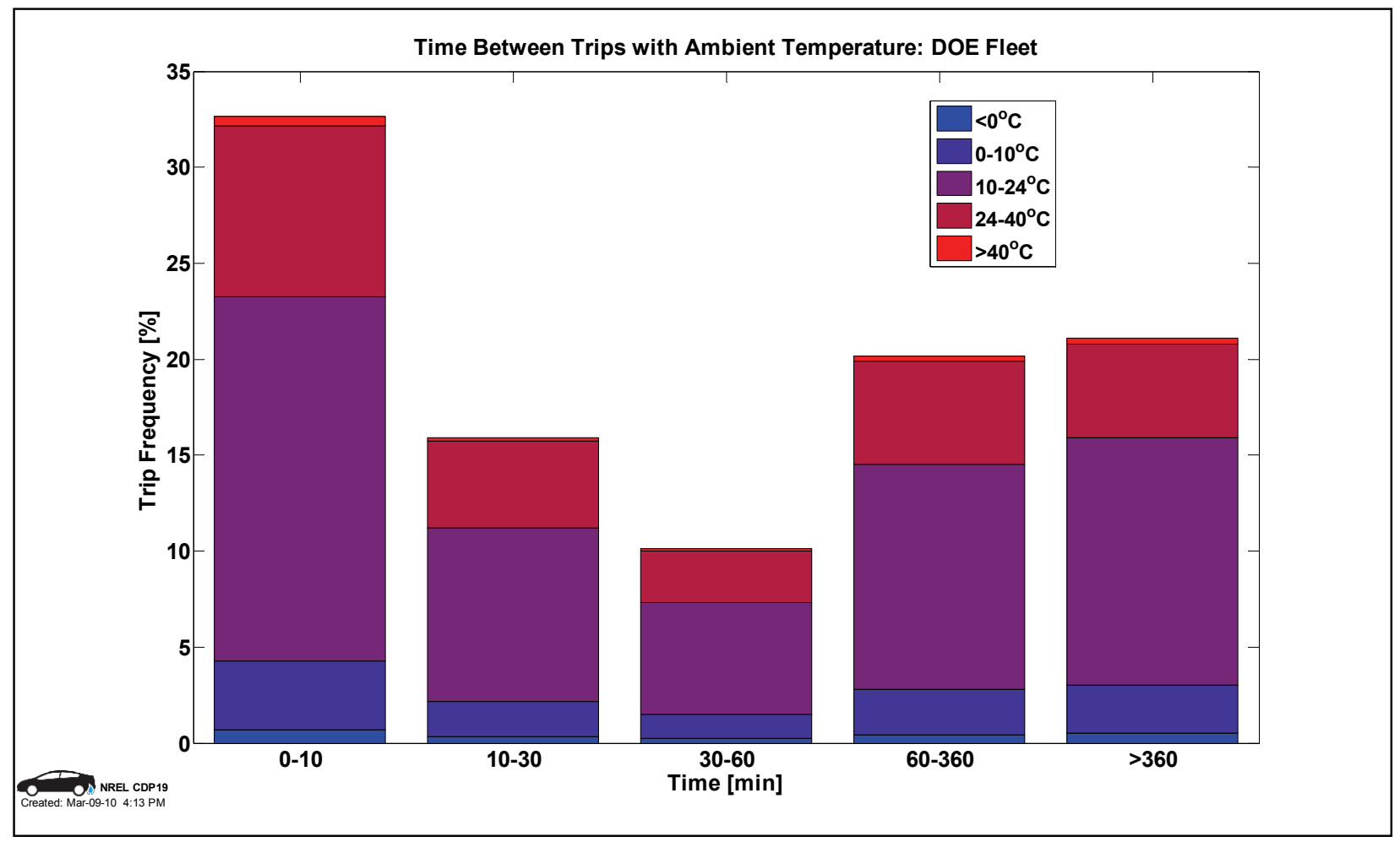

Figure 59: Time between trips \& ambient temperature (CDP19) 


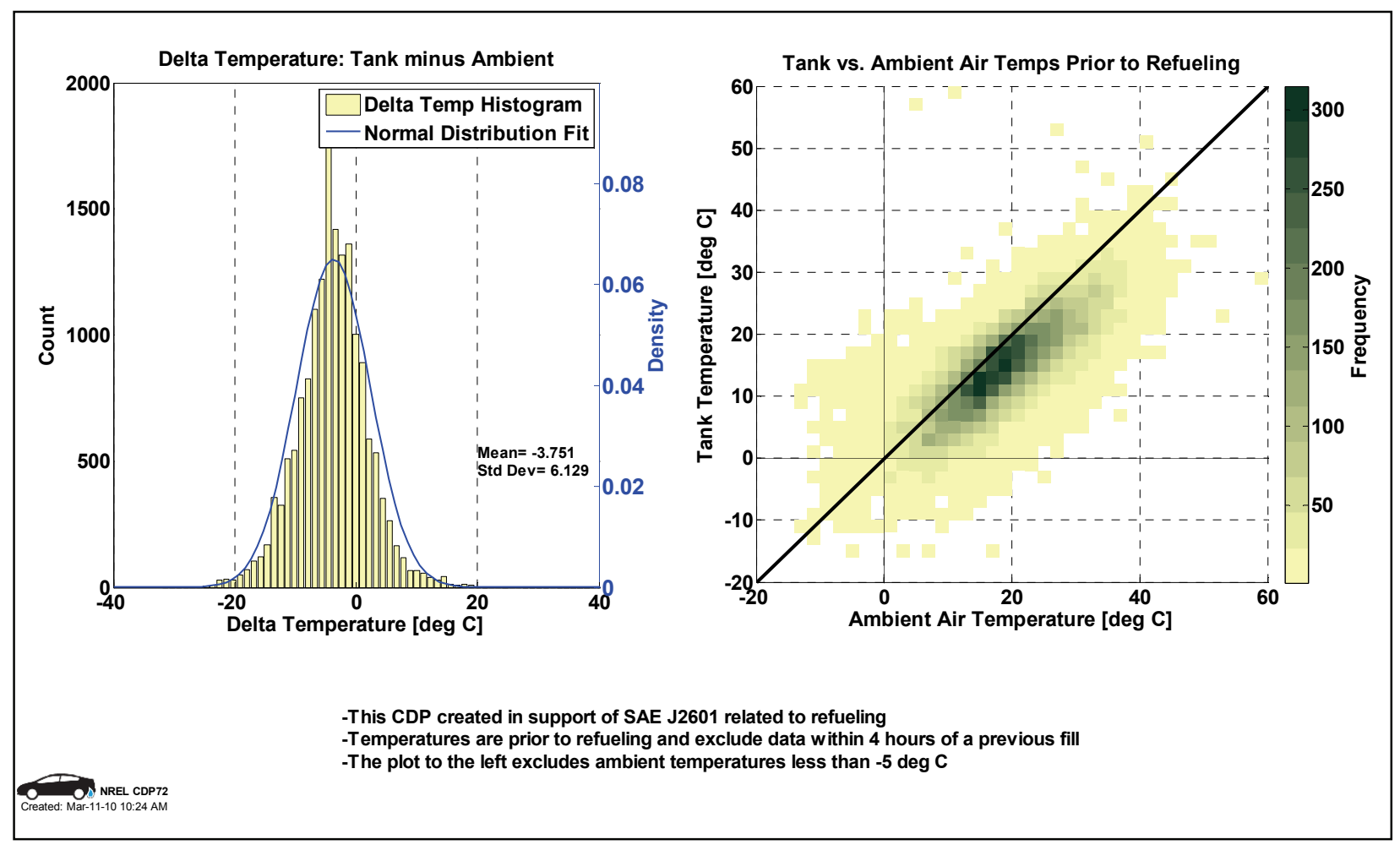

Figure 60: Difference between tank and ambient temperature prior to refueling (CDP72)

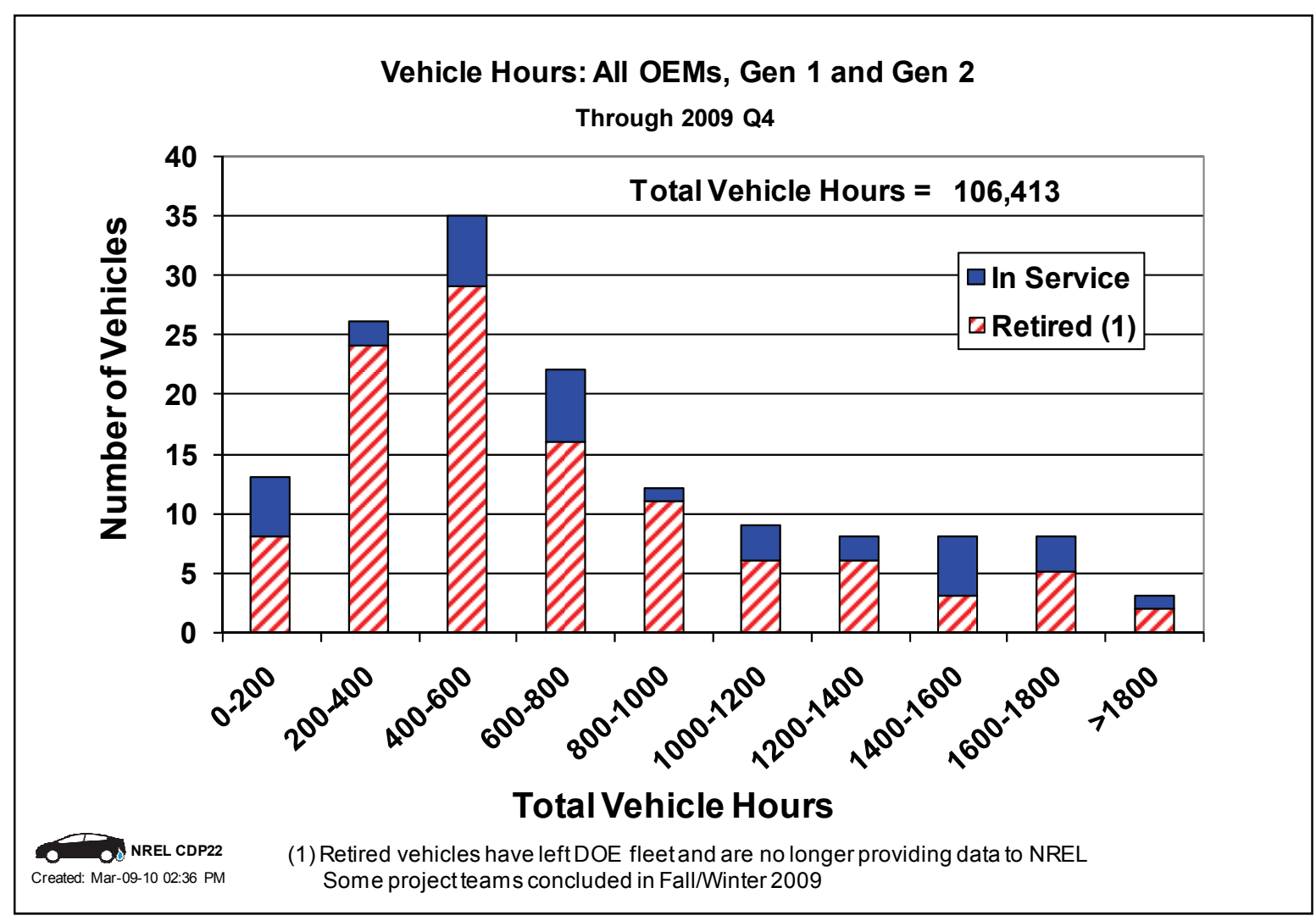

Figure 61: Vehicle operating hours (CDP22) 


\section{Vehicle Miles: All OEMs, Gen 1 and 2}

Through 2009 Q4

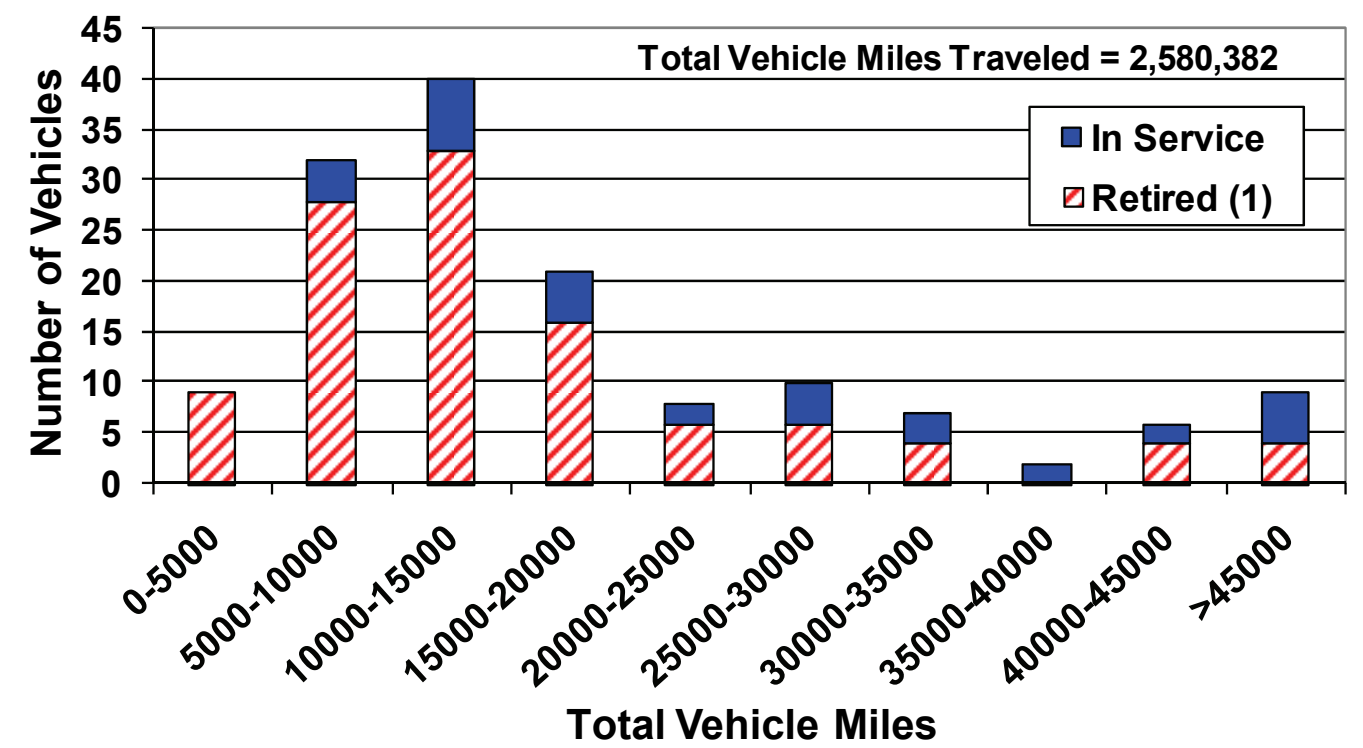

(1) Retired vehicles have left DOE fleet and are no longer providing data to NREL Some project teams concluded in Fall/Winter 2009

Figure 62: Vehicles vs. miles traveled (CDP23)

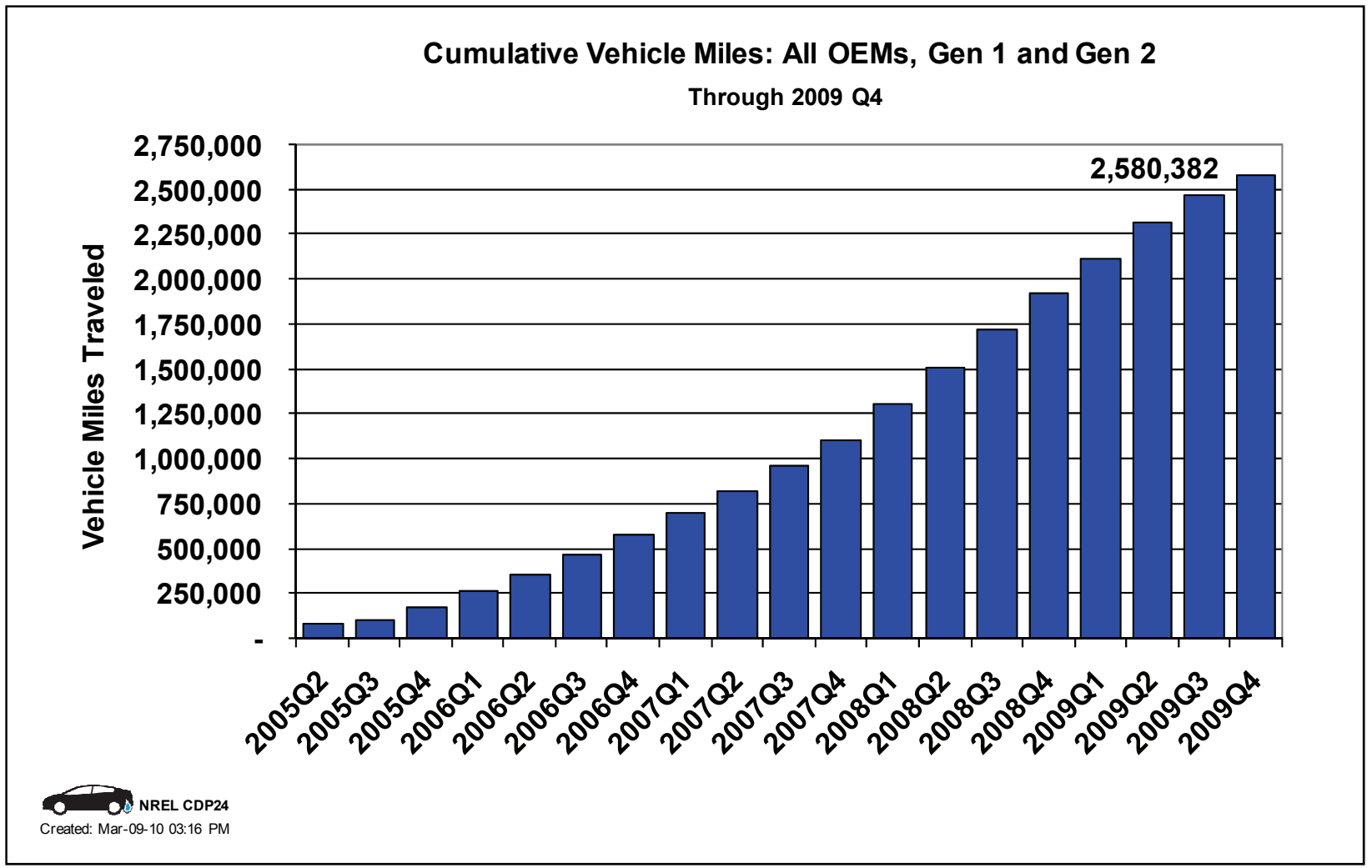

Figure 63: Cumulative vehicle miles traveled (CDP24) 


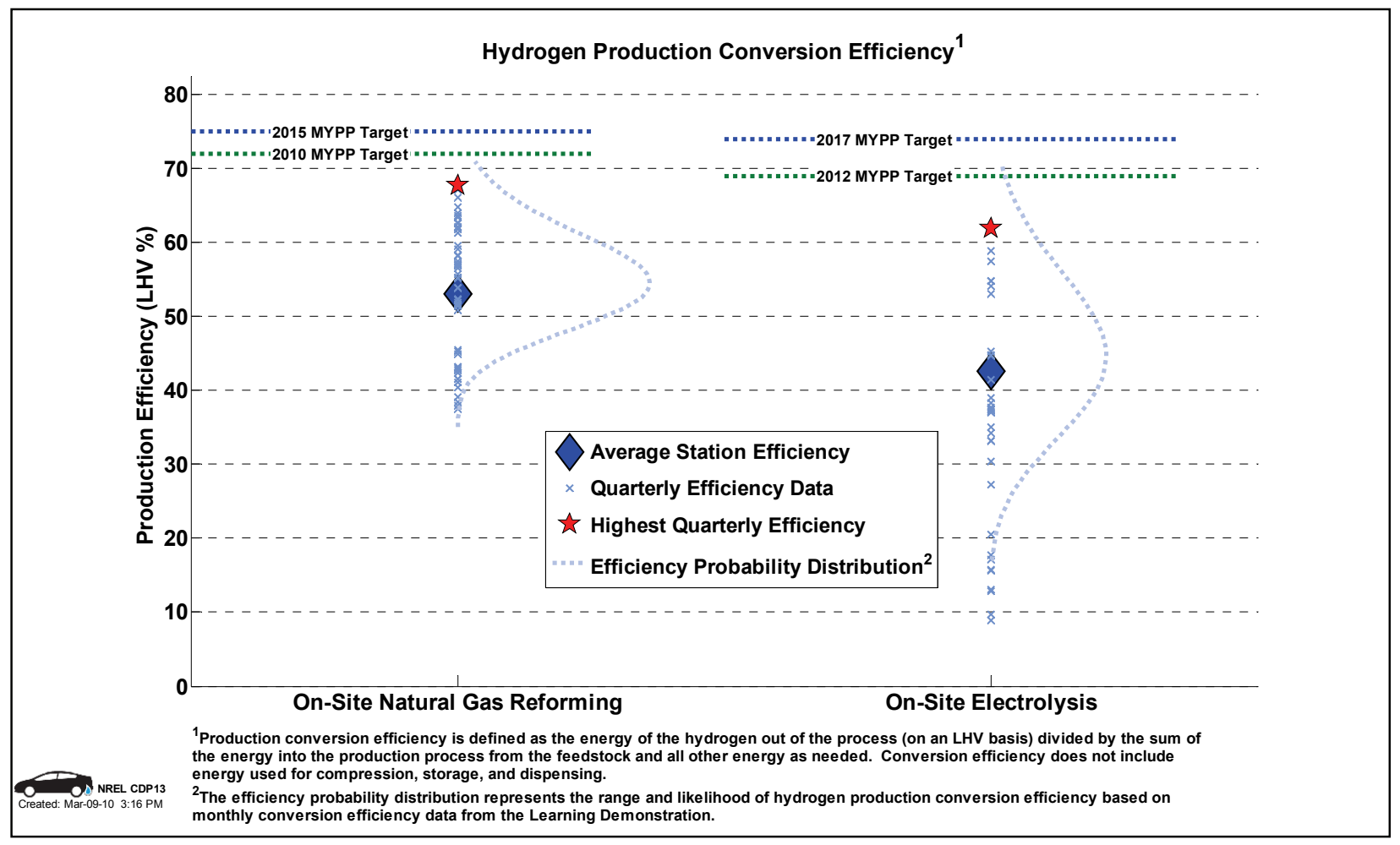

Figure 64: Onsite hydrogen production efficiency (CDP13)

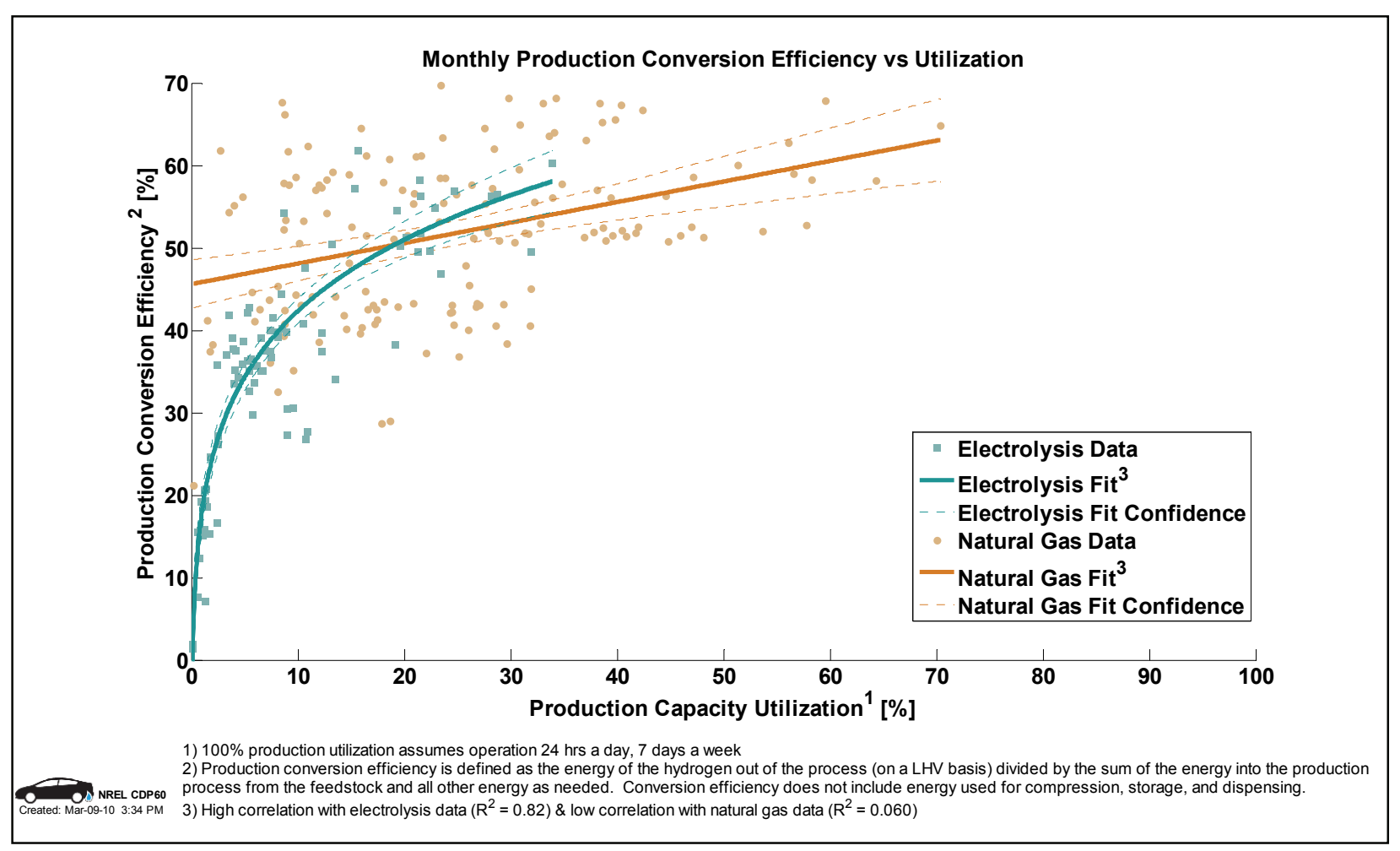

Figure 65: Onsite hydrogen production efficiency vs. capacity utilization (CDP60) 


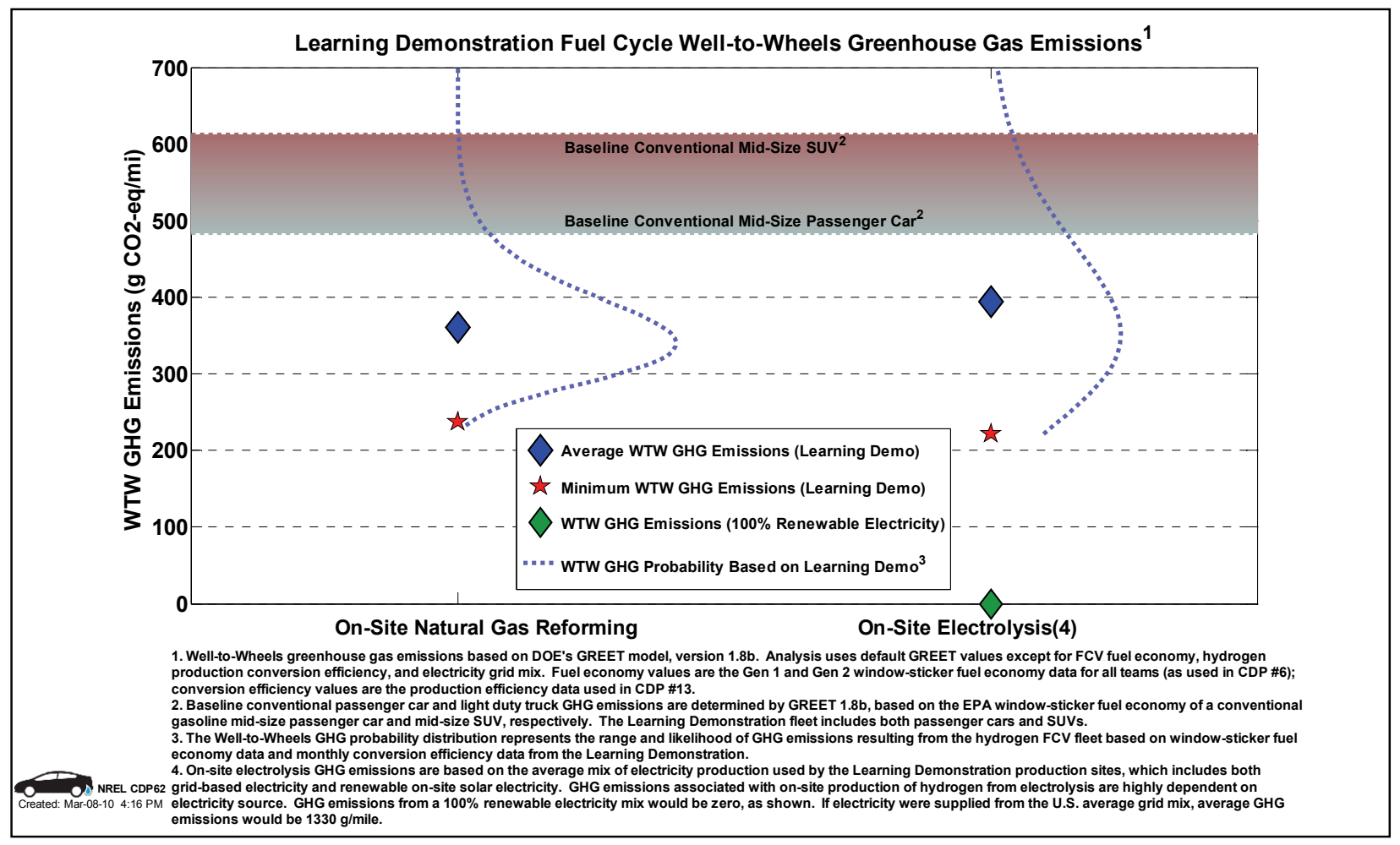

Figure 66: Learning Demonstration vehicle greenhouse gas emissions (CDP62)

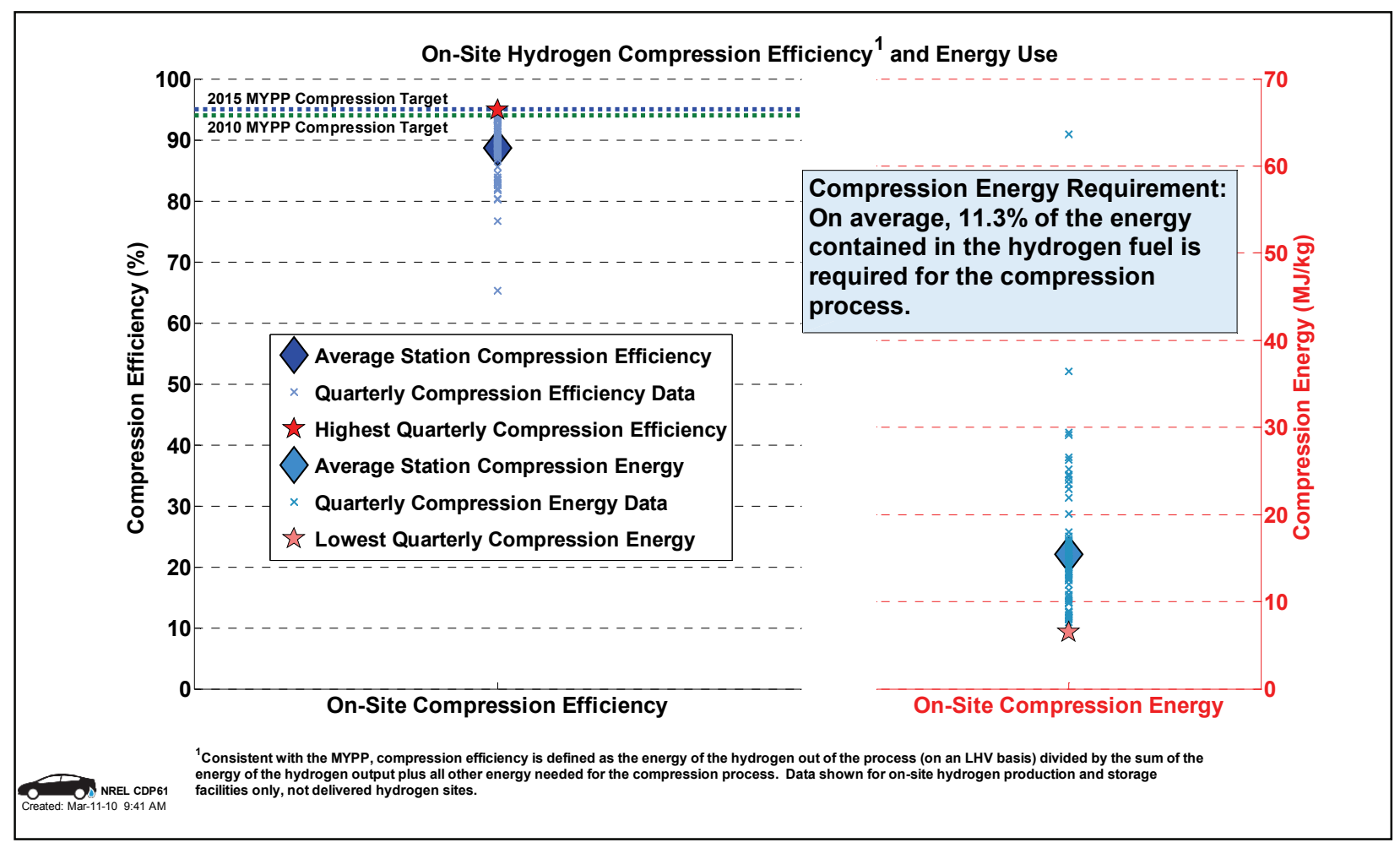

Figure 67: Refueling station compressor efficiency (CDP61) 


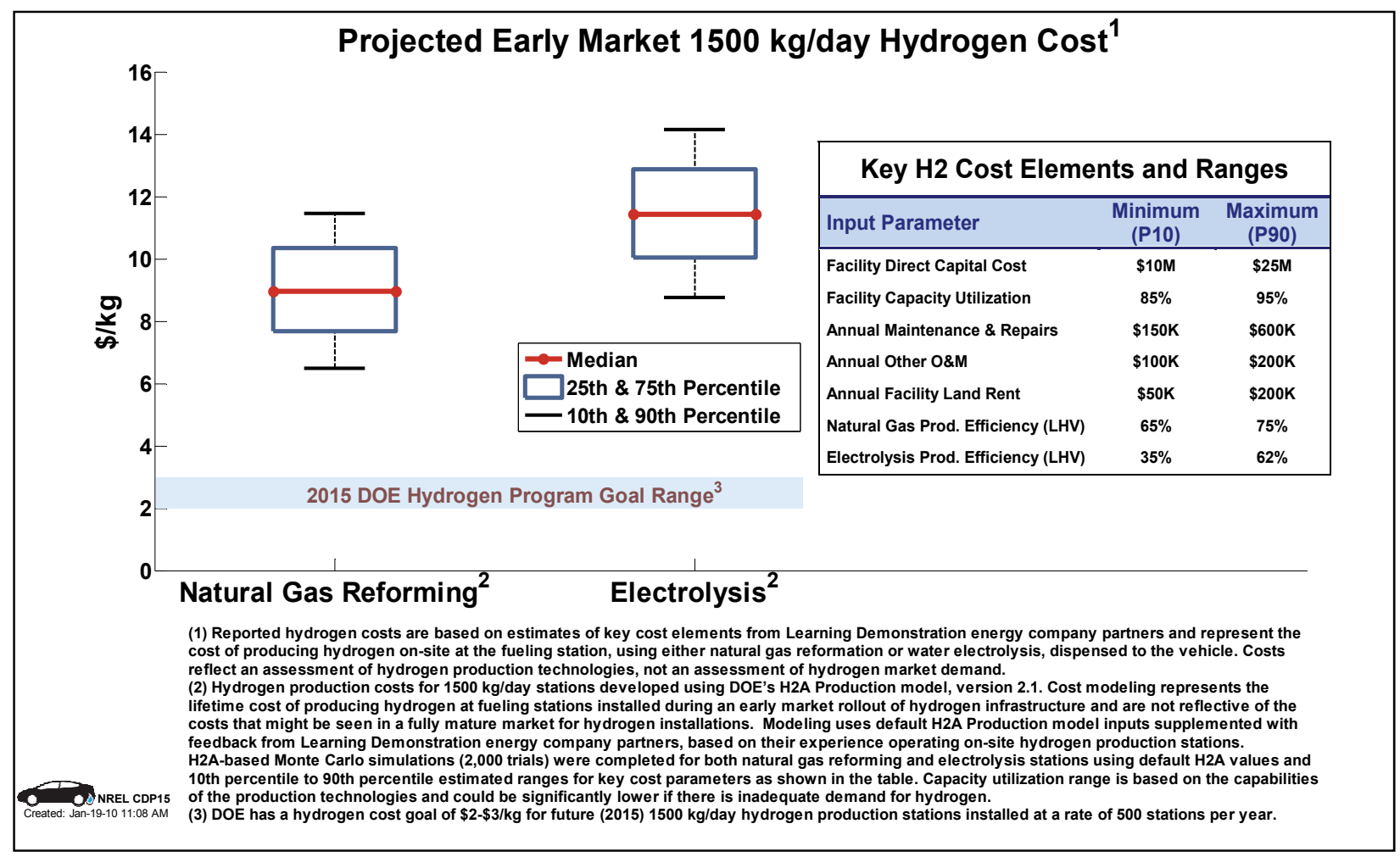

Figure 68: Hydrogen production cost vs. process (CDP15)

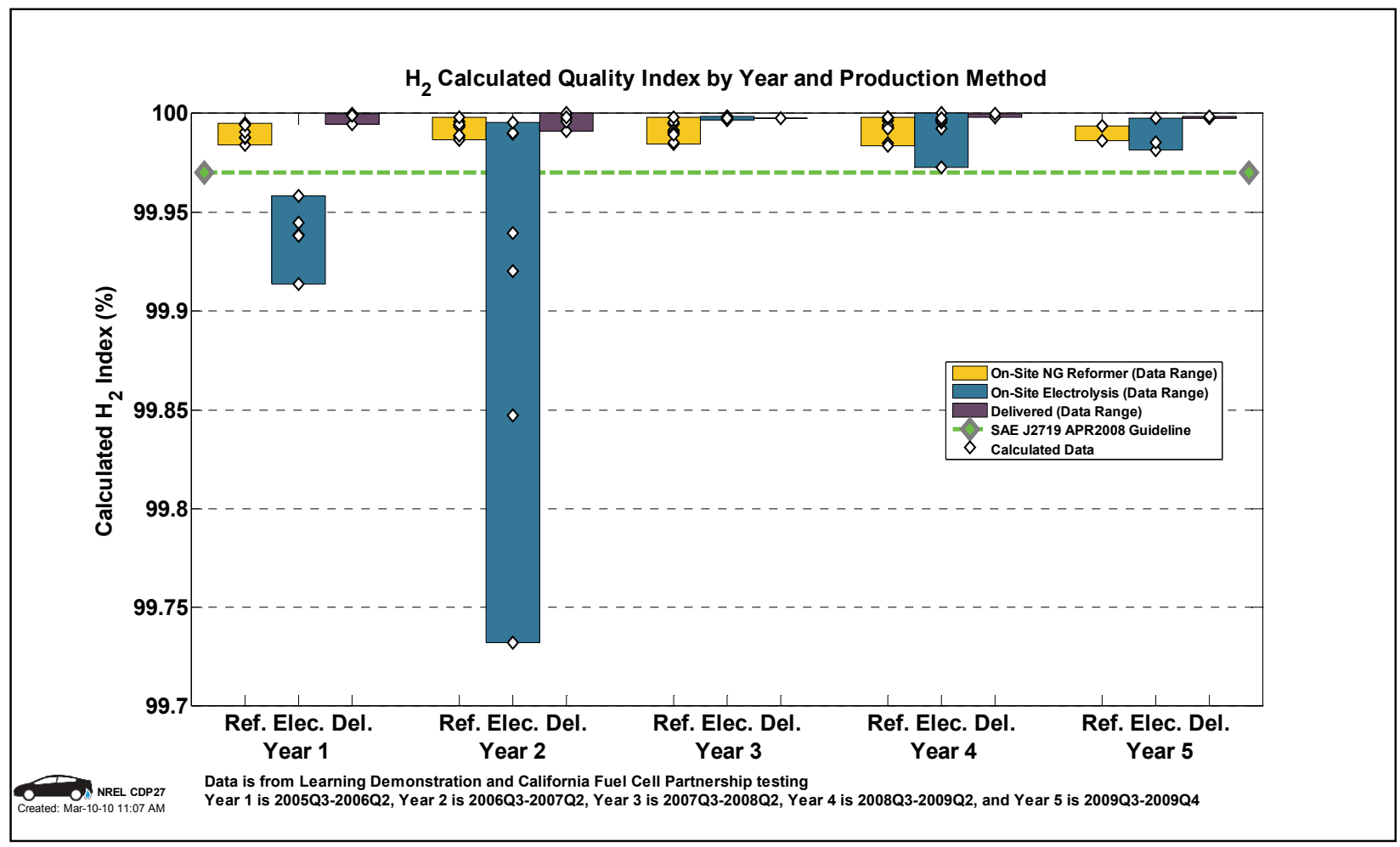

Figure 69: Hydrogen quality index (CDP27) 


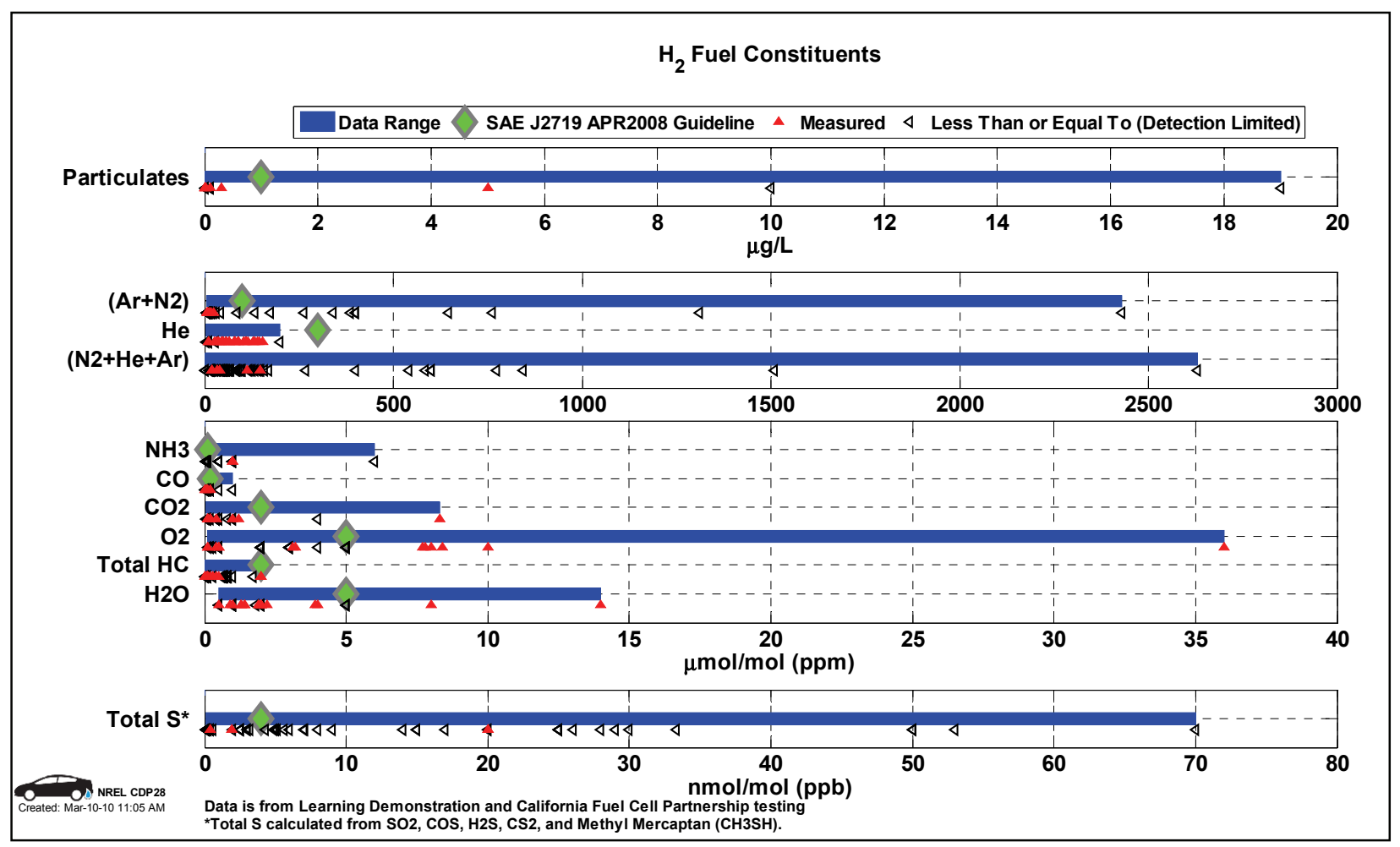

Figure 70: Hydrogen fuel constituents - all (CDP28)

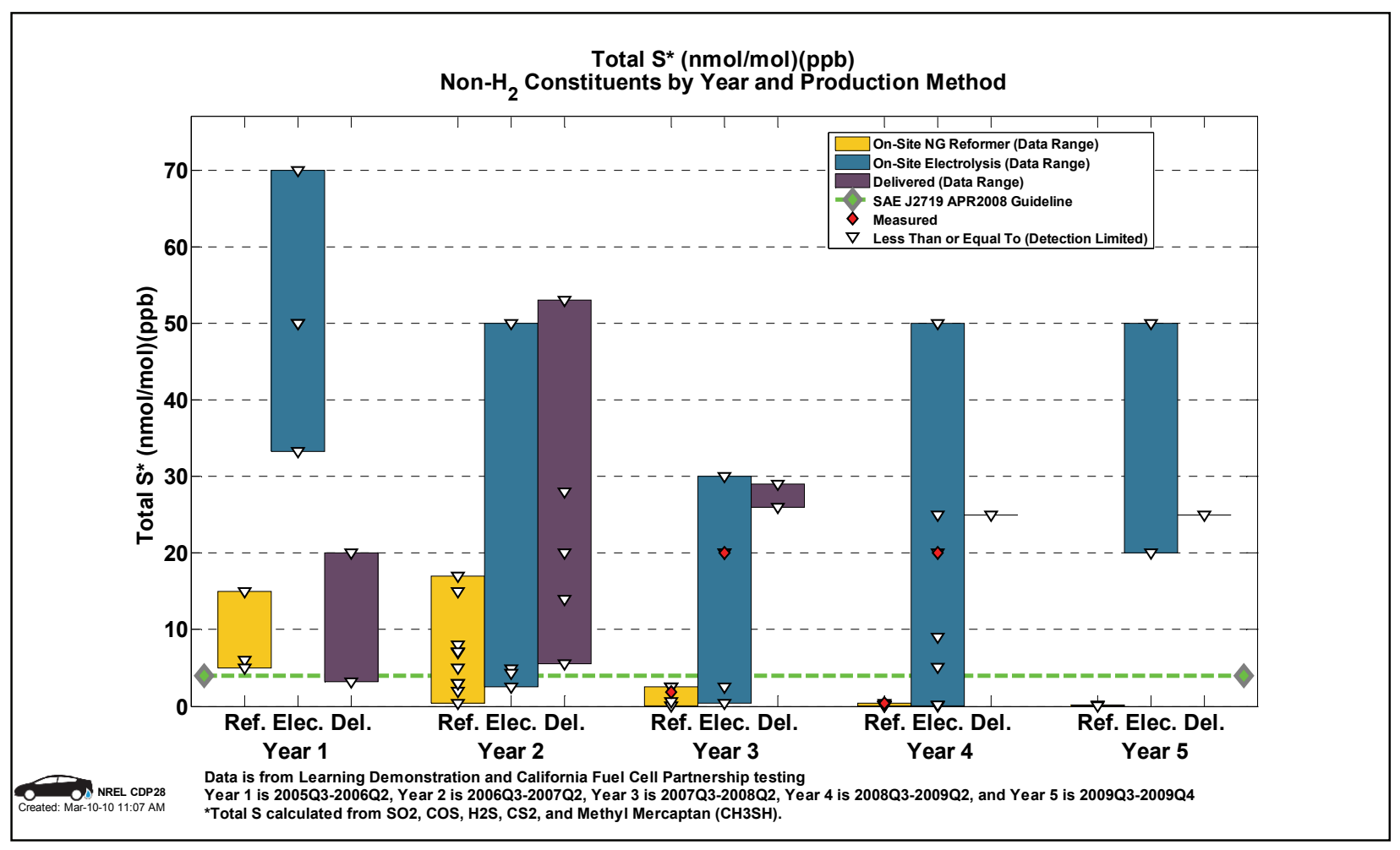

Figure 71: Hydrogen fuel constituents - sulfur (CDP28) 


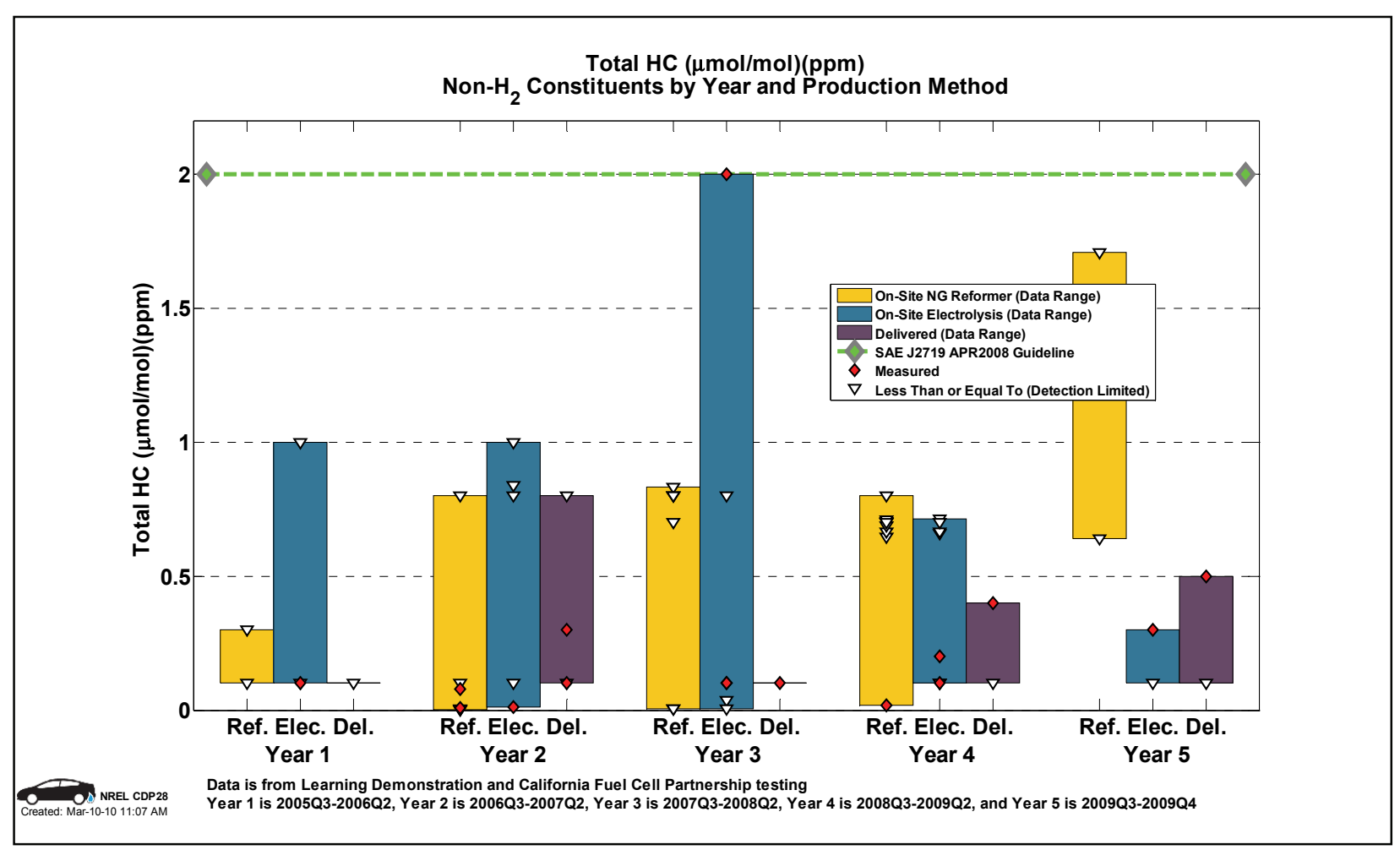

Figure 72: Hydrogen fuel constituents - total hydrocarbons (CDP28)

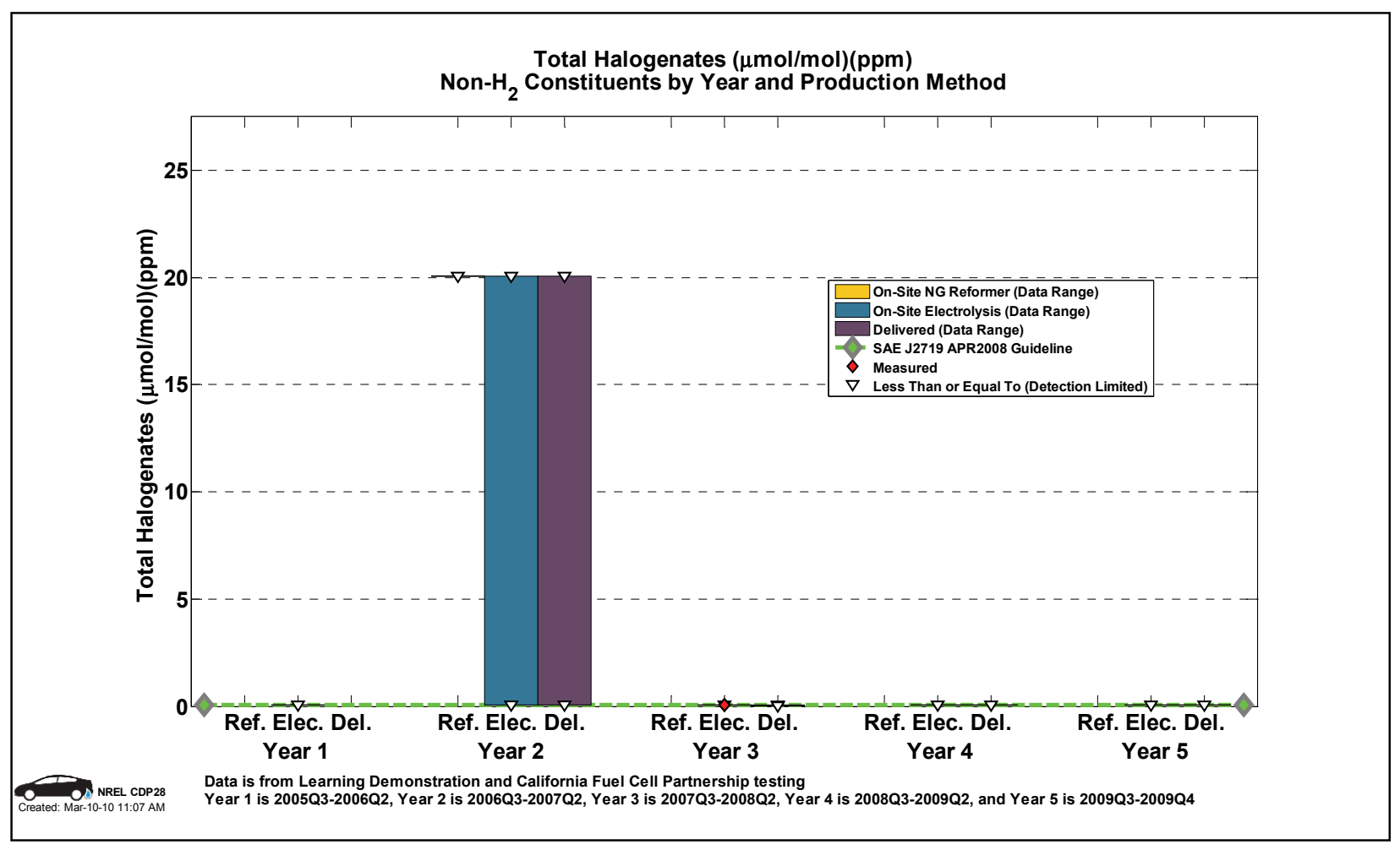

Figure 73: Hydrogen fuel constituents - total halogenates (CDP28) 


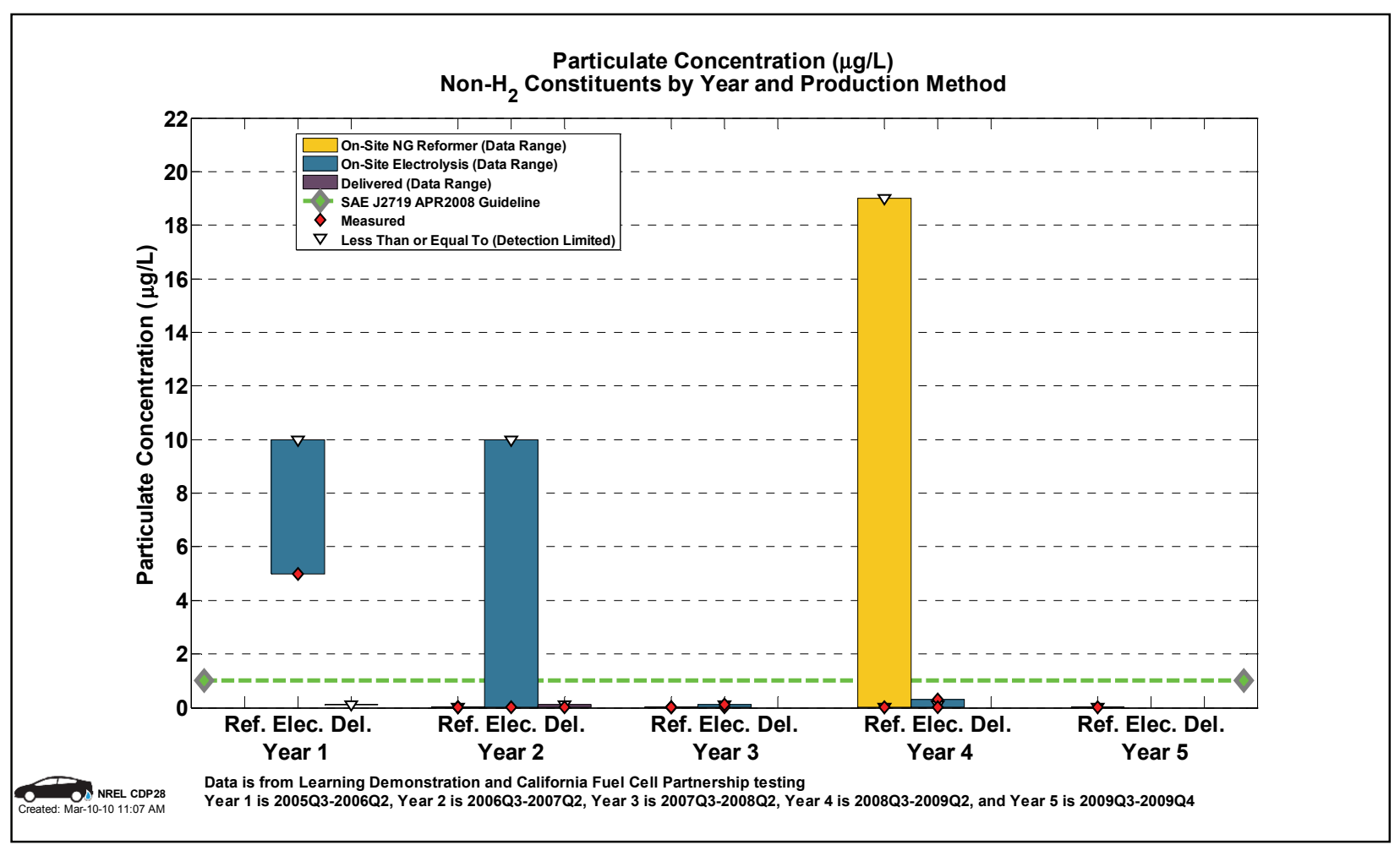

Figure 74: Hydrogen fuel constituents - particulate concentration (CDP28)

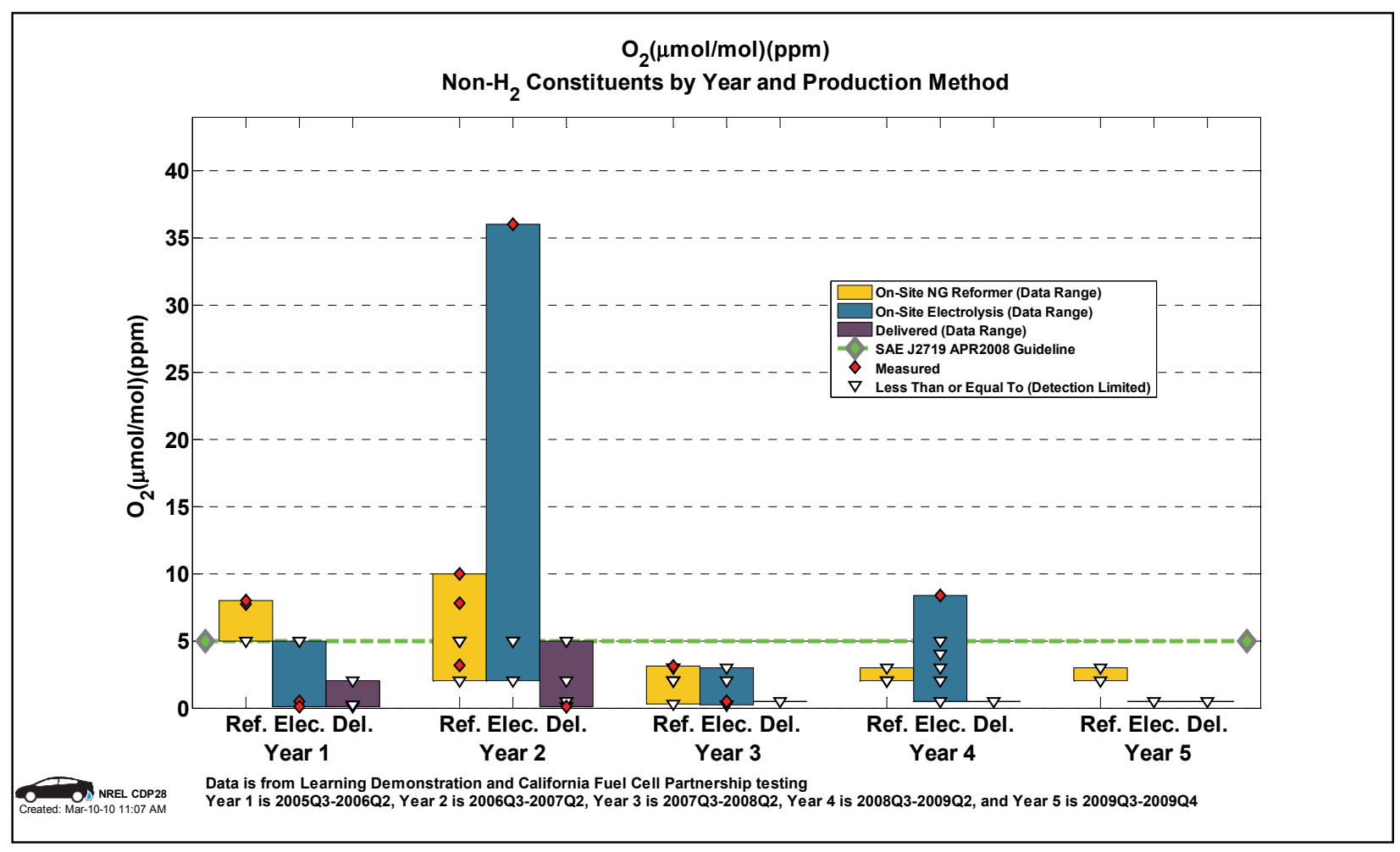

Figure 75: Hydrogen fuel constituents - oxygen (CDP28) 


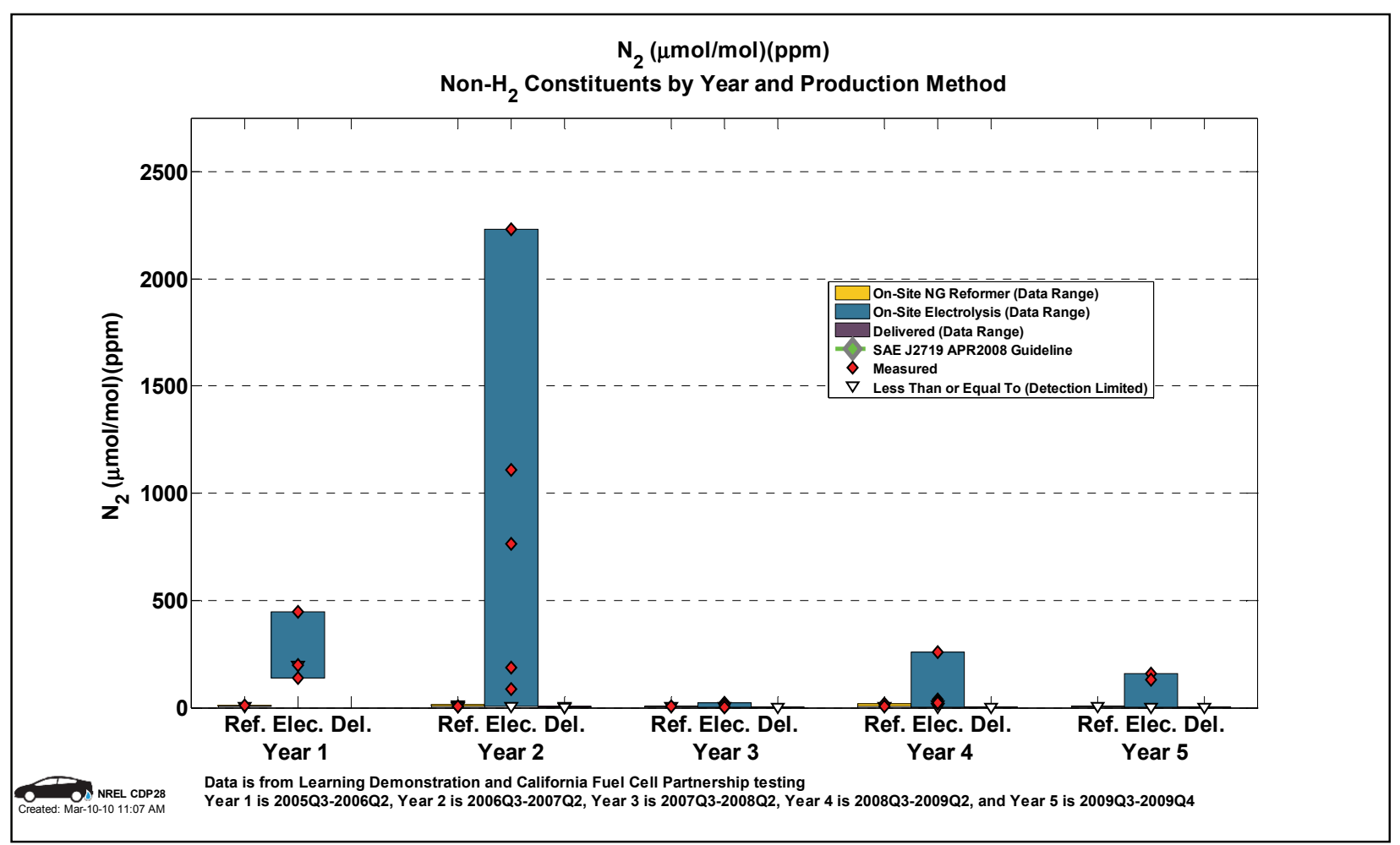

Figure 76: Hydrogen fuel constituents - nitrogen (CDP28)

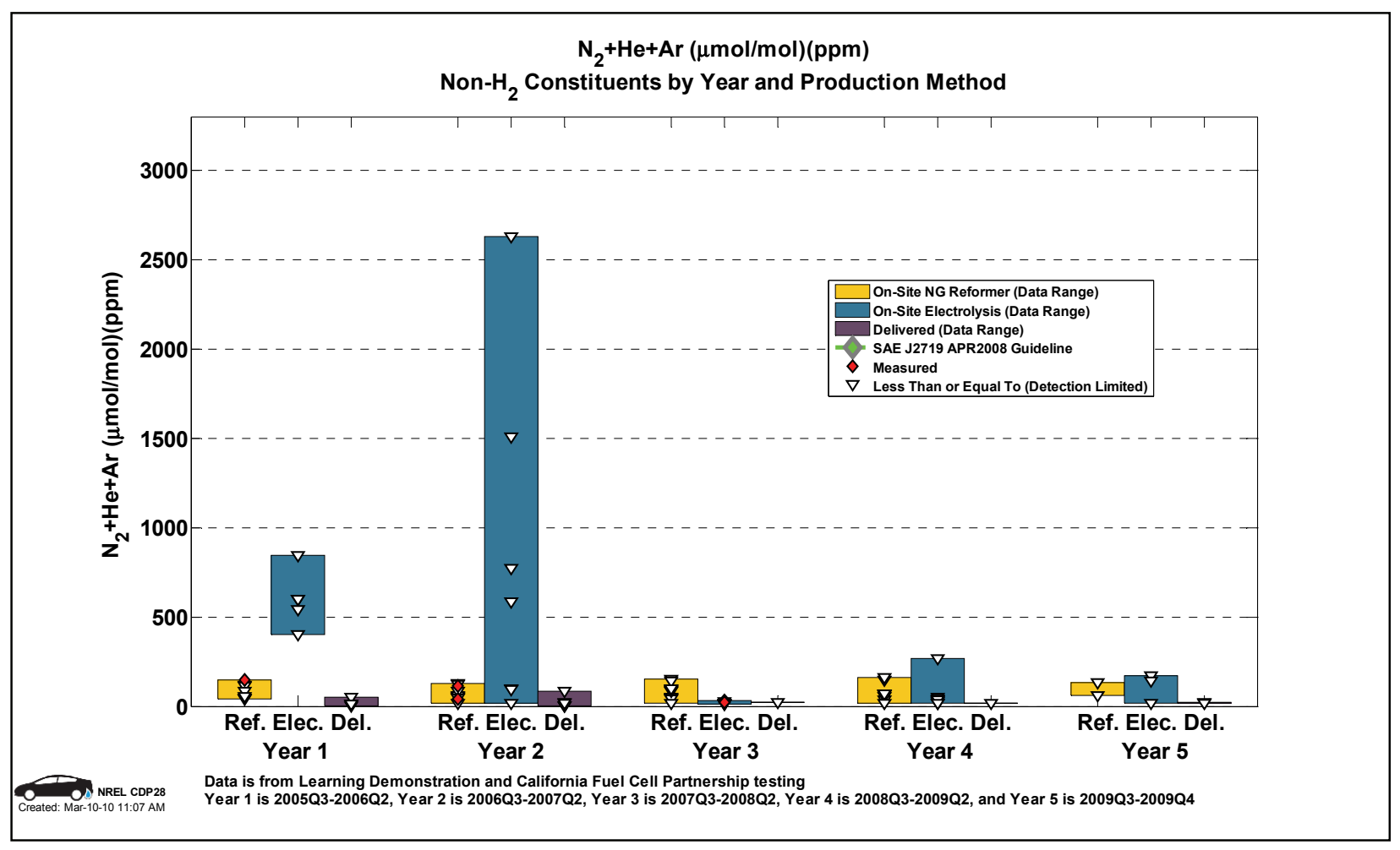

Figure 77: Hydrogen fuel constituents - nitrogen + helium + argon (CDP28) 


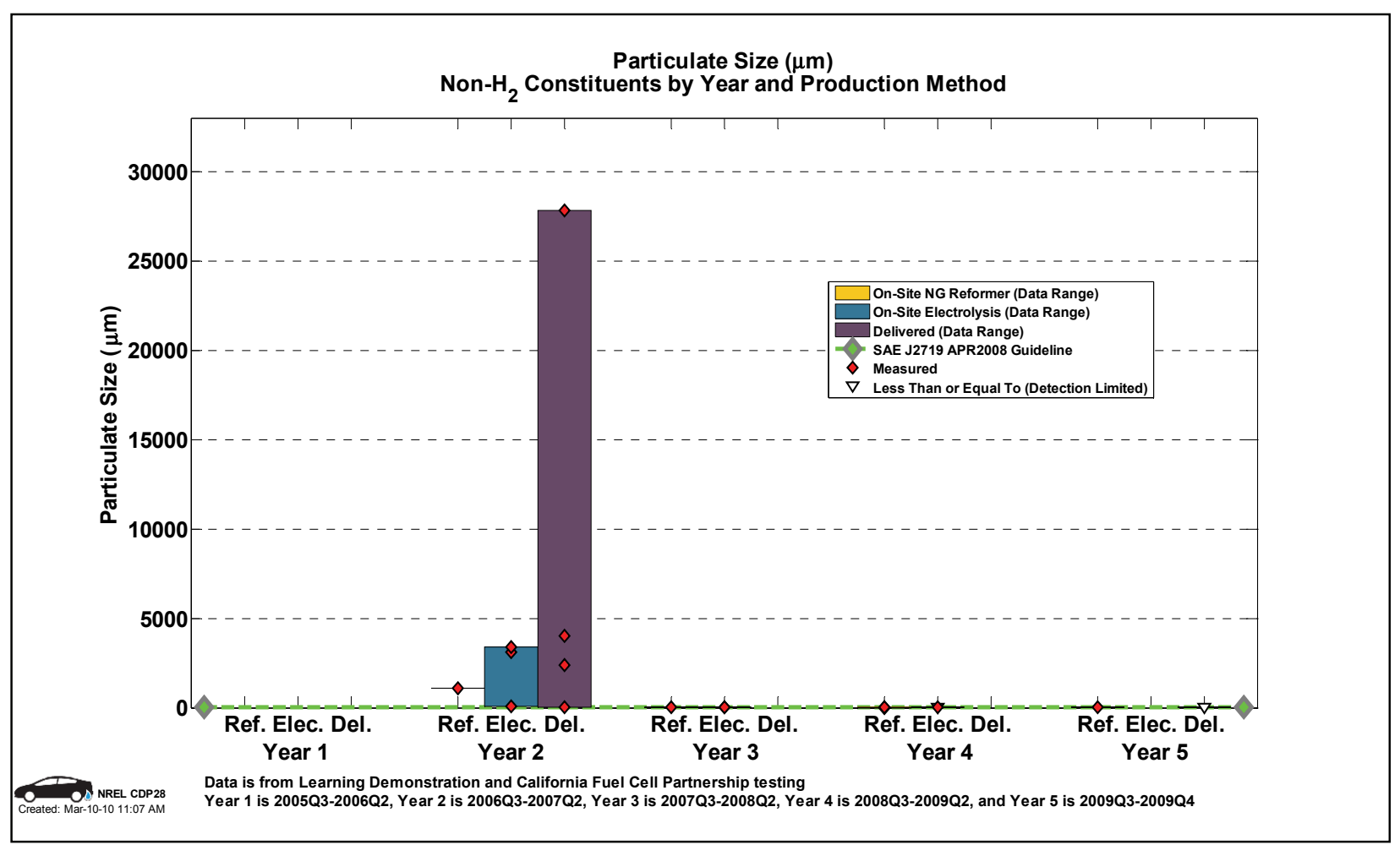

Figure 78: Hydrogen fuel constituents - particulate size (CDP28)

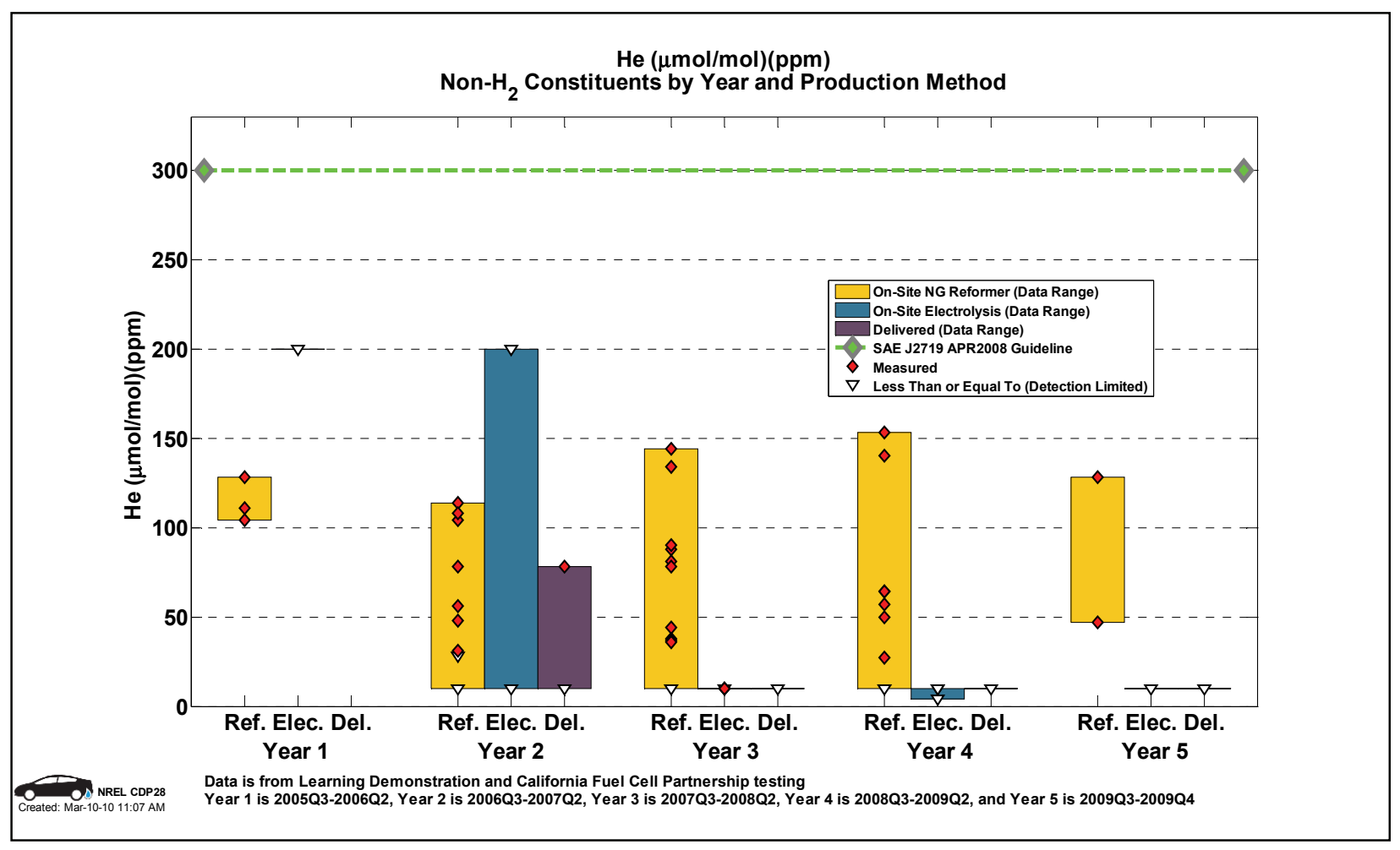

Figure 79: Hydrogen fuel constituents - helium (CDP28) 


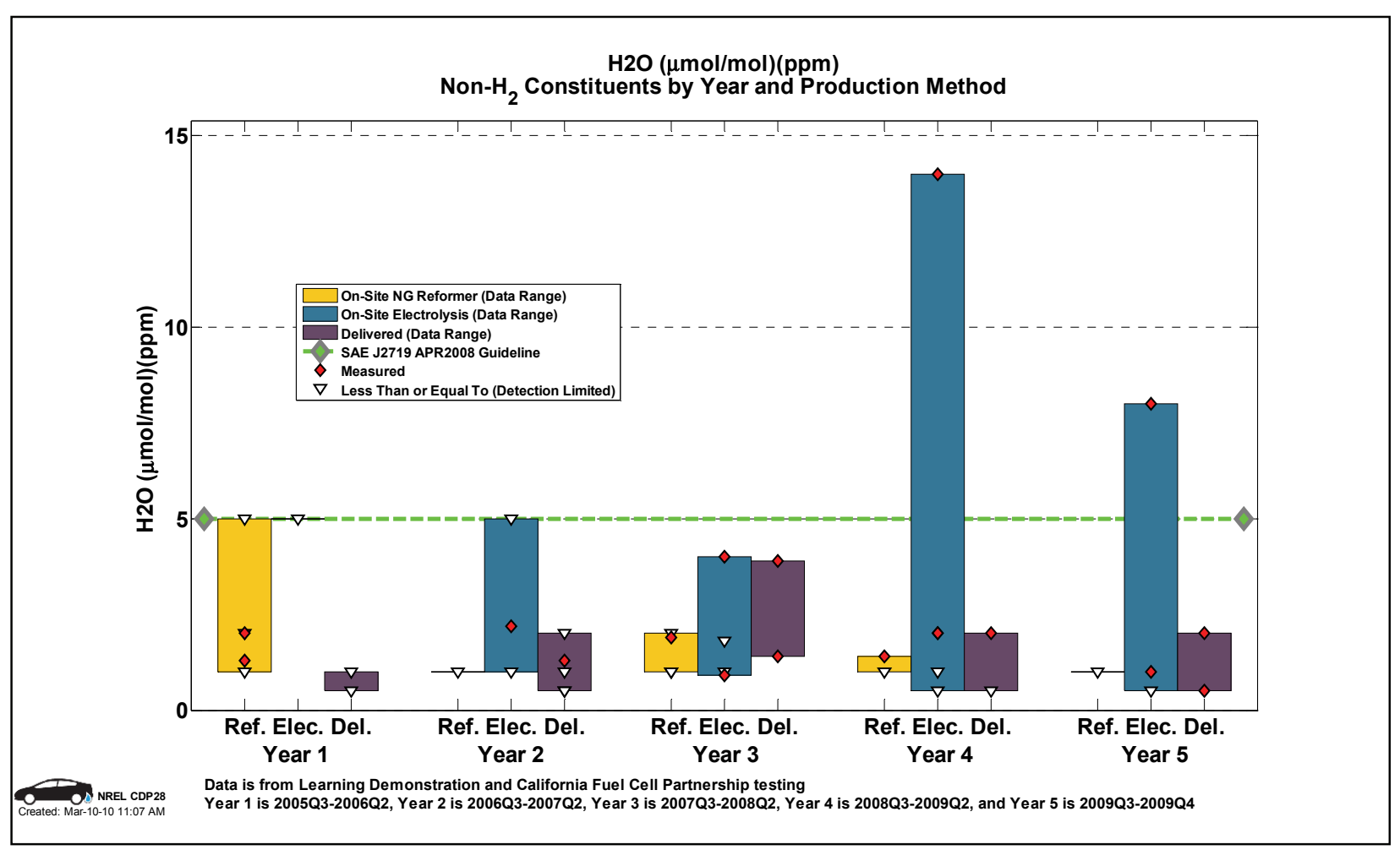

Figure 80: Hydrogen fuel constituents - water (CDP28)

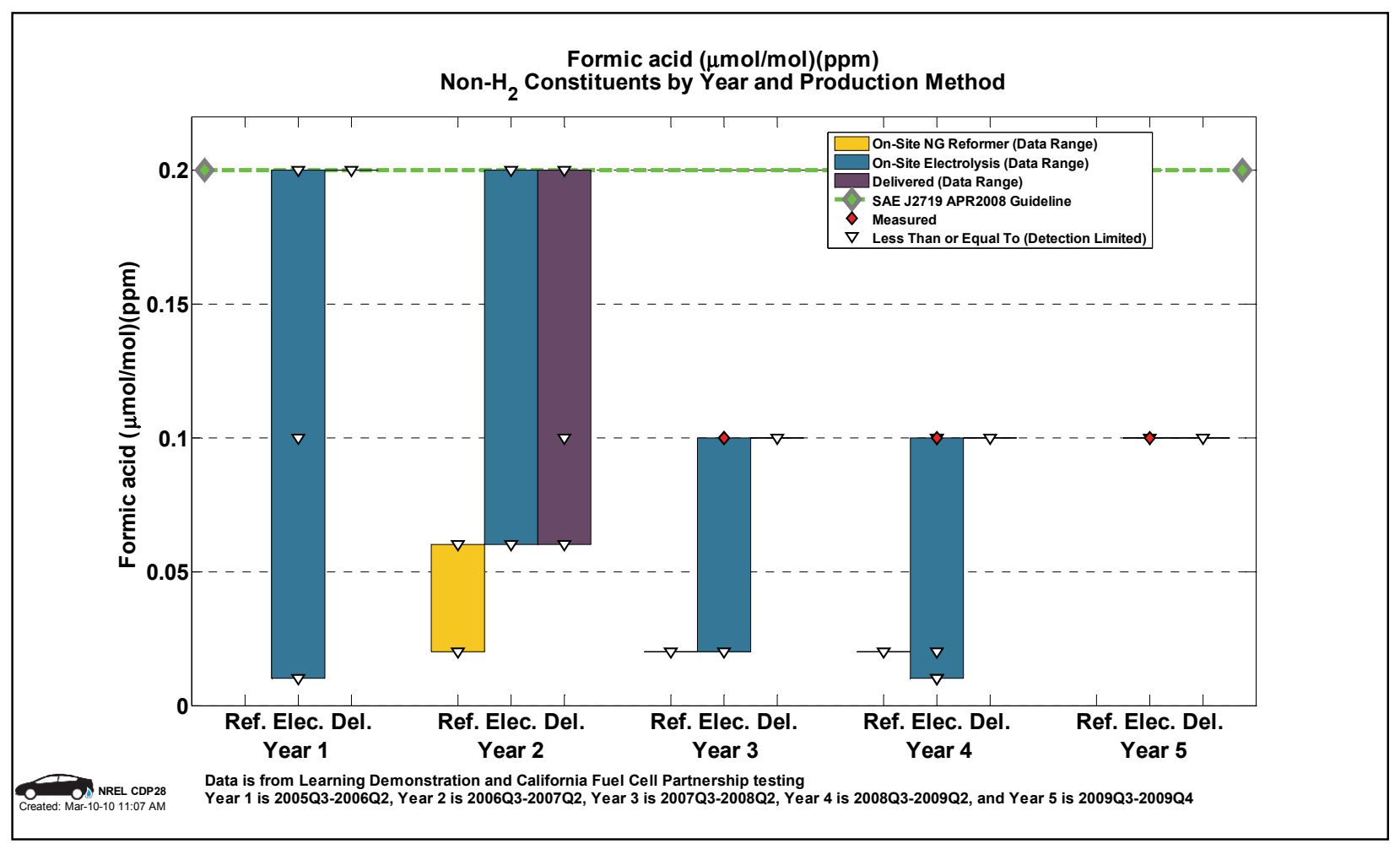

Figure 81: Hydrogen fuel constituents - formic acid (CDP28) 


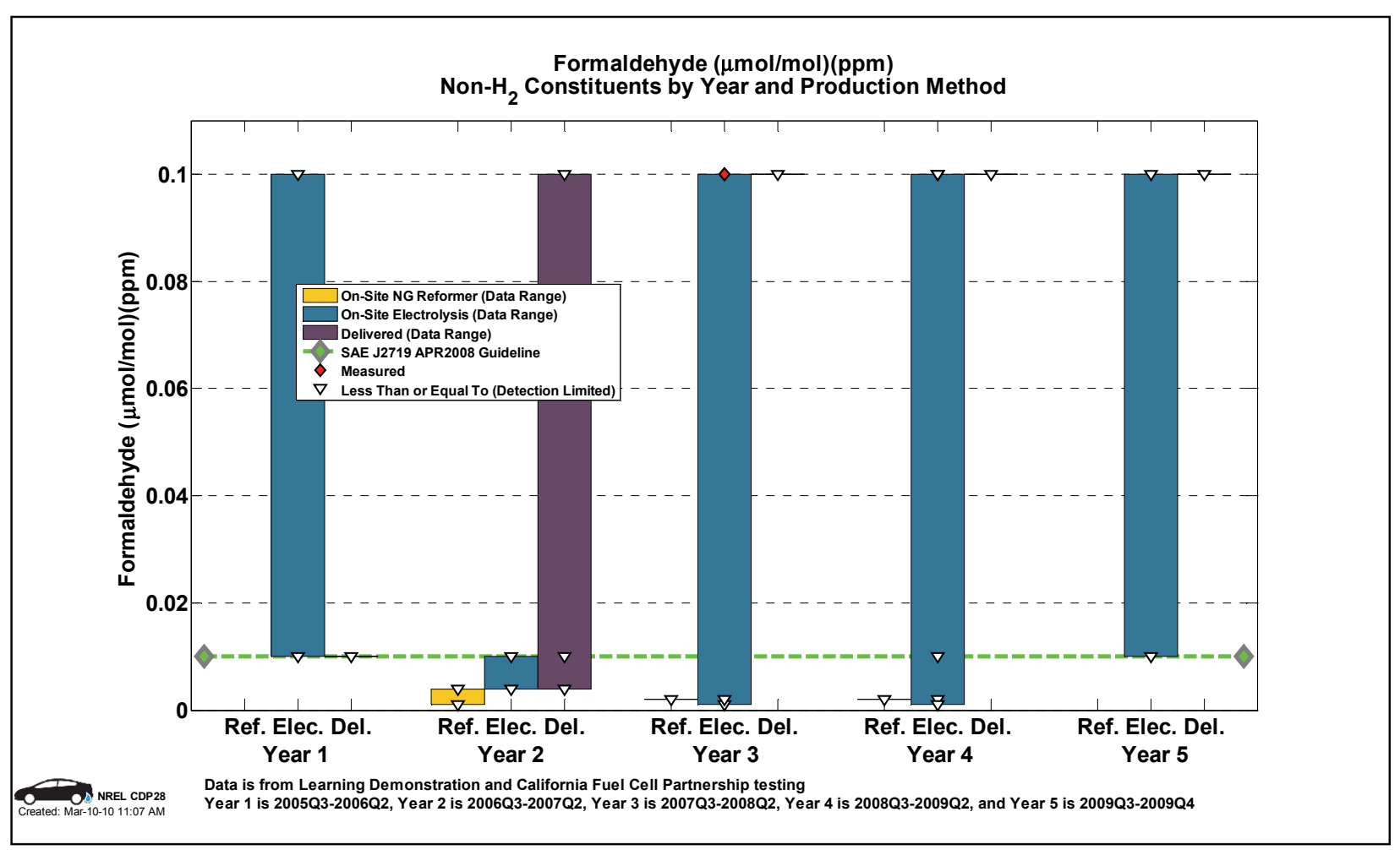

Figure 82: Hydrogen fuel constituents - formaldehyde (CDP28)

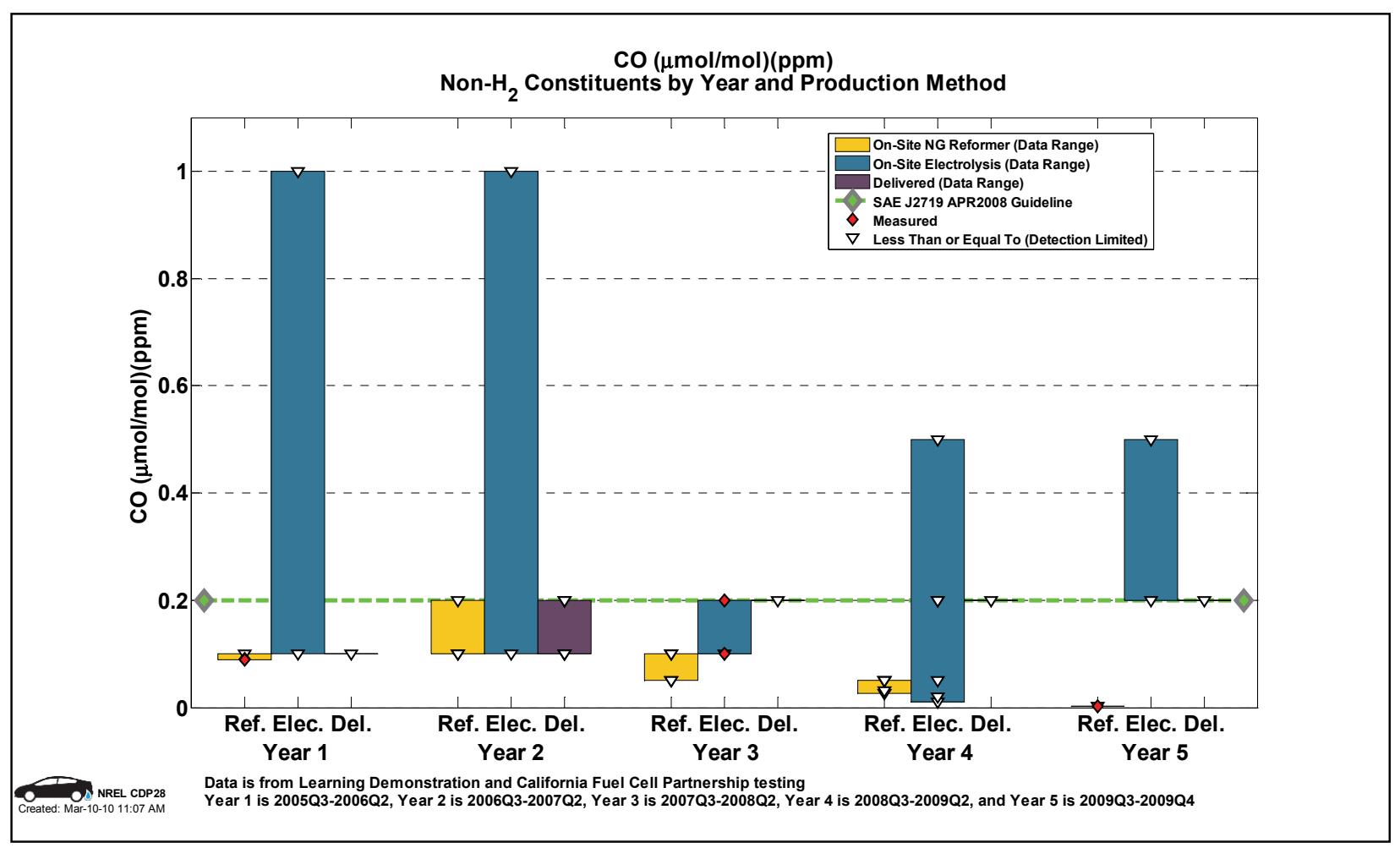

Figure 83: Hydrogen fuel constituents - CO (CDP28) 


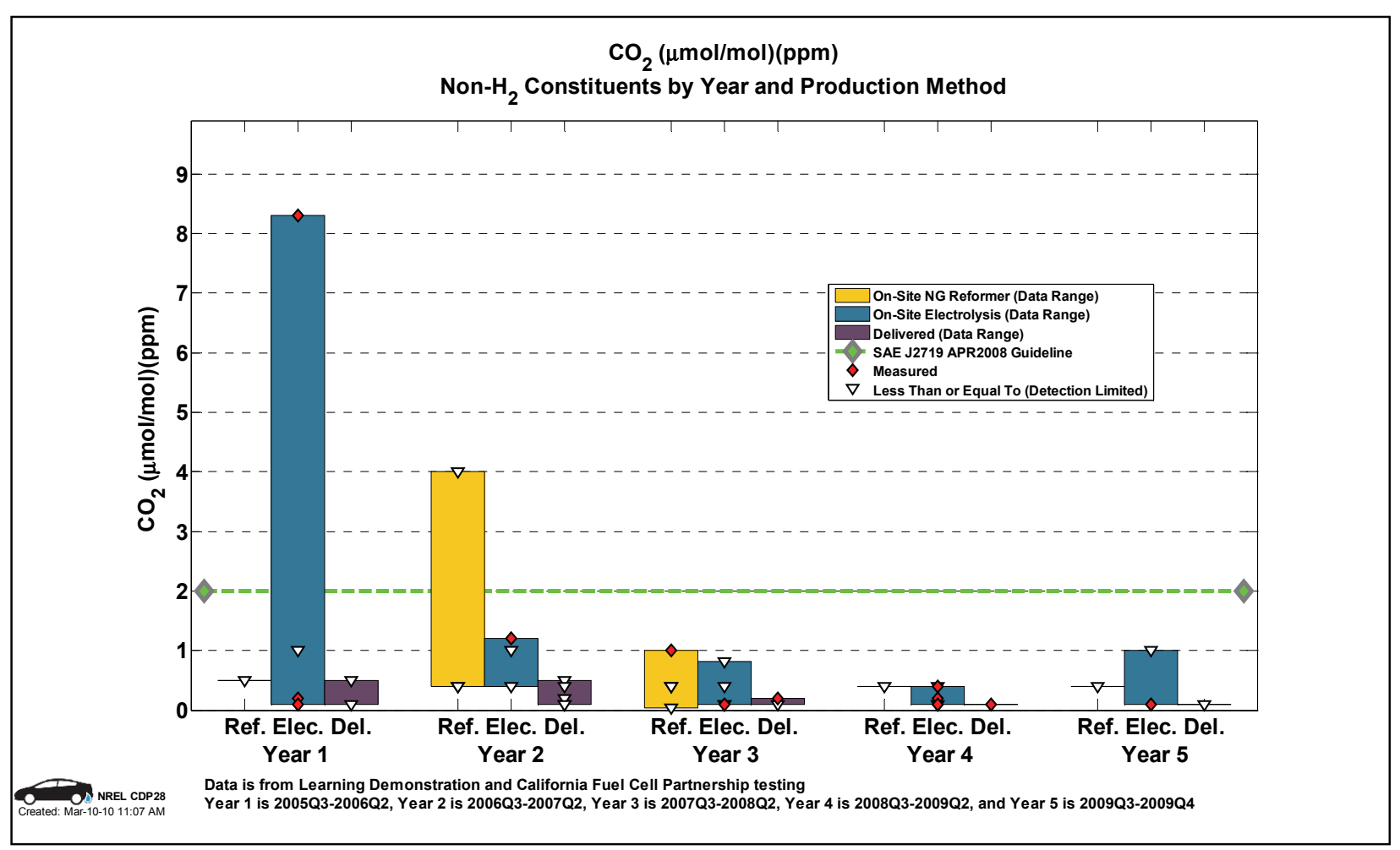

Figure 84: Hydrogen fuel constituents $-\mathrm{CO}_{2}$ (CDP28)

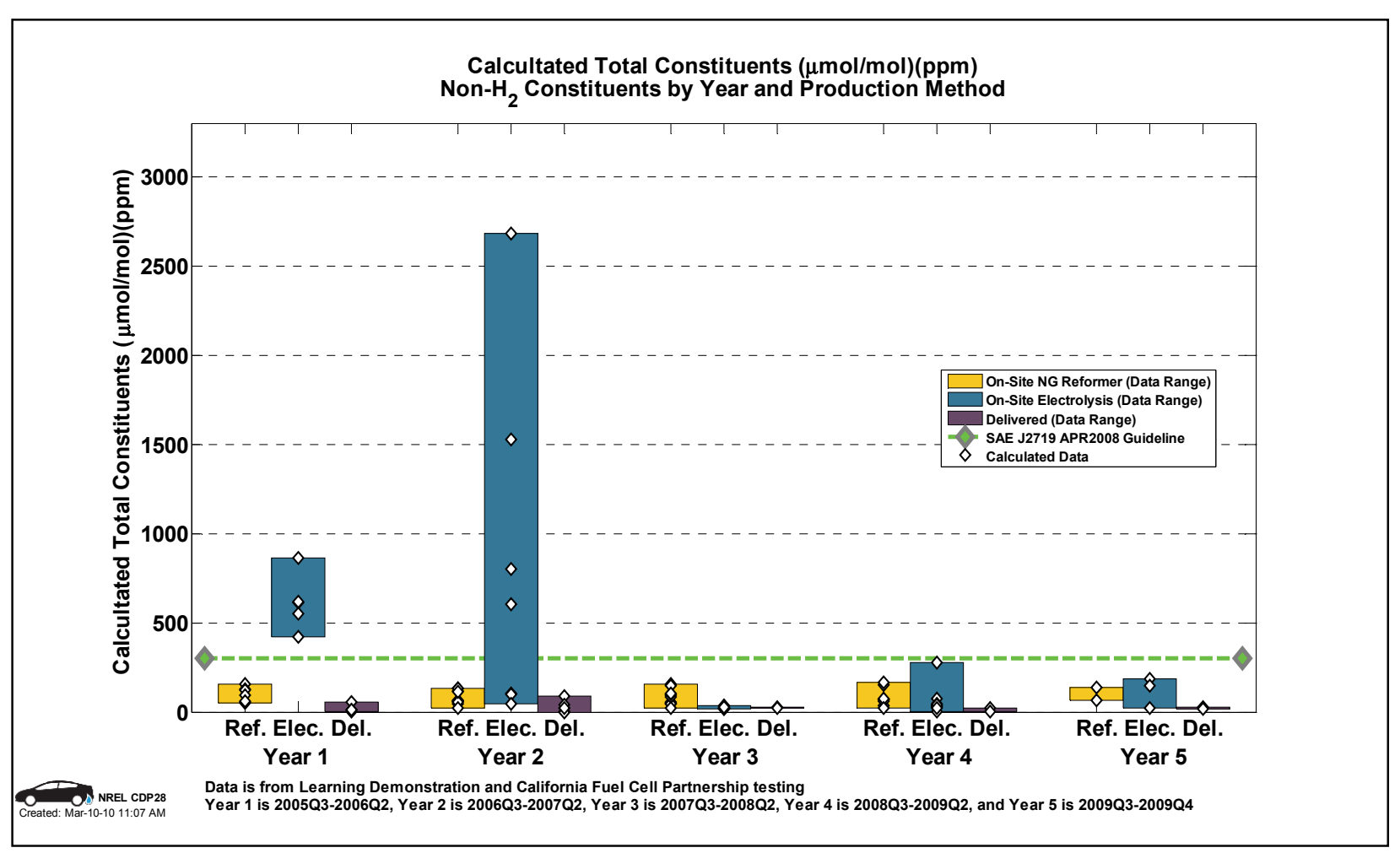

Figure 85: Hydrogen fuel constituents - total (CDP28) 


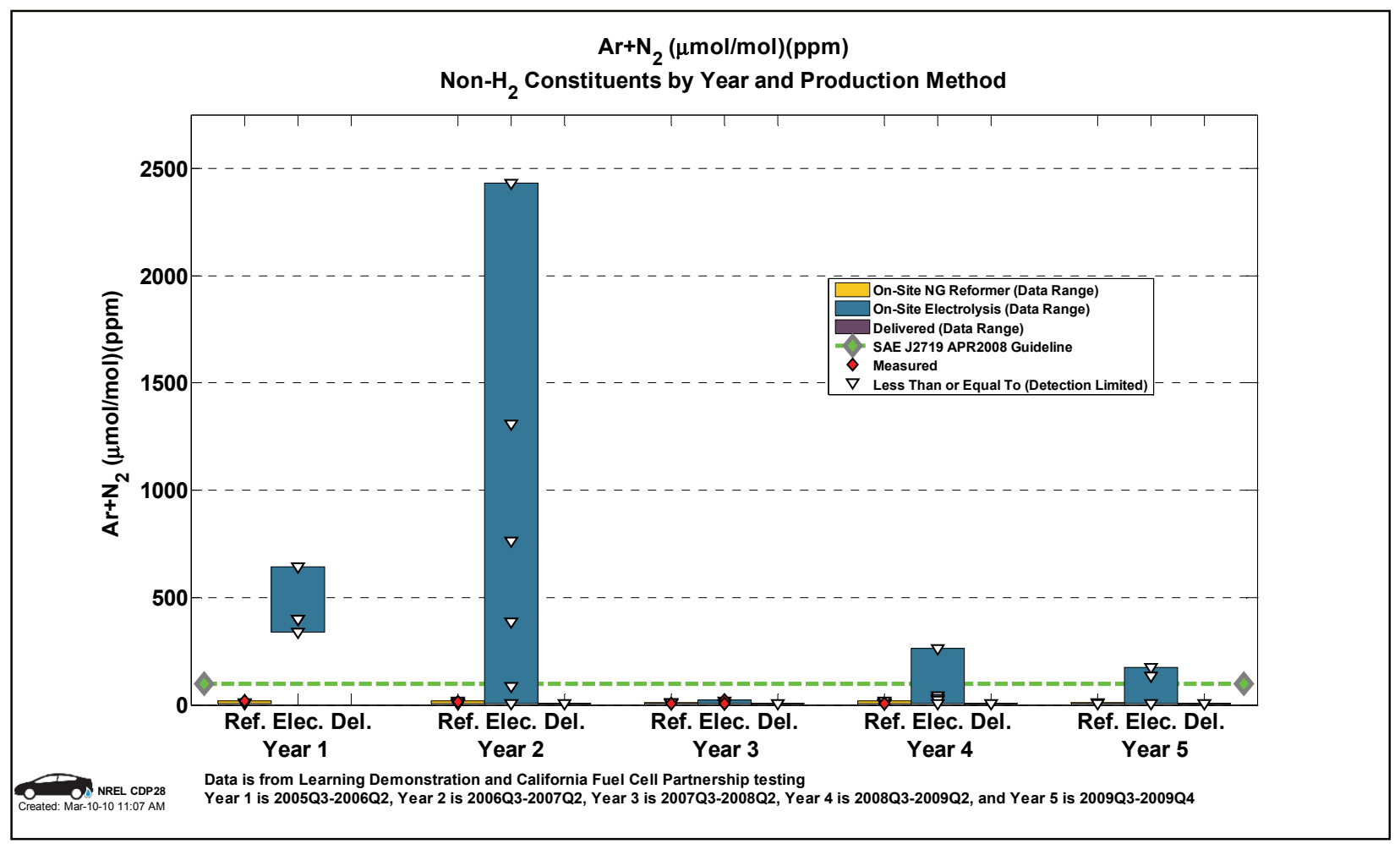

Figure 86: Hydrogen fuel constituents - argon + nitrogen (CDP28)

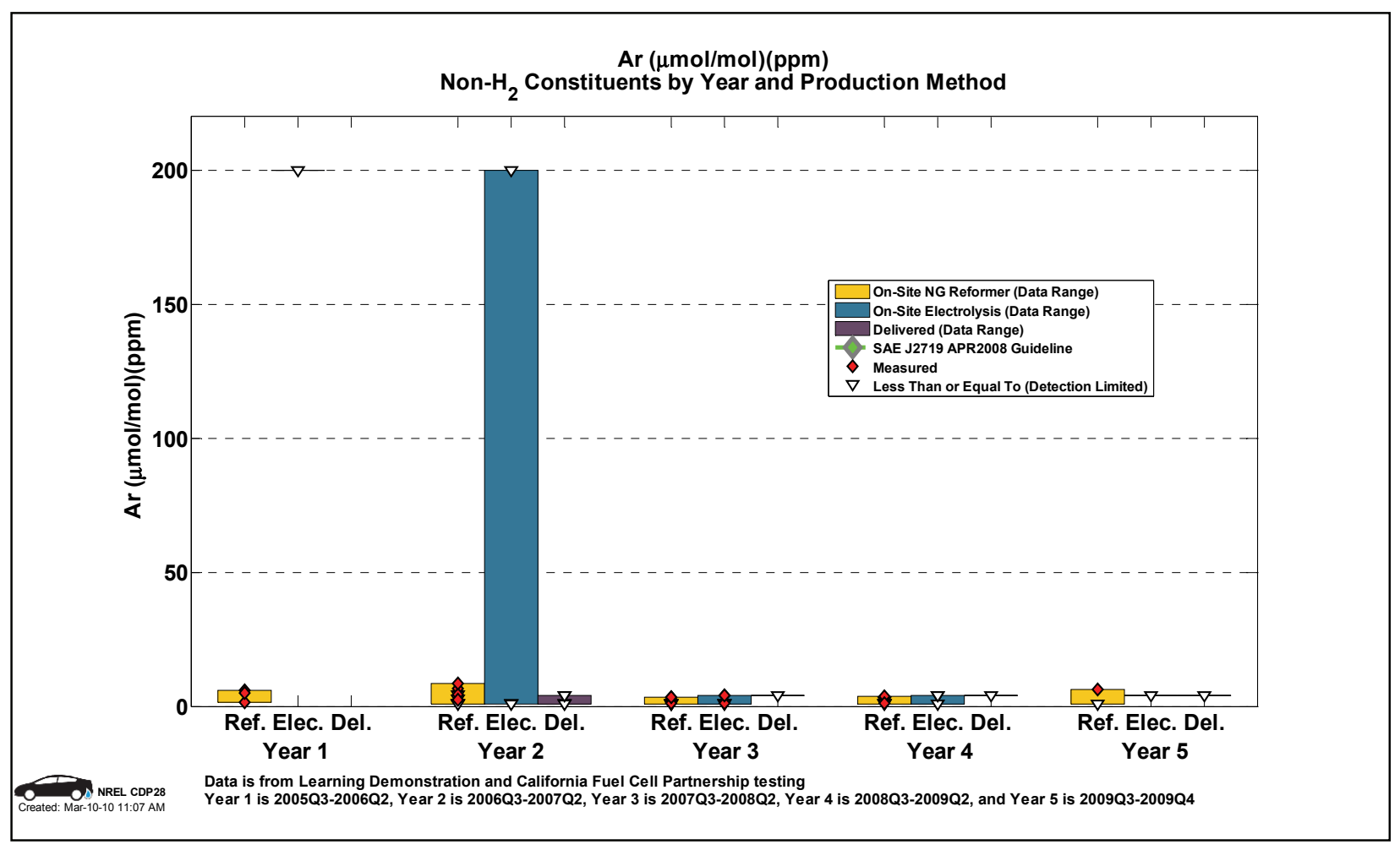

Figure 87: Hydrogen fuel constituents - argon (CDP28) 


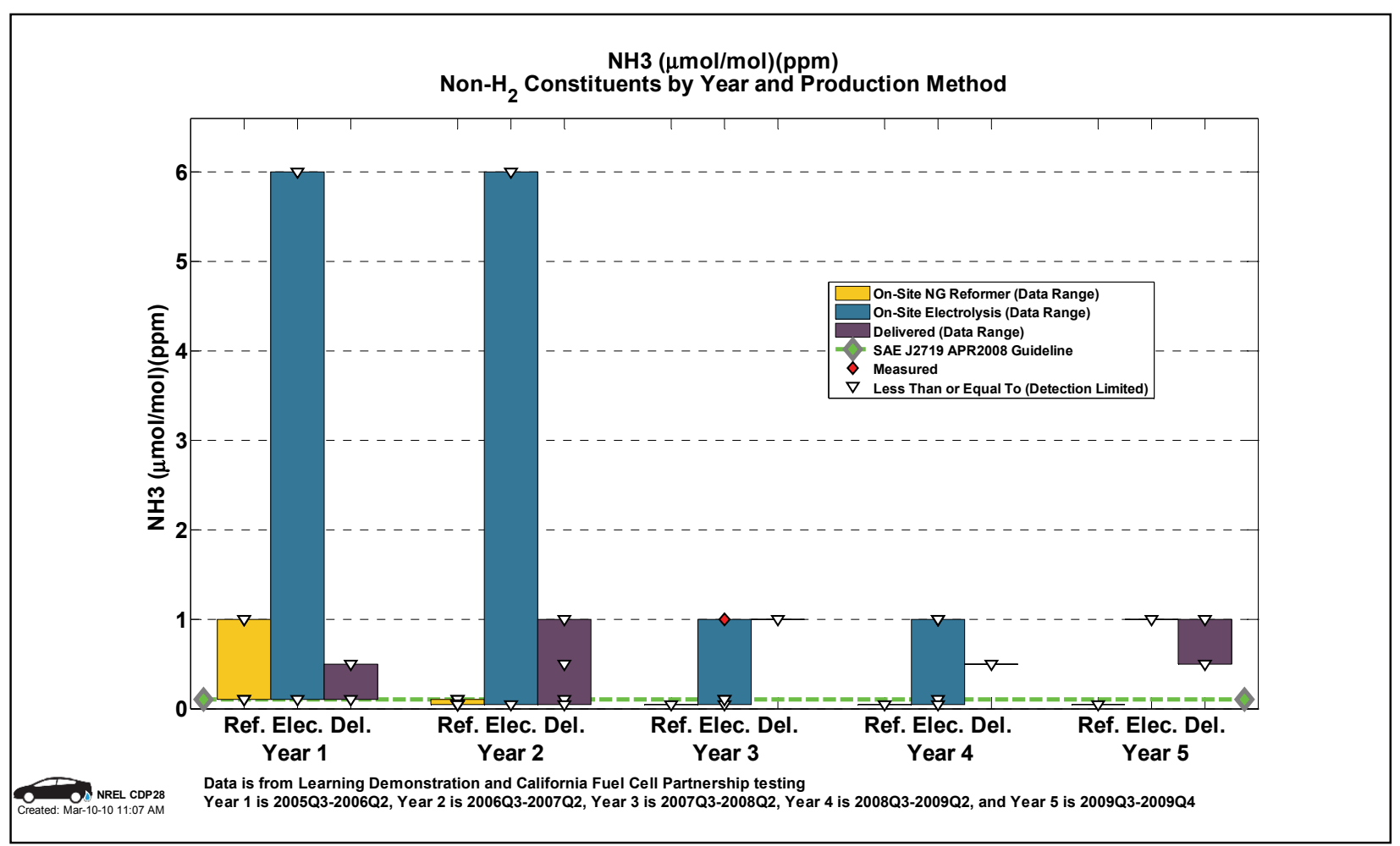

Figure 88: Hydrogen fuel constituents - ammonia (CDP28)

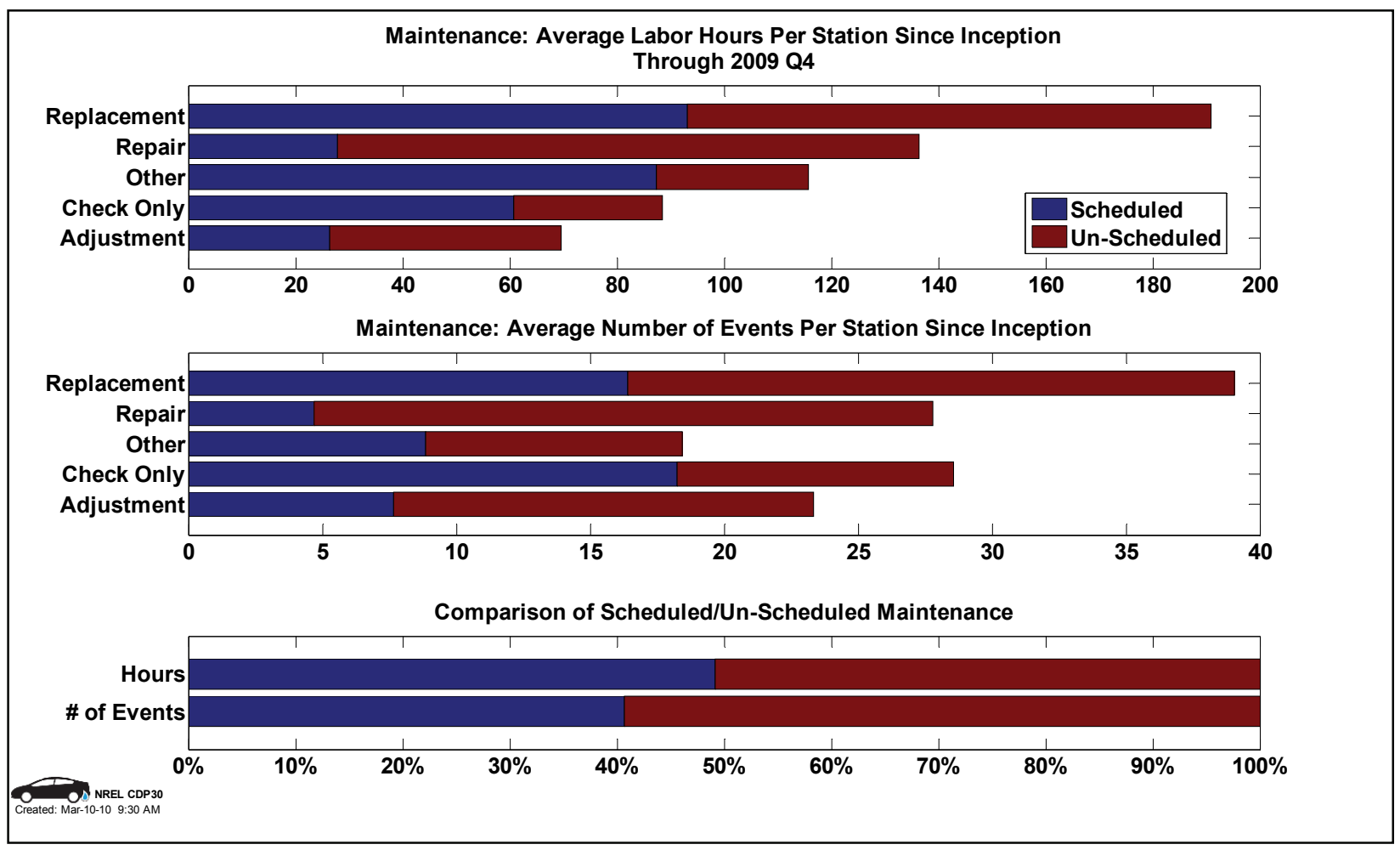

Figure 89: Infrastructure maintenance (CDP30) 
By Number of Events

Total Number of Events $=2491$

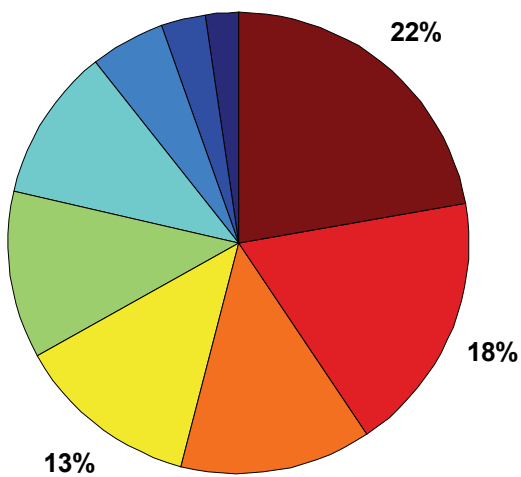

$13 \%$
By Labor Hours

Total Hours $=11430$

\begin{tabular}{|c|}
\hline system control \& safety \\
\hline compressor \\
\hline reformer \\
\hline electrolyzer \\
\hline dispenser \\
\hline other \\
\hline valves \& piping \\
\hline electrical \\
\hline storage \\
\hline
\end{tabular}

$20 \%$

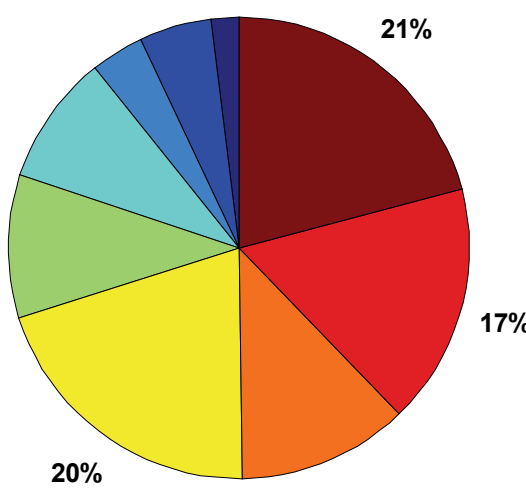

$12 \%$

OS NREL CDP63

Figure 90: Hydrogen fueling station maintenance by system (CDP63)

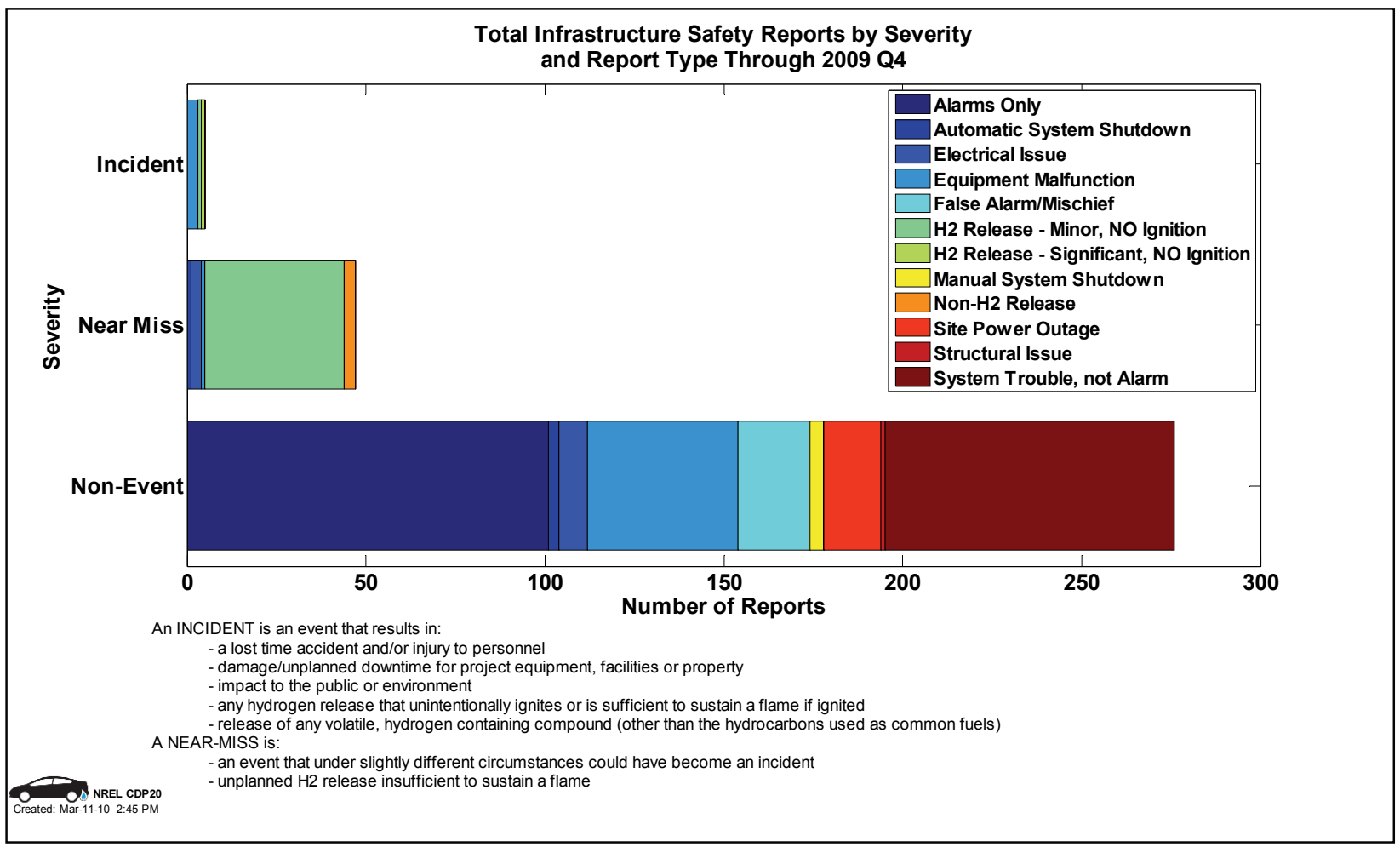

Figure 91: Safety reports - infrastructure (CDP20) 


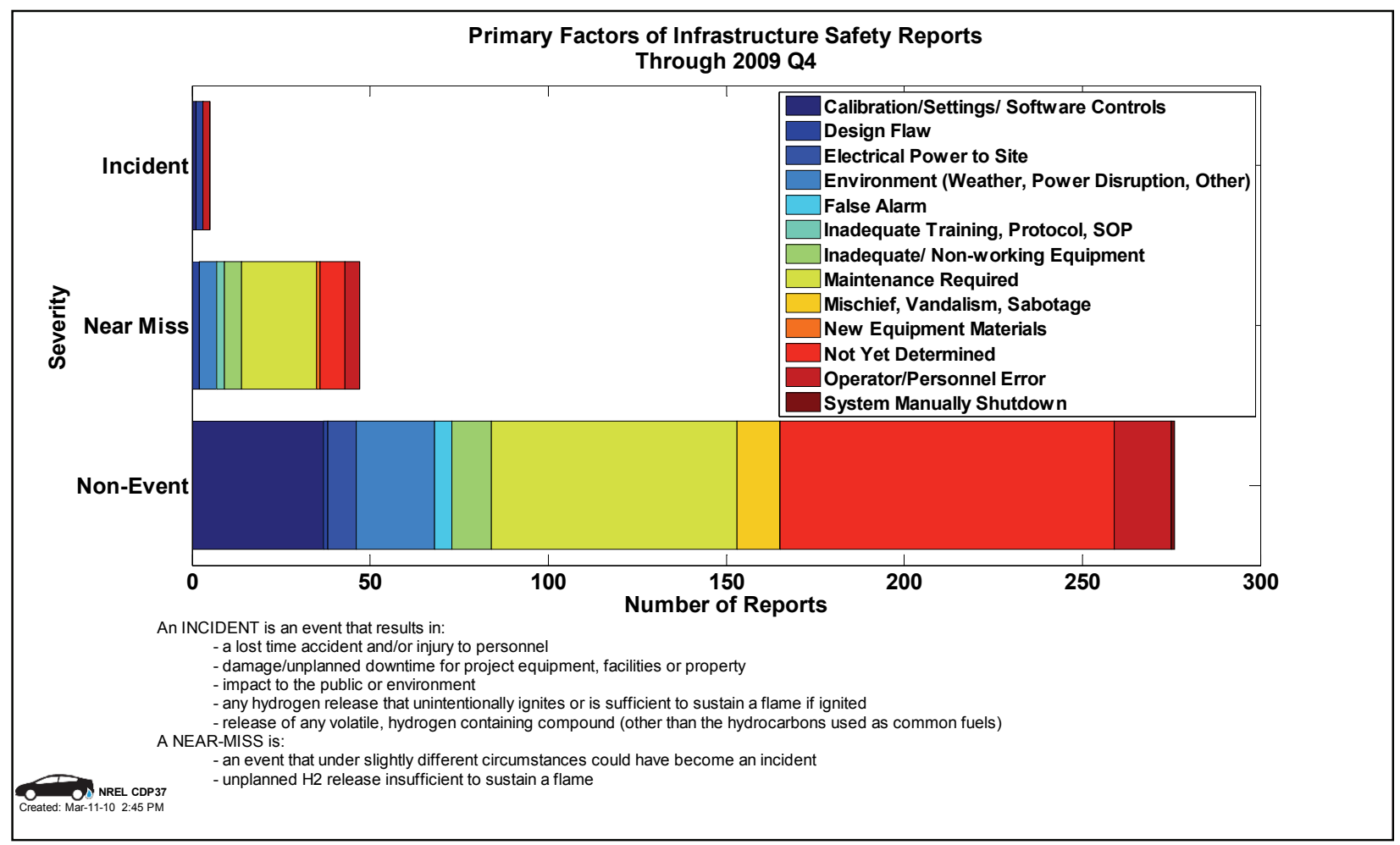

Figure 92: Primary factors of infrastructure reports (CDP37)

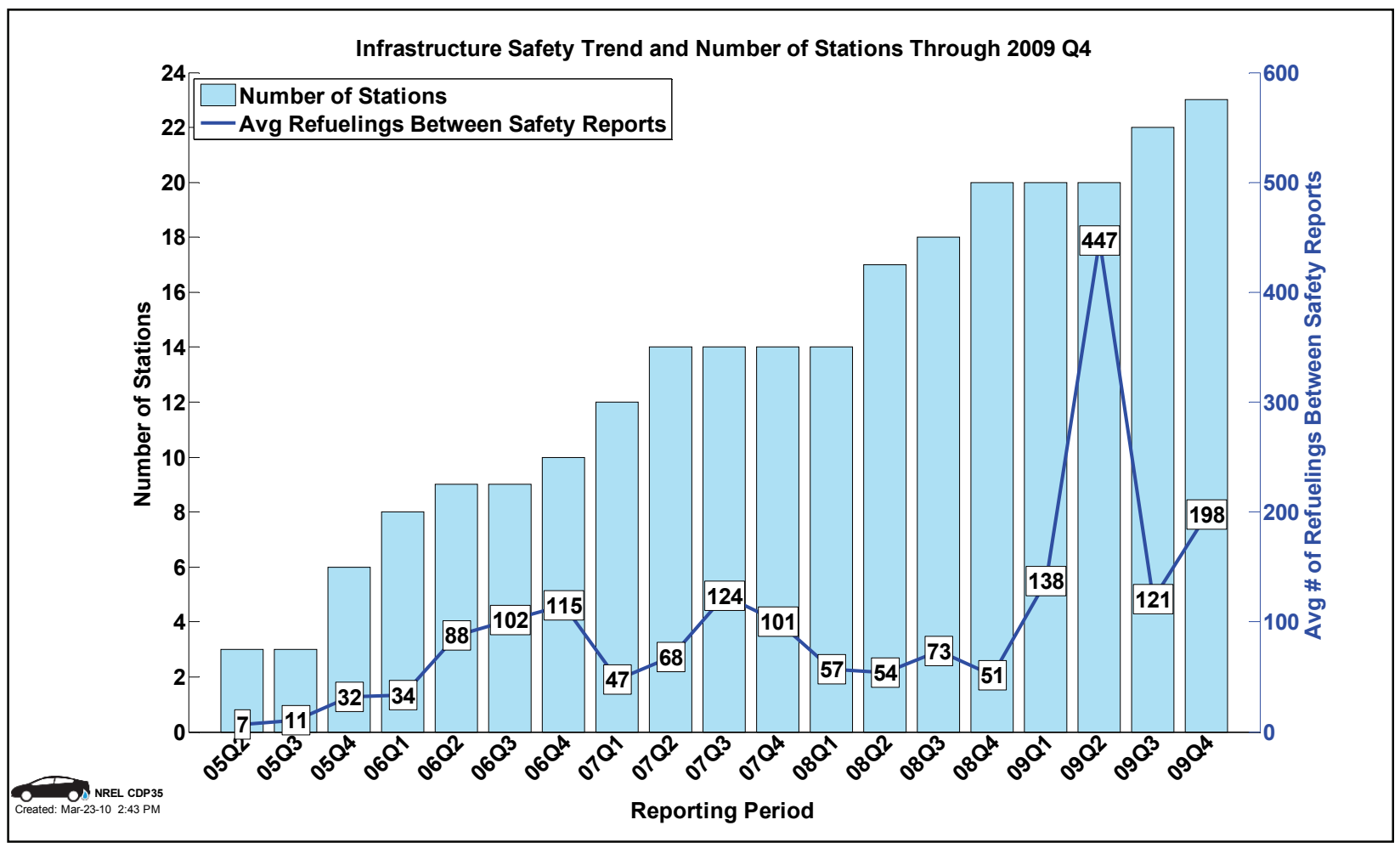

Figure 93: Average refuelings between infrastructure safety reports (CDP35) 


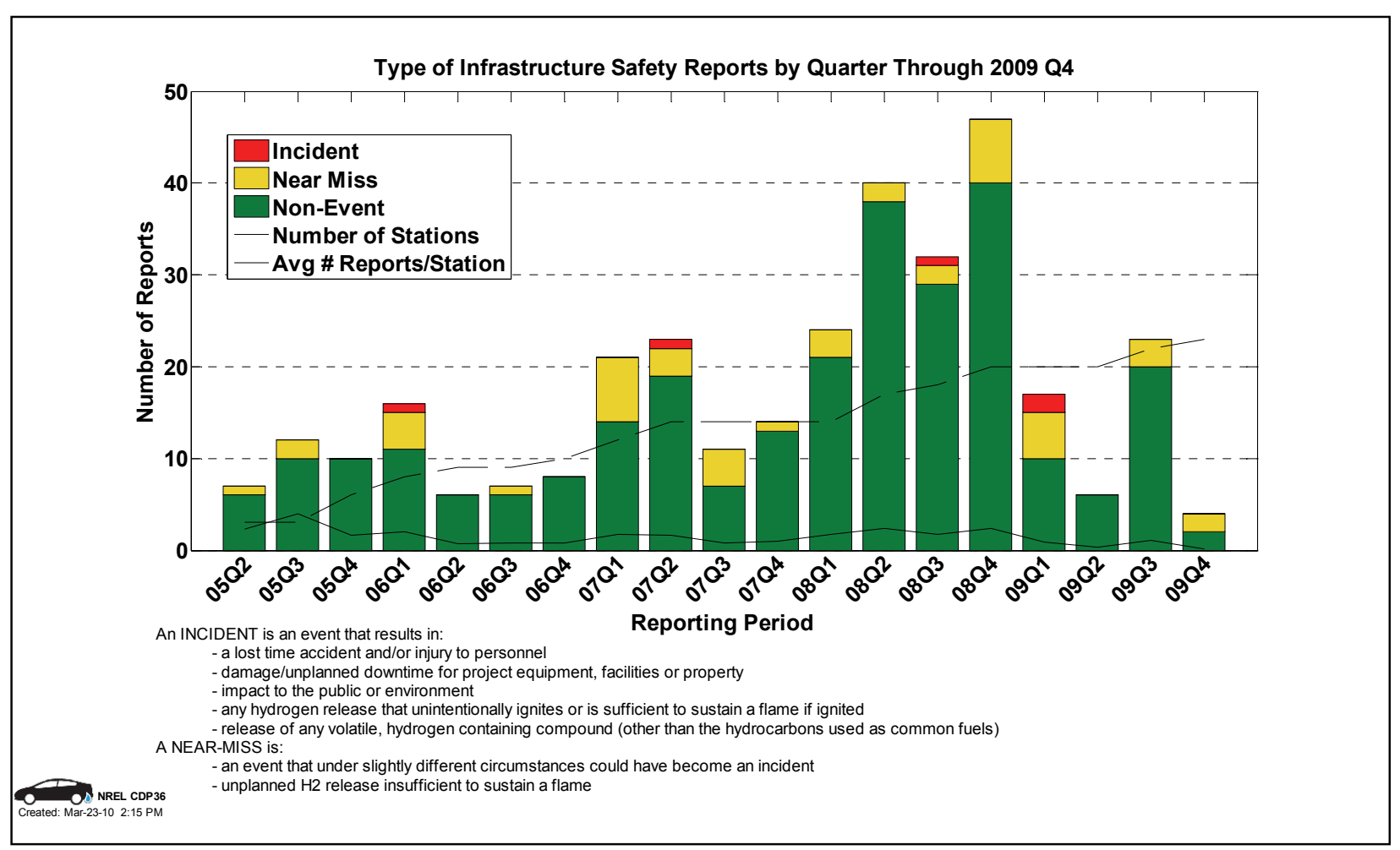

Figure 94: Type of infrastructure safety report by quarter (CDP36)

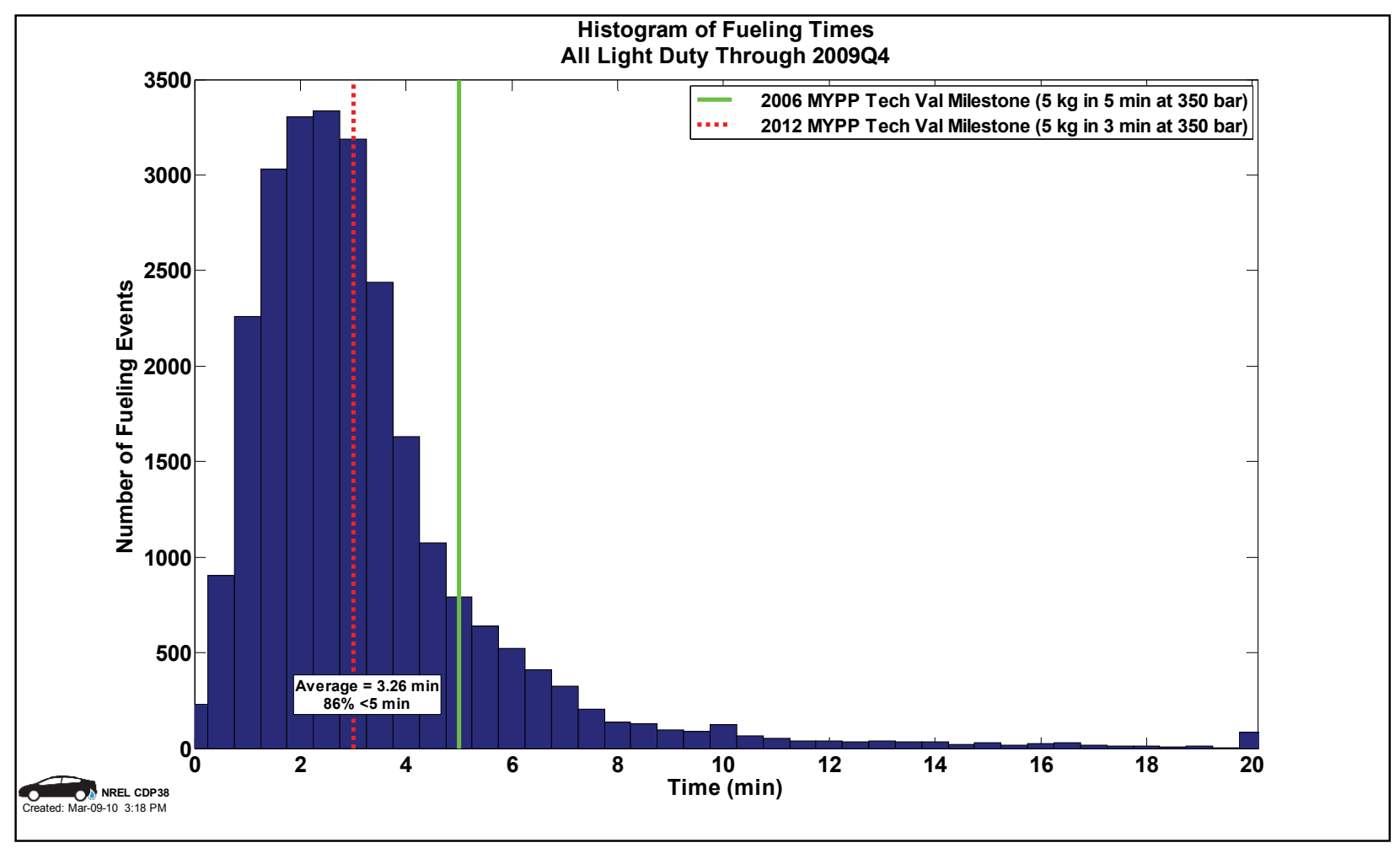

Figure 95: Refueling times (CDP38) 


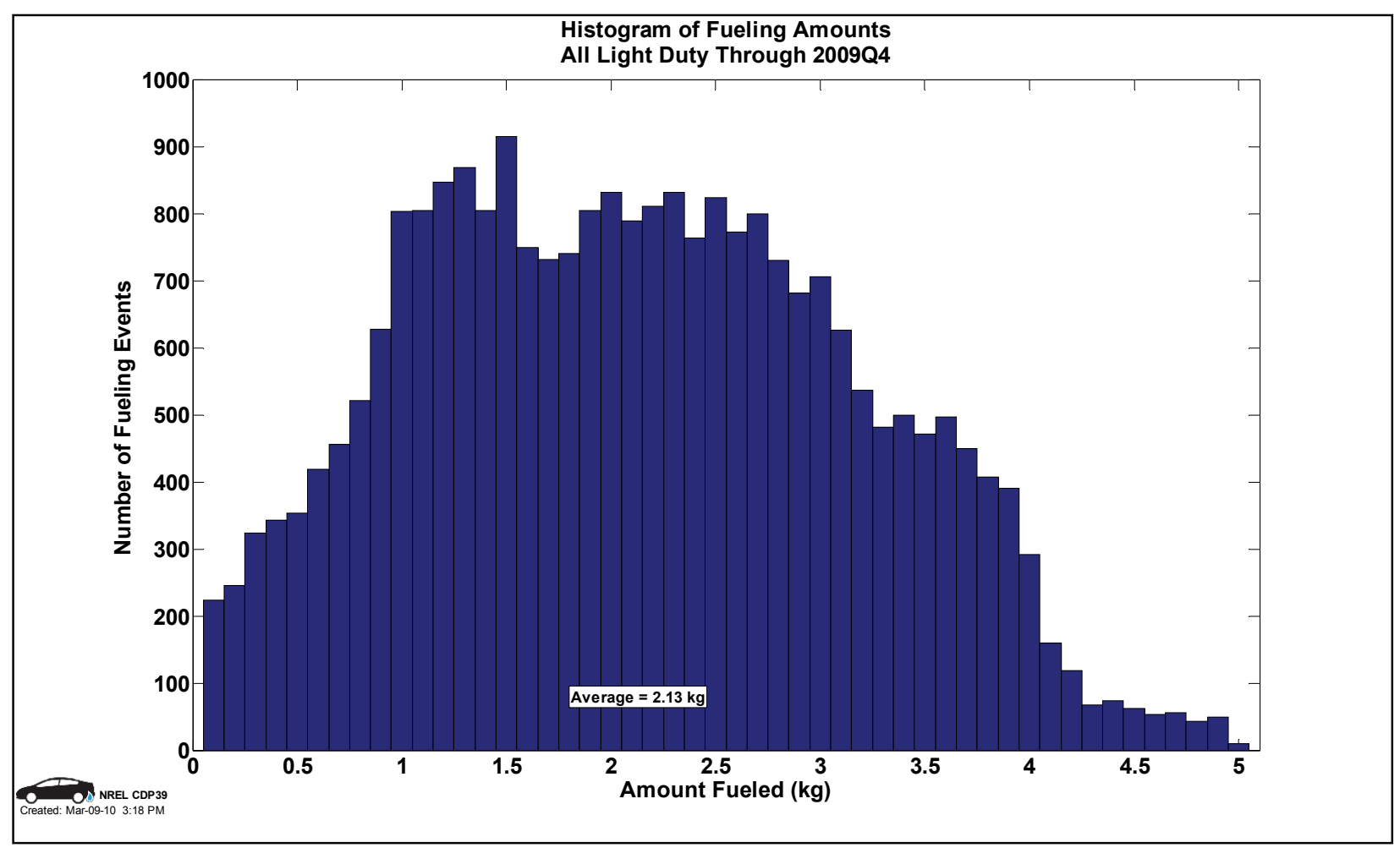

Figure 96: Refueling amounts (CDP39)

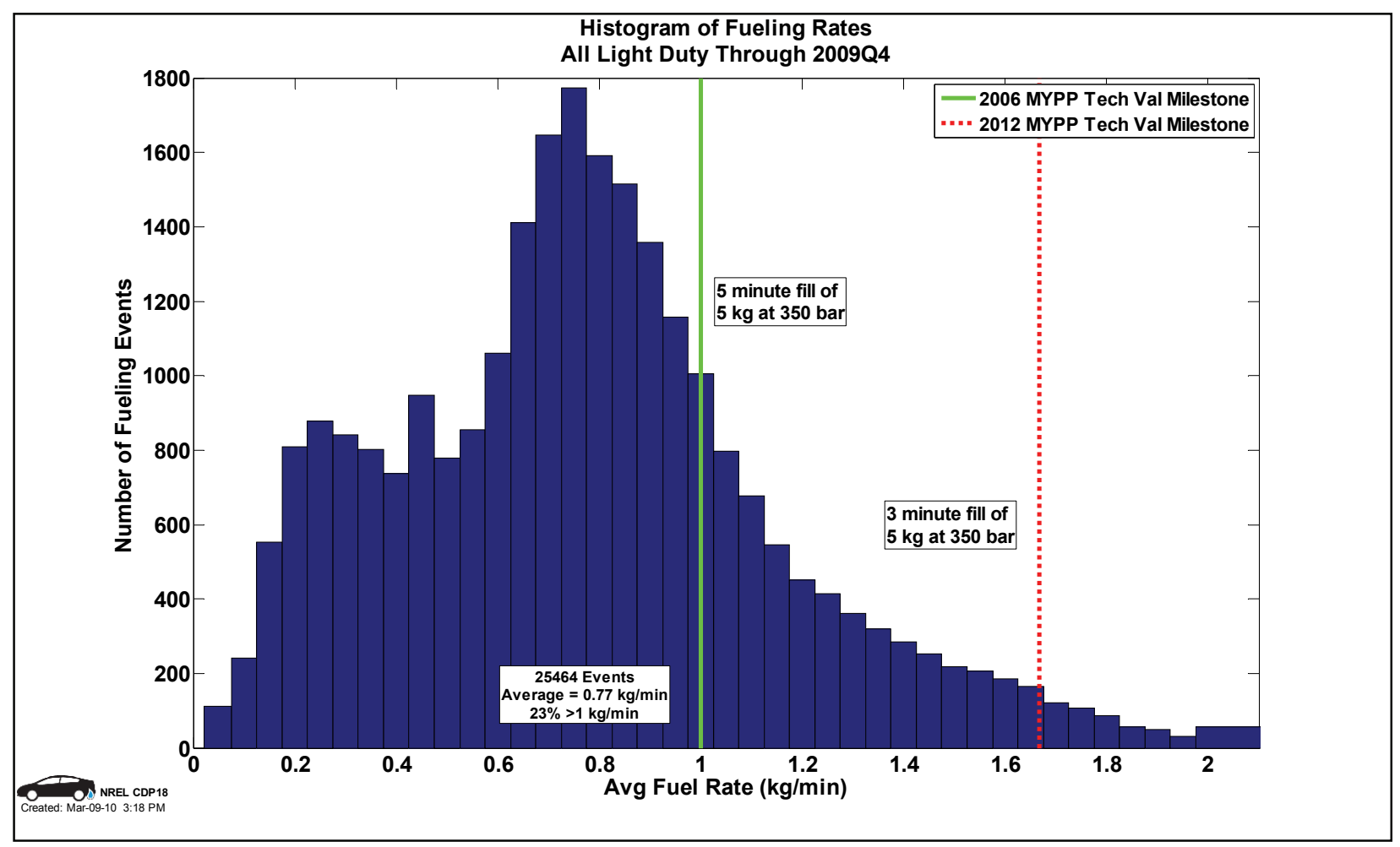

Figure 97: Refueling rates (CDP18) 


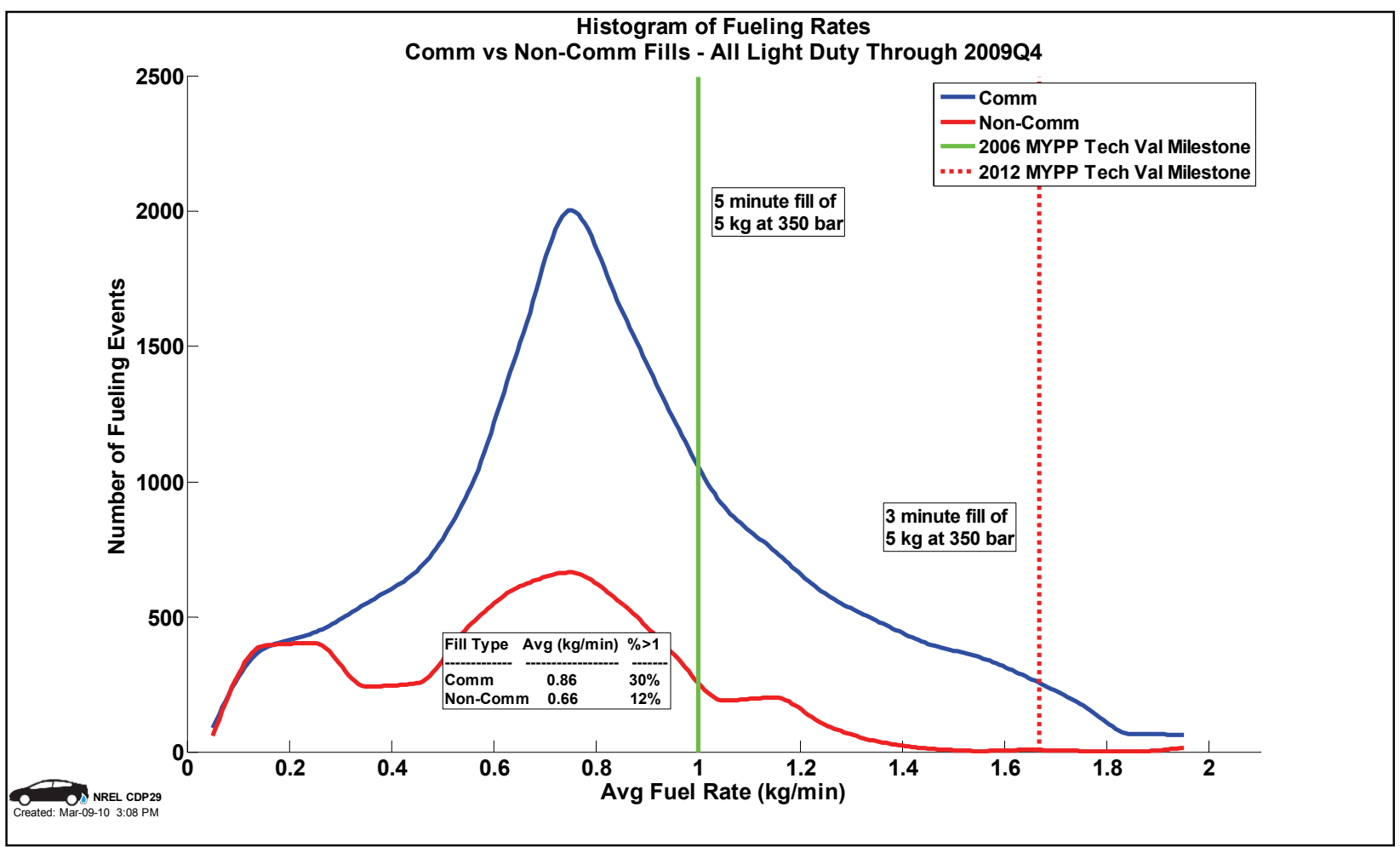

Figure 98: Fueling rates - communication and non-communication fills (CDP29)

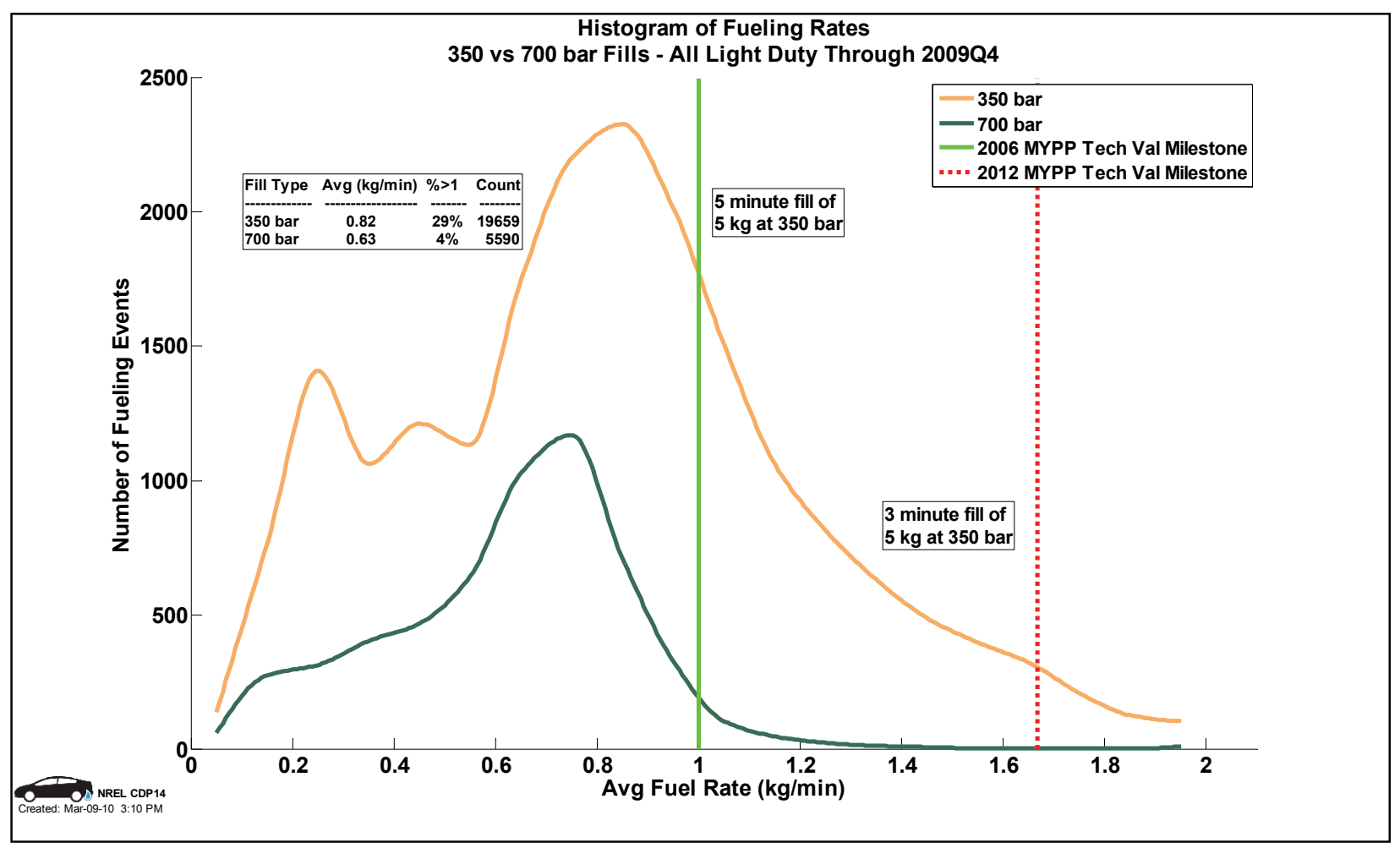

Figure 99: Fueling rates -350 and 700 bar (CDP14) 


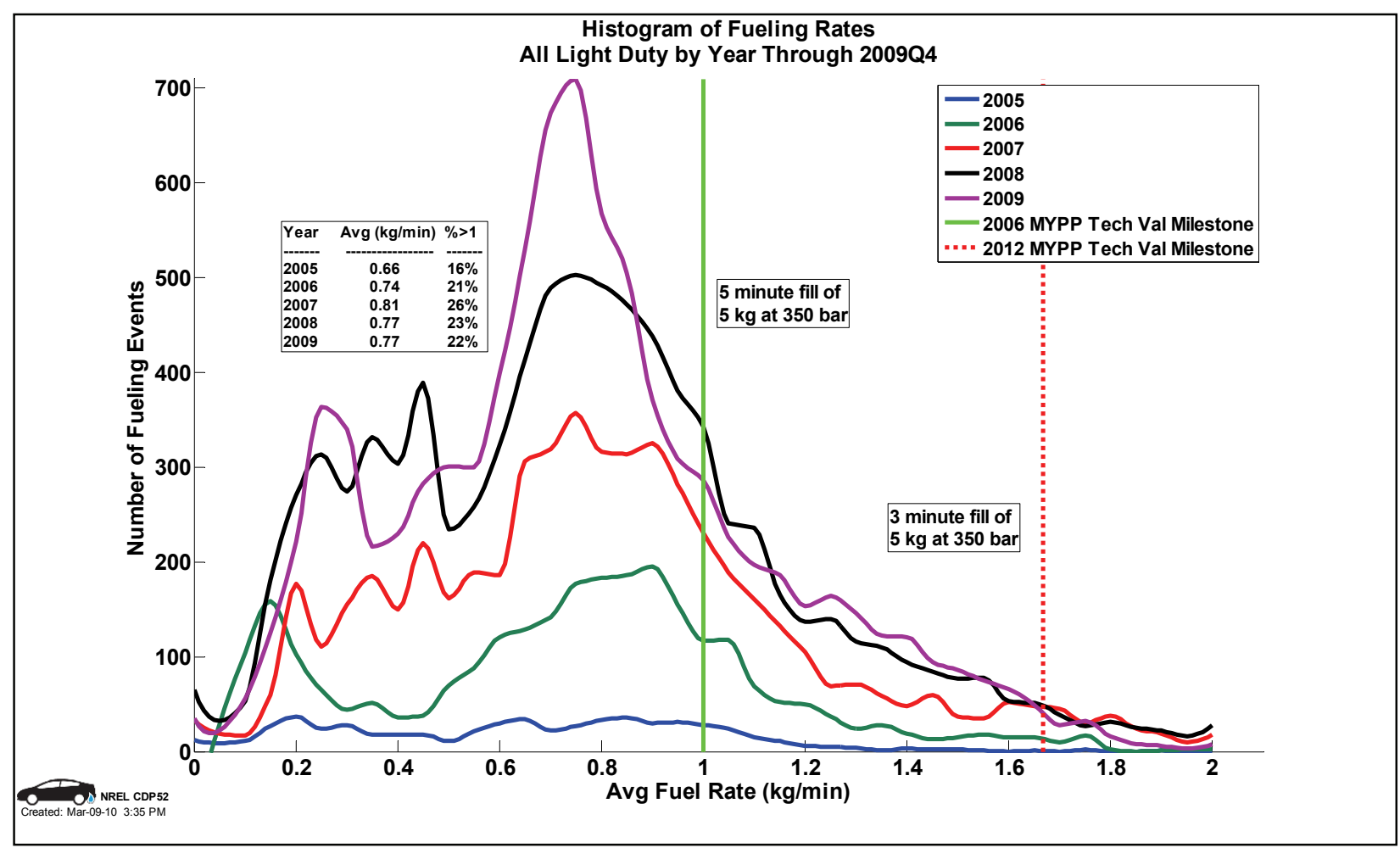

Figure 100: Refueling data by year (CDP52)

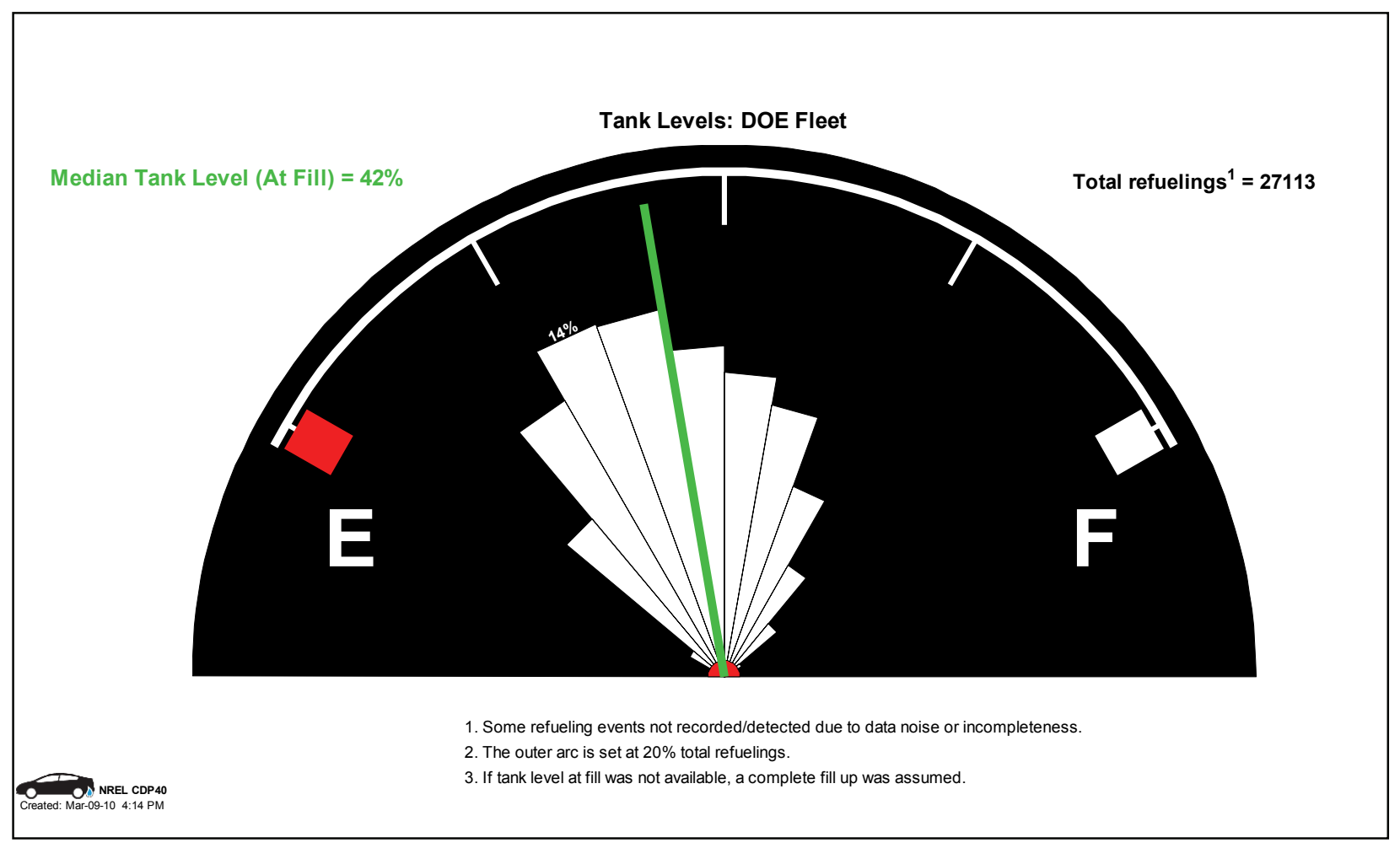

Figure 101: Hydrogen tank level at refueling (CDP40) 


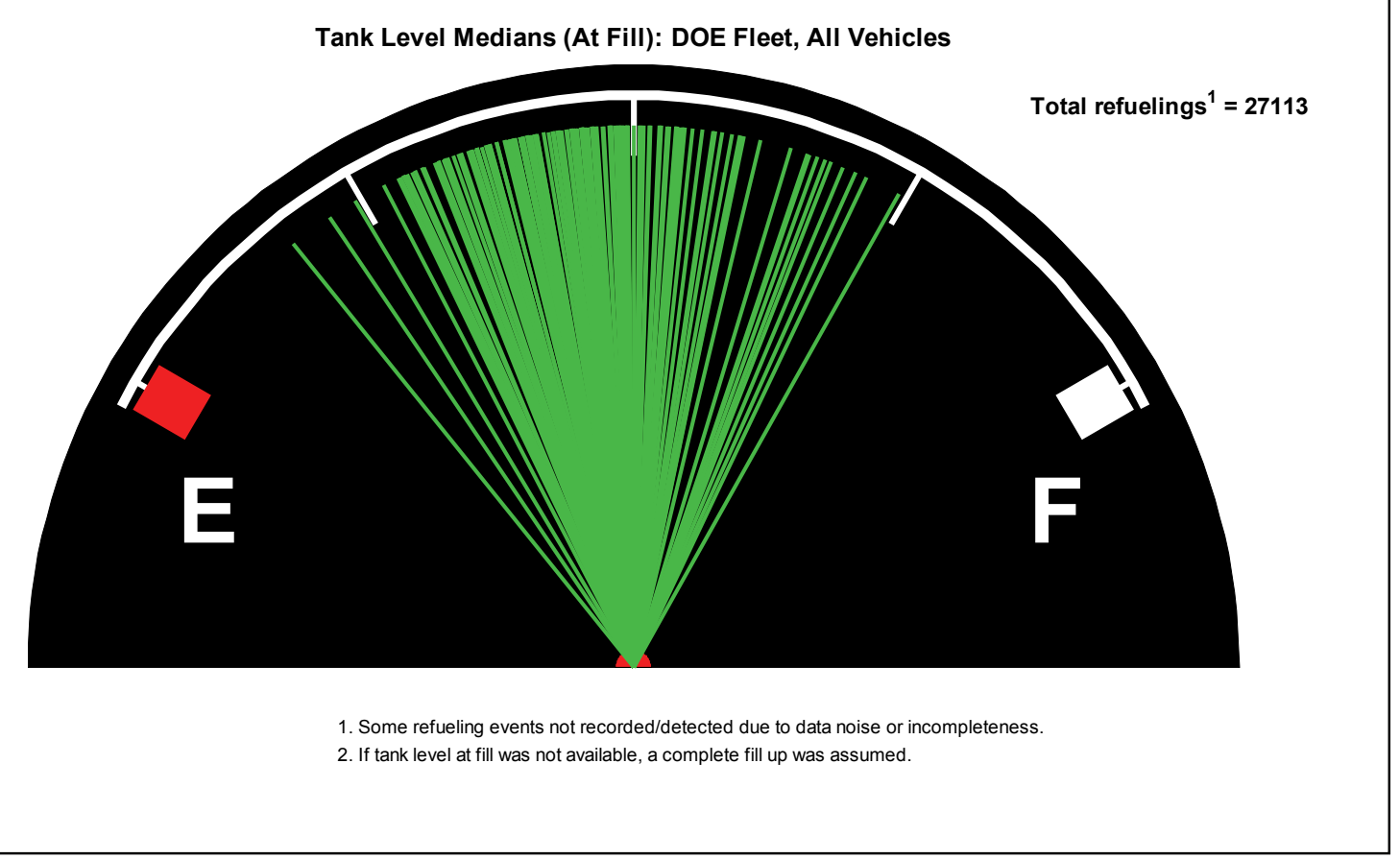

Figure 102: Refueling tank levels - medians (CDP41)

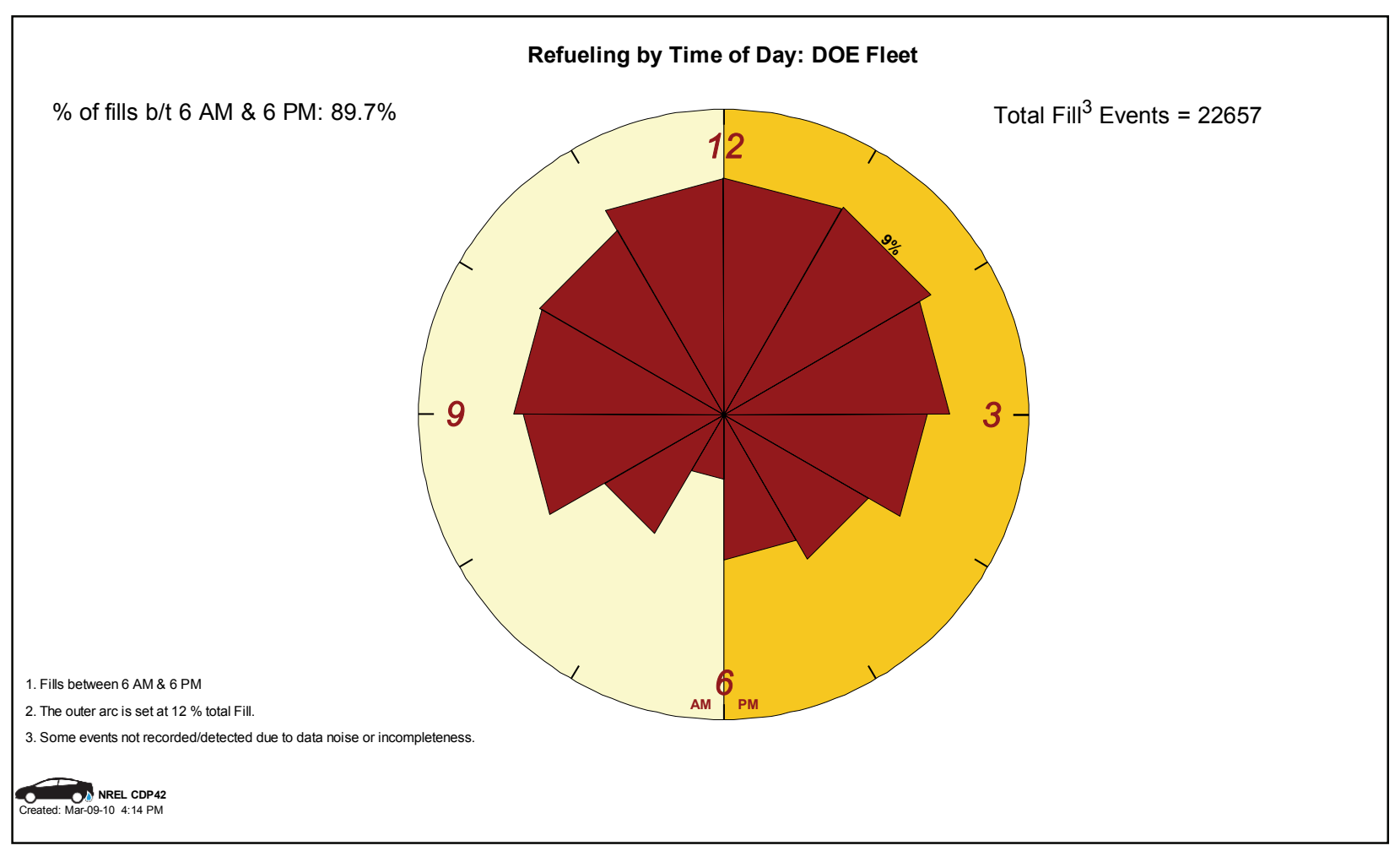

Figure 103: Refueling by time of day (CDP42) 


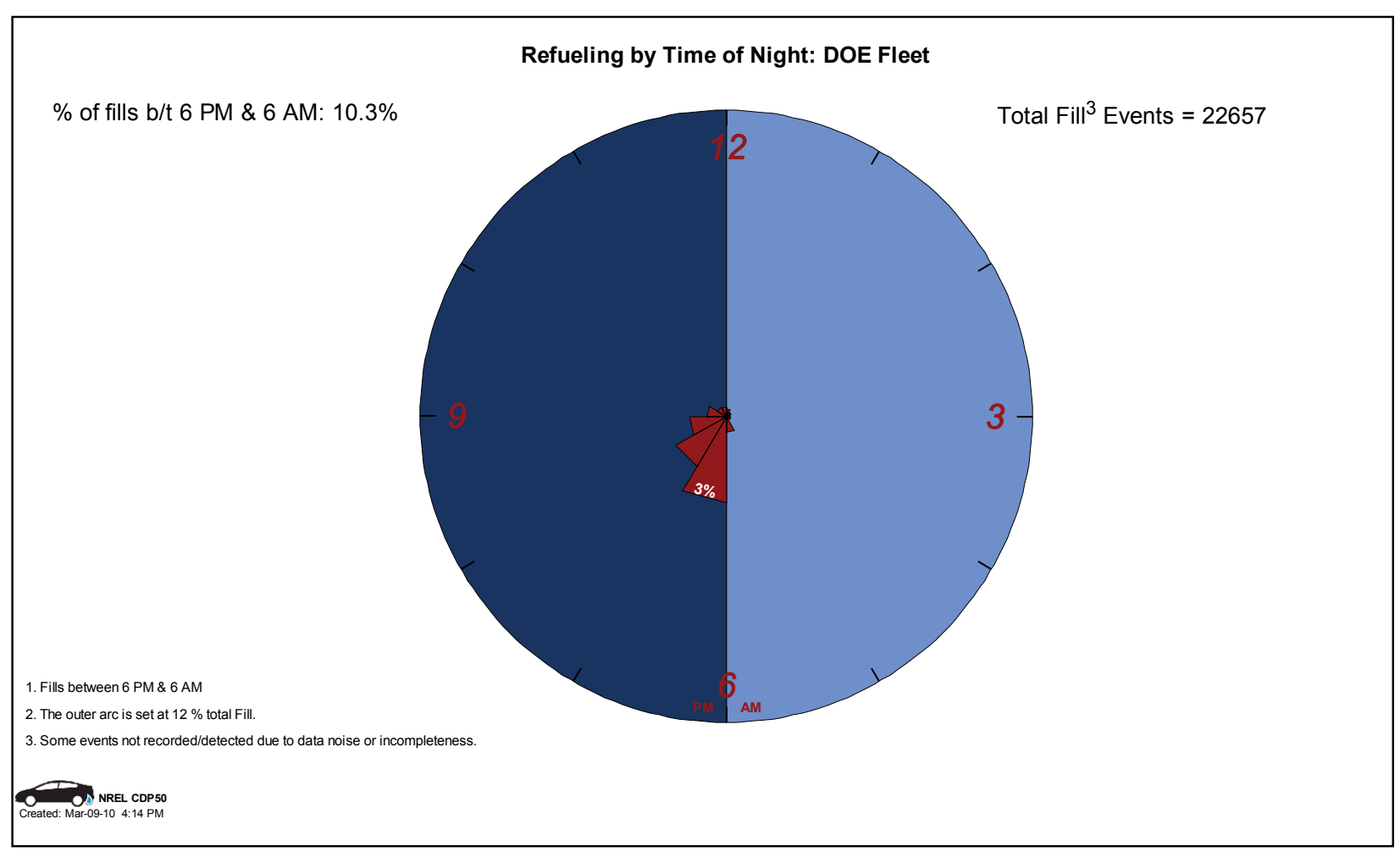

Figure 104: Refueling by time of night (CDP50)

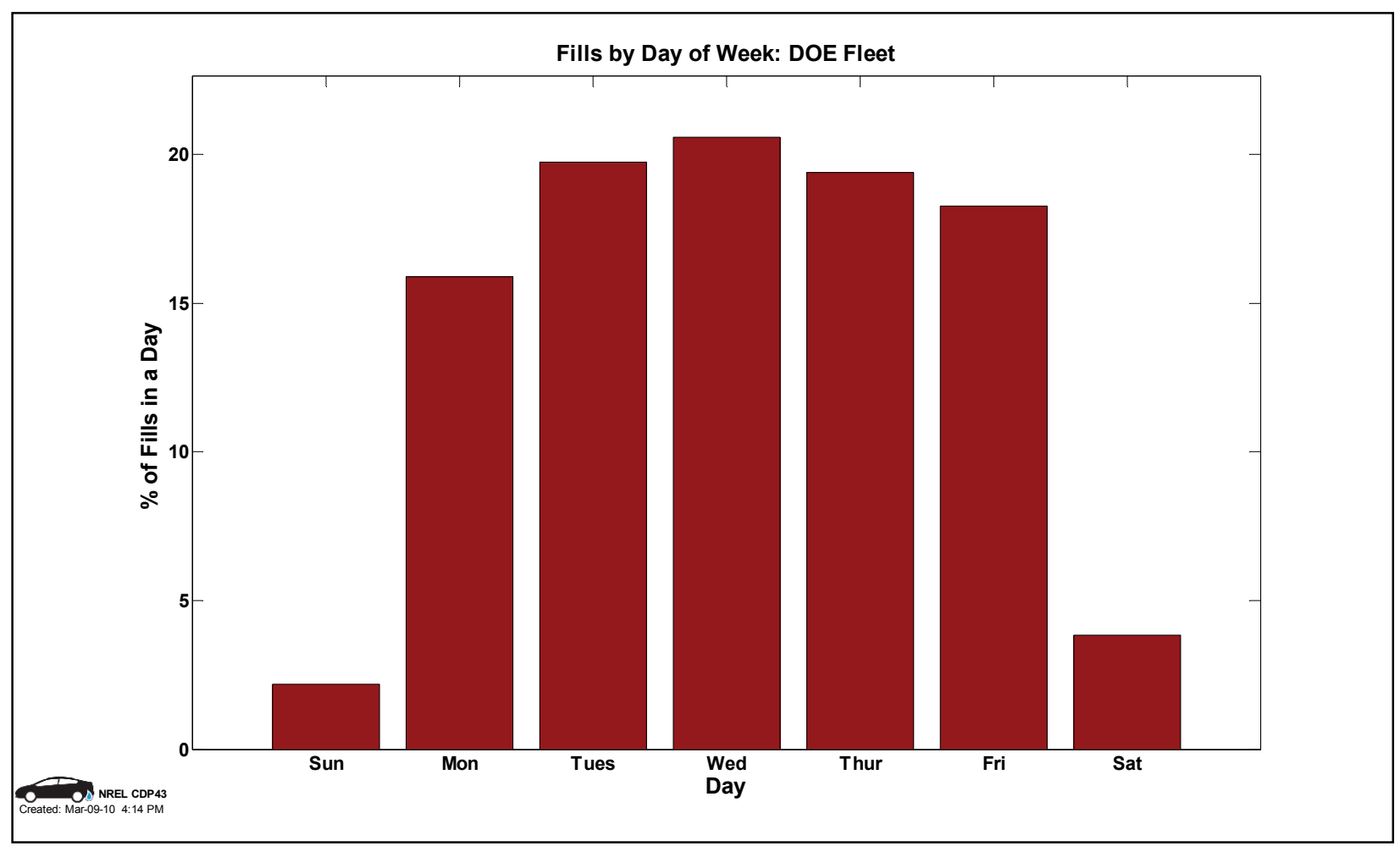

Figure 105: Refueling by day of week (CDP43) 


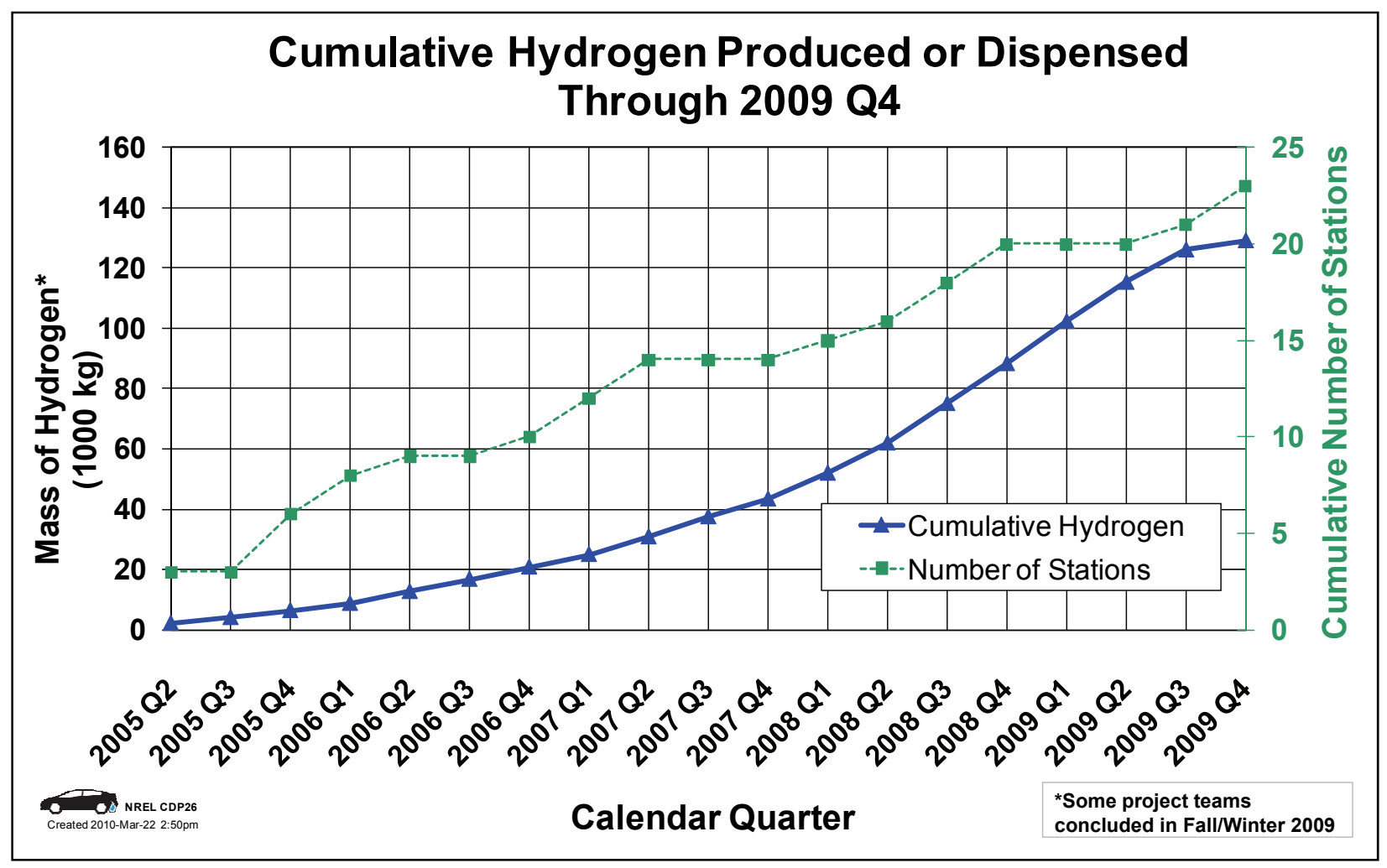

Figure 106: Cumulative hydrogen produced or dispensed (CDP26) 


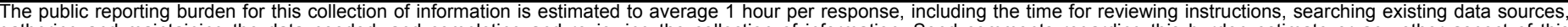

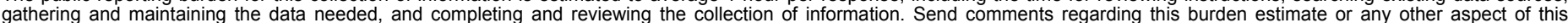

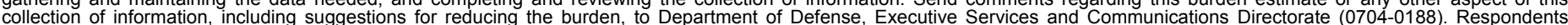

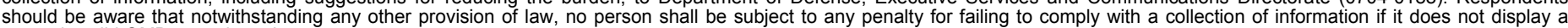

should be aware that notwithstanding

PLEASE DO NOT RETURN YOUR FORM TO THE ABOVE ORGANIZATION.

\begin{tabular}{l|l|l|l} 
1. REPORT DATE $(D D-M M-Y Y Y Y)$ & 2. REPORT TYPE & 3. DATES COVERED (FrOm - TO)
\end{tabular}

September 2010

Technical Report

4. TITLE AND SUBTITLE

Learning Demonstration Interim Progress Report - July 2010 5a. CONTRACT NUMBER

DE-AC36-08-GO28308

5b. GRANT NUMBER

5c. PROGRAM ELEMENT NUMBER

5d. PROJECT NUMBER

NREL/TP-560-49129

5e. TASK NUMBER

$\mathrm{H} 270.8100$

5f. WORK UNIT NUMBER
7. PERFORMING ORGANIZATION NAME(S) AND ADDRESS(ES)

National Renewable Energy Laboratory

1617 Cole Blvd.

Golden, CO 80401-3393
8. PERFORMING ORGANIZATION REPORT NUMBER

NREL/TP-560-49129

9. SPONSORING/MONITORING AGENCY NAME(S) AND ADDRESS(ES)

10. SPONSOR/MONITOR'S ACRONYM(S) NREL

11. SPONSORING/MONITORING AGENCY REPORT NUMBER

12. DISTRIBUTION AVAILABILITY STATEMENT

National Technical Information Service

U.S. Department of Commerce

5285 Port Royal Road

Springfield, VA 22161

13. SUPPLEMENTARY NOTES

14. ABSTRACT (Maximum 200 Words)

This report discusses key results based on data through December 2009 from the U.S. Department of Energy's (DOE) Controlled Hydrogen Fleet and Infrastructure Validation and Demonstration Project, also referred to as the National Fuel Cell Electric Vehicle (FCEV) Learning Demonstration. The report serves to help transfer knowledge and lessons learned within various parts of DOE's hydrogen program, as well as externally to other stakeholders. It is the fourth such report in a series, with previous reports being published in July 2007, November 2007, and April 2008.

15. SUBJECT TERMS

Controlled Hydrogen Fleet and Infrastructure Validation and Demonstration Project; National Fuel Cell Electric Vehicle (FCEV) Learning Demonstration; California Hydrogen Infrastructure Project; Fuel Cell Stack Durability; Fuel Economy; Fuel Cell Efficiency

\begin{tabular}{|c|c|c|c|c|}
\hline \multicolumn{3}{|c|}{ 16. SECURITY CLASSIFICATION OF: } & \multirow{2}{*}{$\begin{array}{l}\text { 17. LIMITATION } \\
\text { OF ABSTRACT } \\
\text { UL }\end{array}$} & \multirow{2}{*}{$\begin{array}{l}\text { 18. NUMBER } \\
\text { OF PAGES }\end{array}$} \\
\hline $\begin{array}{l}\text { a. REPORT } \\
\text { Unclassified }\end{array}$ & $\begin{array}{l}\text { b. ABSTRACT } \\
\text { Unclassified }\end{array}$ & $\begin{array}{l}\text { c. THIS PAGE } \\
\text { Unclassified }\end{array}$ & & \\
\hline
\end{tabular}

19a. NAME OF RESPONSIBLE PERSON

19b. TELEPHONE NUMBER (Include area code) 